\title{
Forearm Fractures in Children
}




\section{Forearm Fractures in Children}

Fractura antebrachii op kinderleeftijd

Joost Colaris 


\section{Colofon:}

\section{Print:}

\section{Schrijen-Lippertz}

\section{Design and layout:}

Topic-art - Eric Lemmens

D\&L graphics - www.dlgraphics.nl

\section{ISBN/EAN: 978-90-8590-059-7}

Copyright: No part of this book may be reproduced, stored in a retrieval system or transmitted in any form or by any means, without written permission of the author or, when appropriate, of the scientific journal in which parts of this book have been published. 


\title{
Forearm Fractures in Children
}

\author{
Fractura antebrachii op kinderleeftijd
}

\section{Proefschrift}

ter verkrijging van de graad van doctor aan de Erasmus Universiteit Rotterdam

op gezag van de

rector magnificus

Prof. dr. H.A.P. Pols

en volgens besluit van het College voor Promoties.

De openbare verdediging zal plaatsvinden op

vrijdag 10 oktober 2014 om 13.30 uur

door

\section{Joost Willem Colaris}

geboren te Heerde 


\section{Promotiecommissie}

\section{Promotor:}

Prof. dr. J.A.N. Verhaar

Overige leden:

Prof. dr. S.E.R. Hovius

Prof. dr. R.G.H.H. Nelissen

Prof. dr. M.H.J. Verhofstad

\section{Copromotor:}

Dr. J.H. Allema 




\section{PART I General InTRODUCTION}

\section{Chapter 1}

Introduction and outline of the thesis

PART II METAPHySEAL BOTH-BONE FRACTURES OF THE DISTAL FOREARM

\section{Chapter 2}

Below-elbow cast for metaphyseal both-bone fractures of the distal forearm in children: a randomised multicentre study Injury. 2012 Jul;43(7):1107-11

\section{Chapter 3}

Re-displacement of stable distal both-bone forearm fractures in children: a randomised controlled multicentre trial Injury. 2013 Apr;44(4):498-503

\section{PART III Diaphyseal Both-bone Forearm Fractures}

\section{Chapter 4}

Early conversion to below-elbow cast for non-reduced diaphyseal both-bone forearm fractures in children is safe: preliminary results of a multicentre randomised controlled trial Arch Orthop Trauma Surg. 2013 Oct;133(10):1407-14

\section{Chapter 5}

Conversion to below-elbow cast after 3 weeks is safe for diaphyseal both-bone forearm fractures in children: a multicentre randomized controlled trial involving 127 children Acta Orthop. 2013 Oct;84(5):489-94 


\section{Content}

\section{Chapter 6}

Single-bone intramedullary fixation of unstable both-bone diaphyseal forearm fractures in children leads to increased re-displacement: a multicentre randomised controlled trial Arch Orthop Trauma Surg. 2013 Aug;133(8):1079-87

\section{PART IV Fracture Displacement}

\section{Chapter 7}

Risk factors for the displacement of fractures of both bones of the forearm in children Bone Joint J. 2013 May;95-B(5):689-93

\section{PART V Limitation of Forearm Rotation}

\section{Chapter 8}

Pronation and supination after forearm fractures in children:

reliability of visual estimation and conventional goniometry measurement Injury. 2010 Jun;41(6):643-6.

\section{Chapter 9}

Which factors affect limitation of pronation/supination after forearm fractures in children? A prospective multicentre study Injury. 2014 Apr;45(4):696-700.

\section{Chapter 10}

Angular malalignment as cause of limitation of forearm rotation:

an analysis of prospectively collected data of both-bone forearm fractures in children Injury. 2014 Jun;45(6):955-9. 
Three-dimensional imaging of children with severe limitation of pronation/supination after a both-bone forearm fracture Arch Orthop Trauma Surg. 2014 Mar;134(3):333-41

PART VI General Discussion and Summary

\section{Chapter 12}

General discussion

\section{Chapter 13}

Recommendations for future research

\section{Chapter 14}

General summary

\section{Chapter 15}

General summary in Dutch / Samenvatting in het Nederlands

PART VIII APPENDICES

PhD Portfolio 


\section{PART I}

\section{GeNerAL INTRODUCTION}

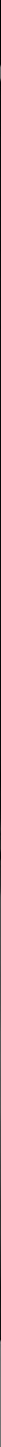




\section{Chapter 1}

\section{Introduction and}

outline of the thesis 
Chapter 1 


\section{INTRODUCTION AND OUTLINE OF THE THESIS}

The forearm consists of the radius and ulna which are connected by the proximal and distal radioulnar joints, the interosseous membrane and several muscles. Forearm rotation, consisting of pronation and supination, is a rotatory motion of the radius around the ulna in combination with subtle translation ${ }^{1}$. The longitudinal axis of the forearm is considered to pass through the centre of the radial head proximally and through the ulnar fovea at the base of the ulnar styloid distally ${ }^{2}$.

Forearm rotation is commonly used in daily life; whereas pronation is used for writing and typing, movements such as perineal hygiene and accepting monetary change require supination. In children up to the age of 15 years, pronation of 50-80 degrees and supination of 80-120 degrees are considered normal ${ }^{3}$. Furthermore a limitation of forearm rotation only affects daily activities if pronation or supination is less than 50 degrees $^{4}$, because the ipsilateral shoulder can compensate mild limitation of pronation by abduction and internal rotation, and mild limitation of supination by adduction and external rotation.

In a number of pathologies forearm rotation can be limited, such as following a forearm fracture. Forearm fractures represent one of the most common fractures in children; a distinction is made between fractures of the radius or the ulna only, and fractures of both the radius and ulna. Furthermore, a differentiation is made between incomplete fractures typical for children (torus, greenstick and bowing) and complete fractures that occur in children as well as in adults. The treatment of these both-bone forearm fractures depends on anatomical location (proximal metaphysis, distal metaphysis or diaphysis) and fracture displacement (minimally displaced or severely displaced).

\section{Metaphyseal both-bone fractures of the distal forearm}

Minimally-displaced metaphyseal both-bone fractures of the distal forearm are divided in torus fractures, and the more severe greenstick and complete fractures. The first group is usually treated with a below-elbow cast (BEC) for pain reduction. The second group is generally treated with an above-elbow cast (AEC) to prevent fracture displacement $\mathrm{t}^{5-8}$. Two studies that randomised between AEC and BEC for metaphyseal fractures of the distal forearm in children, concluded that both casts 


\section{Chapter 1}

are effective to maintain reduction of the fracture, while BEC interfered less with daily activities ${ }^{9-10}$. One of these latter studies reported a significant difference in the arc of elbow motion in favour of the BEC group at time of cast removal and at final examination ${ }^{10}$. However, none of these studies included only both-bone forearm fractures, even though these fractures are notorious for instability and dislocation ${ }^{9,10}$. Therefore, we designed the first randomised study to compare BEC and AEC for the treatment of exclusively minimally-displaced metaphyseal both-bone fractures of the distal forearm in children. (Chapter 2)

Severely displaced metaphyseal both-bone fractures of the distal forearm need to be reduced and stabilised. After reduction, the method of stabilisation ranges from $\mathrm{BEC}$ only, to percutaneous pinning with Kirschner wires in combination with an $\mathrm{AEC}^{5,9,10,12-19}$. Re-displacement of the fractures treated without percutaneous pinning has been described in $7-91 \%$ of children ${ }^{5,13,17-23}$ and such re-displacement can lead to malunion with reduced functional and cosmetic results ${ }^{24,25}$. In case of redisplacement the clinician is often confronted with a treatment dilemma, i.e. whether to accept some degree of re-displacement or to perform a secondary reduction of the fracture. Several randomised studies compared treatment modalities for a combination of single-bone and both-bone forearm fractures in children. Two studies randomised between $\mathrm{AEC}$ and $\mathrm{BEC}$ and found the highest percentage of redisplacement in the AEC group, which could be explained by poor cast moulding ${ }^{9,10}$. Two other studies randomised between AEC with or without percutaneous pinning; re-displacement appeared only in the group without percutaneous pinning and was $21 \%$ in one study and $39 \%$ in the other ${ }^{15,16}$. Although these studies were well performed, none of them distinguished between fractures of the radius or ulna only, and fractures of both the radius and ulna, whereas the latter are often highly instable $9,11,23$. Therefore, we performed a multicentre study designed for only displaced metaphyseal both-bone fractures of the distal forearm in children, which were apparently stable after reduction in the operation room. After randomisation the fractures were treated with AEC alone or by a combination of percutaneous pinning with AEC. (Chapter 3) 


\section{Diaphyseal both-bone forearm fractures}

Treatment modalities for diaphyseal both-bone forearm fractures in children are casting without reduction, closed reduction with casting, closed reduction with intramedullary nailing, and open reduction with intramedullary nailing or plate fixation.

Most minimally-displaced fractures and displaced fractures that are stable after reduction can be treated successfully with an AEC for 6-9 weeks. This AEC is often converted to a BEC in the last weeks of treatment ${ }^{3,8,26-34}$. Although many of these fractures heal without complications, limitation of pronation and supination can occur. An average limitation of 20 degrees in about $15 \%$ of children has been reported $30,35,36$. This limitation of pronation/supination after both-bone diaphyseal forearm fractures in children seems to be caused by both malunion of the radius and/or the ulna, and a contracture of the surrounding soft tissue ${ }^{36-41}$. Early conversion to $\mathrm{BEC}$ in the treatment of these fractures could potentially influence the limitation of pronation and supination in two opposing ways. On the one hand, BEC does not immobilise the elbow and could therefore result in displacement of the fracture, malunion and consequently more limitation. On the other hand, BEC allows free movement of the elbow that could result in fewer contractures of soft tissue and consequently less limitation. Nevertheless, the influence of AEC and BEC on limitation of pronation/supination remains unclear. Therefore, we aimed to clarify the role of $\mathrm{AEC}$ and $\mathrm{BEC}$ on limitation of pronation and supination in both-bone diaphyseal forearm fractures that were minimally-displaced or stable after reduction.

\section{(Chapters 4 and 5)}

Displaced diaphyseal both-bone forearm fractures that are unstable after reduction are generally stabilised by two intramedullary nails. As an alternative, the possibility of single-bone fixation in both-bone forearm fractures combined with a complementary cast has been studied ${ }^{34,42-50}$. Single-bone intramedullary fixation in both-bone forearm fractures offers both advantages and disadvantages. Although insertion and removal of only one nail can reduce operation time and complications, the bone without fixation has a tendency to displace necessitating immobilisation in a cast. To date, only one study (including 20 children, no controls) has prospectively investigated single-bone fixation in both-bone forearm fractures ${ }^{45}$, whereas others used a retrospective design ${ }^{34,42-46,49-52}$. Most studies concluded that 


\section{Chapter 1}

single-bone intramedullary fixation of both-bone diaphyseal forearm fractures in children is a safe and efficacious option with good functional and radiological results ${ }^{34,42-46,49-52}$. However, these results were based on a selection of children who sustained a both-bone forearm fracture that remained aligned and stable after singlebone fixation ${ }^{34,42-46,49-52}$. Therefore, to systematically compare the value of the two types of fixation, we set up a randomised study that compared single-bone with both-bone intramedullary fixation. (Chapter 6)

\section{Fracture displacement}

While many children who sustained a both-bone forearm fracture are treated with cast, fracture displacement may occur and has been reported in $7-91 \%$ of the patients ${ }^{5,13,17-23}$. This displacement might lead to malunion with reduced functional and cosmetic results ${ }^{24,25}$. Despite the high frequency of fracture displacement in cast, the risk factors have not yet been analysed in large prospective studies ${ }^{10,17,19,23,53-55}$. Therefore, we conducted a study to identify risk factors of fracture displacement in cast for both-bone forearm fractures in children. (Chapter 7)

\section{Limitation of forearm rotation}

As mentioned above, both-bone forearm fractures in children can be complicated by a limitation of forearm rotation. Therefore, measurement of pronation and supination is important for clinical decision-making and outcome evaluation for these fractures. Many devices have been developed to measure pronation and supination of the forearm; these include gravity-dependent methods, tubular handles, voltage gated sensors, and measurements of digital photographs ${ }^{29,56-61}$. For many of these devices, reliability is fair to excellent, as expressed by intraclass correlation coefficients $^{62}$ ranging from 0.78 to 0.99 for intrarater reliability ${ }^{56,58,61}$ and from 0.72 to 0.98 for interrater reliability ${ }^{56,57,59,61}$. However, the above-mentioned devices are complex, difficult to use in standard clinical care, and may intimidate young children. Therefore, forearm rotation in children is still generally evaluated by visual estimation or conventional goniometry. The reliability of these two methods was studied in paediatric patients that had previously sustained a forearm fracture.

\section{(Chapter 8)}


Limitation of forearm rotation can be caused by pathology of either the bones or soft tissue in the forearm. Although a malunion is frequently mentioned as the main cause of limitation of forearm rotation ${ }^{25,37,63-68}$ there is no consensus on this. Whereas several studies described limitation without a malunion $35,36,67$, others mentioned malunions without limitation ${ }^{69}$ or persistent limitation after a corrective osteotomy with restoration of anatomical alignment ${ }^{70-72}$. Other bone-related causes of limitation are a synostosis, or an impingement between radius and ulna $66,67,73$. Although the exact role of soft tissue involvement in limitation of rotation is still unclear $^{41,74-78}$, contractures of the interosseous membrane might play a more significant role than contractures of capsules of wrist and elbow ${ }^{69,79}$. Thus, many other clinical factors associated with limitation of forearm rotation have not yet been explored. However, knowledge on these factors can contribute to better clinical care by change of treatment (when required), as well as more detailed information provided to parents and children. Therefore, we analysed the relation between several clinical factors and limitation of forearm rotation in children who sustained a both-bone forearm fracture. (Chapter 9)

Malunion, as cause of limitation of forearm rotation, was previously studied in human upper-extremity cadaver specimens. Artificially created angular deformities of the forearm of 10 degrees or less resulted in minimum limitation of pronation and supination while 20 degrees of angulation caused an important loss ${ }^{66,67}$. Others compared these experimental results with data obtained from clinical and radiographic examination and found that the experimental results predicted the clinical loss of pronation/supination relatively well ${ }^{80}$. Because these findings are highly relevant for clinicians' decision-making regarding whether to accept some degree of re-displacement or to perform a secondary reduction of the fracture, we compared pronation/supination and angular malalignment in a prospective clinical study. (Chapter 10)

Unravelling the exact cause of limitation after a both-bone forearm fracture remains a diagnostic challenge. Although conventional radiographs can be used to detect angular and translational malunions or synostosis, it is difficult to reveal subtle rotational malunions and bony impingement with this method. Evidently, contractures of the interosseous membrane are not detectable on conventional radiographs. To clarify the causes of limitation of pronation/supination after both- 


\section{Chapter 1}

bone forearm fractures in children, we performed a three-dimensional imaging study with computed tomography $(\mathrm{CT})$ and magnetic resonance imaging (MRI) to evaluate the role of rotational malunion, bony impingement and contractures of the interosseous membrane. (Chapter 11) 


\section{REFERENCES}

1. Nakamura T, Yabe Y, Horiuchi Y, Yamazaki N. In vivo motion analysis of forearm rotation utilizing magnetic resonance imaging. Clin Biomech (Bristol, Avon). 1999;14(5):315-20.

2. Means KRJ, Graham TJ. chapter 23 - Disorders of the Forearm Axis. Green's operative hand surgery2011.

3. Daruwalla JS. A study of radioulnar movements following fractures of the forearm in children. Clin Orthop Relat Res. 1979(139):114-20.

4. Morrey BF, Askew LJ, Chao EY. A biomechanical study of normal functional elbow motion. The Journal of bone and joint surgery American volume. 1981;63(6):872-7.

5. Gibbons CL, Woods DA, Pailthorpe C, Carr AJ, Worlock P. The management of isolated distal radius fractures in children. J Pediatr Orthop. 1994;14(2):207-10.

6. Jones K, Weiner DS. The management of forearm fractures in children: a plea for conservatism. J Pediatr Orthop. 1999;19(6):811-5.

7. Noonan KJ, Price CT. Forearm and distal radius fractures in children. J Am Acad Orthop Surg. 1998;6(3):146-56.

8. Younger AS, Tredwell SJ, Mackenzie WG. Factors affecting fracture position at cast removal after pediatric forearm fracture. J Pediatr Orthop. 1997;17(3):332-6.

9. Bohm ER, Bubbar V, Yong Hing K, Dzus A. Above and below-the-elbow plaster casts for distal forearm fractures in children. A randomized controlled trial. J Bone Joint Surg Am. 2006;88(1):1-8.

10. Webb GR, Galpin RD, Armstrong DG. Comparison of short and long arm plaster casts for displaced fractures in the distal third of the forearm in children. J Bone Joint Surg Am. 2006;88(1):9-17.

11. Green JS, Williams SC, Finlay D, Harper WM. Distal forearm fractures in children:the role of radiographs during follow up. Injury. 1998;29(4):309-12.

12. Choi KY, Chan WS, Lam TP, Cheng JC. Percutaneous Kirschner-wire pinning for severely displaced distal radial fractures in children. A report of 157 cases. J Bone Joint Surg Br. 1995;77(5):797-801.

13. Kiely PD, Kiely PJ, Stephens MM, Dowling FE. Atypical distal radial fractures in children. J Pediatr Orthop B. 2004;13(3):202-5.

14. Mani GV, Hui PW, Cheng JC. Translation of the radius as a predictor of outcome in distal radial fractures of children. J Bone Joint Surg Br. 1993;75(5):808-11. 


\section{Chapter 1}

15. McLauchlan GJ, Cowan B, Annan IH, Robb JE. Management of completely displaced metaphyseal fractures of the distal radius in children. A prospective, randomised controlled trial. J Bone Joint Surg Br. 2002;84(3):413-7.

16. Miller BS, Taylor B, Widmann RF, Bae DS, Snyder BD, Waters PM. Cast immobilization versus percutaneous pin fixation of displaced distal radius fractures in children: a prospective, randomized study. J Pediatr Orthop. 2005;25(4):490-4.

17. Proctor MT, Moore DJ, Paterson JM. Redisplacement after manipulation of distal radial fractures in children. J Bone Joint Surg Br. 1993;75(3):453-4.

18. Van Leemput W, De Ridder K. Distal metaphyseal radius fractures in children: reduction with or without pinning. Acta Orthop Belg. 2009;75(3):306-9.

19. Voto SJ, Weiner DS, Leighley B. Redisplacement after closed reduction of forearm fractures in children. J Pediatr Orthop. 1990;10(1):79-84.

20. Blount WP. Forearm fractures in children. 1967. Clin Orthop Relat Res. 2005(432):4-7.

21. Friberg KS. Remodelling after distal forearm fractures in children. I. The effect of residual angulation on the spatial orientation of the epiphyseal plates. Acta Orthop Scand. 1979;50(5):537-46.

22. Haddad FS, Williams RL. Forearm fractures in children: avoiding redisplacement. Injury. 1995;26(10):691-2.

23. Zamzam MM, Khoshhal KI. Displaced fracture of the distal radius in children: factors responsible for redisplacement after closed reduction. J Bone Joint Surg Br. 2005;87(6):8413.

24. Prommersberger KJ, Froehner SC, Schmitt RR, Lanz UB. Rotational deformity in malunited fractures of the distal radius. J Hand Surg [Am]. 2004;29(1):110-5.

25. Roberts JA. Angulation of the radius in children's fractures. J Bone Joint Surg Br. 1986;68(5):751-4.

26. Adamczyk MJ, Riley PM. Delayed union and nonunion following closed treatment of diaphyseal pediatric forearm fractures. J Pediatr Orthop. 2005;25(1):51-5.

27. Bochang C, Jie Y, Zhigang W, Weigl D, Bar-On E, Katz K. Immobilisation of forearm fractures in children: extended versus flexed elbow. J Bone Joint Surg Br. 2005;87(7):994-6.

28. Greenbaum B, Zionts LE, Ebramzadeh E. Open fractures of the forearm in children. J Orthop Trauma. 2001;15(2):111-8.

29. Holdsworth BJ, Sloan JP. Proximal forearm fractures in children: residual disability. Injury. 1982;14(2):174-9. 
30. Kay S, Smith C, Oppenheim WL. Both-bone midshaft forearm fractures in children. J Pediatr Orthop. 1986;6(3):306-10.

31. Luhmann SJ, Gordon JE, Schoenecker PL. Intramedullary fixation of unstable both-bone forearm fractures in children. J Pediatr Orthop. 1998;18(4):451-6.

32. Ono M, Bechtold JE, Merkow RL, Sherman RE, Gustilo RB. Rotational stability of diaphyseal fractures of the radius and ulna fixed with Rush pins and/or fracture bracing. Clin Orthop Relat Res. 1989(240):236-43.

33. Schwarz N, Pienaar S, Schwarz AF, Jelen M, Styhler W, Mayr J. Refracture of the forearm in children. J Bone Joint Surg Br. 1996;78(5):740-4.

34. Shoemaker SD, Comstock CP, Mubarak SJ, Wenger DR, Chambers HG. Intramedullary Kirschner wire fixation of open or unstable forearm fractures in children. J Pediatr Orthop. 1999;19(3):329-37.

35. Hogstrom H, Nilsson BE, Willner S. Correction with growth following diaphyseal forearm fracture. Acta Orthop Scand. 1976;47(3):299-303.

36. Nilsson BE, Obrant K. The range of motion following fracture of the shaft of the forearm in children. Acta Orthop Scand. 1977;48(6):600-2.

37. Dumont CE, Thalmann R, Macy JC. The effect of rotational malunion of the radius and the ulna on supination and pronation. J Bone Joint Surg Br. 2002;84(7):1070-4.

38. Tynan MC, Fornalski S, McMahon PJ, Utkan A, Green SA, Lee TQ. The effects of ulnar axial malalignment on supination and pronation. J Bone Joint Surg Am. 2000;82-A(12):1726-31.

39. van Geenen RC, Besselaar PP. Outcome after corrective osteotomy for malunited fractures of the forearm sustained in childhood. J Bone Joint Surg Br. 2007;89(2):236-9.

40. Weinberg AM, Pietsch IT, Krefft M, Pape HC, van Griensven M, Helm MB, et al. [Pronation and supination of the forearm. With special reference to the humero-ulnar articulation]. Unfallchirurg. 2001;104(5):404-9.

41. Yasutomi T, Nakatsuchi Y, Koike H, Uchiyama S. Mechanism of limitation of pronation/supination of the forearm in geometric models of deformities of the forearm bones. Clin Biomech (Bristol, Avon). 2002;17(6):456-63.

42. Cullen MC, Roy DR, Giza E, Crawford AH. Complications of intramedullary fixation of pediatric forearm fractures. J Pediatr Orthop. 1998;18(1):14-21.

43. Dietz JF, Bae DS, Reiff E, Zurakowski D, Waters PM. Single bone intramedullary fixation of the ulna in pediatric both bone forearm fractures: analysis of short-term clinical and radiographic results. J Pediatr Orthop.30(5):420-4. 


\section{Chapter 1}

44. Flynn JM, Waters PM. Single-bone fixation of both-bone forearm fractures. J Pediatr Orthop. 1996;16(5):655-9.

45. Houshian S, Bajaj SK. Forearm fractures in children. Single bone fixation with elastic stable intramedullary nailing in 20 cases. Injury. 2005;36(12):1421-6.

46. Lee S, Nicol RO, Stott NS. Intramedullary fixation for pediatric unstable forearm fractures. Clin Orthop Relat Res. 2002(402):245-50.

47. Myers GJ, Gibbons PJ, Glithero PR. Nancy nailing of diaphyseal forearm fractures. Single bone fixation for fractures of both bones. J Bone Joint Surg Br. 2004;86(4):581-4.

48. Sharieff GQ, Kanegaye J, Wallace CD, McCaslin RI, Harley JR. Can portable bedside fluoroscopy replace standard, postreduction radiographs in the management of pediatric fractures? Pediatr Emerg Care. 1999;15(4):249-51.

49. Yung PS, Lam CY, Ng BK, Lam TP, Cheng JC. Percutaneous transphyseal intramedullary Kirschner wire pinning: a safe and effective procedure for treatment of displaced diaphyseal forearm fracture in children. J Pediatr Orthop. 2004;24(1):7-12.

50. Alnaib M, Taranu R, Lakkol S, Aldlyami E, Alcelik I, Tulloch C. Radius-only intramedullary nailing for both-bones diaphyseal forearm fractures in children. Acta orthopaedica Belgica. 2011;77(4):458-63.

51. Kirkos JM, Beslikas T, Kapras EA, Papavasiliou VA. Surgical treatment of unstable diaphyseal both-bone forearm fractures in children with single fixation of the radius. Injury. 2000;31(8):591-6.

52. Meier R, Prommersberger KJ, van Griensven M, Lanz U. Surgical correction of deformities of the distal radius due to fractures in pediatric patients. Arch Orthop Trauma Surg. 2004;124(1):1-9.

53. Alemdaroglu KB, Iltar S, Cimen O, Uysal M, Alagoz E, Atlihan D. Risk factors in redisplacement of distal radial fractures in children. J Bone Joint Surg Am. 2008;90(6):122430.

54. Pretell Mazzini J, Rodriguez Martin J. Paediatric forearm and distal radius fractures: risk factors and re-displacement—role of casting indices. Int Orthop.34(3):407-12.

55. Younger AS, Tredwell SJ, Mackenzie WG, Orr JD, King PM, Tennant W. Accurate prediction of outcome after pediatric forearm fracture. J Pediatr Orthop. 1994;14(2):200-6.

56. Armstrong AD, MacDermid JC, Chinchalkar S, Stevens RS, King GJ. Reliability of range-ofmotion measurement in the elbow and forearm. J Shoulder Elbow Surg. 1998;7(6):573-80.

57. Flowers KR, Stephens-Chisar J, LaStayo P, Galante BL. Intrarater reliability of a new method 
and instrumentation for measuring passive supination and pronation: a preliminary study. J Hand Ther. 2001;14(1):30-5.

58. Greene BL, Wolf SL. Upper extremity joint movement: comparison of two measurement devices. Arch Phys Med Rehabil. 1989;70(4):288-90.

59. Karagiannopoulos C, Sitler M, Michlovitz S. Reliability of 2 functional goniometric methods for measuring forearm pronation and supination active range of motion. J Orthop Sports Phys Ther. 2003;33(9):523-31.

60. Patrick J. A study of supination and pronation, with especial reference to the treatment of forearm fractures. J Bone Joint Surg Br. 1946;28:737-48.

61. Urban V, Kalberer F, Roos M, Dumont CE. [Reliability of active range-of-motion measurement of the rotation in the forearm: comparison of three measurement devices]. Z Orthop Ihre Grenzgeb. 2002;140(1):72-6.

62. Weir JP. Quantifying test-retest reliability using the intraclass correlation coefficient and the SEM. J Strength Cond Res. 2005;19(1):231-40.

63. Bronstein AJ, Trumble TE, Tencer AF. The effects of distal radius fracture malalignment on forearm rotation: a cadaveric study. J Hand Surg [Am]. 1997;22(2):258-62.

64. Kasten P, Krefft M, Hesselbach J, Weinberg AM. How does torsional deformity of the radial shaft influence the rotation of the forearm? A biomechanical study. J Orthop Trauma. 2003;17(1):57-60.

65. Kuderna $\mathrm{H}$. [Connection between deviated axis and impaired function after fractures of the forearm (author's transl)]. Unfallchirurgie. 1980;6(1):7-13.

66. Matthews LS, Kaufer H, Garver DF, Sonstegard DA. The effect on supination-pronation of angular malalignment of fractures of both bones of the forearm. J Bone Joint Surg Am. 1982;64(1):14-7.

67. Tarr RR, Garfinkel Al, Sarmiento A. The effects of angular and rotational deformities of both bones of the forearm. An in vitro study. J Bone Joint Surg Am. 1984;66(1):65-70.

68. Trousdale RT, Linscheid RL. Operative treatment of malunited fractures of the forearm. J Bone Joint Surg Am. 1995;77(6):894-902.

69. Nenopoulos SP, Beslikas TA, Gigis JP. Long-term follow-up of combined fractures of the proximal radius and ulna during childhood. J Pediatr Orthop B. 2009;18(5):252-60.

70. Krukhaug Y, Hove LM. Corrective osteotomy for malunited extra-articular fractures of the distal radius: a follow-up study of 33 patients. Scand J Plast Reconstr Surg Hand Surg. 2007;41(6):303-9. 


\section{Chapter 1}

71. Nagy L, Jankauskas L, Dumont CE. Correction of forearm malunion guided by the preoperative complaint. Clin Orthop Relat Res. 2008;466(6):1419-28.

72. Price CT, Knapp DR. Osteotomy for malunited forearm shaft fractures in children. J Pediatr Orthop. 2006;26(2):193-6.

73. Graham TJ, Fischer TJ, Hotchkiss RN, Kleinman WB. Disorders of the forearm axis. Hand clinics. 1998;14(2):305-16.

74. Beyer W, Stolzenburg T, Paris S. [Functional limitation of the forearm after shaft fracture in childhood. Possible role of the antebrachial interosseous membrane: MRI and ultrasound studies]. Unfallchirurgie. 1995;21(6):275-84.

75. Kihara H, Palmer AK, Werner FW, Short WH, Fortino MD. The effect of dorsally angulated distal radius fractures on distal radioulnar joint congruency and forearm rotation. J Hand Surg [Am]. 1996;21(1):40-7.

76. Nakamura T, Yabe Y, Horiuchi Y. [A biomechanical analysis of pronation-supination of the forearm using magnetic resonance imaging: dynamic changes of the interosseous membrane of the forearm during pronation-supination]. Nippon Seikeigeka Gakkai Zasshi. 1994;68(1):14-25.

77. Nakamura T, Yabe Y, Horiuchi Y, Seki T, Yamazaki N. Normal kinematics of the interosseous membrane during forearm pronation-supination-a three-dimensional MRI study. Hand Surg. 2000;5(1):1-10.

78. Price CT, Scott DS, Kurzner ME, Flynn JC. Malunited forearm fractures in children. J Pediatr Orthop. 1990;10(6):705-12.

79. Colaris JW, Biter LU, Allema JH, Bloem RM, van de Ven CP, de Vries MR, et al. Belowelbow cast for metaphyseal both-bone fractures of the distal forearm in children: A randomised multicentre study. Injury. 2012.

80. Sarmiento A, Ebramzadeh E, Brys D, Tarr R. Angular deformities and forearm function. Journal of orthopaedic research : official publication of the Orthopaedic Research Society. 1992;10(1):121-33. 
Introduction 


\section{PART II}

Metaphyseal

BOTH-BONE FRACTURES

OF THE DISTAL FOREARM 


\section{Chapter 2}

\section{Below-ellow cast for}

metaphyseal both-bone fractures of the distal forearm in children: a randomised multicentre study

Injury. 2012 Jul;43(7):1107-11

Colaris JW, Biter LU, Allema JH, Bloem RM, van de Ven CP, de Vries MR, Kerver AJ, Reijman M, Verhaar JA. 


\section{Chapter 2}

\section{AbStRACT}

Introduction: Minimally displaced metaphyseal both-bone fractures of the distal forearm in children are often treated with an above-elbow cast (AEC). Treatment with a below-elbow cast (BEC) could give more comfort, but might lead to fracture displacement reducing pronation and supination. Because this has not been systematically investigated, we set up a randomised multicentre study. The purpose of this study was to find out whether BEC causes equal limitation of pronation and supination but with higher comfort level, compared with AEC.

Patients and methods: In four hospitals, consecutive children aged $<16$ (mean 7.1) years with a minimally displaced metaphyseal both-bone fracture of the distal forearm were randomised to 4 weeks BEC $(n=35)$ or 4 weeks AEC $(n=31)$. Primary outcome was limitation of pronation and supination 6 months after initial trauma. The secondary outcomes were cast comfort, limitation of flexion/extension of wrist/elbow, complications, cosmetics, complaints, and radiological assessment.

Results: A group of 35 children received BEC and 31 children received AEC. All children attended for the final examination at a mean follow-up of 7.0 months (range 5.0-11.6 months). Limitation of pronation and supination 6 months after initial trauma showed no significant difference between the two groups $\left[4.4^{\circ}( \pm 5.8)\right.$ for $\mathrm{BEC}$ and $5.8^{\circ}( \pm 9.8)$ for $\mathrm{AEC}$. Children treated with $\mathrm{BEC}$ had significantly higher cast comfort on a visual analogue scale [5.6 $( \pm 2.7)$ vs. $8.4( \pm 1.4)]$ and needed significantly less help with dressing (8.2 vs. 15.1 days). Six complications occurred in the BEC group and 14 in the AEC group. Other secondary outcomes were similar between the two groups.

Conclusions: Children with minimally displaced metaphyseal both-bone fractures of the distal forearm should be treated with a below-elbow cast. 


\section{INTRODUCTION}

Metaphyseal both-bone fractures of the distal forearm are among the most common injuries in childhood. The minimally displaced fractures are divided in torus fractures and the more severe greenstick and complete fractures. The first group is usually treated with a below-elbow cast (BEC) for comfort. The second group is usually treated with an above-elbow cast (AEC) to prevent fracture displacement ${ }^{1-4}$.

An AEC immobilizes both wrist and elbow that potentially stabilizes the fracture more than immobilization of the wrist only using a BEC. Less fracture stabilization can result in displacement of the fracture leading to malunion, and limitation of pronation and supination. However, AEC can cause more interference with daily activities and give more discomfort than BEC.

Two studies that randomised between AEC and BEC for metaphyseal fractures of the distal forearm in children, concluded that both casts are effective to maintain reduction of the fracture, while BEC interfered less with daily activities ${ }^{5,6}$. One of these studies reported a significant difference in the arc of elbow motion in favour of the BEC group at time of cast removal and at final examination ${ }^{6}$. None of these studies included only both-bone forearm fractures, although these fractures are notorious for instability and dislocation ${ }^{5,7}$. Therefore, we designed the first randomised multicentre study to compare BEC and AEC for the treatment of exclusively minimally displaced metaphyseal both-bone fractures of the distal forearm in children. The purpose of this study was to find out whether BEC causes equal limitation of pronation and supination but with higher comfort level, compared with AEC.

\section{Patients AND methods}

\section{Trial design and participants}

A multicentre randomised trial was performed on consecutive children with a minimally displaced metaphyseal fracture of the radius and ulna, who visited the emergency department of one of four participating hospitals. The participating hospitals were: Erasmus Medical Center (Rotterdam), HAGA Hospital (The Hague), Reinier de Graaf Hospital (Delft) and Sint Franciscus Hospital (Rotterdam). The 


\section{Chapter 2}

regional medical ethics committee approved the study and it was registered in Clinical Trials.gov (NCT00397995). Informed consent was obtained for participation from all the parents and from children aged $\geq 12$ years.

Children aged $<16$ years with a metaphyseal both-bone fracture of the distal forearm were invited to participate (Figure 1).

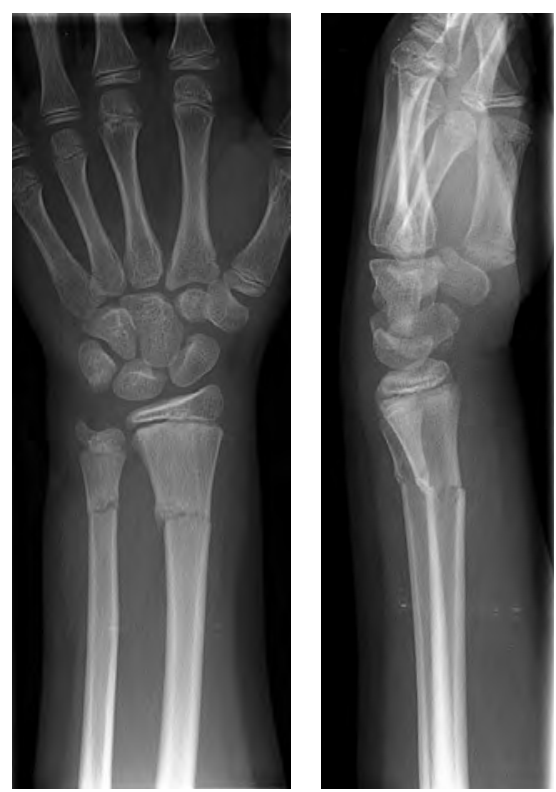

Figure 1. Posteroanterior and lateral radiographs of a metaphyseal both-bone fracture of the distal forearm in a child.

The exclusion criteria were: 1) buckle fractures of both the ulna and radius, 2) fracture sustained longer than one week, 3) a severe open fracture (Gustilo II and III) (8), 4) a relapse fracture in the same location, and 5) need for reduction according to a priori defined criteria (Table 1 ).

The primary outcome measure was limitation of pronation and supination 6 months after the fracture. The secondary outcome measures were cast comfort, limitation of flexion and extension of wrist and elbow, complications, cosmetics, complaints and radiological assessment. 
Table 1. Criteria for reduction of the fracture of radius and/or ulna based on posteroanterior and/or lateral radiographs.

\begin{tabular}{lll} 
Type of displacement & Age in years & Displacement \\
\hline Angulation & $<10$ & $>15$ degrees \\
& $10-16$ & $>10$ degrees \\
Translation & $<16$ & $>$ half of bone diameter \\
Rotation & $<16$ & $>0$
\end{tabular}

\section{Procedures}

The included fractures were randomised between 4 weeks of BEC or 4 weeks of AEC. All casts were applied in neutral position and non-circumferential. All children received a sling for at least 1 week. The children were clinically and radiologically evaluated at 1 and 4 weeks after initial trauma by a resident, supervised by an attending orthopaedic or trauma surgeon. A specialist of plaster revised the cast after 1 week. Where necessary, the fractures were reduced during the period of casting according to the initial reduction criteria (Table 1). Finally, the cast was removed 4 weeks after initial treatment.

One independent orthopaedic surgeon examined all children 2 and 6 months after initial trauma, and measured flexion and extension of wrist and elbow in combination with pronation and supination of both arms. This technique was standardised with the use of a $180^{\circ}$ goniometer constructed of clear, flexible plastic with 2 movable arms of $30 \mathrm{~cm}$. Pronation and supination were scaled with a previously used grading system ${ }^{9}$.

Patients with at least $30^{\circ}$ of functional impairment at the 2 -month examination received a referral for physiotherapy. To evaluate the comfort of the cast a visual analogue scale (VAS) was used; the highest score indicating maximal comfort. In addition, a questionnaire previously used in a similar group of children, evaluated difficulties with 7 daily activities during the period of casting ${ }^{6}$.

Six months after the initial trauma, final radiographs were taken. Both the parents 


\section{Chapter 2}

and the orthopaedic surgeon completed a VAS cosmetics (maximum score indicating best cosmetics) of the fractured arm. In the same consultation, complaints of the fractured arm were documented using a modified grading system. This grading system combines limitation of pronation and supination with complaints in daily life or during strenuous activities. This system was previously used in a similar group of children ${ }^{10}$.

The parents completed the ABILHAND-Kids questionnaire ${ }^{11}$, which is a measure of manual ability for children with upper-limb impairments. The scale is validated for cerebral palsy children and measures a child's ability to manage daily activities that require the use of the upper limbs; the maximum score is 42 .

The independent orthopaedic surgeon measured the sagittal and radioulnar angulation of the fracture on the radiographs at three moments, i.e. directly after trauma, after removal of the cast, and 6 months post trauma. The mean and standard deviation (SD) of the sagittal and radioulnar angulation were calculated to determine the primary displacement, re-displacement during the period of casting, and the final displacement at 6 months. To assess the interrater reproducibility an independent trauma surgeon remeasured the sagittal and radioulnar angulation of the fracture of 45 children.

\section{Randomisation and masking}

An independent physician randomised the children by sealed envelopes with varied block sizes. A surgeon treated the children during the first 4 weeks without masking. One independent orthopaedic surgeon examined all children 2 and 6 months after the initial trauma without masking. Both the independent orthopaedic surgeon and independent trauma surgeon measured the radiographs with masking.

\section{Statistical Methods}

To assess the required number of children, an equivalence test was used to demonstrate the similarity of pronation and supination in both groups. Equivalence between the two groups was defined as a maximum of $10^{\circ}$ difference in pronation or supination. Using an a priori calculation it was determined that, with a power of $82 \%$, a significance of 0.05 and a SD of $15^{\circ}$, the two groups should consist of \pm 30 children each. First it was established whether the variables had a normal distribution using the normality Shapiro-Wilk test. Based on these analyses, the results are presented as means (SD). 
Data were analysed using linear regression analysis. If necessary, adjustments were made for unbalanced covariates. Differences between the two groups (BEC vs. AEC) for the secondary outcome measures were analysed using one-way ANOVA to correct for multiple comparisons (Bonferroni). Statistical analyses were performed with SPSS version 17.0 (SPSS Inc., Chicago, USA).

\section{ResUlts}

Between January 2006 and August 2010 a total of 66 children were included from four hospitals. Of these, 35 children received $B E C$ and 31 children received AEC (Figure 2).

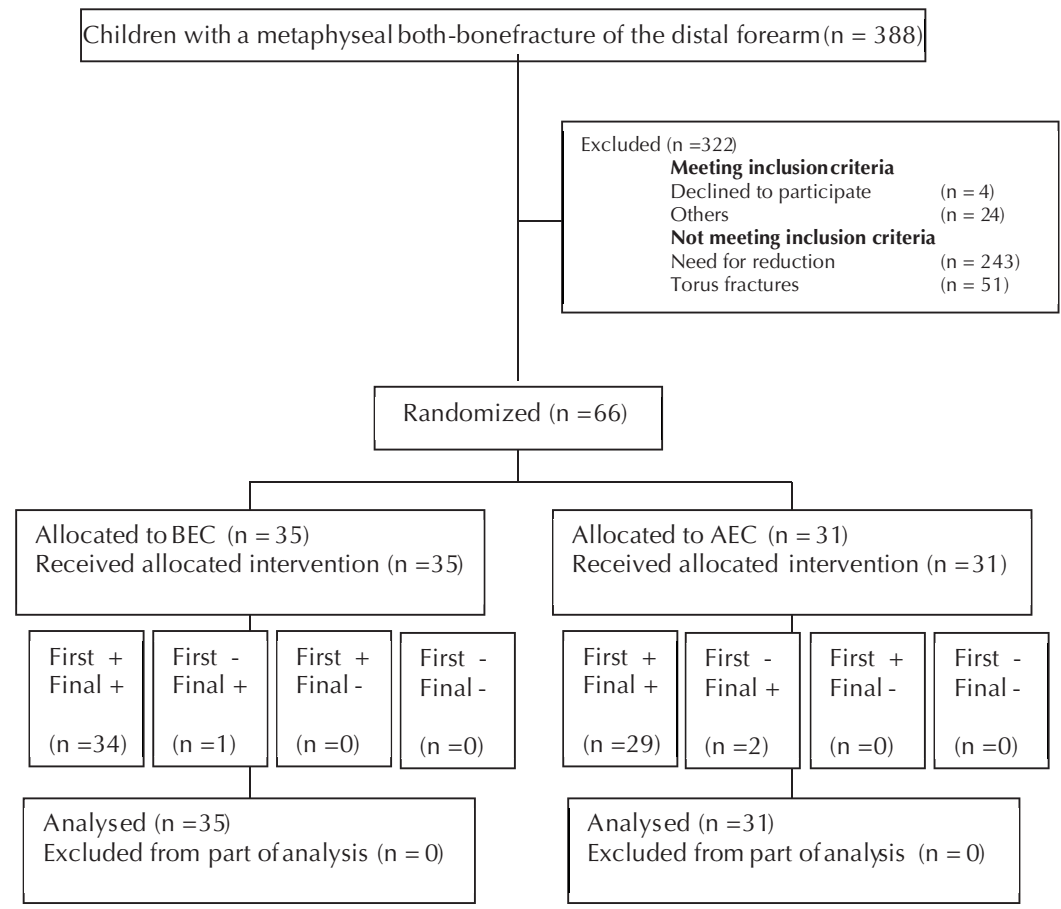

$n=$ number of children; $A E C=$ above elbow cast $B E C=$ below elbow cast; First: first examination;

Final: final examination; + : examined; - : not examined.

Figure 2. Flowchart of enrollment in the study. 


\section{Chapter 2}

Table 2 presents the baseline characteristics of the total study population and per randomisation. All children attended for the final examination at a mean follow-up of 7.0 months (range 5.0-11.6 months).

Table 2. Baseline characteristics of the study population.

\begin{tabular}{lccc} 
& Total & BEC & AEC \\
\hline Number & 66 & 35 & 31 \\
Age in years at time of fracture: mean (SD) & $7.1( \pm 3.5)$ & $7.8( \pm 3.6)$ & $6.3( \pm 3.3)$ \\
Gender, \% male & 56.1 & 48.6 & 64.5 \\
Dominant arm fractured, \% & 30.3 & 25.7 & 35.5 \\
& & & \\
Type fracture radius, \% & & & 12.9 \\
\hline Torus & 7.6 & 2.9 & 80.6 \\
Greenstick & 84.8 & 88.5 & 6.5 \\
Complete & 7.6 & 8.6 & \\
& & & 19.4 \\
Type fracture ulna, \% & & & 77.4 \\
\hline Torus & 19.7 & 20.0 & 3.2 \\
Greenstick & 77.3 & 77.1 & \\
Complete & 3.0 & 2.9 &
\end{tabular}

BEC: below-elbow cast. AEC: above-elbow cast; SD = standard deviation; No significant differences between BEC and AEC groups.

Table 3 presents data on the primary outcome measure. No significant differences in limitation of pronation and supination were found either after cast removal or at 6 months post fracture.

Table 4 presents data on the secondary outcome measures. The group treated with BEC showed significantly higher VAS comfort and needed less help with dressing compared with the AEC group (8.2 vs. 15.1 days: $p=0.024)$. Six complications occurred in the BEC group and 14 complications occurred in the AEC 
Table 3. Limitation of pronation and supination of fractured arm.

BEC $\quad$ AEC

Two months after the fracture

\begin{tabular}{lcc}
\hline None & 15 & 10 \\
1-10 degrees & 10 & 8 \\
11-20 degrees & 3 & 6 \\
21-30 degrees & 3 & 2 \\
$>31$ degrees & 3 & 29 \\
Total & 34 & $10.7( \pm 12.2)^{*}$ \\
Mean limiation / SD (degrees) & $9.1( \pm 12.2)^{*}$ & \\
& & 18 \\
Six months after the fracture & & 7 \\
\hline None & 17 & 3 \\
1-10 degrees & 4 & 2 \\
11-20 degrees & 0 & 1 \\
21-30 degrees & 0 & 31 \\
$>31$ degrees & 35 & $5.8( \pm 9.8)$ \\
Total & $4.4( \pm 5.8)^{*}$ & \\
Mean limitation in degrees (SD) & & \\
*BEC: below-elbow cast. AEC: above-elbow cast; Data are presented as numbers (unless otherwise indicated). \\
SD = standard deviation. \\
* No significant difference in mean limitation of pronation and supination between both groups. \\
Three children missed the two-month examination. & & \\
& &
\end{tabular}

group. These complications consisted of displacement in the cast in 5 children in the $\mathrm{BEC}$ group and in 10 children in the AEC group. In the AEC group two fractures were secondarily reduced. In the BEC group one cast fell off two weeks after the trauma because of loose cast caused by subsided swelling. The AEC group had two cases of excoriation in the elbow crease, and two cases of transient neuropraxia of the superficial radial nerve. For both the number of complications and fracture displacement in the cast, there was no significant difference between the two groups. 


\section{Chapter 2}

Table 4. Data on secondary outcomes.

BEC

\begin{tabular}{lcc}
\hline Days in cast & $28.2( \pm 5.1)$ & $28.5( \pm 5.7)$ \\
Days to first clinical examination & $55.8( \pm 21.6)$ & $61.1( \pm 21.2)$ \\
Days to final clinical examination & $213.9( \pm 36.2)$ & $209.2( \pm 40.9)$ \\
Limitation of wrist flexion-extension of the fractured arm (degrees) & $1.9( \pm 4.4)$ & $1.0( \pm 2.7)$ \\
Limitation of elbow flexion-extension of the fractured arm (degrees) & $0( \pm 2.5)$ & $1.0( \pm 3.7)$ \\
VAS comfort of cast * & $8.4( \pm 1.4)$ & $5.6( \pm 2.7)$ \\
VAS cosmetics fractured arm by parents & $9.4( \pm 0.9)$ & $9.4( \pm 1.0)$ \\
VAS cosmetics fractured arm by orthopedic surgeon & $9.7 \pm 0.6)$ & $9.6( \pm 0.7)$ \\
Total ABILHAND score at final clinical examination & $40.7( \pm 7.1)$ & $41.8( \pm 0.8)$ \\
Complications (number) & 6 & 14 \\
\hline
\end{tabular}

BEC: below-elbow cast. AEC: above-elbow cast; Values are presented as mean ( \pm standard deviation ). VAS: Visual Analogue Scale. * Significant difference between both groups $(p<0.0001)$. Other outcomes are not significantly different.

Using the selected grading system ${ }^{9}$, results in the BEC group were excellent in $48 \%$, good in $46 \%$ and fair in $6 \%$. In the AEC group the results were excellent in $58 \%$, good in $32 \%$, fair in $7 \%$ and poor in $3 \%$. Similar results were found using the modified grading system (10). In the BEC group results were excellent in $77 \%$, good in $14 \%$ and fair in $9 \%$. In the AEC group results were excellent in $74 \%$, good in $19 \%$ and fair in $7 \%$. The results of both grading systems showed no significant difference between the two groups.

Table 5 shows significant differences in the groups in the amount of angulation between the radiographs made directly after trauma, and those made at cast removal and at final examination. In general, angulation increased in the period between trauma and removal of cast, while angulation decreased in the period between removal of cast and final examination. No other significant differences were found between the two groups. 
Table 5. Radiological outcomes.

BEC

\begin{tabular}{lccc}
\hline & Trauma & Removal of cast & Final clinical examination \\
\hline AP ulna & $6.5( \pm 4.1)^{2}$ & $5.5( \pm 4.2)$ & $3.3( \pm 2.6)^{2}$ \\
AP radius & $3.5( \pm 2.8)$ & $4.0( \pm 3.8)$ & $2.3( \pm 2.7)$ \\
Lateral ulna & $6.9( \pm 4.8)^{2}$ & $4.3( \pm 3.3)$ & $3.3( \pm 2.6)^{2}$ \\
Lateral radius & $9.0( \pm 4.9)^{12}$ & $11.4( \pm 6.9)^{1}$ & $4.8( \pm 3.4)^{2}$ \\
& \multicolumn{3}{c}{ AEC } \\
\hline
\end{tabular}

2Radioulnar angulations (PA ulna, PA radius) and sagittal angulations (Lateral ulna, Lateral radius) presented in degrees as mean ( \pm standard deviation ).

No significant differences between $\mathrm{BEC}$ and $\mathrm{AEC}$ groups.

Significant differences ( $p$-value $<0.05$ ) were found between trauma radiographs and respectively radiographs removal of cast (') and radiographs final examination (2).

The interrater reproducibility of the radiological assessment showed an intraclass correlation of 0.81 and 0.89 for the radioulnar angulation of the ulna and radius, respectively. The intraclass correlation of the sagittal angulation was 0.92 for the ulna and 0.87 for the radius.

\section{Discussion}

This randomised multicentre trial shows that BEC is as effective as AEC in the treatment of minimally displaced metaphyseal both-bone fractures of the distal forearm in children. The children treated with BEC had similar limitation of pronation and supination, significantly higher cast comfort, needed significantly less help with dressing, and showed a tendency towards fewer complications. 


\section{Chapter 2}

\section{Previous studies}

In contrast with our results, an earlier study (6) found more limitation of pronation and supination in the AEC group than in the BEC group. Our mean limitation of pronation and supination was higher compared to these previous studies. This can be explained by our inclusion of patients with only both-bone fractures.

In a retrospective study of almost exclusively displaced both-bone forearm fractures treated with AEC after reduction, Daruwalla et al. found excellent results in $50 \%$, good results in $33 \%$, fair results in $17 \%$, and no poor results ${ }^{9}$. Using the same grading system, our results seemed to be better, possibly caused by the absence of displaced fractures in our study group.

Using the modified grading system, in a selected group of malunited diaphyseal both-bone forearm fractures others reported $82 \%$ excellent results, $10 \%$ good results and $8 \%$ fair results ${ }^{10}$. These better results, despite the severity of malunited diaphyseal fractures, might be explained by the retrospective analysis and longer follow-up period.

We found twice as many fracture displacement in the group treated with AEC than in those treated with BEC. Similar findings have been reported by others ${ }^{5,6}$. Immobilization of the elbow does not seem to prevent fracture displacement of a metaphyseal fracture of the distal forearm; this might be due to less moulding around the lower arm caused by the more difficult to apply AEC.

\section{Radiographic assessment}

Radiographic assessment showed that angulation increased in the period between trauma and removal of the cast, which might be explained by the secondary dislocation of the fracture during cast treatment. Decreased angulation in the period between removal of cast and final examination might be explained by remodelling by growth.

\section{Limitations}

This study has several limitations. Primarily, neither the children nor the independent orthopaedic surgeon were blinded during clinical follow-up, which might have influenced the clinical measurements. Obviously, blinding of the children was not possible because different types of cast were used. However, both the radiographic 
assessors were blinded for the type of cast. The second limitation is our period of follow-up in this group of children with capacity for remodelling by growth. Although a follow-up of almost 7 months seems to be short, others found no change in clinical or radiographic status from 6 months after treatment to the final followup at an average of 2.8 years in children treated for displaced forearm fractures ${ }^{12}$. Thereby Nilsson et al. described a persistent limitation during long term follow-up despite correction by growth and others advised an osteotomy to correct malunion as early as 6 months after trauma ${ }^{13,14}$. Nevertheless, most children in our study regained a full range of pronation and supination after seven months.

\section{Future research and study}

Future studies could try to answer the following question: Why do fractures displace more in $\mathrm{AEC}$ than in $\mathrm{BEC}$ ?

\section{Conclusions}

This randomised multicentre trial shows that there is similar limitation of pronation and supination after treatment of minimally displaced metaphyseal both-bone fractures of the distal forearm in children with either BEC or AEC. Children treated with $\mathrm{BEC}$ experienced significantly more cast comfort and significantly less interference with daily activities during the period of casting. To conclude, children with minimally displaced metaphyseal both-bone fractures of the distal forearm should be treated with a properly applied below-elbow cast. 
Chapter 2 


\section{References}

1. Gibbons CL, Woods DA, Pailthorpe C, Carr AJ, Worlock P. The management of isolated distal radius fractures in children. J Pediatr Orthop. 1994;14(2):207-10.

2. Jones K, Weiner DS. The management of forearm fractures in children: a plea for conservatism. J Pediatr Orthop. 1999;19(6):811-5.

3. Noonan KJ, Price CT. Forearm and distal radius fractures in children. J Am Acad Orthop Surg. 1998;6(3):146-56.

4. Younger AS, Tredwell SJ, Mackenzie WG. Factors affecting fracture position at cast removal after pediatric forearm fracture. J Pediatr Orthop. 1997;17(3):332-6.

5. Bohm ER, Bubbar V, Yong Hing K, Dzus A. Above and below-the-elbow plaster casts for distal forearm fractures in children. A randomized controlled trial. J Bone Joint Surg Am. 2006;88(1):1-8.

6. Webb GR, Galpin RD, Armstrong DG. Comparison of short and long arm plaster casts for displaced fractures in the distal third of the forearm in children. J Bone Joint Surg Am. 2006;88(1):9-17.

7. Green JS, Williams SC, Finlay D, Harper WM. Distal forearm fractures in children:the role of radiographs during follow up. Injury. 1998;29(4):309-12.

8. Gustilo RB, Simpson L, Nixon R, Ruiz A, Indeck W. Analysis of 511 open fractures. Clin Orthop Relat Res. 1969;66:148-54.

9. Daruwalla JS. A study of radioulnar movements following fractures of the forearm in children. Clin Orthop Relat Res. 1979(139):114-20.

10. Price CT, Scott DS, Kurzner ME, Flynn JC. Malunited forearm fractures in children. J Pediatr Orthop. 1990;10(6):705-12.

11. Arnould C, Penta M, Renders A, Thonnard JL. ABILHAND-Kids: a measure of manual ability in children with cerebral palsy. Neurology. 2004;63(6):1045-52.

12. Miller BS, Taylor B, Widmann RF, Bae DS, Snyder BD, Waters PM. Cast immobilization versus percutaneous pin fixation of displaced distal radius fractures in children: a prospective, randomized study. J Pediatr Orthop. 2005;25(4):490-4.

13. Nilsson BE, Obrant K. The range of motion following fracture of the shaft of the forearm in children. Acta Orthop Scand. 1977;48(6):600-2.

14. Price CT, Knapp DR. Osteotomy for malunited forearm shaft fractures in children. J Pediatr Orthop. 2006;26(2):193-6. 

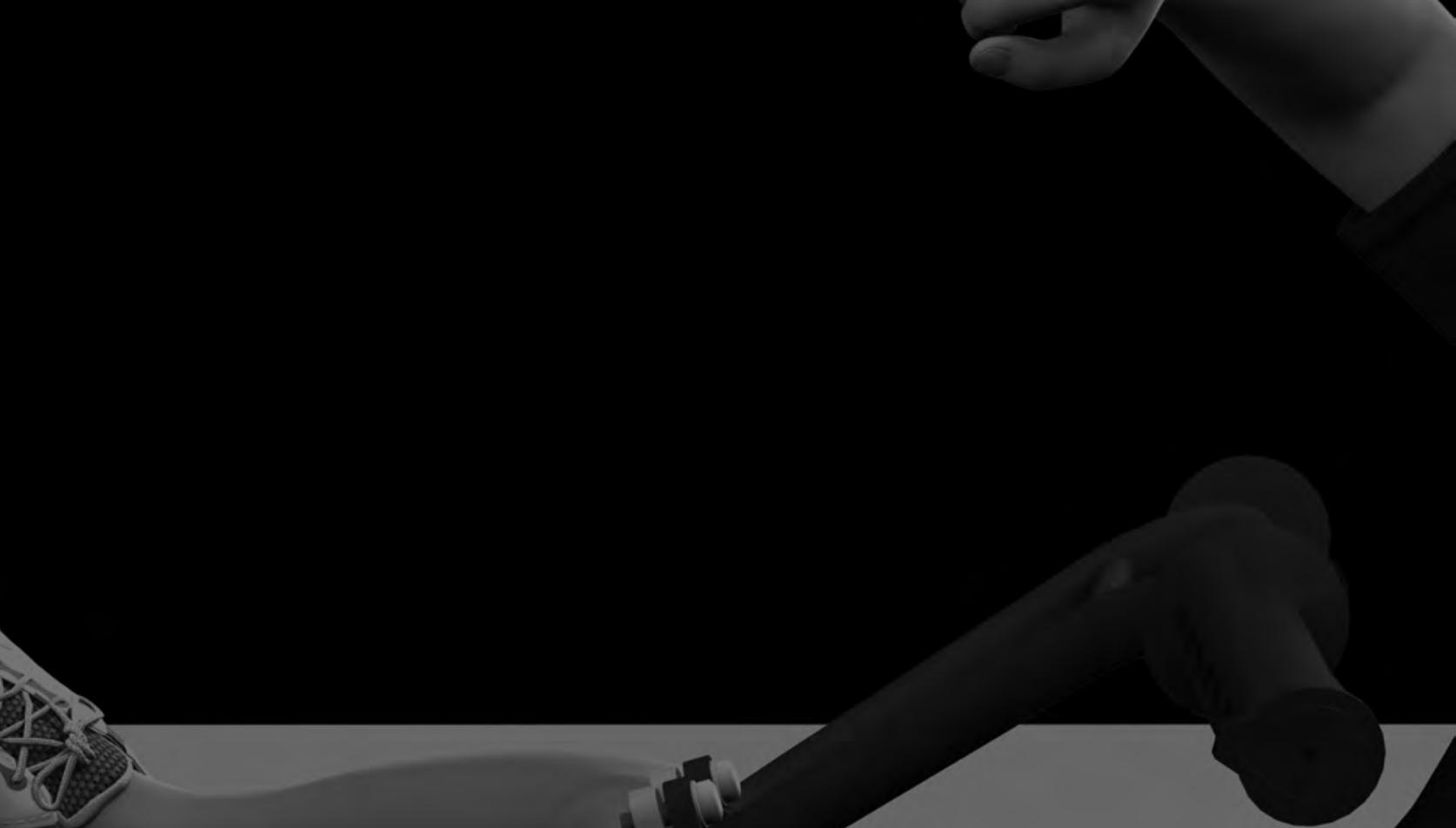


\section{ChAPTER 3}

\section{Re-displacement of stable distal}

\section{both-bone forearm fractures in}

children: a randomised

\section{controlled multicentre trial}

Injury. 2013 Apr;44(4):498-503

Colaris JW, Allema JH, Biter LU, de Vries MR, van de Ven CP, Bloem RM, Kerver AJ, Reijman M, Verhaar JA. 


\section{Chapter 3}

\section{AbStRACT}

Introduction: Displaced metaphyseal both-bone fractures of the distal forearm are generally reduced and stabilised by an above-elbow cast (AEC) with or without additional pinning. The purpose of this study was to find out if re-displacement of a reduced stable metaphyseal both-bone fracture of the distal forearm in a child could be prevented by stabilisation with Kirschner wires.

Methods: Consecutive children aged $<16$ years with a displaced metaphyseal bothbone fracture of the distal forearm $(n=128)$ that was stable after reduction were randomised to AEC with or without percutaneous fixation with Kirschner wires. The primary outcome was re-displacement of the fracture.

Results: A total of 67 children were allocated to fracture reduction and AEC and 61 to reduction of the fracture, fixation with Kirschner wires and AEC. The follow-up rate was $96 \%$ with a mean follow-up of 7.1 months. Fractures treated with additional pinning showed less re-displacement ( $8 \%$ vs. $45 \%$ ), less limitation of pronation and supination (mean limitation $6.9( \pm 9.4)$ vs. $14.3( \pm 13.6)$ degrees) but more complications (14 vs. 1$)$.

Conclusions: Pinning of apparent stable both-bone fractures of the distal forearm in children might reduce fracture re-displacement. The frequently seen complications of pinning might be reduced by a proper surgical technique. 


\section{INTRODUCTION}

Metaphyseal fractures of the distal forearm are common in childhood (1-3). Nondisplaced fractures are generally treated with cast while displaced fractures need to be reduced and stabilised. After reduction, the method of stabilisation ranges from below-elbow cast only to percutaneous pinning with Kirschner wires ( $K$ wires) in combination with an above-elbow cast (AEC) $)^{4-14}$. Re-displacement of the fractures treated without percutaneous pinning has been described in $7-91 \%$ of patients ${ }^{6,7,11-}$ 13,15-18 and such re-displacement can lead to malunion with reduced functional and cosmetic results ${ }^{19,20}$. In case of re-displacement the clinician is often confronted with a treatment dilemma, i.e. whether to accept some degree of re-displacement or to perform a secondary reduction of the fracture.

Several randomised studies compared treatment modalities for a combination of single-bone and both-bone forearm fractures in children. Two studies randomised between $\mathrm{AEC}$ and below-elbow cast and found the highest percentage of redisplacement in the AEC group, which could be explained by poor cast moulding ${ }^{4,14}$. Two other studies randomised between AEC with or without percutaneous pinning; redisplacement appeared only in the group without percutaneous pinning and was $21 \%$ in one and $39 \%$ in the other study ${ }^{9,10}$. Although these studies were well performed, none distinguished between fractures of the radius or ulna only, and fractures of both the radius and ulna, whereas the latter are notorious for their instability ${ }^{4,18,21}$.

Therefore, we performed a multicentre study designed for only displaced metaphyseal both-bone fractures of the distal forearm in children, which were apparent stable after reduction in the operation room. After randomisation the fractures were treated with AEC alone or a combination of percutaneous pinning with AEC.

The purpose of this study was to find out if re-displacement of a reduced stable metaphyseal both-bone fracture of the distal forearm in a child could be prevented by stabilisation with $\mathrm{K}$ wires. 


\section{Chapter 3}

\section{Materials AND Methods}

\section{Trial design and participants}

This trial was part of a prospective multicentre study that followed several types of both-bone forearm fractures in children. For the present study consecutive children with a displaced metaphyseal fracture of the distal radius and ulna (Figure 1) were included after a visit at the emergency department of one of four participating Dutch hospitals: Erasmus Medical Center (Rotterdam), HAGA Hospital (The Hague), Reinier de Graaf Hospital (Delft) and Sint Franciscus Hospital (Rotterdam).
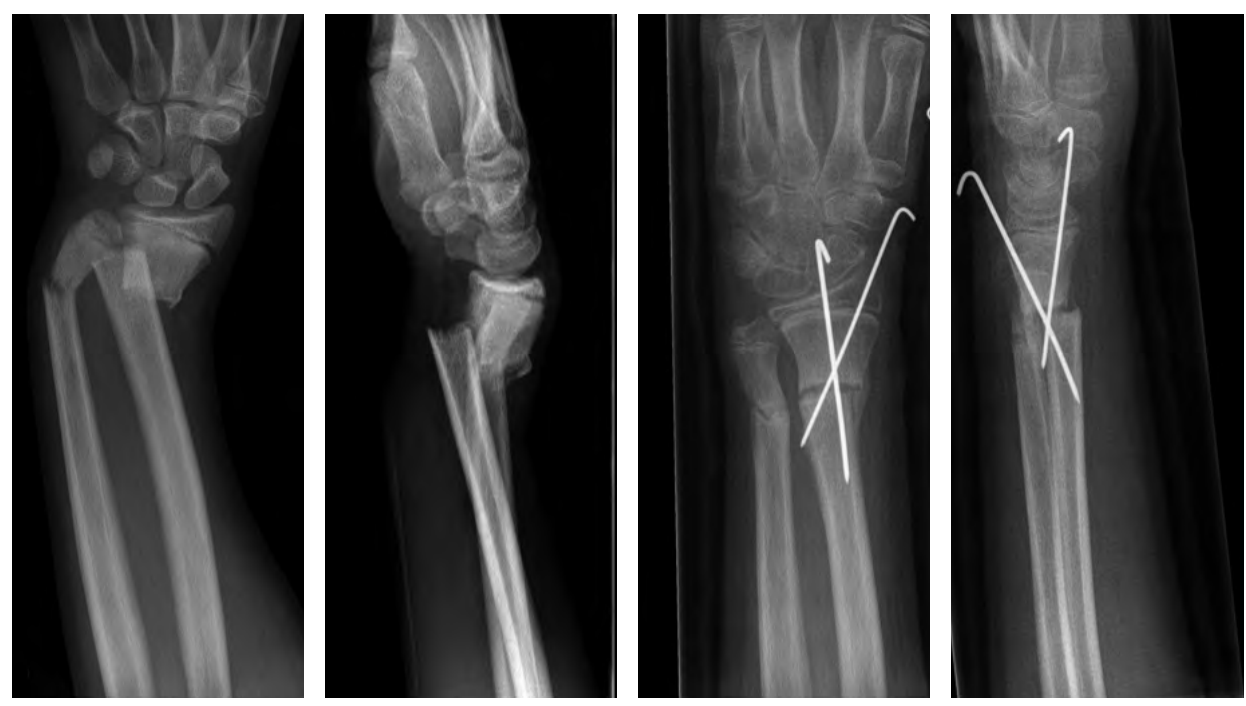

Figure 1. Posteroanterior and lateral radiographs of a displaced distal both-bone forearm fracture which is stabilised by two Kirschner wires.

The regional medical ethics committee approved the study, which was registered in ClinicalTrials.gov with registry identifier NCT00397852. Informed consent was obtained from all parents and from all children aged $\geq 12$ years.

Only included were children aged $<16$ years who sustained a displaced metaphyseal both-bone fracture of the distal forearm that was stable after closed reduction in the operating room. The criteria for reduction of the fracture were $a$ 
priori defined and based on previous studies (5, 6, 8, 22-28). A fracture was reduced if radius and/or ulna showed displacement on a posteroanterior and/or lateral radiograph. Displacement of the fracture was based on angulation $(>15$ degrees for children aged less than 10 years old and $>10$ degrees for children between 10 and 16 years old) and/or translation ( $>$ half of the bone diameter) and/or any rotation of radius and/or ulna.

Exclusion criteria were fractures older than 1 week, severe open fractures (Gustilo II and III) (29), and re-fractures. The primary outcome was re-displacement of the fracture. Secondary outcomes were limitation of pronation and supination, limitation of flexion and extension of wrist and elbow, complication rate, complaints in daily life, radiological assessment and cosmetics of the fractured arm.

\section{Procedures}

A surgeon reduced the fracture in the operating room under general anaesthesia with fluoroscopic guidance. After optimal reduction by closed means, the fracture was tested for stability. A fracture was defined as unstable if full range of pronation and supination of the proximal forearm caused re-displacement of the fracture. This test for stability was used before in a group of children with forearm fracturest. Unstable fractures were excluded and treated with percutaneous pinning and AEC for 4 weeks. The remaining fractures were defined as stable and were randomised between AEC alone and percutaneous pinning with AEC, both for 4 weeks.

The surgeon performed the percutaneous pinning according to a standard technique $^{10}$. A small skin incision was made over the radial styloid and blunt dissection of soft tissue was carried down to the bone. A K wire was directed proximally and ulnarly across the fracture site, engaging the opposite cortex. A second $\mathrm{K}$ wire was inserted from dorsal to volar across the fracture site through a small incision over the interval between the fourth and fifth dorsal compartments after blunt dissection down to the bone. Injury to the sensory branch of the radial nerve and the extensor tendons was avoided. The $\mathrm{K}$ wires were bent, cut and left transcutaneous. Additionally, the surgeon applied an AEC in the operation room. Primarily a stockinet and layer of wool were applied to protect the skin, bony prominences and $\mathrm{K}$ wires. Secondarily a well-fitted plaster slab was applied which covered approximately $2 / 3$ of the circumference of the arm. Finally, a bandage was 


\section{Chapter 3}

wrapped around the arm. The elbow was set in 90 degrees of flexion and the wrist in neutral position. All children received a sling for at least 1 week.

The children underwent clinical and radiological evaluation at 1,2 and 4 weeks after initial trauma. During these visits, a cast technician revised and renewed the casts where necessary. Re-displacement of the fracture was defined by the loss of reduction (angulation and/or translation) according to the primary reduction criteria. These re-displaced fractures required a second reduction with percutaneous pinning in the operating room. Finally, both the cast and the $\mathrm{K}$ wires were removed in the outpatient clinic after 4 weeks.

One orthopaedic surgeon (who was not involved in treatment and was not blinded) examined all children at 2 and 6 months after initial trauma. Flexion and extension of wrist and elbow in combination with pronation and supination of both arms were evaluated by a standardised procedure (Table 2$)^{31}$.

The pronation and supination were scaled using the grading system as described by Daruwalla with excellent, good, fair and poor results for respectively 0-10, 11-20, $21-30$ and $\geq 31$ degrees of limitation (Table 3 ) $^{23}$. Children with at least 30 degrees of functional impairment at 2 months examination received a referral for physiotherapy.

At the 6-month examination, parents and the orthopaedic surgeon completed a visual analogue scale (VAS) cosmetics, with maximum score for similar appearance of the fractured and non-fractures arm, to evaluate forearm alignment and scars. During the same examination, the parents filled in the ABILHAND-Kids questionnaire, that is a measure of manual ability for children with upper limb impairments (Table 2). The scale is validated for cerebral palsy children and measures a child's ability to manage daily activities that require the use of the upper limbs, with a maximum score of $42^{32}$.

Antero-posterior and lateral radiographs were taken at scheduled times (Table 4). The first radiographs were made in the emergency room followed by radiographs after reduction and during follow-up at 1,2 and 4 weeks. The final radiographs were made at 6 months after the trauma. Angulation, translation, shortening and rotation of fractures of all available radiographs were measured by the orthopaedic surgeon to determine primary displacement, displacement during the first 4 weeks, and final displacement at 6 months. The presence of rotation was evaluated by differences in width of ulna and radius on lateral and posteroanterior radiographs (33). 


\section{Randomisation and masking}

An independent physician randomised the children by sealed envelopes with varied block sizes. The children, parents and clinicians were not blinded for randomisation.

\section{Statistical methods}

To assess the number of children required for this trial, a superiority test was used to demonstrate a difference in re-displacement of 17\% between both groups: $3 \%$ redisplacement in the group treated with percutaneous pinning with AEC, and $20 \%$ re-displacement in the group treated with AEC alone $6,8,9,11,13,16,17,24,34-39$. With an a priori calculation it was determined that, with a power of $80 \%$ and a significance of 0.05, the two groups should consist of \pm 55 children each.

First, it was established whether the variables had a normal distribution using the normality Shapiro-Wilk test. Based on these analyses, the results are presented as means (standard deviations (SD)). The primary research question was analysed using logistic regression analysis (re-displacement as dependent variable, and intervention as independent variable). If necessary, adjustments for unbalanced covariates took place. Differences between both groups (percutaneous pinning with AEC vs. AEC alone) for the secondary outcome measures were analysed by one-way Anova to correct for multiple comparisons (Bonferroni). Statistical analyses were performed with SPSS 17.0 (SPSS Inc., Chicago, USA).

To assess the interrater reproducibility an independent trauma surgeon remeasured the angulation of the fracture of 45 children.

\section{Results}

Between January 2006 and August 2010 a total of 388 children with a metaphyseal both-bone fracture of the distal forearm were treated in the four Dutch hospitals. After exclusion for several reasons (details are given in Figure 2), 128 children were included of which 67 were allocated to AEC and 61 to $\mathrm{K}$ wires with AEC. 


\section{Chapter 3}

Figure 2. Flow diagram of enrollment

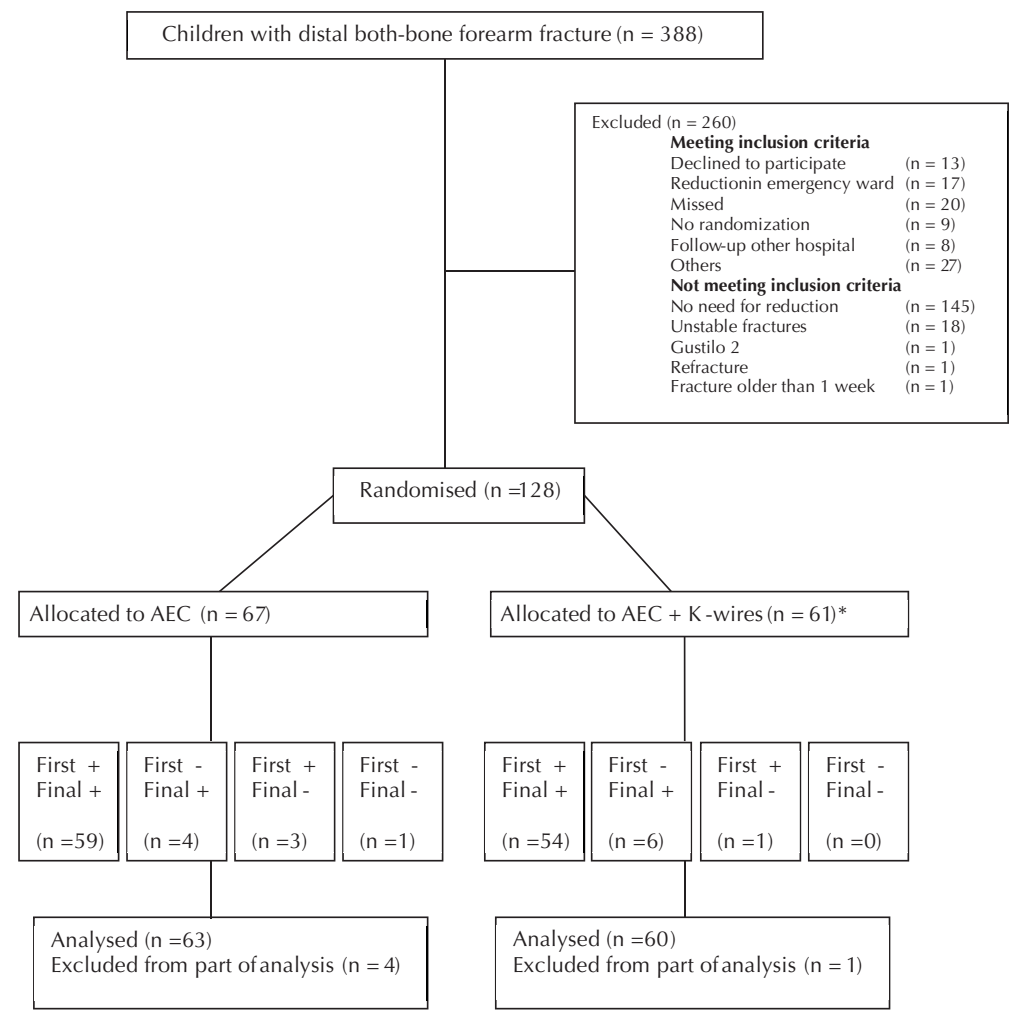

$n=$ number of children; $A E C=$ above elbow cast; First: first examination;

Final: final examination; + : examined; - : not examined; *insertion of $K$-wires failed in one child. 
The follow-up rate was $96 \%$ with a mean follow-up of 7.1 months. Table 1 shows the baseline characteristics of the total study population according to the randomisation group.

Table 1. Baseline characteristics

\begin{tabular}{lccc} 
& Total & AEC & K-wires + AEC \\
\hline Number of children & 128 & 67 & 61 \\
Age at time of fracture, years (mean \pm SD) & $8.8( \pm 3.1)$ & $8.7( \pm 3.2)$ & $9.0( \pm 3.0)$ \\
Gender, \% male & 64.8 & 62.7 & 67.2 \\
Dominant arm fractured, \% & 45.7 & 47.0 & 44.3 \\
& & & \\
Type fracture radius, \% & 0 & 0 & 0 \\
\hline Torus & 22.2 & 23.4 & 20.0 \\
Greenstick & 77.8 & 76.6 & 80.0 \\
Complete & & & \\
Type fracture ulna, \% & & & 6.7 \\
\hline Torus & 7.1 & 7.6 & 50.0 \\
Greenstick & 46.9 & 48.5 & 43.3 \\
Complete & 46.0 & & \\
\hline
\end{tabular}

AEC: Above Elbow Cast; K-wires: Kirschner wires; SD = standard deviation.

There are no significant differences between the groups. 


\section{Chapter 3}

In the AEC group 30 fractures showed re-displacement of which 17 were reduced a second time. In the group with additional $\mathrm{K}$ wires, five fractures showed redisplacement of which one fracture was reduced a second time (Table 2).

Table 2. Outcomes.

\begin{tabular}{lcc} 
& AEC & K-wires + AEC \\
& $n=67$ & $\mathbf{n}=61$ \\
\hline Re-displacement, \% * & 44.8 & 8.2 \\
Days in cast & $33.4( \pm 8.8)$ & $32.2( \pm 6.1)$ \\
Days untill first clinical examination & $68.4( \pm 25.4)$ & $69.7( \pm 28.5)$ \\
Days untill final clinical examination & $216.3( \pm 49.1)$ & $215.5( \pm 47.2)$ \\
Referral to physiotherapy ,\% & 54.5 & 35.6 \\
Number of visits to physiotherapy & $3.9( \pm 7.3)$ & $2.6( \pm 6.1)$ \\
Limitation of wrist flexion-extension of the fractured arm, degrees & $4.4( \pm 6.2)$ & $3.8( \pm 7.4)$ \\
Limitation of elbow flexion-extension of the fractured arm, degrees & $0.5( \pm 2.0)$ & $0.2( \pm 2.1)$ \\
VAS cosmetics fractured arm by parents & $8.5( \pm 1.8)$ & $8.0( \pm 2.2)$ \\
VAS cosmetics fractured arm by orthopedic surgeon & $8.9( \pm 1.2)$ & $8.4( \pm 1.3)$ \\
Total ABILHAND score at final clinical examination & $41.5( \pm 1.6)$ & $41.9( \pm 0.4)$ \\
\hline Values are presented as mean $( \pm$ standard deviation ) unless stated otherwise. AEC: above elbow cast; K-wires: \\
Kirschner wires; VAS: Visual Analogue Scale. & & \\
* Significant difference (p<0.0001). & &
\end{tabular}

Re-displacement in the group with additional $\mathrm{K}$ wires was caused by suboptimal position of the $\mathrm{K}$ wires in 2 children and re-displacement of the ulna in 3 children. Fracture re-displacement was first observed in 14 children at the 1-week examination, in 19 children at the 2-week examination and in 2 children at the 4week examination. Thereby, we found a similar rate of re-displacement in greenstick and complete fractures.

Pronation and supination at the final examination showed significantly less limitation in the group initially treated with additional K wires (Table 3). 
Table 3. Limitation of pronation and supination of fractured arm.

\begin{tabular}{|c|c|c|}
\hline & $\begin{array}{c}\text { AEC } \\
n=67\end{array}$ & $\begin{array}{c}\text { K-wires + AEC } \\
n=61\end{array}$ \\
\hline \multicolumn{3}{|l|}{ Two months after the fracture } \\
\hline none & 9.7 & 11.0 \\
\hline $1-10$ degrees & 22.6 & 34.5 \\
\hline $11-20$ degrees & 14.5 & 18.2 \\
\hline 21-30 degrees & 14.5 & 14.5 \\
\hline$>31$ degrees & 38.7 & 21.8 \\
\hline Mean limitation (+SD), degrees & $27.2( \pm 21.9)$ & $21.9( \pm 21.4)$ \\
\hline \multicolumn{3}{|l|}{ Six months after the fracture } \\
\hline none & 23.8 & 48.3 \\
\hline 1-10 degrees & 31.7 & 31.7 \\
\hline $11-20$ degrees & 19.0 & 10.0 \\
\hline 21-30 degrees & 14.3 & 8.3 \\
\hline$>31$ degrees & 11.2 & 1.7 \\
\hline Mean limitation (+SD), degrees & $14.3( \pm 13.6)^{*}$ & $6.9( \pm 9.4)^{*}$ \\
\hline \multicolumn{3}{|c|}{ AEC: Above Elbow Cast; K-wires: Kirschner wires. Data are presented as percentage. } \\
\hline \multicolumn{3}{|l|}{ SD = standard deviation. } \\
\hline * Significant difference $(p=0.001$ & & \\
\hline
\end{tabular}

Thereby, more complications occurred in the group treated with $\mathrm{K}$ wires and AEC than in the group treated with AEC (14 vs 1). The complications seen in the group treated with $\mathrm{K}$ wires and AEC were 7 subcutaneous $\mathrm{K}$ wires, 3 re-fractures, 2 superficial infections, 1 failed insertion of $K$ wires and 1 transient neuropraxia. This last complication occurred also once in the group treated with only AEC.

Other secondary outcomes were similar in both groups and are shown in Table 2.

Measurement of the radiographs (Table 4) revealed a decrease in angulation and translation after reduction in both groups and an increase in angulation in the period between reduction and removal of the cast only in the group treated with 


\section{Chapter 3}

AEC alone. Furthermore, a decrease in angulation in the period between the removal of the cast and the final examination was seen in both groups.

Table 4. Radiological outcomes.

\begin{tabular}{|c|c|c|c|c|c|c|c|c|}
\hline & & $\mathrm{AE}$ & & & & $A E C+K$ & -wires & \\
\hline & Trauma & $\begin{array}{l}\text { After } \\
\text { reduction }\end{array}$ & $\begin{array}{l}\text { Removal } \\
\text { of cast }\end{array}$ & Final & Trauma & $\begin{array}{c}\text { After } \\
\text { reduction }\end{array}$ & $\begin{array}{l}\text { Removal } \\
\text { of cast }\end{array}$ & Final \\
\hline Angulation & & & & & & & & \\
\hline AP ulna & $13( \pm 12)^{2}$ & $5( \pm 4)^{23}$ & $6( \pm 4)^{4}$ & $4( \pm 3)^{34}$ & $14( \pm 11)^{2}$ & $5( \pm 4)^{2}$ & $5( \pm 4)$ & $4( \pm 3)$ \\
\hline AP radius & $12( \pm 9)^{2}$ & $5( \pm 4)^{23}$ & $8( \pm 7)^{134}$ & $5( \pm 4)^{14}$ & $15( \pm 12)^{2}$ & $4( \pm 3)^{23}$ & $4( \pm 2)^{14}$ & $3( \pm 2)^{134}$ \\
\hline Lateral ulna & $21( \pm 17)^{2}$ & $5( \pm 4)^{23}$ & $6( \pm 5)^{4}$ & $3( \pm 3)^{34}$ & $19( \pm 15)^{2}$ & $5( \pm 5)^{23}$ & $5( \pm 4)^{4}$ & $4( \pm 3)^{34}$ \\
\hline Lateral radius & $21( \pm 12)^{2}$ & $7( \pm 5)^{123}$ & $13( \pm 11)^{134}$ & $8( \pm 5)^{14}$ & $22( \pm 11)^{2}$ & $5( \pm 4)^{12}$ & $6( \pm 5)^{13}$ & $4( \pm 2)^{13}$ \\
\hline Translation & & & & & & & & \\
\hline PA ulna & $12( \pm 24)^{2}$ & $4( \pm 11)^{2}$ & * & * & $9( \pm 25)$ & $6( \pm 14)$ & * & * \\
\hline $\mathrm{PA}$ radius & $24( \pm 28)^{2}$ & $7( \pm 9)^{2}$ & * & * & $29( \pm 36)^{2}$ & $6( \pm 9)^{2}$ & * & * \\
\hline Lateral ulna & $19( \pm 31)^{2}$ & $5( \pm 13)^{2}$ & * & * & $10( \pm 24)^{2}$ & $4( \pm 9)^{2}$ & * & * \\
\hline Lateral radius & $54( \pm 47)^{2}$ & $8( \pm 13)^{2}$ & * & * & $63( \pm 45)^{2}$ & $5( \pm 9)^{2}$ & * & * \\
\hline Shortening of $r$ & nd/or ulna & & & & & & & \\
\hline$\%$ & 68.2 & & & & 67.8 & & & \\
\hline Rotation of rad & lor ulna & & & & & & & \\
\hline$\%$ & 15.2 & & & & 21.7 & & & \\
\hline $\begin{array}{l}\text { Angulation: Ra } \\
\text { degrees as me }\end{array}$ & $\begin{array}{l}\text { r angulation } \\
\text { tandard devi }\end{array}$ & $\begin{array}{l}\text { (PA ulna, PA } \\
\text { ation ). }\end{array}$ & A radius) and sa & agittal angul & tion (Lateral & ulna, Latera & radius) p & resented in \\
\hline $\begin{array}{l}\text { Translation: Ra } \\
\text { percentage of }\end{array}$ & $\begin{array}{l}\text { r translation } \\
\text { th of ulna or }\end{array}$ & $\begin{array}{l}\text { (PA ulna, PA } \\
\text { radius as me }\end{array}$ & $\begin{array}{l}\text { A radius) and sa } \\
\text { ean ( } \pm \text { standarc }\end{array}$ & $\begin{array}{l}\text { agittal transl } \\
\text { d deviation ) }\end{array}$ & ion (Lateral & ulna, Latera & radius) p & resented in \\
\hline Shortening anc & n as percent & age of appe & arance. & & & & & \\
\hline${ }^{1}$ Significant di & between $b$ & oth groups. & & & & & & \\
\hline 234 Significant & ces within & e group & & & & & & \\
\hline
\end{tabular}

The interrater reproducibility of the radiological assessment by measurement of angulation of the ulna and radius on both the posterioanterior and lateral radiographs showed an intraclass correlation (ICC) range of 0.81-0.92. 


\section{Discussion}

The purpose of this study was to find out if re-displacement of a reduced stable metaphyseal both-bone fracture of the distal forearm in a child could be prevented by stabilisation with $\mathrm{K}$ wires. As expected, this study shows that additional percutaneous pinning decreased fracture re-displacement compared to AEC alone. It was also found that children treated with additional pinning showed a small but significant decrease of limitation of pronation and supination after 7 months. Nevertheless, the group treated with additional pinning paid the price with a higher rate of complications. Most of these complications consisted of subcutaneous $\mathrm{K}$ wires that could probably have been avoided by not cutting the transcutaneous $\mathrm{K}$ wires too short.

\section{Previous studies}

Previous randomised trials reported re-displacement after reduction of distal metaphyseal forearm fractures in children treated with an AEC in 15-42\% $4,9,10,14$ while retrospective studies found $7-91 \% \%^{6,7,11-13,15-18}$. Our re-displacement rate of $45 \%$ in the group treated with AEC alone is relatively high and could be explained by more instable both-both forearm fractures and the application of a plaster slab instead of a circumferential cast directly after reduction.

Our group of children treated with $\mathrm{K}$ wires showed more re-displacement than reported previously ${ }^{5,6,10,12}$. This re-displacement was caused by technical errors in 2 children and re-displacement of the non-fixated ulna in 3 children.

Similar to other studies ${ }^{9,11}$ only $51 \%$ of our re-displaced fractures were reduced a second time, although this was suggested in our study protocol. Although not planned, this illustrates the reluctance of the treating surgeons to choose for a second reduction (for various reasons). On the one hand the treating surgeon may hope or expect correction of the malunion due to growth, on the other hand the surgeon may be reluctant to burden the child again or finds it difficult to accept failure of the initial treatment.

Additional operations after the first reduction were mainly caused by a second reduction and removal of subcutaneous $\mathrm{K}$ wires. In contrast with an earlier study ${ }^{9}$, in the present study the $\mathrm{K}$ wires were generally removed in the outpatient clinic without problems, which substantially decreases the number of re-operations. 


\section{Chapter 3}

The limitation of pronation and supination in the children treated with AEC alone was higher in the present study than in earlier reports ${ }^{5,8-10,13,23,40}$. Our less favourable outcomes might be explained by the inclusion of only children with both-bone forearm fractures, the prospective nature of our study, the high rate and relatively short time of follow-up. On closer examination, we found a limitation of pronation and supination of $\geq 30$ degrees in 11 children treated with AEC and in 3 children treated with K wires and AEC. Only 6 of these children showed a malunion at final radiographs. These findings support the opinion that malunion is not the only cause of limitation of pronation and supination after both-bone forearm fractures in children ${ }^{27,41-45}$.

\section{Radiological assessment}

As expected, measurement of the radiographs revealed a decrease in angulation and translation after reduction in both groups, which is explained by a correct reduction. The increase in angulation in the period between reduction and removal of the cast only in the group treated with AEC alone was caused by re-displacement. In both groups, a decrease in angulation in the period between the removal of the cast and the final examination was caused by correction due to growth.

\section{Study limitations}

The first limitation was the wide age range of the included children combined with our strict reduction criteria. This study was part of a prospective multicentre randomised study that followed all types of both-bone forearm fractures in children and used the same reduction criteria for metaphyseal and diaphyseal forearm fractures. Although we adjusted the criteria for reduction to two age groups, the reduction criteria for metaphyseal fractures in the youngest children may have been too strict.

The second limitation was our relatively short time of follow-up. A longer period of follow-up might reduce the number of children with an impairment of function as is described by Price et al. ${ }^{40}$.

To conclude, this is the first randomised multicentre study to evaluate displaced metaphyseal both-bone fractures of the distal forearm in children. Pinning of apparent stable both-bone fractures of the distal forearm in children might reduce 


\section{Displaced metaphyseal fractures}

fracture re-displacement and might result in less limitation of pronation and supination. The frequently seen complications of pinning might be reduced by a proper surgical technique. 


\section{Chapter 3}

\section{REFERENCES}

1. Jones IE, Cannan R, Goulding A. Distal forearm fractures in New Zealand children: annual rates in a geographically defined area. N Z Med J. 2000;113(1120):443-5.

2. Reed FE, Jr., Apple DF, Jr. Ipsilateral fractures of the elbow and forearm. South Med J. 1976;69(2):149-51.

3. Worlock P, Stower M. Fracture patterns in Nottingham children. J Pediatr Orthop. 1986;6(6):656-60.

4. Bohm ER, Bubbar V, Yong Hing K, Dzus A. Above and below-the-elbow plaster casts for distal forearm fractures in children. A randomized controlled trial. J Bone Joint Surg Am. 2006;88(1):1-8.

5. Choi KY, Chan WS, Lam TP, Cheng JC. Percutaneous Kirschner-wire pinning for severely displaced distal radial fractures in children. A report of 157 cases. J Bone Joint Surg Br. 1995;77(5):797-801.

6. Gibbons CL, Woods DA, Pailthorpe C, Carr AJ, Worlock P. The management of isolated distal radius fractures in children. J Pediatr Orthop. 1994;14(2):207-10.

7. Kiely PD, Kiely PJ, Stephens MM, Dowling FE. Atypical distal radial fractures in children. J Pediatr Orthop B. 2004;13(3):202-5.

8. Mani GV, Hui PW, Cheng JC. Translation of the radius as a predictor of outcome in distal radial fractures of children. J Bone Joint Surg Br. 1993;75(5):808-11.

9. McLauchlan GJ, Cowan B, Annan IH, Robb JE. Management of completely displaced metaphyseal fractures of the distal radius in children. A prospective, randomised controlled trial. J Bone Joint Surg Br. 2002;84(3):413-7.

10. Miller BS, Taylor B, Widmann RF, Bae DS, Snyder BD, Waters PM. Cast immobilization versus percutaneous pin fixation of displaced distal radius fractures in children: a prospective, randomized study. J Pediatr Orthop. 2005;25(4):490-4.

11. Proctor MT, Moore DJ, Paterson JM. Redisplacement after manipulation of distal radial fractures in children. J Bone Joint Surg Br. 1993;75(3):453-4.

12. Van Leemput W, De Ridder K. Distal metaphyseal radius fractures in children: reduction with or without pinning. Acta Orthop Belg. 2009;75(3):306-9.

13. Voto SJ, Weiner DS, Leighley B. Redisplacement after closed reduction of forearm fractures in children. J Pediatr Orthop. 1990;10(1):79-84. 


\section{Displaced metaphyseal fractures}

14. Webb GR, Galpin RD, Armstrong DG. Comparison of short and long arm plaster casts for displaced fractures in the distal third of the forearm in children. J Bone Joint Surg Am. 2006;88(1):9-17.

15. Blount WP. Forearm fractures in children. 1967. Clin Orthop Relat Res. 2005(432):4-7.

16. Friberg KS. Remodelling after distal forearm fractures in children. I. The effect of residual angulation on the spatial orientation of the epiphyseal plates. Acta Orthop Scand. 1979;50(5):537-46.

17. Haddad FS, Williams RL. Forearm fractures in children: avoiding redisplacement. Injury. 1995;26(10):691-2.

18. Zamzam MM, Khoshhal KI. Displaced fracture of the distal radius in children: factors responsible for redisplacement after closed reduction. J Bone Joint Surg Br. 2005;87(6):841-3.

19. Prommersberger KJ, Froehner SC, Schmitt RR, Lanz UB. Rotational deformity in malunited fractures of the distal radius. J Hand Surg [Am]. 2004;29(1):110-5.

20. Roberts JA. Angulation of the radius in children's fractures. J Bone Joint Surg Br. 1986;68(5):751-4.

21. Green JS, Williams SC, Finlay D, Harper WM. Distal forearm fractures in children:the role of radiographs during follow up. Injury. 1998;29(4):309-12.

22. Boyer BA, Overton B, Schrader W, Riley P, Fleissner P. Position of immobilization for pediatric forearm fractures. Journal of pediatric orthopedics. 2002;22(2):185-7.

23. Daruwalla JS. A study of radioulnar movements following fractures of the forearm in children. Clin Orthop Relat Res. 1979(139):114-20.

24. Jones K, Weiner DS. The management of forearm fractures in children: a plea for conservatism. J Pediatr Orthop. 1999;19(6):811-5.

25. Maric D, Petkovic L, Tomasevic V, Bajic L, Gajdobranski D, Marcikic A. [Osteosynthesis with Kirschner wires in the treatment of dislocation fractures of the forearm in children]. Med Pregl. 2002;55(3-4):140-5.

26. Noonan KJ, Price CT. Forearm and distal radius fractures in children. J Am Acad Orthop Surg. 1998;6(3):146-56.

27. Tynan MC, Fornalski S, McMahon PJ, Utkan A, Green SA, Lee TQ. The effects of ulnar axial malalignment on supination and pronation. J Bone Joint Surg Am. 2000;82-A(12):1726-31.

28. Zimmermann R, Gabl M, Angermann P, Lutz M, Reinhart C, Kralinger F, et al. [Late sequelae of fractures of the distal third of the forearm during the growth period]. Handchir Mikrochir Plast Chir. 2000;32(4):242-9. 


\section{Chapter 3}

29. Gustilo RB, Simpson L, Nixon R, Ruiz A, Indeck W. Analysis of 511 open fractures. Clin Orthop Relat Res. 1969;66:148-54.

30. Myers GJ, Gibbons PJ, Glithero PR. Nancy nailing of diaphyseal forearm fractures. Single bone fixation for fractures of both bones. J Bone Joint Surg Br. 2004;86(4):581-4.

31. Colaris J, van der Linden M, Selles R, Coene N, Allema JH, Verhaar J. Pronation and supination after forearm fractures in children: Reliability of visual estimation and conventional goniometry measurement. Injury. 2010;41(6):643-6.

32. Arnould C, Penta M, Renders A, Thonnard JL. ABILHAND-Kids: a measure of manual ability in children with cerebral palsy. Neurology. 2004;63(6):1045-52.

33. Naimark A, Kossoff J, Leach RE. The disparate diameter. A sign of rotational deformity in fractures. J Can Assoc Radiol. 1983;34(1):8-11.

34. Chan CF, Meads BM, Nicol RO. Remanipulation of forearm fractures in children. N Z Med J. 1997;110(1047):249-50.

35. Cullen MC, Roy DR, Giza E, Crawford AH. Complications of intramedullary fixation of pediatric forearm fractures. J Pediatr Orthop. 1998;18(1):14-21.

36. Richter D, Ostermann PA, Ekkernkamp A, Muhr G, Hahn MP. Elastic intramedullary nailing: a minimally invasive concept in the treatment of unstable forearm fractures in children. J Pediatr Orthop. 1998;18(4):457-61.

37. Vainionpaa S, Bostman O, Patiala H, Rokkanen P. Internal fixation of forearm fractures in children. Acta Orthop Scand. 1987;58(2):121-3.

38. Voto SJ, Weiner DS, Leighley B. Use of pins and plaster in the treatment of unstable pediatric forearm fractures. J Pediatr Orthop. 1990;10(1):85-9.

39. Younger AS, Tredwell SJ, Mackenzie WG. Factors affecting fracture position at cast removal after pediatric forearm fracture. J Pediatr Orthop. 1997;17(3):332-6.

40. Price CT, Scott DS, Kurzner ME, Flynn JC. Malunited forearm fractures in children. J Pediatr Orthop. 1990;10(6):705-12.

41. Dumont CE, Thalmann R, Macy JC. The effect of rotational malunion of the radius and the ulna on supination and pronation. J Bone Joint Surg Br. 2002;84(7):1070-4.

42. van Geenen RC, Besselaar PP. Outcome after corrective osteotomy for malunited fractures of the forearm sustained in childhood. J Bone Joint Surg Br. 2007;89(2):236-9.

43. Weinberg AM, Pietsch IT, Krefft M, Pape HC, van Griensven M, Helm MB, et al. [Pronation and supination of the forearm. With special reference to the humero-ulnar articulation]. Unfallchirurg. 2001;104(5):404-9. 


\section{Displaced metaphyseal fractures}

44. Yasutomi T, Nakatsuchi Y, Koike H, Uchiyama S. Mechanism of limitation of pronation/supination of the forearm in geometric models of deformities of the forearm bones. Clin Biomech (Bristol, Avon). 2002;17(6):456-63.

45. Nilsson BE, Obrant $\mathrm{K}$. The range of motion following fracture of the shaft of the forearm in children. Acta Orthop Scand. 1977;48(6):600-2. 


\section{Chapter 4}

Early conversion to below-elbow cast for non-reduced diaphyseal both-bone forearm fractures in children is safe: preliminary results of a multicentre randomised controlled trial

Arch Orthop Trauma Surg. 2013 Oct;133(10):1407-14

Colaris JW, Reijman M, Allema JH, Biter LU, Bloem RM, van de Ven CP, de Vries MR, Kerver AJ, Verhaar JA. 


\section{Chapter 4}

\section{Abstract}

Introduction: This multicentre randomised controlled trial was designed to explore whether 6 weeks above-elbow cast (AEC) or 3 weeks AEC followed by 3 weeks below-elbow cast (BEC) cause similar limitation of pronation and supination in nonreduced diaphyseal both-bone forearm fractures in children.

Materials and Methods: Children were randomly allocated to 6 weeks AEC or to 3 weeks AEC followed by 3 weeks BEC. The primary outcome was limitation of pronation and supination after 6 months. The secondary outcomes were redisplacement of the fracture, complication rate, limitation of flexion and extension of wrist and elbow, cast comfort, cosmetics, complaints in daily life and assessment of radiographs.

Results: A group of 23 children was treated with 6 weeks AEC and 24 children with 3 weeks AEC and 3 weeks BEC. The follow-up rate was $98 \%$ with a mean follow-up of 7.0 months.

The mean limitation of pronation and supination was $23.3( \pm 22.0)$ for children treated with AEC and $18.0( \pm 16.9)$ for children treated with AEC and BEC. The other study outcomes were similar in both groups.

Conclusions: Early conversion to BEC is safe in the treatment of non-reduced diaphyseal both-bone forearm fractures in children. 


\section{INTRODUCTION}

Both-bone diaphyseal forearm fractures are common in children and are generally treated with cast, intramedullary nails or plates. The treatment with cast usually consists of an above-elbow cast (AEC) for 6-9 weeks, although conversion to a below-elbow cast (BEC) at the end of treatment is frequently seen ${ }^{1-11}$. Although many of these fractures heal without complications, limitation of pronation and supination can occur. An average limitation of 20 degrees in about $15 \%$ of children has been reported $^{6,12,13}$.

This limitation of pronation and supination after both-bone diaphyseal forearm fractures in children seems to be caused by both malunion of the radius and/or the ulna, and a contracture of the surrounding soft tissue ${ }^{13-18}$.

Early conversion to BEC in the treatment of these fractures could potentially effect the limitation of pronation and supination in two opposing ways. On the one hand, BEC does not immobilise the elbow and could therefore result in displacement of the fracture, malunion and consequently more limitation. On the other hand, BEC allows free movement of the elbow that could result in less contractures of soft tissue and consequently less limitation.

Nevertheless, the influence of AEC and BEC on limitation of pronation and supination remains unclear. Therefore, this multicentre randomised controlled trial aimed to clarify the role of AEC and BEC on limitation of pronation and supination in non-reduced both-bone diaphyseal forearm fractures in children. Specifically, the following question was explored: do 6 weeks AEC as compared with 3 weeks AEC followed by 3 weeks BEC cause similar limitation of pronation and supination?

\section{Materials ANd Methods}

\section{Trial design and participants}

A multicentre randomised controlled trial was performed that included consecutive children with a diaphyseal forearm fracture of the radius and ulna who visited the emergency department of one of four participating hospitals. The Dutch hospitals participating in this study were Erasmus Medical Center (Rotterdam), HAGA Hospital (The Hague), Reinier de Graaf Hospital (Delft) and Sint Franciscus Hospital 


\section{Chapter 4}

(Rotterdam). The regional medical ethics committee approved the study and it was registered in Clinical Trials.gov with registry identifier NCT00314600. Informed consent was obtained for participation from all parents and from all children aged $\geq 12$ years.

We included children with an age $<16$ years who sustained a diaphyseal bothbone forearm fracture without need for reduction (Figure 1).

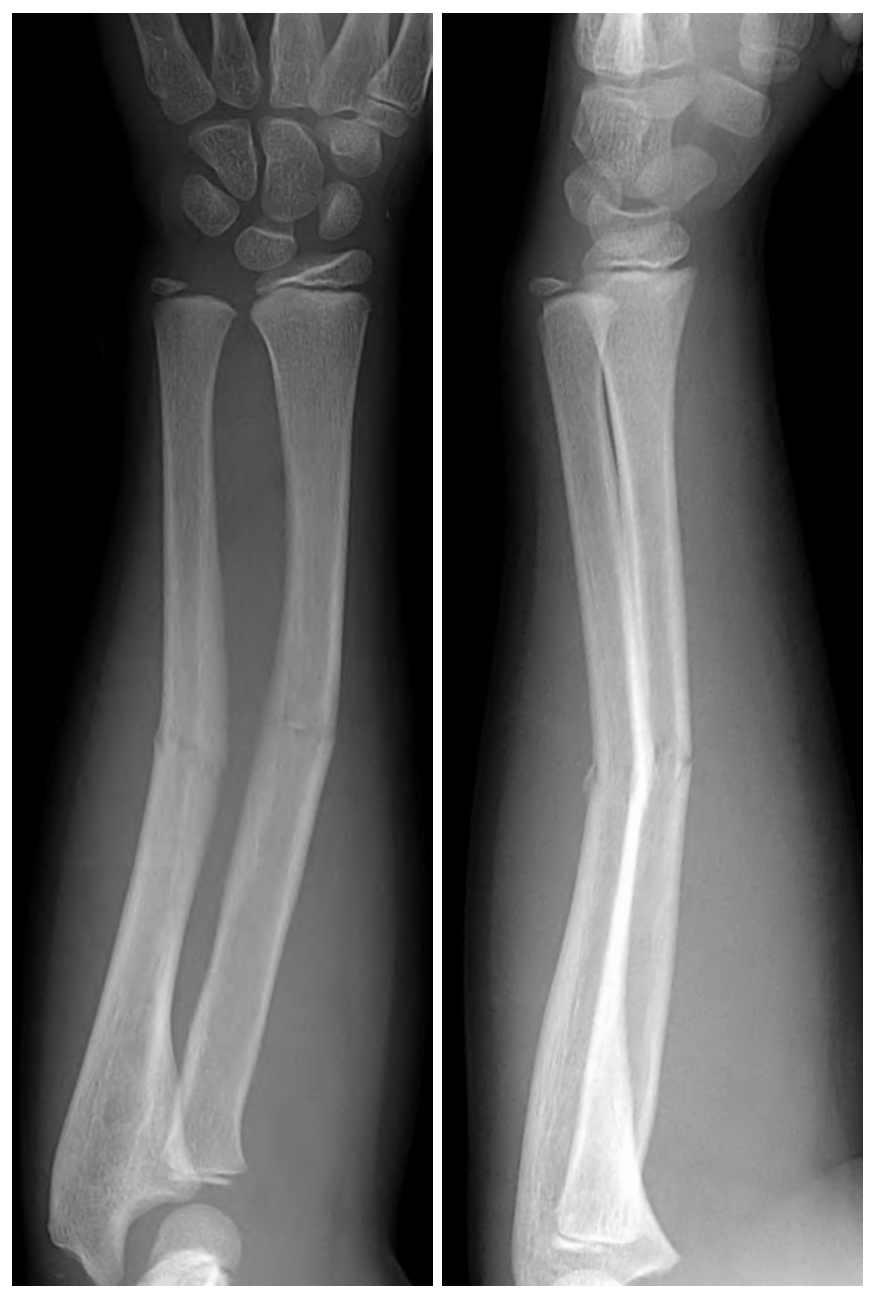

Figure 1. Radiographs of a minimally displaced diaphyseal both-bone forearm fracture 
The criteria for reduction were a priori defined and based on earlier studies $(3,15$, 19-26) (Table 1). Exclusion criteria were fractures older than 1 week, severe open fractures (Gustilo II and III) (27) and re-fractures.

Table 1. Criteria for reduction of the fracture of radius and/or ulna based on posteroanterior and/or lateral radiographs.

\begin{tabular}{lcc} 
Type of displacement & Age in years & Displacement \\
\hline Angulation & $<10$ & $>15$ degrees \\
& $10-16$ & $>10$ degrees \\
Translation & $<16$ & $>$ half of bone diameter \\
Rotation & $<16$ & $>0$
\end{tabular}

Because most published studies do not adequately address true, final range of pronation and supination ${ }^{28}$ we choose limitation of pronation and supination compared to the non-injured site 6 months after the initial trauma as primary outcome. The secondary outcomes were re-displacement of the fracture, complication rate, limitation of flexion and extension of wrist and elbow, cast comfort, cosmetics, complaints in daily life, and assessment of radiographs. The children were allocated to either 6 weeks of AEC or to 3 weeks of AEC followed by 3 weeks of BEC.

\section{Procedures}

Trained nurses applied the AEC in the plaster room of the emergency department. First, a stockinet and layer of wool were applied to protect the skin and bony prominences. Then, a well-fitted plaster slab was applied which covered about 2/3 of the circumference of the arm. Finally, a bandage was wrapped around the arm. The elbow was set in 90 degrees of flexion and the forearm in neutral position. All children received a sling for at least 1 week. The children visited a surgeon at 1, 3 and 6 weeks after the initial trauma. A cast technician revised and renewed the casts where necessary. In children allocated to BEC, the cast technician applied a circumferential BEC after 3 weeks; this BEC allowed free movement of the elbow joint. 


\section{Chapter 4}

Fracture displacement, as defined by the loss of reduction according to the primary reduction criteria (Table 1), required new fracture reduction. Finally, the cast was removed 6 weeks after initial treatment.

One orthopaedic surgeon (not involved in the primary treatment) examined all children 2 and 6 months after the initial trauma. Flexion and extension of wrist and elbow in combination with pronation and supination of both arms were evaluated using a standardised procedure ${ }^{29}$. The pronation and supination were scaled using the grading system as described by Daruwalla with excellent, good, fair and poor results for, respectively, 0-10, 11-20, 21-30 and $\geq 31$ degrees of limitation ${ }^{3}$.

Children with at least 30 degree of functional impairment at the 2-month examination were referred to physiotherapy. Furthermore, the parents filled in a visual analogue scale (VAS) to evaluate the comfort of the cast, with the highest score for maximal comfort. In addition, the parents were asked to fill in a questionnaire to evaluate difficulties with seven activities of daily living during the period of cast. This questionnaire has previously been used in a similar group of children ${ }^{30}$.

The parents and the orthopaedic surgeon completed a VAS cosmetics of the fractured arm, with a maximum score for similar appearance of the fractured and non-fractured arm. In the same consultation, complaints of the fractured arm were documented using a modified grading system. This grading system combines limitation of pronation and supination with complaints in daily life or during strenuous activities. It has previously been used in a similar group of children ${ }^{31}$. The parents also filled in an ABILHAND-Kids questionnaire ${ }^{32}$, which is a measure of manual ability for children with upper limb impairments. This scale has been validated for children with cerebral palsy and measures a child's ability to manage daily activities that require use of the upper limbs, with a maximum score of $42^{32}$.

Radiographs were taken in the emergency room followed by radiographs during follow-up at 1, 3 and 6 weeks. The final radiographs were made 6 months after the initial trauma. The orthopaedic surgeon measured angulation, translation, rotation and shortening of fractures to determine primary displacement, displacement during treatment with cast and final displacement at 6 months. The presence of rotation was evaluated by differences in the width of the ulna and radius on lateral and posterioanterior radiographs ${ }^{33}$. 


\section{Randomisation and masking}

An independent physician randomised the children by sealed envelopes with varied block sizes. None of the children, parents, surgeon, cast technician and independent orthopaedic surgeon was blinded for allocation.

\section{Statistical methods}

The primary aim of the study was to determine whether 6 weeks AEC compared with 3 weeks AEC and 3 weeks BEC, cause equal limitation of pronation and supination 6 months after the initial trauma. The required number of children for this equivalence study was calculated a priori. Equivalence between the two groups was defined as a maximum of 15 degrees less pronation or supination in the group treated with AEC and BEC. We chose 15 degrees of limitation in order to stay within the safe margins of good results as graded previously ${ }^{3}$. With an a priori calculation it was determined that with a power of $80 \%$, an alpha of 0.05 and a standard deviation (SD) of 15 degrees, the two groups should consist of \pm 30 children each.

First, it was established whether the variables had a normal distribution using the normality Shapiro-Wilk test. Based on these analyses, the results are presented as means and SD. The primary research question was analysed using linear regression analysis (limitation of pronation and supination of the fractured arm 6 months after initial trauma as dependent variable, and the intervention as independent variable). If necessary, adjustments for unbalanced covariates were made. Differences between the two groups for the secondary outcome measures were analysed by one-way Anova to correct for multiple comparisons (Bonferroni). Statistical analyses were performed with SPSS 17.0 (SPSS Inc., Chicago, USA).

\section{Results}

Between January 2006 and August 2010 a total of 47 children were included in the four Dutch hospitals. A group of 23 children was randomised to 6 weeks AEC and 24 children were randomised to 3 weeks AEC followed by 3 weeks BEC (Figure 2). 


\section{Chapter 4}

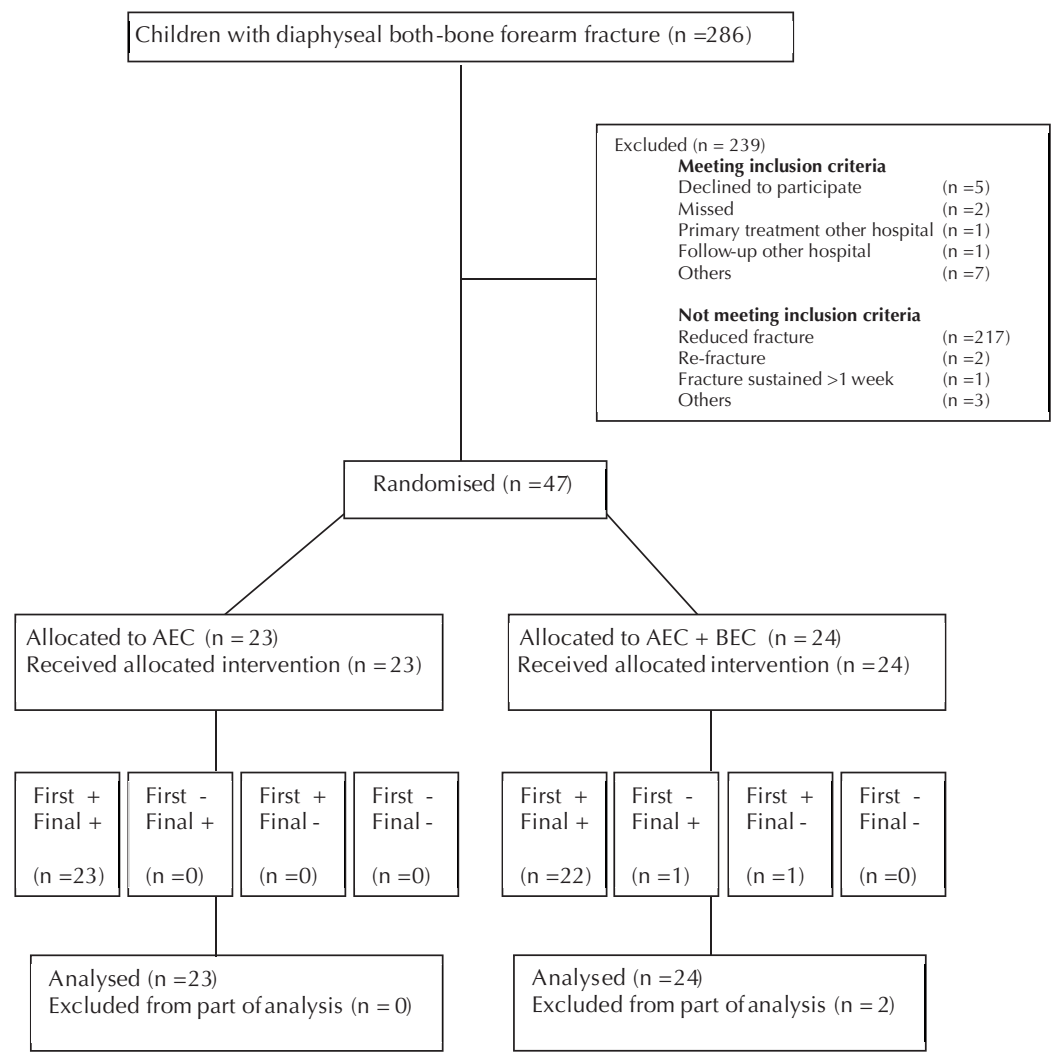

$n=$ number of children; $A E C=$ above elbow cast; $B E C=$ below elbow cast First: first examination;

Final: final examination; + : examined; - : not examined.

Figure 2. Flowchart of enrolment in the study. 
Table 2 shows the baseline characteristics of the total study population and per randomisation.

Table 2. Baseline characteristics of the study population.

\begin{tabular}{lccc} 
& Total & AEC & AEC + BEC \\
\hline Number of children & 47 & 23 & 24 \\
Age in years at time of fracture: mean (SD) & $6.4( \pm 3.4)$ & $6.5( \pm 3.5)$ & $6.2( \pm 3.4)$ \\
Gender, \% male & 48.9 & 56.5 & 41.7 \\
Dominant arm fractured, \% & 41.3 & 40.9 & 41.7 \\
& & & \\
Type fracture radius, \% & 68.1 & & 62.5 \\
\hline Greenstick & 31.9 & 26.1 & 37.5 \\
Complete & 57.1 & 60.3 & 52.7 \\
Location of fracture of radius*, \% & & & \\
& & & 66.7 \\
Type fracture ulna, \% & 61.7 & 56.5 & 33.3 \\
\hline Greenstick & 38.3 & 43.5 & 42.6 \\
Complete & 42.6 & 41.7 & \\
Location of fracture of ulna*, \% & & & \\
\hline AEC: above-elbow cast; BEC: below-elbow cast; SD $=$ standard deviation; * & &
\end{tabular}

The location of the fracture was calculated by dividing the distance of the fracture to the wrist by the length of the bone; Values are presented as median; There are no significant differences between the two groups.

Our follow-up rate was $98 \%$ at a mean of $213.2( \pm 45.4)$ days for children treated with AEC, and $214.0( \pm 44.0)$ days for children treated with AEC and BEC.

Table 3 shows that there were no significant differences in limitation of pronation and supination at 2 and 6 months follow-up. The mean limitation of pronation and supination at 6 months follow-up was $23.3( \pm 22.0)$ for children treated with AEC and $18.0( \pm 16.9)$ for children treated with AEC and BEC. 


\section{Chapter 4}

Table 3. Limitation of pronation and supination of the fractured arm.

AEC $\quad A E C+B E C$

\section{Two months after fracture}

None

6.8

13.1

1-10 degrees

20.3

31.1

11-20 degrees

25.4

19.7

21-30 degrees

$>31$ degrees

Mean limitation/SD (degrees)

$27.9( \pm 22.1)$

$20.8( \pm 17.9)$

Six months after fracture

None

21.3

32.8

1-10 degrees

19.7

28.1

11-20 degrees

29.5

21.9

21-30 degrees

11.5

10.9

$>31$ degrees

18.0

6.3

Mean limitation/SD (degrees)

$17.8( \pm 16.1)$

$11.3( \pm 11.5)$

AEC: Above-elbow cast; BEC: Below-elbow cast; Data are presented as percentage; SD = standard deviation; No significant differences after correction for baseline imbalanced variables, namely age, dominant arm and type of fracture radius.

Using the grading system for limitation of pronation and supination ${ }^{3}$, the results of children treated with AEC were excellent in $26 \%$, good in $26 \%$, fair in $17 \%$ and poor in $31 \%$. For the children treated with AEC and BEC these results were excellent in $26 \%$, good in $26 \%$, fair in $31 \%$ and poor in $17 \%$. Similar results were found using the modified grading system ${ }^{31}$. In the AEC group results were excellent in $43 \%$, good in $22 \%$ and fair in $35 \%$. In the group treated with AEC and BEC results were excellent in $39 \%$, good in $44 \%$ and fair in $17 \%$.

The secondary outcome measures are reported in Table 4 and show similar results for both groups. No significant difference was found between the groups on the questionnaire used to evaluate difficulties with the 7 daily activities during the period of cast $^{30}$. 
Table 4. Data on secondary outcomes.

\begin{tabular}{lcc} 
& AEC & AEC + BEC \\
\hline VAS comfort & $6.2( \pm 1.6)$ & $8.0( \pm 1.9)$ \\
VAS cosmetics fractured arm by parents & $8.1( \pm 2.6)$ & $7.4( \pm 2.6)$ \\
VAS cosmetics fractured arm by orthopaedic surgeon & $8.1( \pm 1.9)$ & $7.9( \pm 2.2)$ \\
Total ABILHAND score at final clinical examination & $41.6( \pm 1.1)$ & $41.7( \pm 1.1)$ \\
Days in cast & $42.6( \pm 3.6)$ & $43.3( \pm 7.9)$ \\
Days until first clinical examination & $74.7( \pm 28.9)$ & $79.7( \pm 25.8)$ \\
Days until final clinical examination & $213.2( \pm 45.4)$ & $214.0( \pm 44.0)$ \\
Referral to physiotherapy, \% & 43.5 & 47.8 \\
Number of visits to physiotherapy & $3.2( \pm 5.7)$ & $3.7( \pm 6.1)$ \\
Limitation of wrist flexion-extension of the fractured arm, degrees & $2.4( \pm 5.4)$ & $1.7( \pm 3.6)$ \\
Limitation of elbow flexion-extension of the fractured arm, degrees & $0.4( \pm 2.1)$ & $1.1( \pm 3.0)$ \\
\hline
\end{tabular}

AEC: above-elbow cast; BEC: below-elbow cast; VAS: visual analogue scale; Values are presented as mean $( \pm$ standard deviation) unless stated otherwise; There are no significant differences between the two groups.

There were 9 complications in the group treated with AEC and 8 complications in the group treated with AEC and BEC (Table 5). Fracture displacement was seen in 11 children, 10 of whom had AEC during the displacement. Fracture displacement was observed in 3 children at the 1-week examination, in 5 children at the 3 -week examination and in 3 children at the 6-week examination. Two of these displaced fractures were reduced and one was stabilised with intramedullary nails. Similar rates of displacement were found for greenstick and complete fractures.

Table 5. Data on complications.

\begin{tabular}{lcc} 
& AEC & AEC + BEC \\
\hline Displacement during cast & 5 & 6 \\
Re-fracture & 2 & 2 \\
Transient neuropraxia & 1 & - \\
Wound dehiscence after intramedullary nails & 1 & - \\
Total complications & 9 & 8
\end{tabular}

AEC = above-elbow cast; BEC = below-elbow cast; Values are presented as number of complications; No significant difference was found between the two groups. 


\section{Chapter 4}

Radiographs made directly after trauma and at final examination show that fracture angulation decreased over time (Table 6). Translation was calculated only at the start of treatment because formation of callus disturbed measurements in the later periods. Rotation and shortening of fractures were only seen on radiographs made directly after trauma.

Table 6. Data on radiological outcomes.

AEC Trauma Removal of cast Final

\section{Angulation}

PA ulna

$P A$ radius

Lateral ulna

Lateral radius

Translation

PA ulna

$P A$ radius

Lateral ulna

Lateral radius

$$
6( \pm 3)
$$

$$
5( \pm 4)
$$

$7( \pm 4)$

$5( \pm 4)$

$11( \pm 6)^{1}$

$5( \pm 4)$

$11( \pm 5)$

$11( \pm 5)^{1}$
$A E C+B E C$

Trauma Removal of cast Final

$\begin{array}{ccc}8( \pm 7) & 6( \pm 5) & 5( \pm 4) \\ 8( \pm 6) & 8( \pm 6) & 7( \pm 6) \\ ( \pm 12) & 7( \pm 5) & 7( \pm 5) \\ 15( \pm 11) & 13( \pm 7)^{1} & 11( \pm 6)^{1}\end{array}$

$1( \pm 3)$

$4( \pm 9)$

$5( \pm 15)$

$1( \pm 3)$

Shortening of radius and/or ulna

$\%$ 4.3

0

Rotation of radius and/or ulna

$\%$ 4.3

0

Angulation: Radioulnar angulation (PA ulna, PA radius) and sagittal angulation (Lateral ulna, Lateral radius) presented in degrees as mean ( \pm standard deviation).

Translation: Radioulnar translation (PA ulna, PA radius) and sagittal translation (Lateral ulna, Lateral radius) presented in percentage of the width of ulna or radius as mean ( \pm standard deviation).

Shortening and rotation as percentage of appearance.

*Translation not relevant because of formation of callus.

1 Significant difference within one group.

No significant difference between $\mathrm{AEC}$ and $\mathrm{AEC}+\mathrm{BEC}$ group. 
None of the included fractures was primarily reduced, although 19 fractures should have been directly reduced according to the reduction criteria. Five of these fractures were reduced during the treatment with cast, and one of these fractures was stabilised with intramedullary nails. We found a malunion on final radiographs in 4 children treated with AEC with, respectively, 0, 35, 50 and 75 degrees of limitation of pronation and supination. Seven children treated with AEC and BEC suffered from a malunion with, respectively, 0, 10, 10, 20, 25, 40 and 55 degrees of limitation.

\section{Discussion}

This randomised controlled trial evaluated the influence of early conversion from $\mathrm{AEC}$ to $\mathrm{BEC}$ in the treatment of non-reduced diaphyseal both-bone forearm fractures in children. No significant difference was found on several clinical and radiographic outcomes. At 6 months follow-up, both groups showed a similar but high limitation of pronation and supination. Thereby, early conversion did not result in more redisplacement of the fracture.

A limitation of pronation and supination of $>30$ degrees at final follow-up was found in 8 children treated with AEC ( 3 complete fractures and 5 greenstick fractures) and in 4 children treated with AEC and BEC ( 3 complete fractures and 1 greenstick fractures). Malunions were seen in 3 of these 8 children treated with AEC and in 2 of these 4 children treated with AEC and BEC. Consequently, malunion does not seem to be the only cause of limitation of pronation and supination in this group of children. Furthermore, the higher incidence of limitation in the group treated with only AEC suggests a possible role of immobilisation of the elbow. In contrast with BEC, AEC makes movement of the elbow impossible which can result in limitation of pronation and supination due to contracture of the joint capsules, periarticular soft tissues and the interosseous membrane. The absence of limitation of flexion and extension of elbow and wrist makes a contracture of joint capsules and periarticular soft tissue less plausible. Therefore, limitation of pronation and supination may be caused by a malunion and/or contracture of the interosseous membrane, as also indicated by others ${ }^{14,15,17,18,34,35}$.

Although restoration of forearm rotation is essential in evaluating the success of forearm fracture management in children, most studies do not adequately address 


\section{Chapter 4}

true, final range of pronation and supinatio ${ }^{28}$. Compared with earlier studies, in the present study limitation of pronation and supination was relatively high. Using the grading system (3) we found excellent results in $26 \%$ of both groups, whereas others reported excellent results in $44 \%^{3}, 77 \%{ }^{31}, 83 \%{ }^{36}, 89 \%{ }^{6}$ and $100 \%{ }^{2,22,37}$. Our less favourable results may be caused by our prospective study design with its high rate of follow-up, detailed measurements, and our high percentage of malunions.

Previous studies reported fracture displacement in conservatively treated forearm fractures in $7-27 \%$ of their patients ${ }^{2,6,22,38-41}$, whereas we found $23 \%$. The fracture displacement occurred in $91 \%$ during treatment with AEC and in $73 \%$ of them during the first 3 weeks. Therefore, even minimally displaced diaphyseal bothbone forearm fractures in children have a tendency to displace, and this is not prevented by immobilisation of the elbow in an AEC.

\section{Study Limitations}

This study had several limitations. First, the number of children did not reach the estimated \pm 30 required in each group. The force of the trauma needed to fracture the diaphysis of both the radius and ulna seemed more often to cause a fracture that needed reduction. This corresponds with our finding that only $24 \%$ of diaphyseal both-bone forearm fractures in the present study were non-reduced fractures. A previously scheduled time frame made further inclusion of patients impossible. Therefore, because this study was statistically underpowered, the results should be interpreted with caution.

Second, not all fractures were reduced according to our a priori defined criteria. Possible explanations for this could be errors in the measurement of displacement, or expectation of correction by growth. Nevertheless only non-reduced fractures were included.

\section{Conclusion}

Early conversion to BEC is safe in the treatment of children with non-reduced diaphyseal both-bone forearm fractures and does not seem to influence forearm rotation. Displacement of the fracture is often seen which requires vigilance, especially during the first 3 weeks of treatment. 


\section{References}

1. Adamczyk MJ, Riley PM. Delayed union and nonunion following closed treatment of diaphyseal pediatric forearm fractures. J Pediatr Orthop. 2005;25(1):51-5.

2. Bochang C, Jie Y, Zhigang W, Weigl D, Bar-On E, Katz K. Immobilisation of forearm fractures in children: extended versus flexed elbow. J Bone Joint Surg Br. 2005;87(7):994-6.

3. Daruwalla JS. A study of radioulnar movements following fractures of the forearm in children. Clin Orthop Relat Res. 1979(139):114-20.

4. Greenbaum B, Zionts LE, Ebramzadeh E. Open fractures of the forearm in children. J Orthop Trauma. 2001;15(2):111-8.

5. Holdsworth BJ, Sloan JP. Proximal forearm fractures in children: residual disability. Injury. 1982;14(2):174-9.

6. Kay S, Smith C, Oppenheim WL. Both-bone midshaft forearm fractures in children. J Pediatr Orthop. 1986;6(3):306-10.

7. Luhmann SJ, Gordon JE, Schoenecker PL. Intramedullary fixation of unstable both-bone forearm fractures in children. J Pediatr Orthop. 1998;18(4):451-6.

8. Ono M, Bechtold JE, Merkow RL, Sherman RE, Gustilo RB. Rotational stability of diaphyseal fractures of the radius and ulna fixed with Rush pins and/or fracture bracing. Clin Orthop Relat Res. 1989(240):236-43.

9. Schwarz N, Pienaar S, Schwarz AF, Jelen M, Styhler W, Mayr J. Refracture of the forearm in children. J Bone Joint Surg Br. 1996;78(5):740-4.

10. Shoemaker SD, Comstock CP, Mubarak SJ, Wenger DR, Chambers HG. Intramedullary Kirschner wire fixation of open or unstable forearm fractures in children. J Pediatr Orthop. 1999;19(3):329-37.

11. Younger AS, Tredwell SJ, Mackenzie WG. Factors affecting fracture position at cast removal after pediatric forearm fracture. J Pediatr Orthop. 1997;17(3):332-6.

12. Hogstrom H, Nilsson BE, Willner S. Correction with growth following diaphyseal forearm fracture. Acta Orthop Scand. 1976;47(3):299-303.

13. Nilsson BE, Obrant $K$. The range of motion following fracture of the shaft of the forearm in children. Acta Orthop Scand. 1977;48(6):600-2.

14. Dumont CE, Thalmann R, Macy JC. The effect of rotational malunion of the radius and the ulna on supination and pronation. J Bone Joint Surg Br. 2002;84(7):1070-4. 


\section{Chapter 4}

15. Tynan MC, Fornalski S, McMahon PJ, Utkan A, Green SA, Lee TQ. The effects of ulnar axial malalignment on supination and pronation. J Bone Joint Surg Am. 2000;82-A(12):1726-31.

16. van Geenen RC, Besselaar PP. Outcome after corrective osteotomy for malunited fractures of the forearm sustained in childhood. J Bone Joint Surg Br. 2007;89(2):236-9.

17. Weinberg AM, Pietsch IT, Krefft M, Pape HC, van Griensven M, Helm MB, et al. [Pronation and supination of the forearm. With special reference to the humero-ulnar articulation]. Unfallchirurg. 2001;104(5):404-9.

18. Yasutomi T, Nakatsuchi Y, Koike H, Uchiyama S. Mechanism of limitation of pronation/supination of the forearm in geometric models of deformities of the forearm bones. Clin Biomech (Bristol, Avon). 2002;17(6):456-63.

19. Boyer BA, Overton B, Schrader W, Riley P, Fleissner P. Position of immobilization for pediatric forearm fractures. Journal of pediatric orthopedics. 2002;22(2):185-7.

20. Choi KY, Chan WS, Lam TP, Cheng JC. Percutaneous Kirschner-wire pinning for severely displaced distal radial fractures in children. A report of 157 cases. J Bone Joint Surg Br. 1995;77(5):797-801.

21. Gibbons CL, Woods DA, Pailthorpe C, Carr AJ, Worlock P. The management of isolated distal radius fractures in children. J Pediatr Orthop. 1994;14(2):207-10.

22. Jones $\mathrm{K}$, Weiner DS. The management of forearm fractures in children: a plea for conservatism. J Pediatr Orthop. 1999;19(6):811-5.

23. Mani GV, Hui PW, Cheng JC. Translation of the radius as a predictor of outcome in distal radial fractures of children. J Bone Joint Surg Br. 1993;75(5):808-11.

24. Maric D, Petkovic L, Tomasevic V, Bajic L, Gajdobranski D, Marcikic A. [Osteosynthesis with Kirschner wires in the treatment of dislocation fractures of the forearm in children]. Med Pregl. 2002;55(3-4):140-5.

25. Noonan KJ, Price CT. Forearm and distal radius fractures in children. J Am Acad Orthop Surg. 1998;6(3):146-56.

26. Zimmermann R, Gabl M, Angermann P, Lutz M, Reinhart C, Kralinger F, et al. [Late sequelae of fractures of the distal third of the forearm during the growth period]. Handchir Mikrochir Plast Chir. 2000;32(4):242-9.

27. Gustilo RB, Simpson L, Nixon R, Ruiz A, Indeck W. Analysis of 511 open fractures. Clin Orthop Relat Res. 1969;66:148-54.

28. Franklin CC, Robinson J, Noonan K, Flynn JM. Evidence-based medicine: management of pediatric forearm fractures. Journal of pediatric orthopedics. 2012;32 Suppl 2:S131-4. 
29. Colaris J, van der Linden M, Selles R, Coene N, Allema JH, Verhaar J. Pronation and supination after forearm fractures in children: Reliability of visual estimation and conventional goniometry measurement. Injury. 2010;41(6):643-6.

30. Webb GR, Galpin RD, Armstrong DG. Comparison of short and long arm plaster casts for displaced fractures in the distal third of the forearm in children. J Bone Joint Surg Am. 2006;88(1):9-17.

31. Price CT, Scott DS, Kurzner ME, Flynn JC. Malunited forearm fractures in children. J Pediatr Orthop. 1990;10(6):705-12.

32. Arnould C, Penta M, Renders A, Thonnard JL. ABILHAND-Kids: a measure of manual ability in children with cerebral palsy. Neurology. 2004;63(6):1045-52.

33. Naimark A, Kossoff J, Leach RE. The disparate diameter. A sign of rotational deformity in fractures. J Can Assoc Radiol. 1983;34(1):8-11.

34. Jupiter JB, Fernandez DL, Levin LS, Wysocki RW. Reconstruction of posttraumatic disorders of the forearm. J Bone Joint Surg Am. 2009;91(11):2730-9.

35. van Geenen RC, Besselaar PP. Outcome after corrective osteotomy for malunited fractures of the forearm sustained in childhood. The Journal of bone and joint surgery British volume. 2007;89(2):236-9.

36. Shah AS, Lesniak BP, Wolter TD, Caird MS, Farley FA, Vander Have KL. Stabilization of adolescent both-bone forearm fractures: a comparison of intramedullary nailing versus open reduction and internal fixation. J Orthop Trauma.24(7):440-7.

37. Boero S, Michelis MB, Calevo MG, Stella M. Multiple forearm diaphyseal fracture: reduction and plaster cast control at the end of growth. Int Orthop. 2007;31(6):807-10.

38. Chan CF, Meads BM, Nicol RO. Remanipulation of forearm fractures in children. N Z Med J. 1997;110(1047):249-50.

39. Monga $\mathrm{P}$, Raghupathy $\mathrm{A}$, Courtman NH. Factors affecting remanipulation in paediatric forearm fractures. J Pediatr Orthop B.19(2):181-7.

40. Voto SJ, Weiner DS, Leighley B. Redisplacement after closed reduction of forearm fractures in children. J Pediatr Orthop. 1990;10(1):79-84.

41. Schmittenbecher PP. State-of-the-art treatment of forearm shaft fractures. Injury. 2005;36 Suppl 1:A25-34. 

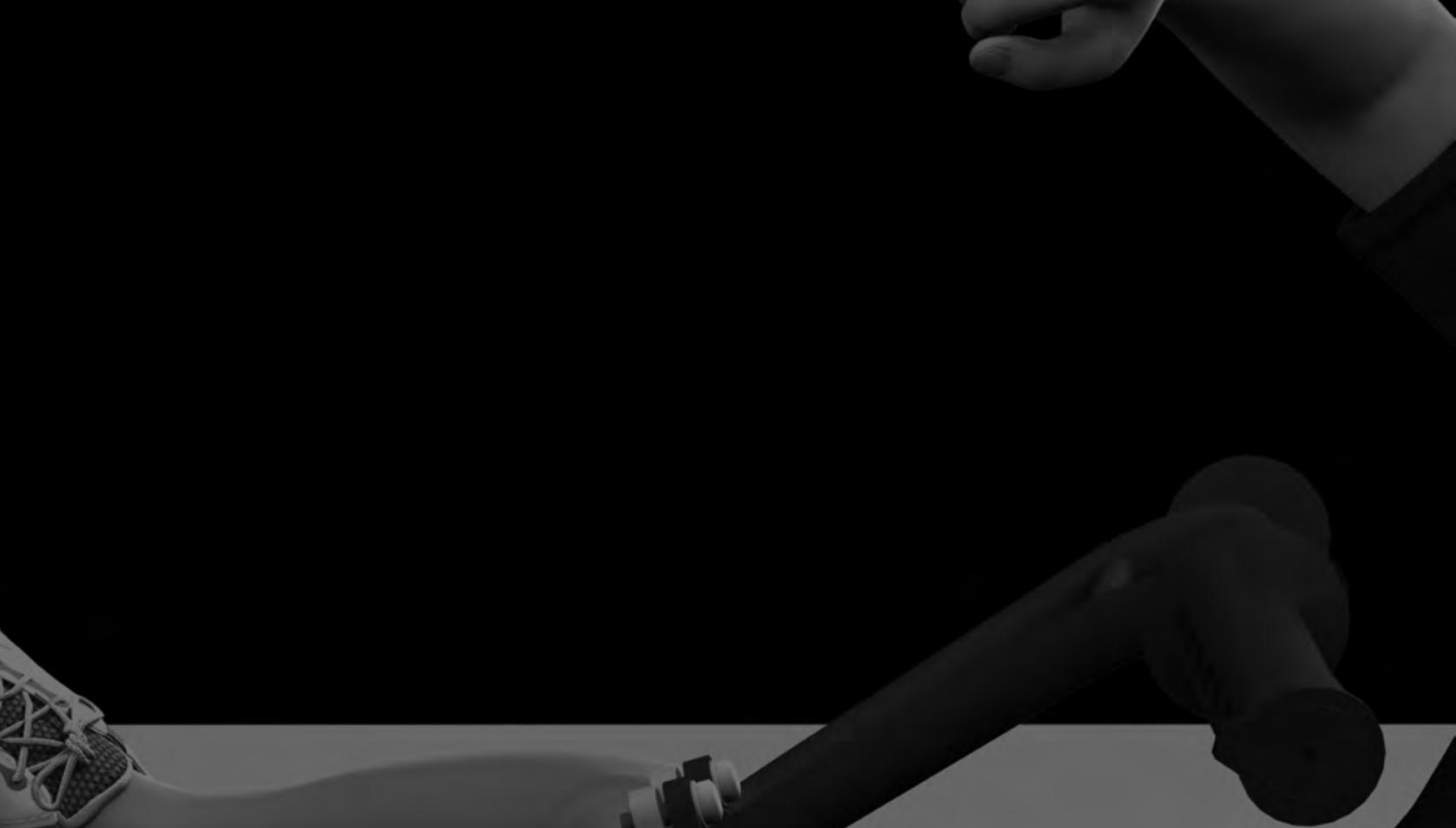


\section{ChAPTER 5}

Conversion to below-elbow cast

after 3 weeks is safe for diaphyseal both-bone forearm

fractures in children:

a multicentre randomized

controlled trial involving 127

children

Acta Orthop. 2013 Oct;84(5):489-94

Colaris JW, Allema JH, Biter LU, Reijman M, van de Ven CP, de Vries MR, Bloem RM, Kerver AJ, Verhaar JA. 


\section{Chapter 5}

\section{AbStRACT}

Background: It is unclear whether it is safe to convert above- elbow cast (AEC) to below-elbow cast (BEC) in a child who has sustained a displaced diaphyseal bothbone forearm fracture that is stable after reduction. In this multicentre study, we wanted to answer the question: does early conversion to BEC cause similar forearm rotation to that after treatment with AEC alone?

Children and methods: Children were randomly allocated to 6 weeks of AEC, or 3 weeks of AEC followed by 3 weeks of BEC. The primary outcome was limitation of pronation/supination after 6 months. The secondary outcomes were re-displacement of the fracture, limitation of flexion/extension of the wrist and elbow, complication rate, cast comfort, complaints in daily life, and cosmetics of the fractured arm.

Results: 62 children were treated with 6 weeks of AEC, and 65 children were treated with 3 weeks of AEC plus 3 weeks of BEC. The follow-up rate was 60/62 and 64/65, respectively with a mean time of $6.9(4.7-13)$ months. The limitation of pronation/ supination was similar in both groups (18 degrees for the AEC group and 11 degrees for the AEC/BEC group). The secondary outcomes were similar in both groups, with the exception of cast comfort, which was in favour of the AEC/BEC group.

Interpretation: Early conversion to BEC is safe and results in greater cast comfort. 


\section{INTRODUCTION}

Most displaced diaphyseal both-bone forearm fractures in children can be treated successfully with closed reduction and above-elbow cast (AEC) for 6-9 weeks, but $\mathrm{AEC}$ is often converted to below-elbow cast (BEC) in the last weeks of treatment. Although most of these fractures heal uneventfully, limitation of pronation and supination can give disappointing results. Previous studies have found an average limitation of 20 degrees in about $15 \%$ of children. The cause of this limitation is unknown, but malunion and contracture of soft tissues have been suggested in some studies $^{1-9}$. Early conversion to BEC in the treatment of these fractures could potentially affect limitation of pronation and supination in 2 opposing ways. On the one hand, early conversion to BEC could result in fracture displacement, leading to malunion and resulting in limitation of pronation and supination. On the other hand, AEC may lead to a limitation of pronation and supination because of contracture of soft tissue by immobilisation of the elbow. We therefore set up a randomized controlled multicentre trial to answer the following question: does early conversion from $A E C$ to $B E C$ cause forearm rotation that is similar to that from $A E C$ alone in reduced stable diaphyseal both-bone forearm fractures in children?

\section{Children AND Methods}

\section{Trial design and participants}

We performed a multicentre randomized trial on consecutive children with a displaced diaphyseal both-bone forearm fracture that was stable after reduction, who visited the emergency department of one of 4 participating Dutch hospitals: Erasmus Medical Center (Rotterdam), HAGA Hospital (The Hague), Reinier de Graaf Hospital (Delft), and Sint Franciscus Hospital (Rotterdam). The regional medical ethics committee approved the study and it was registered at Clinical Trials.gov with registry identifier NCT00398242. The trial was performed in compliance with the Helsinki Declaration. Informed consent for participation was obtained from all parents and from all children aged $\geq 12$ years.

We included all children aged $<16$ years who sustained a displaced diaphyseal both-bone forearm fracture that was stable after reduction (Figure 1). A diaphyseal 


\section{Chapter 5}

fracture was defined as a fracture in the shaft of the bone between the distal and proximal metaphysis. The criteria for reduction are given in Table 1. Exclusion criteria were unstable fractures, fractures older than 1 week, severe open fractures (Gustilo II and III), and re-fractures.

Our primary outcome was limitation of pronation and supination 6 months after the initial trauma. The secondary outcomes were re-displacement of the fracture, limitation of flexion and extension of the wrist and elbow, complication rate, cast comfort, complaints in daily life, and cosmetics of the fractured arm.
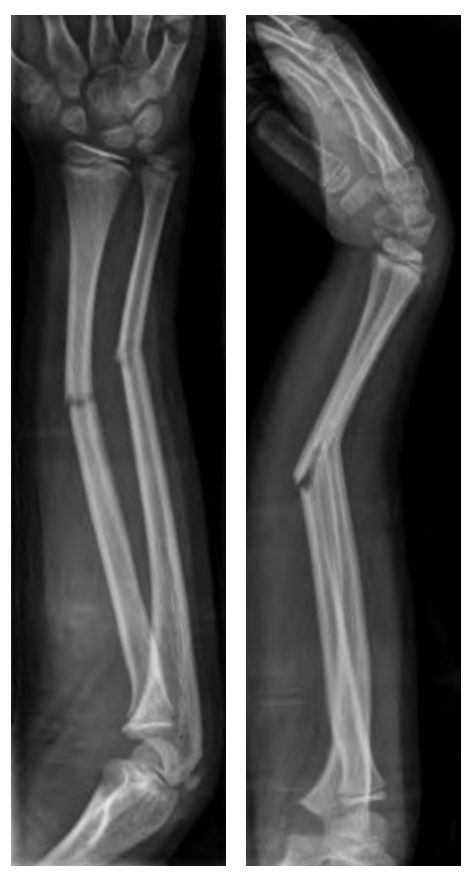

Figure 1. Radiographs of a displaced diaphyseal both-bone fracture

\section{Procedures}

A surgeon reduced the fracture in the operating room under general anaesthesia with fluoroscopic guidance. After optimal closed reduction, the fracture was tested for stability. A fracture was defined as unstable if full pronation and supination of 
Table 1. Criteria for reduction of the fracture of radius and/or ulna based on posteroanterior and/or lateral radiographs

\begin{tabular}{lcc} 
Type of deformity & Age in years & Deformity \\
\hline Angulation & $<10$ & $>15$ degrees \\
& $10-16$ & $>10$ degrees \\
Translation & $<16$ & $>$ half of bone diameter \\
Rotation & $<16$ & $>0$ \\
\hline
\end{tabular}

the proximal forearm caused re-displacement of the fracture under fluoroscopic vision. This test for stability has been used before in a group of children with forearm fractures ${ }^{10}$. Unstable fractures ${ }^{24}$ were excluded and treated with intramedullary nails. The remaining fractures were defined as stable and were randomized to 6 weeks of AEC or to 3 weeks of AEC followed by 3 weeks of BEC. The surgeon applied an AEC in the operation room. First, a stockinet and layer of wool were applied to protect the skin and bony prominences. Then, a well-fitted plaster slab was applied which covered approximately two-thirds of the circumference of the arm. Finally, a bandage was wrapped around the arm. The elbow was set in 90 degrees of flexion and the forearm in neutral position. All children received a sling for at least 1 week.

The children underwent clinical and radiographic evaluation by a surgeon at 1,3 , and 6 weeks after initial trauma. A cast technician revised this plaster cast to circumferential plaster cast after 1 week and applied a new circumferential synthetic cast after 3 weeks (AEC or BEC). The BEC extended only to the elbow. Fracture displacement, as defined by the loss of reduction according to the primary reduction criteria (Table 1), required new fracture reduction. Finally, the cast was removed 6 weeks after initial treatment.

An orthopaedic surgeon (JWC, who was not involved in treatment) examined all children at 2 and 6 months after the initial trauma using a standardized technique to measure flexion and extension of the wrist and elbow, in combination with pronation and supination of both arms ${ }^{11}$. The pronation and supination were scaled using a previously employed grading system ${ }^{12}$ with excellent, good, fair, and poor results for, respectively, $0-10,11-20,21-30$, and 31 degrees of limitation. All 


\section{Chapter 5}

children with at least 30 degrees of functional impairment at the 2-month examination were referred to a physiotherapist. At the 2-month examination, the parents and children evaluated the comfort of the cast using a visual analogue scale (VAS) with highest score for maximal comfort, and a questionnaire to evaluate difficulties in performing 7 daily activities during the period of cast. This questionnaire had previously been used for a similar group of children ${ }^{13}$.

6 months after the initial trauma, the parents and JWC completed a VAS regarding cosmetics of the fractured arm, with highest score for similar cosmetics in the injured and uninjured arm. In the same consultation, complaints concerning the fractured arm were documented using a modified grading system. This grading system combines limitation of pronation and supination with complaints covering daily life or during strenuous activities. It had been used previously for a similar group of children ${ }^{14}$. Thereafter, the parents filled in an ABILHAND-Kids questionnaire, which is a measure of manual ability in children with upper limb impairments.

Radiographs were taken in the emergency room. These were followed by radiographs after reduction and during follow- up at 1, 3, and 6 weeks. The final radiographs were taken 6 months after the initial trauma. Angulation, translation, rotation, and shortening of fractures were measured on the radiographs to determine primary displacement, displacement during treatment with cast, and final displacement at 6 months. Rotation of the fractured bones was analysed from differences in the diameter of the diaphysis of the ulna and radius ${ }^{15}$. To assess the interrater reproducibility, the angulation of the fracture was re-measured in 45 children by a trauma surgeon. The interrater reproducibility of the radiological assessment showed an intraclass correlation (ICC) of 0.81 (95\% Cl: $0.68-0.89)$ and 0.89 (95\% Cl: $0.81-0.94)$ for the radioulnar angulation of the ulna and radius, respectively. The ICC of sagittal angulation was $0.92(95 \% \mathrm{Cl}$ : $0.85-0.95)$ for the ulna and 0.87 (95\% Cl: $0.77-0.92)$ for the radius.

\section{Randomization and masking}

A physician who was not involved in treatment randomized the children using sealed envelopes with varied block sizes. The randomization took place after the fracture was reduced and defined as stable. The study was not blinded regarding the children, parents, and clinicians. JWC collected all the data. 


\section{Statistics}

This study was an equivalency study in which we wanted to determine whether the index treatment (a combination of $\mathrm{AEC}$ and $\mathrm{BEC}$ ) was no better or worse than the control treatment (AEC alone). The main aim of the study was to address the question: do 6 weeks of AEC, or 3 weeks of AEC and 3 weeks of BEC, cause equal limitation of pronation and supination 6 months after the initial trauma? We assessed the numbers of children required with assumption of similarity of pronation and supination in both groups. Similarity between the 2 groups was defined as a maximum of 15 degrees less pronation or supination in the group treated with AEC and BEC. We chose 15 degrees of limitation to stay within the safe margins of good results as graded previously ${ }^{12}$. With an a priori calculation, it was determined that with a power of $80 \%$, a significance level of 0.05 , and a standard deviation (SD) of 15 degrees, the groups should consist of 30 children each.

First, we assessed whether the variables had a normal distribution using the Shapiro-Wilk test for normality. Based on these analyses, the results are presented as mean (SD). The primary research question was examined using linear regression analysis. If necessary, adjustments for unbalanced covariates were made. To check for linearity, we plotted the standardized residuals of the variables used against the standardized predicted values. If there was doubt with respect to violation of assumptions regarding distribution of residuals, we carried out a Mann-Whitney test comparing the 2 groups regarding the average of the measurements. Differences between both groups (AEC vs. AEC plus BEC) for the secondary outcome measures were analysed by one-way ANOVA to correct for multiple comparisons (Bonferroni). Statistical analysis was performed with SPSS software version 17.0. 


\section{Chapter 5}

\section{RESULTS}

Between January 2006 and August 2010, 127 children were included in the study. 62 children were randomized to 6 weeks of $\mathrm{AEC}$ and 65 children were randomized to 3 weeks of AEC followed by 3 weeks of BEC (Figure 2). Despite the randomization, there was a substantial difference in age at the time of fracture, dominant arm fractured, and fracture type of the radius (Table 2). For this reason, the statistical analyses were corrected for these baseline variables.

Fractures were reduced in the operating room in $68 \%$ of the children in the AEC group and in $70 \%$ of the children in the other group (AEC and $B E C$ ). The remaining fractures were reduced at the emergency department. The follow-up rate was $98 \%$, with a mean follow-up time of 6.9 (4.7-12.9) months.

At 6-month follow-up, the mean limitation of pronation and supination was 18 degrees (95\% Cl: 0-50) for children treated with AEC, and 11 degrees (Cl: 0-34) for children treated with AEC and BEC ( $p=0.05)$. With and without adjustment for unbalanced covariates, no significant differences in primary outcome were found (Table 3).

Using the grading system for limitation of pronation and supination ${ }^{12}$, the results in the AEC-alone group were excellent in $21 \%$, good in $38 \%$, fair in $26 \%$, and poor in $15 \%$. In the group treated with $\mathrm{AEC}$ and $\mathrm{BEC}$, the results were excellent in $33 \%$, good in $37 \%$, fair in $27 \%$, and poor in $3 \%$. Similar results were found using the modified grading system ${ }^{14}$. In the AEC group, the results were excellent in 33\%, good in $42 \%$, and fair in $25 \%$. In the group treated with AEC and BEC, the results were excellent in $48 \%$, good in $30 \%$, fair in $20 \%$, and poor in $2 \%$.

The secondary outcome measures showed a higher VAS for comfort in the group of children treated with AEC and BEC $(p<0.001)$ (Table 4). 


\section{Displaced stable diaphyseal fractures}

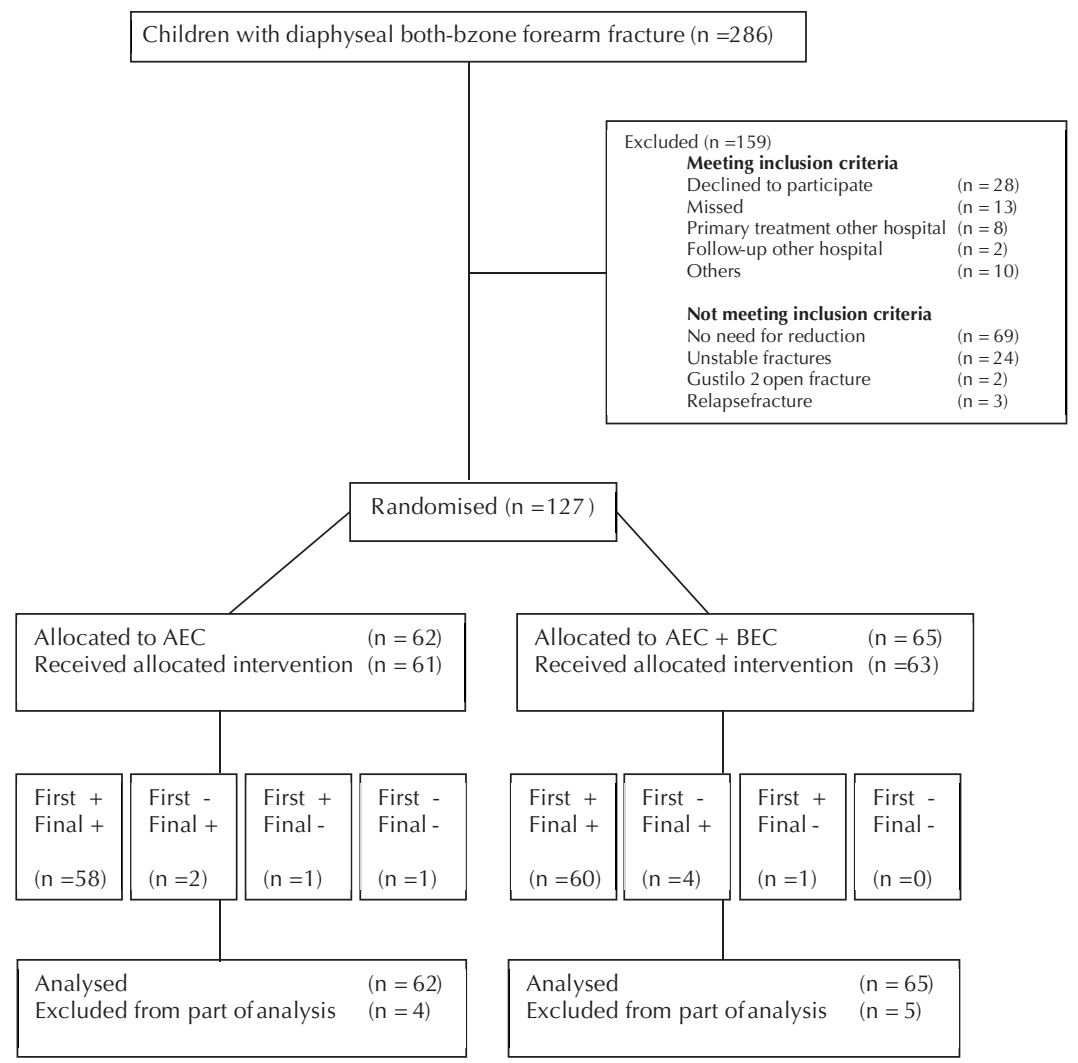

$n=$ number of children; $A E C=$ above elbow cast $; B E C=$ below elbow cast $;$ First: first examination;

Final: final examination; + : examined; - : not examined.

Figure 2. Flowchart of enrolment in the study 


\section{Chapter 5}

Table 2. Baseline characteristics of the study population

\begin{tabular}{lccc} 
& Total & AEC & AEC + BEC \\
\hline Number of children & 127 & 62 & 65 \\
Age at time of fracture, years mean (SD) & $7.9(3.2)$ & $8.7(3.3)$ & $7.1(2.9)$ \\
Male sex & 69 & 69 & 68 \\
Dominant arm fractured & 38 & 24 & 52
\end{tabular}

Fracture type radius*

Greenstick

46

34

58

Complete

54

66

42

Location of fracture of radius,

$($ mean \pm SD)

49

$50(13)$

49 (14)

Fracture type ulna

Greenstick

55

48

63

Complete

45

53

38

Location of fracture of ulna, (mean \pm SD)

37

$39(13)$

$35(10)$

AEC: Above Elbow Cast; BEC: Below Elbow Cast; Values are presented as percentage unless stated otherwise;

The location of the fracture was calculated by dividing the distance of the fracture to the wrist by the length of the bone. 


\section{Displaced stable diaphyseal fractures}

Table 3. Data on limitation of pronation and supination of the fractured arm

\begin{tabular}{lcc} 
& AEC & AEC + BEC \\
\hline 2 months after fracture & 7 & 13 \\
\hline None & 20 & 31 \\
$1-10$ & 25 & 20 \\
$11-20$ & 15 & 8 \\
$21-30$ & 32 & 28 \\
$>31$ degrees & $28[0 ; 72]$ & $21[0 ; 57]$ \\
Mean limitation / $95 \% \mathrm{Cl}$ & & \\
& & 33 \\
6 months after fracture & 21 & 28 \\
\hline None & 20 & 22 \\
$1-10$ & 30 & 11 \\
$11-20$ & 12 & 6 \\
$21-30$ & 18 & $11[0 ; 34]$ \\
$>31$ degrees & $18[0 ; 50]$ & 28 \\
Mean limitation / $95 \% \mathrm{Cl}$ &
\end{tabular}

AEC: Above-elbow cast; BEC: Below-elbow cast; Data are presented as percentage; With and without adjustment for unbalanced covariates no significant differences were found. 


\section{Chapter 5}

Table 4. Data on secondary outcomes

\begin{tabular}{lcc} 
& AEC & AEC + BEC \\
\hline VAS cast comfort* & $4.4(2.3)$ & $8.1(1.8)$ \\
VAS cosmetics fractured arm by parents & $7.8(2.2)$ & $8.6(1.9)$ \\
VAS cosmetics fractured arm by orthopaedic surgeon & $8.0(2.0)$ & $8.9(1.6)$ \\
Total ABILHAND score at final clinical examination & $40(7.5)$ & $41(5.3)$ \\
Total complications, \% & 52 & 39 \\
Secondary dislocation, \% & 37 & 31 \\
Secondary reduction, \% & 11 & 3 \\
Days in cast & $44(8)$ & $44(5)$ \\
Days until first clinical examination & $79(26)$ & $78(26)$ \\
Days until final clinical examination & $211(43)$ & $208(38)$ \\
Referral to physiotherapy, \% & 59 & 38 \\
Number of visits to physiotherapy & $4.1(5.8)$ & $2.2(4.0)$ \\
Limitation of wrist flexion-extension of the fractured arm (degrees) & $3.4(6.9)$ & $1.6(3.8)$ \\
Limitation of elbow flexion-extension of the fractured arm (degrees) & $1.2(4.4)$ & $0.5(1.9)$ \\
\hline Values are presented as mean (SD) unless stated otherwise; VAS: Visual & Analogue Scale; * Significant difference (p< \\
0.001) after correcting for imbalance of baseline variables, namely age, dominant arm and type of fracture radius.
\end{tabular}

Table 5. Data on complications

\begin{tabular}{lcc} 
& AEC & AEC + BEC \\
\hline Displacement during cast & 23 & 20 \\
Re-fracture & 5 & 3 \\
Transient neuropraxia & 2 & 2 \\
Excoriation elbow crease & 1 & - \\
Nonunion & 1 & - \\
Total complications & 32 & 25 \\
\hline
\end{tabular}

$\mathrm{AEC}=$ above-elbow cast; $\mathrm{BEC}=$ below-elbow cast; Values are presented as number of complications; No significant difference was found between the two groups. 
The questionnaire ${ }^{13}$, which evaluated difficulties during the period of cast, gave similar results between the 2 groups.

There were 32 complications in 27 children treated with AEC and 25 complications in 23 children treated with AEC and BEC (Table 5). Most complications consisted of fracture re-displacement. Almost half of all re-displacements occurred in the group with reduction of the fracture in the emergency department, and all redisplacements occurred during the first 3 weeks. 9 of 43 re-displaced fractures were reduced again and treated after reduction with cast in 4 children, and with intramedullary nails and cast in 5 children. In 34 children, the re-displacement of the fracture was accepted. Furthermore, greenstick and complete fractures showed a similar rate of re-displacement.

At final follow-up, 23 children ( 12 of whom were aged $\geq 10$ years) developed a malunion as defined by our primary reduction criteria (Table 6). Although all 23 fractures showed re-displacement in cast, 3 were reduced a second time. The malunion was localized in the proximal half of the diaphysis of the radius and of the ulna in 15 and 3 children, respectively. Of the 23 children with a malunion, 7 regained almost full pronation and supination while 8 children suffered from a limitation of $\geq 31$ degrees. 


\section{Chapter 5}

Table 6. Radiological outcomes

\begin{tabular}{|c|c|c|c|c|c|c|c|c|}
\hline & \multicolumn{4}{|c|}{ AEC } & \multicolumn{4}{|c|}{$\mathrm{AEC}+\mathrm{K}$-wires } \\
\hline & Trauma & $\begin{array}{c}\text { After } \\
\text { reduction }\end{array}$ & $\begin{array}{l}\text { Removal } \\
\text { of cast }\end{array}$ & Final & Trauma & $\begin{array}{c}\text { After } \\
\text { reduction }\end{array}$ & $\begin{array}{l}\text { Removal } \\
\text { of cast }\end{array}$ & Final \\
\hline \multicolumn{9}{|l|}{ Angulation } \\
\hline PA ulna & $13( \pm 9)$ & $3( \pm 3)$ & $4( \pm 3)$ & $6( \pm 4)$ & $13( \pm 12)$ & $4( \pm 4)$ & $6( \pm 4)$ & $6( \pm 4)$ \\
\hline PA radius & $14( \pm 8)$ & $5( \pm 3)$ & $6( \pm 4)$ & $6( \pm 4)$ & $12( \pm 10)$ & $6( \pm 3)$ & $7( \pm 5)$ & $7( \pm 5)$ \\
\hline Lateral ulna & $25( \pm 18)$ & $6( \pm 5)$ & $5( \pm 5)$ & $4( \pm 4)$ & $26( \pm 16)$ & $6( \pm 4)$ & $7( \pm 5)$ & $6( \pm 4)$ \\
\hline Lateral radius & $28( \pm 17)$ & $9( \pm 5)$ & $10( \pm 6)$ & $8( \pm 5)$ & $28( \pm 16)$ & $7( \pm 5)$ & $9( \pm 5)$ & $8( \pm 5)$ \\
\hline \multicolumn{9}{|l|}{ Translation } \\
\hline PA ulna & $7( \pm 20)$ & $3( \pm 8)$ & * & * & $3( \pm 9)$ & $3( \pm 9)$ & * & * \\
\hline PA radius & $3( \pm 8)$ & $5( \pm 11)$ & * & * & $11( \pm 21)$ & $11( \pm 19)$ & * & * \\
\hline Lateral ulna & $10( \pm 27)$ & $7( \pm 17)$ & * & * & $9( \pm 23)$ & $11( \pm 24)$ & * & * \\
\hline Lateral radius & $9( \pm 25)$ & $4( \pm 10)$ & * & * & $9( \pm 26)$ & $13( \pm 23)$ & * & * \\
\hline \multicolumn{9}{|c|}{ Shortening of radius and/or ulna } \\
\hline$\%$ & 13.8 & & & & 13.6 & & & \\
\hline \multicolumn{9}{|c|}{ Rotation of radius and/or ulna } \\
\hline$\%$ & 6.2 & & & & 1.7 & & & \\
\hline \multicolumn{9}{|c|}{$\begin{array}{l}\text { Angulation: Radioulnar angulation (PA ulna, PA radius) and sagittal angulation (Lateral ulna, Lateral radius) presented } \\
\text { in degrees as mean ( } \pm \text { standard deviation). }\end{array}$} \\
\hline \multirow{2}{*}{\multicolumn{9}{|c|}{$\begin{array}{l}\text { Translation: Radioulnar translation (PA ulna, PA radius) and sagittal translation (Lateral ulna, Lateral radius) presented } \\
\text { in percentage of the width of ulna or radius as mean ( } \pm \text { standard deviation). }\end{array}$}} \\
\hline & & & & & & & & \\
\hline \multicolumn{9}{|c|}{ Shortening and rotation as percentage of appearance. } \\
\hline \multicolumn{9}{|c|}{ *Translation not relevant because of formation of callus. } \\
\hline \multicolumn{9}{|c|}{ No significant differences between AEC and AEC + BEC group are found. } \\
\hline
\end{tabular}




\section{DISCUSSION}

We found that in the treatment of reduced stable diaphyseal both-bone forearm fractures in children, conversion from AEC to BEC was safe 3 weeks after the initial trauma. Limitation in flexion and extension of the elbow did not occur in either of the groups.

We found a limitation of pronation and supination of 30 degrees at final follow-up in 15 of 127 children, 8 of whom also suffered a radiographic malunion. 6 children with a radio- graphic malunion at final follow-up showed no limitation of pronation and supination. These findings demonstrate that limitation of pronation and supination is caused by malunion and contractures, as previously stated by other authors ${ }^{1,2,4,5,16,17}$. The idea of contractures of injured soft tissue being a cause of limitation of pronation and supination was supported by a trend of better forearm rotation in the BEC group, in which children could rotate the forearm early to prevent contractures.

Compared with previous studies, limitation of pronation and supination was relatively high in our children. Using the grading system ${ }^{12}$, we found that $21 \%$ (AEC) and $33 \%$ (AEC and BEC) had excellent results, whereas other authors have found excellent results in $44-100 \%$ of such children ${ }^{9,12,14,18-20}$. The modified grading system ${ }^{14}$ resulted in $33 \%$ and $48 \%$ excellent results in our 2 groups, as compared to $82 \%$ in another study ${ }^{14}$. Our prospective analysis, inclusion of only the more severe both-bone forearm fractures, and the high percentage of malunions may have been responsible for our less favourable results.

Previous studies have found a re-displacement rate of $7-27 \%$ in nonoperatively treated forearm fractures, whereas we found a rate of $4 \%{ }^{9,18,20-24}$. Our higher rate of re-displacement might be explained by our strict malunion criteria, the prospective follow-up with scheduled radiographs, our test for stability, and the type of cast (non-circumferential cast applied directly after reduction). Although BEC allows free movement of the elbow, in our study conversion to BEC after 3 weeks did not cause re-displacement of fractures. In our patients, all re-displacements occurred in the AEC group during the first 3 weeks of treatment.

In the statistical analysis, we were aware that strict correction for multiple testing was not necessary because of the evaluation of predefined hypotheses. 


\section{Chapter 5}

However, we chose a conservative method to test the secondary outcome parameters. In addition, we also tested the secondary outcome without correction for multiple testing (using a p-value of 0.05), and even then no differences were found between groups.

Our study had several limitations. First, several fractures were reduced at the emergency department instead of in the operating room. The slightly higher rate of re-displacement in fractures reduced at the emergency department (42\% vs. 30\%) led us to suspect that testing of fracture stability without anaesthesia and fluoroscopy is less optimal. Fortunately, there was an equal distribution of fractures reduced in the emergency room in the 2 groups, and this study investigated treatment modalities after reduction. Secondly, not all re-displaced fractures were reduced following our study protocol. This was probably due to the expectation of correction of the malunion by growth, and the reluctance of the surgeon to propose a second reduction in view of the effect on the child. Thirdly, the outcome of the test for stability after reduction was a subjective opinion of the treating physician. No tests for stability of fractures are objective, and the test used was the only one to appear in literature (25). The final limitation was our (short) period of follow-up in this young population with a capacity for correction by growth. Nevertheless, these diaphyseal fractures (especially in older children) show less correction than distal metaphyseal fractures in younger children.

In summary, our results suggest that reduced stable diaphyseal both-bone forearm fractures in children can be safely treated by 3 weeks of above-elbow cast and 3 weeks of below-elbow cast. Re-displacement of the fracture might be identified early by radiography at set times. 


\section{Displaced stable diaphyseal fractures}

\section{REFERENCES}

1. Dumont CE, Thalmann R, Macy JC. The effect of rotational malunion of the radius and the ulna on supination and pronation. J Bone Joint Surg Br. 2002;84(7):1070-4.

2. Tynan MC, Fornalski S, McMahon PJ, Utkan A, Green SA, Lee TQ. The effects of ulnar axial malalignment on supination and pronation. J Bone Joint Surg Am. 2000;82-A(12):1726-31.

3. van Geenen RC, Besselaar PP. Outcome after corrective osteotomy for malunited fractures of the forearm sustained in childhood. J Bone Joint Surg Br. 2007;89(2):236-9.

4. Weinberg AM, Pietsch IT, Krefft M, Pape HC, van Griensven M, Helm MB, et al. [Pronation and supination of the forearm. With special reference to the humero-ulnar articulation]. Unfallchirurg. 2001;104(5):404-9.

5. Yasutomi T, Nakatsuchi $\mathrm{Y}$, Koike H, Uchiyama S. Mechanism of limitation of pronation/supination of the forearm in geometric models of deformities of the forearm bones. Clin Biomech (Bristol, Avon). 2002;17(6):456-63.

6. Nilsson BE, Obrant K. The range of motion following fracture of the shaft of the forearm in children. Acta Orthop Scand. 1977;48(6):600-2.

7. Bhaskar AR, Roberts JA. Treatment of unstable fractures of the forearm in children. Is plating of a single bone adequate? J Bone Joint Surg Br. 2001;83(2):253-8.

8. Hogstrom H, Nilsson BE, Willner S. Correction with growth following diaphyseal forearm fracture. Acta Orthop Scand. 1976;47(3):299-303.

9. Kay S, Smith C, Oppenheim WL. Both-bone midshaft forearm fractures in children. J Pediatr Orthop. 1986;6(3):306-10.

10. Myers GJ, Gibbons PJ, Glithero PR. Nancy nailing of diaphyseal forearm fractures. Single bone fixation for fractures of both bones. J Bone Joint Surg Br. 2004;86(4):581-4.

11. Colaris J, van der Linden M, Selles R, Coene N, Allema JH, Verhaar J. Pronation and supination after forearm fractures in children: Reliability of visual estimation and conventional goniometry measurement. Injury. 2010;41(6):643-6.

12. Daruwalla JS. A study of radioulnar movements following fractures of the forearm in children. Clin Orthop Relat Res. 1979(139):114-20.

13. Webb GR, Galpin RD, Armstrong DG. Comparison of short and long arm plaster casts for displaced fractures in the distal third of the forearm in children. J Bone Joint Surg Am. 2006;88(1):9-17. 


\section{Chapter 5}

14. Price CT, Scott DS, Kurzner ME, Flynn JC. Malunited forearm fractures in children. J Pediatr Orthop. 1990;10(6):705-12.

15. Naimark A, Kossoff J, Leach RE. The disparate diameter. A sign of rotational deformity in fractures. J Can Assoc Radiol. 1983;34(1):8-11.

16. Jupiter JB, Fernandez DL, Levin LS, Wysocki RW. Reconstruction of posttraumatic disorders of the forearm. J Bone Joint Surg Am. 2009;91(11):2730-9.

17. van Geenen RC, Besselaar PP. Outcome after corrective osteotomy for malunited fractures of the forearm sustained in childhood. The Journal of bone and joint surgery British volume. 2007;89(2):236-9.

18. Bochang C, Jie Y, Zhigang W, Weigl D, Bar-On E, Katz K. Immobilisation of forearm fractures in children: extended versus flexed elbow. J Bone Joint Surg Br. 2005;87(7):994-6.

19. Boero S, Michelis MB, Calevo MG, Stella M. Multiple forearm diaphyseal fracture: reduction and plaster cast control at the end of growth. Int Orthop. 2007;31(6):807-10.

20. Jones K, Weiner DS. The management of forearm fractures in children: a plea for conservatism. J Pediatr Orthop. 1999;19(6):811-5.

21. Chan CF, Meads BM, Nicol RO. Remanipulation of forearm fractures in children. N Z Med J. 1997;110(1047):249-50.

22. Monga $\mathrm{P}$, Raghupathy $\mathrm{A}$, Courtman $\mathrm{NH}$. Factors affecting remanipulation in paediatric forearm fractures. J Pediatr Orthop B.19(2):181-7.

23. Voto SJ, Weiner DS, Leighley B. Redisplacement after closed reduction of forearm fractures in children. J Pediatr Orthop. 1990;10(1):79-84.

24. Schmittenbecher PP. State-of-the-art treatment of forearm shaft fractures. Injury. 2005;36 Suppl 1:A25-34.

25. Meier R, Prommersberger KJ, van Griensven M, Lanz U. Surgical correction of deformities of the distal radius due to fractures in pediatric patients. Arch Orthop Trauma Surg. 2004;124(1):1-9. 
Displaced stable diaphyseal fractures 

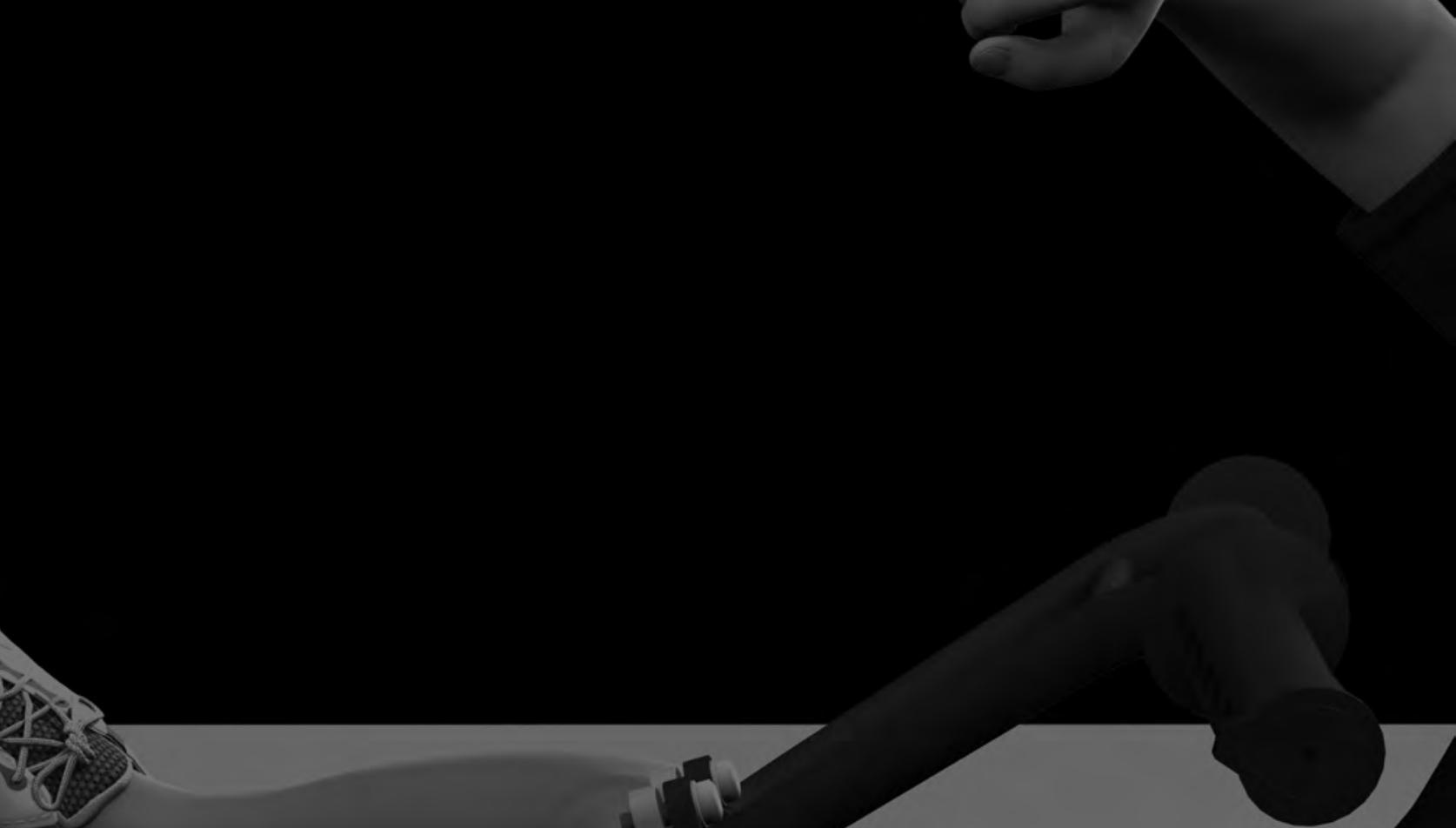


\section{Chapter 6}

Single-bone intramedullary

fixation of unstable both-bone

diaphyseal forearm fractures in

children leads to increased

re-displacement:

a multicentre randomised

controlled trial

Arch Orthop Trauma Surg. 2013 Aug;133(8):1079-87

Colaris J, Reijman M, Allema JH, Kraan G, van Winterswijk P,

de Vries M, van de Ven C, Verhaar J. 


\section{Chapter 6}

\section{AbStRACT}

Introduction: Both-bone diaphyseal forearm fractures in children can be stabilised without cast by a flexible intramedullary nail in both the radius and the ulna. Adequate results with single-bone fixation combined with a complementary cast are also reported. However, because those results are based on a selection of children, this trial investigates whether single-bone intramedullary fixation, compared with both-bone intramedullary fixation, results in similar pronation and supination in children with an unstable diaphyseal both-bone forearm fracture.

Materials and methods: In four Dutch hospitals, 24 consecutive children aged $<16$ years with a displaced unstable both-bone diaphyseal forearm fracture were randomly allocated to single-bone or both-bone intramedullary fixation. Primary outcome was limitation of pronation and supination 9 months after initial trauma. Secondary outcomes were limitation of flexion/extension of wrist/elbow, complication rate, operation time, cosmetics of the fractured arm, complaints in daily life, and assessment of radiographs.

Results: Between January 2006 and August 2010, 11 children were randomised to single-bone fixation and 13 to both-bone fixation. In the both-bone fixation group, two fractures were stabilized by only one nail. In both groups, median limitation of pronation/supination at 9-months follow-up was 5-10 degrees. In both groups operation time was similar but in the single-bone fixation group cast immobilisation was longer (median of 37 vs. 28 days). In four children, re-displacement of the fracture occurred in those fractures without an intramedullary nail.

Conclusions: These results caution against the use of single-bone fixation in all bothbone forearm fractures. This method may lead to increased re-displacement and reduced clinical results. 


\section{INTRODUCTION}

Diaphyseal both-bone forearm fractures are frequently seen in children. During impact of trauma, the high energy level often results in a displaced fracture. The displacement generally needs to be corrected and stabilised by a cast, intramedullary nails and/or plates.

Fixation by intramedullary nails has gained popularity because of good clinical and radiographic results ${ }^{1-6}$. Flexible intramedullary nails are generally used to stabilise paediatric fractures with two nails ${ }^{7-9}$. Initially, one pre-bent nail is inserted in the relatively straight intramedullary canal and creates a bending moment. Then, a second pre-bent nail is inserted with the concavity of the nail opposite the first one creating a counteracting force which stabilises the fracture. Furthermore, bothbone forearm fractures fixated with two intramedullary nails do not need stabilisation by a complementary cast.

In contrast to single-bone fractures, with both-bone forearm fractures the narrow intramedullary canal of the radius and ulna makes insertion of two nails in one bone impossible. For that reason the radius and ulna are fixated separately with a single flexible intramedullary nail, with the concavity of the nails in the same direction. This results in an absence of the stabilising effect of the counteracting force of two nails with opposite concavity.

As an alternative, the possibility of single-bone fixation in both-bone forearm fractures combined with a complementary cast has been studied ${ }^{2,5,10-17}$. Single-bone intramedullary fixation in both-bone forearm fractures offers both advantages and disadvantages. Although insertion and removal of only one nail can reduce operation time and complications, the bone without fixation has a tendency to displace necessitating immobilisation in a cast.

To date, only one study (20 children, no controls) has prospectively investigated single-bone fixation in both-bone forearm fractures ${ }^{12}$, whereas others used a retrospective design 2,5,10-13,16-19. Most studies concluded that single-bone intramedullary fixation of both-bone diaphyseal forearm fractures in children is a safe and efficacious option with good functional and radiological results, 2, 10-13,16-19. Nevertheless, these results were based on a selection of children who sustained a both-bone forearm fracture that remained aligned and stable after single-bone fixation ${ }^{2,5,10-13,16-19}$. 


\section{Chapter 6}

To systematically compare the value of the two types of fixation, the present randomised study investigates whether single-bone intramedullary fixation, compared with both-bone intramedullary fixation, results in similar pronation and supination in children with an unstable diaphyseal both-bone forearm fracture.

\section{Patients AND MEthods}

\section{Trial design and participants}

A multicentre randomised controlled clinical trial was performed including all consecutive children with a displaced unstable diaphyseal forearm fracture of the radius and ulna. These children visited the emergency department of one of the four participating Dutch hospitals: Erasmus Medical Center (Rotterdam), HAGA Hospital (The Hague), Reinier de Graaf Hospital (Delft) and Sint Franciscus Hospital (Rotterdam).

The regional Medical Ethics committee approved the study (registered in Clinical Trials.gov: NCT00314587). Informed consent was obtained for participation from all parents and from all children aged $\geq 12$ years.

Included were all children aged $<16$ years who sustained a displaced diaphyseal both-bone forearm fracture that was unstable after reduction (Fig. 1).
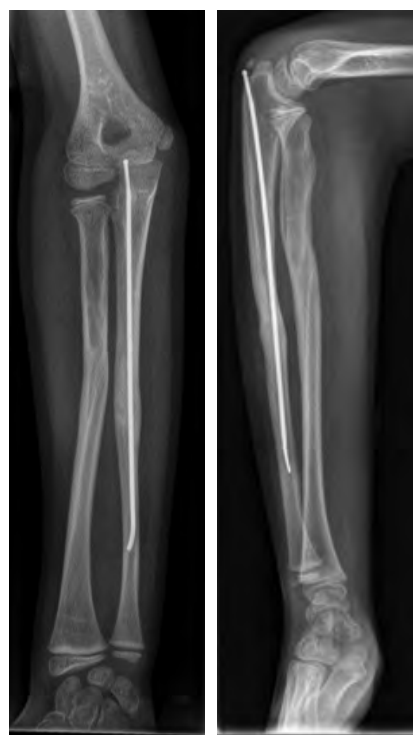

Figure 1. Single-bone intramedullary fixation of both-bone diaphyseal forearm fracture.

A diaphyseal fracture was defined as a fracture in the shaft of the bone between the distal and proximal metaphysis. The criteria for reduction were a priori defined and based on previous studies ${ }^{20-29}$, i.e. in children aged $<10$ years an angulation of $>15$ degrees, translation of $>$ half the diameter of the bone, or any rotation, was defined as displaced. For children aged 10-16 years, an angulation of $>10$ degrees, translation of $>$ half the diameter of the bone, or any rotation, was defined as displaced. 
Exclusion criteria were stable fractures, fractures older than 1 week, severe open fractures (Gustilo II and III) ${ }^{30}$, and re-fractures.

Primary outcome was limitation of pronation and supination compared to the uninjured arm, 9 months after the initial trauma. Secondary outcomes were limitation of flexion/extension of wrist and elbow, complication rate, operation time, cosmetic results, complaints in daily life, and assessment of radiographs.

\section{Procedure}

A surgeon reduced the fracture under fluoroscopic guidance (in the operating room) with the child under general anaesthesia. After optimal reduction, the fracture was tested for stability. A fracture was defined as unstable if maximal pronation/ supination of the proximal forearm caused re-displacement of the fracture. This test for stability has previously been used in children with a forearm fracture (19). Stable fractures were excluded and treated with cast immobilisation.

The unstable fractures were randomised between single-bone and both-bone intramedullary fixation. In case of allocation to single-bone fixation, the surgeon could stabilise the most unstable bone with an intramedullary nail. Titanium Elastic

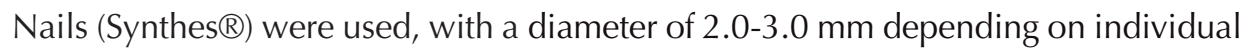
patient anatomy. After incision of the skin and blunt dissection, the radius was pinned retrograde via an entry hole proximal to the distal physis, while the ulna was pinned anterograde via an entry hole distal to the olecranon physis. If reduction or insertion of the intramedullary nail failed by closed means, the fracture was opened by small incision. The nails were either buried or left transcutaneous, depending on the surgeon's choice. After stabilisation of either the ulna or radius or both bones, the surgeon applied an above-elbow cast in the operation room. Primarily a stockinet and layer of wool were applied to protect the skin and bony prominences. Secondarily a well-fitted plaster slab was applied which covered approximately $2 / 3$ of the circumference of the arm. Finally, a bandage was wrapped around the arm. The elbow was set in 90 degrees of flexion and the wrist in neutral position. All children received a sling for at least 1 week.

All children underwent clinical and radiological evaluation at 1, 3 and 6 weeks after the initial trauma by a surgeon. A cast technician revised and renewed the cast where necessary. Re-displacement, as defined by the loss of reduction according to 


\section{Chapter 6}

the primary reduction criteria, required secondary reduction and intramedullary fixation of both bones. The cast was removed 3 weeks after initial treatment. The nails were removed in the outdoor patient clinic if left transcutaneous during the first 2 months, or in the operation room if buried during the first 8 months.

One orthopaedic surgeon, who was not involved in the primary treatment, examined all children 2 and 9 months after initial trauma using a standardised technique to measure flexion/extension of wrist and elbow in combination with pronation/supination of both $\mathrm{arms}^{31}$. The pronation/supination was scaled using the grading system as described by Daruwalla with excellent, good, fair and poor results for 0, 11-20, 21-30 and more than 31 degrees of limitation, respectively ${ }^{22}$. Patients with at least 30 degree of functional impairment at the 2-months examination were referred to a physiotherapist.

Nine months after the initial trauma final posteroanterior and lateral radiographs were taken. In the same consultation, both the parents and the orthopaedic surgeon completed a VAS cosmetics of the fractured arm with maximum score for similar appearance of the fractured and non-fractured arm. Thereby, complaints of the fractured arm were documented by a modified grading system. This grading system combines the limitation of pronation/supination with complaints in daily life or during strenuous activities; this system was successfully applied in a similar group of children ${ }^{32}$. Furthermore, the parents filled in an ABILHAND-Kids questionnaire ${ }^{33}$ : this is a measure of manual ability for children with upper limb impairments. The scale is validated for children with cerebral palsy and measures a child's ability to manage daily activities that require the use of the upper limbs, with a maximum score of 42 for no impairments.

The orthopaedic surgeon measured all available radiographs to determine primary displacement, displacement during treatment with cast immobilisation, and final displacement at 9-months follow-up.

\section{Randomisation and masking}

A physician (who was not involved in the treatment) randomised the children by sealed envelopes with varied block sizes. The orthopaedic surgeon examined all children 2 and 9 months after initial trauma and measured the radiographs without masking. Obviously, the children and parents were not blinded for treatment. 


\section{Statistical methods}

The primary aim of the study was to investigate whether single-bone fixation, compared with both-bone fixation, causes equal limitation of pronation/supination at 9 -months post-trauma. To assess the number of children required, an equivalence test was used to demonstrate the similarity of pronation/supination in both groups. Equivalence between the two groups was defined as a maximum of 15 degrees less pronation or supination in the group treated with single-bone fixation after 9 months. For this study, we decided on 15 degrees of limitation in order to remain in the safe margin of good results as graded previously ${ }^{22}$. With an a priori calculation it was determined that with a power of $80 \%$, an alpha of 0.05 and a standard deviation of 15 degrees, each group should consist of 30 children.

First, it was established whether the variables had a normal distribution using the normality Shapiro-Wilk test. Based on these analyses, the results are presented as median and interquartile range (IQR). The primary research question was analysed using linear regression analysis (limitation of pronation/supination of the fractured arm 9 months after initial trauma as dependent variable, and intervention as independent variable). If necessary, adjustments for unbalanced covariates were made. Differences between the groups for the secondary outcome measures were analysed by one-way ANOVA to correct for multiple comparisons (Bonferroni).

Patients were analysed according to the intention to treat principle for the primary and secondary outcomes. Additionally, we performed a per protocol analysis, in which the patients were analysed according to the intervention they finally received.

Statistical analyses were performed with SPSS 17.0 (SPSS Inc., Chicago, USA). 


\section{Chapter 6}

\section{RESULTS}

Between January 2006 and August 2010 a total of 24 children were included: of these, 11 were randomised to single-bone fixation and 13 to both-bone fixation (Fig. 2). The group with single-bone fixation consisted of 7 fractures with fixation of only the radius, and 4 with fixation of only the ulna. The group randomised to both-bone fixation consisted of 11 fractures with fixation of both the ulna and radius, and 2 with fixation of only the ulna. For the latter 2 children, the change in treatment was on one occasion caused by a life-threatening problem elsewhere in the hospital, and on another occasion by an exhausting procedure of $180 \mathrm{~min}$ with an apparent stable fixation of both-bones by fixation of only the ulna. Because the two children with a change in treatment had poor results, we decided to present both the intention-to-treat analysis and per-protocol analysis.

Table 1 presents the baseline characteristics of the total study population and per randomisation. In the group allocated to single-bone fixation one child had a grade 1 open fracture. Two fractures in this latter group needed an open reduction, whereas in the group with both-bone fixation 6 fractures needed an open reduction. Of the 2 children treated with single-bone fixation instead of the allocated bothbone fixation, both needed an open reduction. All children in the study attended the final examination. 
Table 1. Baseline characteristics of the study population.

\begin{tabular}{lccccc} 
& Total & \multicolumn{2}{c}{ 1-bone fixation } & \multicolumn{2}{c}{ 2-bone fixation } \\
\hline & & ITT & PP & ITT & PP \\
\hline No. of children & 24 & 11 & 13 & 13 & 11 \\
Median age at time of fracture in years (IQR) & $10.4(6.8)$ & $8.8(6.0)$ & $9.1(6.3)$ & $11.5(5.5)$ & $10.9(7.2)$ \\
Gender, \% male & 58.3 & 45.5 & 53.8 & 69.2 & 63.6 \\
Dominant arm fractured (\%) & 41.7 & 36.4 & 38.5 & 46.2 & 45.5
\end{tabular}

Type fracture radius (\%)

$\begin{array}{llllll}\text { Greenstick } & 30.4 & 36.4 & 33.3 & 25.0 & 27.3 \\ \text { Complete } & 69.6 & 63.6 & 66.7 & 75.0 & 72.7\end{array}$

Type fracture ulna (\%)

\begin{tabular}{llllll}
\hline Greenstick & 30.4 & 36.4 & 33.3 & 25.0 & 27.3 \\
Complete & 69.6 & 63.6 & 66.7 & 75.0 & 72.7
\end{tabular}

A0 classification $(\mathrm{n})^{*}$

\begin{tabular}{lccccc}
\hline $22-D / 2.1$ & 3 & 2 & 2 & 1 & 1 \\
$22-D / 4.1$ & 11 & 4 & 6 & 7 & 5 \\
$22-D / 5.1$ & 9 & 5 & 5 & 4 & 4 \\
$22-D / 5.2$ & 1 & 0 & 0 & 1 & 1
\end{tabular}

$\mathrm{IQR}=$ interquartile range; ITT = intention to treat analysis; $\mathrm{PP}=$ per protocol analysis; * $\mathrm{AO}$ classification of paediatric long-bone fractures. 


\section{Chapter 6}

Table 2. Data on limitation of pronation and supination of the fractured arm.

\section{1-bone fixation 2-bone fixation}

Two months after fracture

\begin{tabular}{lcccc} 
& ITT & PP & ITT & PP \\
\hline No. of children & 11 & 13 & 13 & 11 \\
None & 0 & 0 & 0 & 0 \\
1-10 degrees & 3 & 3 & 2 & 2 \\
11-20 degrees & 3 & 3 & 4 & 4 \\
21-30 degrees & 3 & 3 & 3 & 3 \\
$>31$ degrees & 2 & 4 & 4 & 2 \\
Median limitation in degrees (IQR) & $20(15)$ & $25(23)$ & $25(25)$ & $20(15)$
\end{tabular}

Nine months after fracture

\begin{tabular}{lcccc} 
& ITT & PP & ITT & PP \\
\hline No. of children & 11 & 13 & 13 & 11 \\
None & 3 & 3 & 5 & 5 \\
1-10 degrees & 5 & 5 & 2 & 2 \\
$11-20$ degrees & 3 & 3 & 4 & 4 \\
$21-30$ degrees & 0 & 0 & 0 & 0 \\
$>31$ degrees & 0 & 2 & 2 & 0 \\
Median limitation in degrees (IQR) & $10(15)$ & $10(18)$ & $10(20)$ & $5(15)$
\end{tabular}

Data are presented as number of children; ITT = intention to treat analysis; PP = per protocol analysis;

IQR: interquartile range.

Table 2 shows the median limitation of pronation/supination at 2 and 9 months follow-up. For both groups, the median limitation of pronation/supination at 9 months was 5-10 degrees. A malunion, as defined by primary reduction criteria, was found in 3 children at final follow-up with 5, 20 and 40 degrees limitation of pronation/supination, respectively. One of these 3 children suffered from an open fracture and another one needed an open reduction and sustained a re-fracture. These 3 children were aged 10, 11 and 13 years, respectively. 
Table 3. Grading system of limitation of pronation and supination.

\begin{tabular}{lllllllll} 
& \multicolumn{3}{c}{ Grading by Daruwalla (19) } & \multicolumn{3}{c}{ Modified grading by Price et al. (29) } \\
\hline & \multicolumn{3}{c}{ 1-bone fixation } & \multicolumn{2}{c}{ 2-bone fixation } & \multicolumn{2}{c}{ 1-bone fixation } & 2-bone fixation \\
\multicolumn{1}{r}{} & ITT & PP & ITT & PP & ITT & PP & ITT & PP \\
\hline N & 11 & 13 & 13 & 11 & 11 & 13 & 13 & 11 \\
Excellent & 3 & 3 & 5 & 5 & 5 & 5 & 5 & 5 \\
Good & 6 & 6 & 4 & 4 & 4 & 4 & 2 & 2 \\
Fair & 2 & 2 & 2 & 2 & 2 & 3 & 5 & 4 \\
Poor & - & 2 & 2 & - & - & 1 & 1 & - \\
\hline
\end{tabular}

$\mathrm{ITT}=$ intention to treat analysis; $\mathrm{PP}=$ per protocol analysis; $\mathrm{N}=$ number of children.

Table 4. Data on secondary outcomes.

\begin{tabular}{|c|c|c|c|c|}
\hline & \multicolumn{2}{|c|}{ 1-bone fixation } & \multicolumn{2}{|c|}{ 2-bone fixation } \\
\hline & ITT & $\mathrm{PP}$ & ITT & PP \\
\hline No. of children & 11 & 13 & 13 & 11 \\
\hline VAS cosmetics fractured arm by parents & $8.3(2.4)$ & $8.3(2.9)$ & $8.5(2.8)$ & $9.0(1.6)$ \\
\hline VAS cosmetics fractured arm by orthopaedic surgeon & $8.8(1.5)$ & $8.4(3.8)$ & $7.7(3.9)$ & $8.0(3.6)$ \\
\hline Total ABILHAND score at final clinical examination & $42.0(1.0)$ & $42.0(1.0)$ & $42.0(0.5)$ & $42.0(0)$ \\
\hline$\geq 1$ complication, $\%$ & 36.4 & 46.2 & 30.8 & 18.2 \\
\hline No. of days in cast & $37.0(21.0)$ & $37.0(20.5)$ & $28.0(16.5)$ & $22.0(16.0)$ \\
\hline Operation time in minutes & $67(82)$ & $67(81)$ & $60(68)$ & $60(63)$ \\
\hline Days until removal of hardware & $57.5(204.5)$ & $80.5(208.5)$ & $184.5(173.0)$ & $184.5(176.5)$ \\
\hline Days until first clinical examination & $74.0(66.0)$ & $70(60)$ & $54.0(71.5)$ & $52(78)$ \\
\hline Days until final clinical examination & $338.0(70.0)$ & $309(78.5)$ & $292.0(54.0)$ & $293(51.0)$ \\
\hline Referral to physiotherapy, \% & 45.5 & 53.8 & 69.2 & 63.6 \\
\hline $\begin{array}{l}\text { Limitation of wrist flexion-extension } \\
\text { of the fractured arm (degrees) }\end{array}$ & $0(5.0)$ & $0(7.5)$ & $0(15.0)$ & $0(15.0)$ \\
\hline $\begin{array}{l}\text { Limitation of elbow flexion-extension } \\
\text { of the fractured arm (degrees) }\end{array}$ & $0(0)$ & $0(2.5)$ & $0(0)$ & $0(0)$ \\
\hline
\end{tabular}




\section{Chapter 6}

Table 3 gives the results of the (modified) grading systems of the limitation of pronation and supination.

For the secondary outcome measures (Table 4), children with single-bone fixation were treated for a longer period with cast and had earlier removal of the hardware; however, the operation time was similar for both groups.

Table 5 presents the complications in both groups. Re-displacement of the fracture occurred in four children (11, 12, 16 and 19 degrees of angulation, respectively) during the first 6 weeks and only of fractures without an intramedullary nail. One child sustained a re-fracture after removal of the nails, while another child had a re-fracture of both the radius and ulna with bending of the nails inside the bones. Only the re-fractures were secondarily reduced. Furthermore, one superficial infection was seen and treated with oral antibiotics. One child who was treated with single-bone fixation of the ulna developed a non-union of the ulna and was successfully treated with removal of the nail, open reduction and internal fixation with a plate.

Table 5. Complications occurring in the present study.

\begin{tabular}{lcccc} 
& \multicolumn{2}{c}{ 1-bone fixation } & \multicolumn{2}{c}{ 2-bone fixation } \\
& ITT & PP & ITT & PP \\
\hline No. of children & 11 & 13 & 13 & 11 \\
Re-displacement of fracture & 3 & 4 & 1 & 0 \\
Transient neurapraxia & 1 & 2 & 2 & 1 \\
Re-fracture & 1 & 1 & 1 & 1 \\
Excoriation skin & 1 & 1 & 0 & 0 \\
Superficial infection & 0 & 0 & 1 & 1 \\
Nail removal impossible & 0 & 0 & 1 & 1 \\
Nonunion & 0 & 1 & 1 & 0 \\
No. of complications & 6 & 9 & 7 & 4 \\
\hline
\end{tabular}

Data are presented as number of children; ITT = intention to treat analysis; $\mathrm{PP}=$ per protocol analysis. 


\section{Discussion}

This study compared single-bone and both-bone intramedullary fixation of unstable diaphyseal both-bone fractures in children and indicates that single-bone fixation leads to increased re-displacement and poorer clinical outcome. Although the median limitation of pronation/supination was similar in both groups, a higher rate of complications occurred in the single-bone fixation group. These complications were mainly caused by re-displacement of the fracture without a nail. Furthermore, fractures stabilised with only one nail were immobilised in a cast for a longer period. Surprisingly, the operation time was similar in both groups. These findings in combination with the risks of infection and anaesthesia (for insertion and removal of the nails), makes us believe that a child has virtually no profit from the treatment of single-bone fixation compared with reduction and conservative treatment in cast. In our opinion, unstable both-bone forearm fractures should be treated with two intramedullary nails with cast.

At 9-months follow-up, in both groups a relatively large number of children had a limitation of pronation/supination of $\geq 20$ degrees. This group of children was diverse: 2 had a malunion at final examination, 1 child was operated on a second time because of a non-union, another child re-fractured his forearm, and 2 children were treated without complications but were immobilised in cast for 37 and 42 days, respectively. Therefore, in our study population the cause of the limitation of pronation/supination seems to be multifactorial.

Other studies investigating intramedullary stabilisation of both-bone forearm fractures reported that limitation of pronation/supination occurs in $0-20 \%$ of patients $2,5,11,12,14,16-19,34-41$, whereas this occurred in $67 \%$ of our group. A possible explanation for our high rate is our prospective study design with no children lost to follow-up, and our high rate of complications resulting in less favourable outcomes.

In other studies, the overall better results of single-bone fixation can be explained by their selective treatment of fractures with single-bone or both-bone fixation ${ }^{2,5,10-14,16-19}$. In those studies, the surgeon could choose per-operatively for single-bone or both-bone fixation depending on the stability of the fracture, whereas we used a randomisation protocol irrespective of the level of stability.

In the present study, re-displacement of the fracture occurred in 4 children and only in those treated with single-bone fixation. Not surprisingly, all re-displacements 


\section{Chapter 6}

were seen in the bone without intramedullary fixation. Such re-displacement in single-bone intramedullary fixation of both-bone forearm fractures is not uncommon ${ }^{2,5,10,13}$. Therefore, in children, we suggest that unstable both-bone diaphyseal forearm fractures should be stabilised with an intramedullary nail in both the radius and ulna to prevent re-displacement.

\section{Study limitations}

Some study limitations need to be addressed. First, the number of included children is small: of the 249 children with a displaced diaphyseal both-bone forearm fracture only 24 were classified as unstable. This rareness of unstable fractures is reflected in other studies with small numbers of children ${ }^{10-14,17,18,42,43}$. Nevertheless, the possibility exists that our test for fracture stability was inadequate or not properly accomplished. Although we present the first randomised controlled trial of singleversus both-bone intramedullary fixation, our study was statistically underpowered and the results should be interpreted with caution.

Second, the follow-up period was only 9 months. Although this seems short, in other children treated for displaced forearm fractures no change was found in clinical or radiographic status from 6 months post-treatment until final follow-up at (mean) 2.8 years $^{44}$. Another group described a persistent limitation during long-term follow-up despite correction by growth ${ }^{45}$, and others advised an osteotomy to correct malunion as early as 6 months after trauma ${ }^{46}$. Although malunions in children can correct with growth, these diaphyseal malunions are less likely to correct than distal malunions because of the relatively long distance to the most active distal growth plate.

\section{Conclusion}

The results of this first randomised controlled study caution against the use of singlebone fixation in all displaced unstable both-bone diaphyseal forearm fractures in children. The single-bone fixation method may lead to increased fracture redisplacement and poorer clinical results. 


\section{Displaced unstable diaphyseal fractures}

\section{ReferenCES}

1. Amit Y, Salai M, Chechik A, Blankstein A, Horoszowski H. Closing intramedullary nailing for the treatment of diaphyseal forearm fractures in adolescence: a preliminary report. J Pediatr Orthop. 1985;5(2):143-6.

2. Cullen MC, Roy DR, Giza E, Crawford AH. Complications of intramedullary fixation of pediatric forearm fractures. J Pediatr Orthop. 1998;18(1):14-21.

3. Luhmann SJ, Gordon JE, Schoenecker PL. Intramedullary fixation of unstable both-bone forearm fractures in children. J Pediatr Orthop. 1998;18(4):451-6.

4. Roy DR, Crawford AH. Operative management of fractures of the shaft of the radius and ulna. Orthop Clin North Am. 1990;21(2):245-50.

5. Shoemaker SD, Comstock CP, Mubarak SJ, Wenger DR, Chambers HG. Intramedullary Kirschner wire fixation of open or unstable forearm fractures in children. J Pediatr Orthop. 1999;19(3):329-37.

6. Verstreken L, Delronge G, Lamoureux J. Shaft forearm fractures in children: intramedullary nailing with immediate motion: a preliminary report. J Pediatr Orthop. 1988;8(4):450-3.

7. Dietz HG, Schmittenbecher PP, Slongo T, Wilkins KE. AO manual of fracture management. ESIN in children2006.

8. Metaizeau JP, Ligier JN. [Surgical treatment of fractures of the long bones in children. Interference between osteosynthesis and the physiological processes of consolidation. Therapeutic indications]. Journal de chirurgie. 1984;121(8-9):527-37.

9. Prevot J, Lascombes P, Ligier JN. [The ECMES [Centro-Medullary Elastic Stabilising Wiring) osteosynthesis method in limb fractures in children. Principle, application on the femur. Apropos of 250 fractures followed-up since 1979]. Chirurgie. 1993;119(9):473-6.

10. Dietz JF, Bae DS, Reiff E, Zurakowski D, Waters PM. Single bone intramedullary fixation of the ulna in pediatric both bone forearm fractures: analysis of short-term clinical and radiographic results. J Pediatr Orthop.30(5):420-4.

11. Flynn JM, Waters PM. Single-bone fixation of both-bone forearm fractures. J Pediatr Orthop. 1996;16(5):655-9.

12. Houshian S, Bajaj SK. Forearm fractures in children. Single bone fixation with elastic stable intramedullary nailing in 20 cases. Injury. 2005;36(12):1421-6.

13. Lee $\mathrm{S}$, Nicol RO, Stott NS. Intramedullary fixation for pediatric unstable forearm fractures. Clin Orthop Relat Res. 2002(402):245-50. 


\section{Chapter 6}

14. Myers GJ, Gibbons PJ, Glithero PR. Nancy nailing of diaphyseal forearm fractures. Single bone fixation for fractures of both bones. J Bone Joint Surg Br. 2004;86(4):581-4.

15. Sharieff GQ, Kanegaye J, Wallace CD, McCaslin RI, Harley JR. Can portable bedside fluoroscopy replace standard, postreduction radiographs in the management of pediatric fractures? Pediatr Emerg Care. 1999;15(4):249-51.

16. Yung PS, Lam CY, Ng BK, Lam TP, Cheng JC. Percutaneous transphyseal intramedullary Kirschner wire pinning: a safe and effective procedure for treatment of displaced diaphyseal forearm fracture in children. J Pediatr Orthop. 2004;24(1):7-12.

17. Alnaib M, Taranu R, Lakkol S, Aldlyami E, Alcelik I, Tulloch C. Radius-only intramedullary nailing for both-bones diaphyseal forearm fractures in children. Acta orthopaedica Belgica. 2011;77(4):458-63.

18. Kirkos JM, Beslikas T, Kapras EA, Papavasiliou VA. Surgical treatment of unstable diaphyseal both-bone forearm fractures in children with single fixation of the radius. Injury. 2000;31(8):591-6.

19. Meier R, Prommersberger KJ, van Griensven M, Lanz U. Surgical correction of deformities of the distal radius due to fractures in pediatric patients. Arch Orthop Trauma Surg. 2004;124(1):1-9.

20. Boyer BA, Overton B, Schrader W, Riley P, Fleissner P. Position of immobilization for pediatric forearm fractures. Journal of pediatric orthopedics. 2002;22(2):185-7.

21. Choi KY, Chan WS, Lam TP, Cheng JC. Percutaneous Kirschner-wire pinning for severely displaced distal radial fractures in children. A report of 157 cases. J Bone Joint Surg Br. 1995;77(5):797-801.

22. Daruwalla JS. A study of radioulnar movements following fractures of the forearm in children. Clin Orthop Relat Res. 1979(139):114-20.

23. Gibbons CL, Woods DA, Pailthorpe C, Carr AJ, Worlock P. The management of isolated distal radius fractures in children. J Pediatr Orthop. 1994;14(2):207-10.

24. Jones K, Weiner DS. The management of forearm fractures in children: a plea for conservatism. J Pediatr Orthop. 1999;19(6):811-5.

25. Mani GV, Hui PW, Cheng JC. Translation of the radius as a predictor of outcome in distal radial fractures of children. J Bone Joint Surg Br. 1993;75(5):808-11.

26. Maric D, Petkovic L, Tomasevic V, Bajic L, Gajdobranski D, Marcikic A. [Osteosynthesis with Kirschner wires in the treatment of dislocation fractures of the forearm in children]. Med Pregl. 2002;55(3-4):140-5. 


\section{Displaced unstable diaphyseal fractures}

27. Noonan KJ, Price CT. Forearm and distal radius fractures in children. J Am Acad Orthop Surg. 1998;6(3):146-56.

28. Tynan MC, Fornalski S, McMahon PJ, Utkan A, Green SA, Lee TQ. The effects of ulnar axial malalignment on supination and pronation. J Bone Joint Surg Am. 2000;82-A(12):1726-31.

29. Zimmermann R, Gabl M, Angermann P, Lutz M, Reinhart C, Kralinger F, et al. [Late sequelae of fractures of the distal third of the forearm during the growth period]. Handchir Mikrochir Plast Chir. 2000;32(4):242-9.

30. Gustilo RB, Simpson L, Nixon R, Ruiz A, Indeck W. Analysis of 511 open fractures. Clin Orthop Relat Res. 1969;66:148-54.

31. Colaris J, van der Linden M, Selles R, Coene N, Allema JH, Verhaar J. Pronation and supination after forearm fractures in children: Reliability of visual estimation and conventional goniometry measurement. Injury. 2010;41(6):643-6.

32. Price CT, Scott DS, Kurzner ME, Flynn JC. Malunited forearm fractures in children. J Pediatr Orthop. 1990;10(6):705-12.

33. Arnould C, Penta M, Renders A, Thonnard JL. ABILHAND-Kids: a measure of manual ability in children with cerebral palsy. Neurology. 2004;63(6):1045-52.

34. Altay M, Aktekin CN, Ozkurt B, Birinci B, Ozturk AM, Tabak AY. Intramedullary wire fixation for unstable forearm fractures in children. Injury. 2006;37(10):966-73.

35. Jubel A, Andermahr J, Isenberg J, Issavand A, Prokop A, Rehm KE. Outcomes and complications of elastic stable intramedullary nailing for forearm fractures in children. J Pediatr Orthop B. 2005;14(5):375-80.

36. Kapoor V, Theruvil B, Warwick DJ, Uglow MG. Distal radio-ulnar joint subluxation following intramedullary nailing of the radius in a child. J Bone Joint Surg Br. 2004;86(4):592-4.

37. Kucukkaya M, Kabukcuoglu Y, Tezer M, Eren T, Kuzgun U. The application of open intramedullary fixation in the treatment of pediatric radial and ulnar shaft fractures. J Orthop Trauma. 2002;16(5):340-4.

38. Kumar G. Comparison of short and long arm plaster casts for displaced fractures in the distal third of the forearm in children. J Bone Joint Surg Am. 2006;88(8):1888; author reply -9.

39. Lascombes $\mathrm{P}$, Haumont $\mathrm{T}$, Journeau $\mathrm{P}$. Use and abuse of flexible intramedullary nailing in children and adolescents. J Pediatr Orthop. 2006;26(6):827-34.

40. Qidwai SA. Treatment of diaphyseal forearm fractures in children by intramedullary Kirschner wires. J Trauma. 2001;50(2):303-7. 


\section{Chapter 6}

41. Richter D, Ostermann PA, Ekkernkamp A, Muhr G, Hahn MP. Elastic intramedullary nailing: a minimally invasive concept in the treatment of unstable forearm fractures in children. J Pediatr Orthop. 1998;18(4):457-61.

42. Calder PR, Achan P, Barry M. Diaphyseal forearm fractures in children treated with intramedullary fixation: outcome of K-wire versus elastic stable intramedullary nail. Injury. 2003;34(4):278-82.

43. Majed A, Baco AM. Nancy nail versus intramedullary-wire fixation of paediatric forearm fractures. J Pediatr Orthop B. 2007;16(2):129-32.

44. Miller BS, Taylor B, Widmann RF, Bae DS, Snyder BD, Waters PM. Cast immobilization versus percutaneous pin fixation of displaced distal radius fractures in children: a prospective, randomized study. J Pediatr Orthop. 2005;25(4):490-4.

45. Nilsson BE, Obrant $\mathrm{K}$. The range of motion following fracture of the shaft of the forearm in children. Acta Orthop Scand. 1977;48(6):600-2.

46. Price CT, Knapp DR. Osteotomy for malunited forearm shaft fractures in children. J Pediatr Orthop. 2006;26(2):193-6. 
Displaced unstable diaphyseal fractures 


\section{Chapter 7}

\section{Risk factors for the displacement of fractures of both bones of the forearm in children}

Bone Joint J. 2013 May;95-B(5):689-93

Colaris JW, Allema JH, Reijman M, Biter LU, de Vries MR, van de Ven CP, Bloem RM, Verhaar JA. 


\section{Chapter 7}

\section{Abstract}

Forearm fractures in children have a tendency to displace in a cast leading to malunion with reduced functional and cosmetic results. In order to identify risk factors for displacement, a total of 247 conservatively treated fractures of the forearm in 246 children with a mean age of 7.3 years (SD 3.2; 0.9 to 14.9) were included in a prospective multicentre study. Multivariate logistic regression analyses were performed to assess risk factors for displacement of reduced or non-reduced fractures in the cast. Displacement occurred in 73 patients (29.6\%), of which 65 (89.0\%) were in above-elbow casts. The mean time between the injury and displacement was 22.7 days (0 to 59). The independent factors found to significantly increase the risk of displacement were a fracture of the non-dominant arm $(p=0.024)$, a complete fracture $(p=0.040)$, a fracture with translation of the ulna on lateral radiographs ( $p$ $=0.014)$ and shortening of the fracture $(p=0.019)$. Fractures of both forearm bones in children have a strong tendency to displace even in an above-elbow cast. Severe fractures of the non-dominant arm are at highest risk for displacement. Radiographs at set times during treatment might identify early displacement, which should be treated before malunion occurs, especially in older children with less potential for remodelling. 


\section{INTRODUCTION}

Displacement of fractures of both forearm bones in children treated in a cast has been described in between $7 \%$ and $91 \%$ of cases $^{1-5}$, and can lead to malunion with reduced functional and cosmetic results ${ }^{6,7}$. Despite the high rate of displacement, there has not hitherto been an analysis of risk factors in large prospective studies ${ }^{3-5,8-11}$. We therefore performed a prospective multicentre study to identify the risk factors for displacement of reduced and unreduced fractures of both bones of the forearm in children when treated in a cast.

\section{Patients and Methods}

Between January 2006 and August 2010 a total of 247 children aged $<16$ years with fractures of both bones of the forearm were included in a prospective study involving four hospitals (Fig. 1, Table 1). The study had ethical approval and informed consent was obtained from all parents, and children aged $>12$ years. The criteria for reduction were based on previous studies (Table 2) ${ }^{1,12-20}$. Exclusion criteria were: torus fractures of both the radius and ulna; fractures sustained more than a week before presentation; severe open fractures (Gustilo II and III) ${ }^{21}$; and re-fractures. Exclusion criteria included those fixed with Kirschner (K-) wires or intramedullary nails, fractures without final radiographs, initially displaced fractures without reduction and reduced fractures with displacement on the first subsequent radiograph. The study protocol distinguished different types of fractures. Distal metaphyseal fractures not requiring reduction were treated with a below- or above-elbow cast for four weeks ${ }^{22}$, whereas distal metaphyseal fractures needing reduction were treated with or without K-wires and an above-elbow cast for four weeks ${ }^{23}$. Diaphyseal fractures not requiring reduction and reduced stable diaphyseal fractures were treated for six weeks with an aboveelbow cast or a combination of three weeks above and three weeks below. Unstable diaphyseal fractures were fixed with one or two intramedullary nails and three weeks in an above-elbow cast. The cast was applied in a standard way by a trained nurse in the emergency department or a surgeon in the operating room. Firstly, a stockinette and layer of wool were applied to protect the skin and bony prominences. Second, a well-fitted plaster slab was applied that covered approximately two-thirds of the circumference of the arm. Finally a bandage was wrapped around the arm. 


\section{Chapter 7}

Radiographs were taken at presentation, after reduction and during treatment. An orthopaedic surgeon (JWC) who was not involved in primary treatment measured angulation, translation as a percentage of the width of radius/ulna rotation (yes/no) and shortening (yes/no) of all fractures. Rotation was detected by differences in the diameter of the diaphysis of radius and ulna on posteroanterior and lateral radiographs ${ }^{24}$.

A reduced or an unreduced fracture that showed progressive displacement (Fig. 2) during follow-up was defined as displaced if further reduction was needed according to the criteria for primary reduction (Table 2). In order to assess the interrater reproducibility of the radiological assessment, a trauma surgeon (LUB) who was not involved in treatment re-measured the angulation of the fracture in 45 children. 


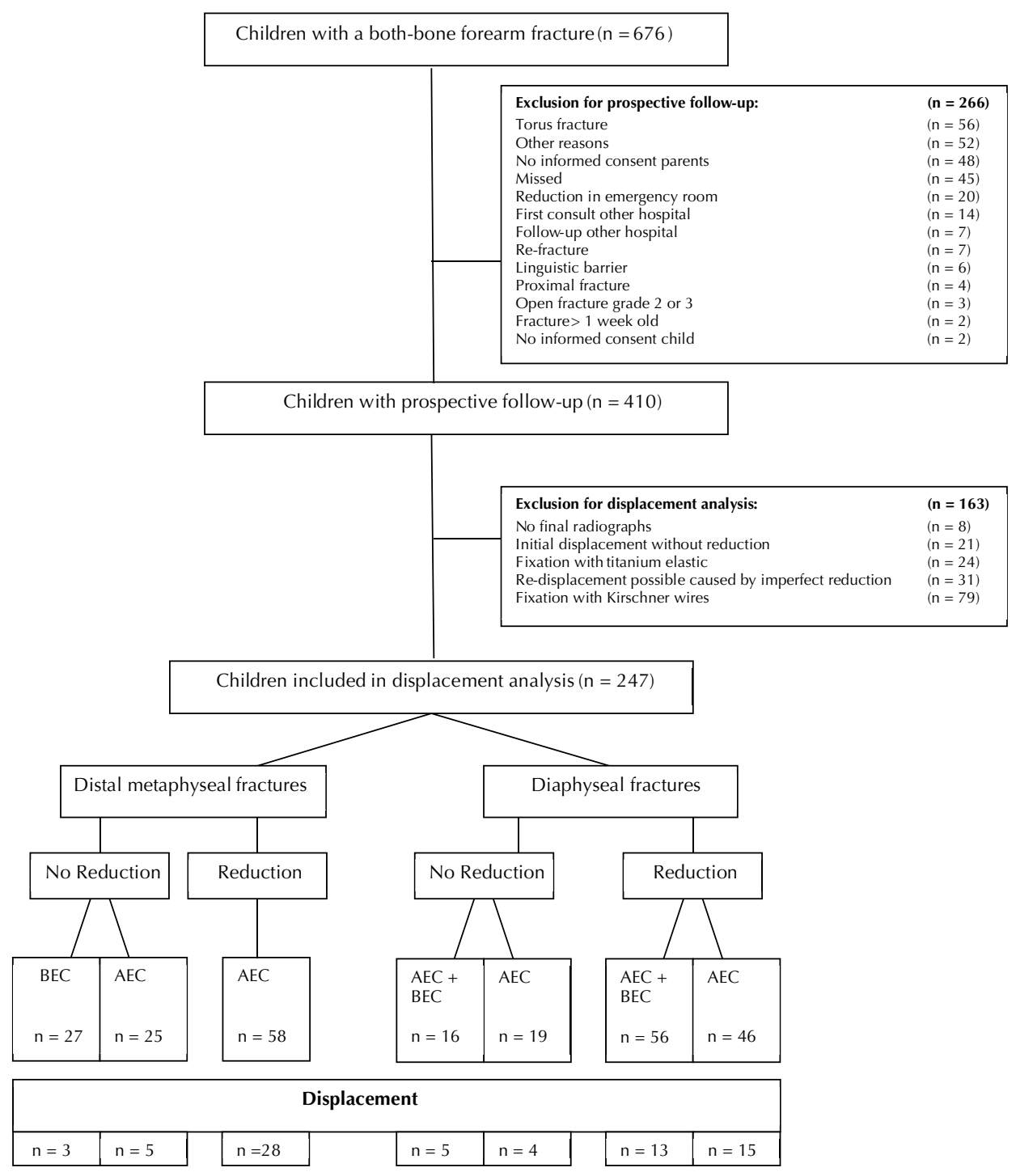

Figure 1. Flowchart of enrolment in the study (B-/AEC, below-/above-elbow cast). 


\section{Chapter 7}
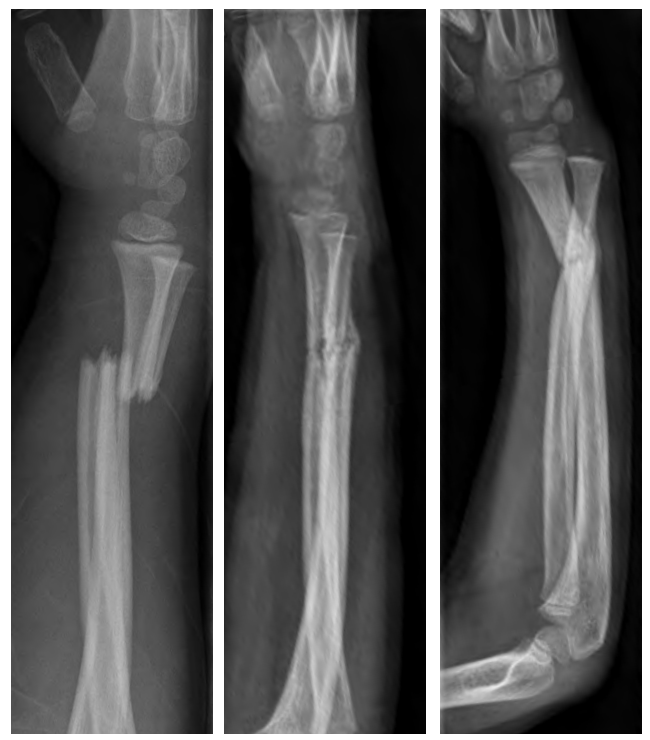

Figure 2. Lateral radiographs showing a both-bone forearm fracture (left) which was properly reduced (centre) but showed re-displacement after four weeks (right). This fracture demonstrates all risk factors: complete fracture in non-dominant arm with shortening and translation of the ulna on the lateral radiograph.

\section{Statistical analysis}

Our dependent variable was displacement of the fracture in the cast and we assessed whether this was related to any of the following factors: gender, hand dominance, location of the fracture (diaphysis vs distal metaphysis), type of fracture (greenstick or complete), primary displacement (angulation, translation, shortening, rotation), reduction of the fracture, location of reduction (emergency ward, operating room), type of cast (above- or below-elbow) and quality of cast (cast-index) ${ }^{25}$. Fractures other than complete were defined as greenstick fractures. The choice of risk factors was based on previous studies $3-5,8-11,26,27$.

In order to assess which factors were related to displacement of the fracture in the cast, multivariate logistic regression analysis (enter method) was used to calculate odds ratios (ORs) including 95\% confidence intervals $(95 \% \mathrm{Cl})$. In all analyses, a two-sided p-value of $\leq 0.05$ was considered significant. Statistical analyses were performed with SPSS 17.0 (SPSS Inc., Chicago, Illinois). 
Table 1. Demographics

\begin{tabular}{ll}
\hline Children & 247 \\
Mean age (yrs) (SD; range) & $7.3(3.2 ; 0.0$ to 14.9) \\
Male (n, \%) & $147(59.5)$ \\
Fracture on dominant arm (n, \%) & $98(39.7)$ \\
Right arm fractured & $96(38.9)$ \\
Location (n, \%) & \\
Diaphysis & $137(55.5)$ \\
Metaphysis & $110(44.5)$ \\
Type of fracture (n, \%) & \\
Both greensticks & $111(44.9)$ \\
Both complete & $64(25.9)$ \\
Greenstick (ulna) + complete (radius) & $34(13.8)$ \\
Complete (ulna) + greenstick (radius) & $17(6.9)$ \\
Torus (ulna) + greenstick (radius) & $12(4.9)$ \\
Greenstick (ulna) + torus (radius) & $4(1.6)$ \\
Torus (ulna) + complete (radius) & $4(1.6)$ \\
Complete (ulna) + torus (radius) & $1(0.4)$ \\
\hline
\end{tabular}

Table 2. Criteria for reduction of the fracture of radius and/or ulna based on posteroanterior and/or lateral radiographs

\begin{tabular}{lcc} 
Type of deformity & Age in years & Deformity \\
\hline Angulation & $<10$ & $>15$ degrees \\
& $10-16$ & $>10$ degrees \\
Translation & $<16$ & $>$ half of bone diameter \\
Rotation & $<16$ & $>0$
\end{tabular}




\section{Chapter 7}

\section{RESULTS}

The fracture re-displaced in 73 children (29.6\%). Re-displacement occurred more frequently in distal metaphyseal fractures compared with diaphyseal fractures $(32.7 \%$ (36 of 110) vs $27.0 \%$ (37 of 137)). The mean time between the injury and displacement was 22.7 days (SD 13.5; 0 to 59), and 65 re-displacements (89.0\%) were in an above-elbow cast (Fig. 2).

The factors that were significantly and independently associated with redisplacement were hand dominance and three factors associated with the severity of the fracture, namely complete fractures, translation of the ulna on lateral radiographs and shortening (Table 3, Fig. 2).

\section{Discussion}

We found that $29.6 \%$ of fractures of both bones of the forearm in children treated in a cast displaced, the risk of which was increased in more severe fractures of the nondominant arm. Earlier authors reported displacement of between $7 \%$ and $91 \%$ of fractures in the distal metaphysis ${ }^{1-5,28-31}$ and between $7 \%$ and $27 \%$ of fractures in the diaphysis ${ }^{4,15,26,32-35}$ compared with $33 \%$ and $27 \%$ respectively in our study. Our relatively high percentage of displacement can be explained by the inclusion of only both-bone fractures, which are more unstable than single-bone fractures ${ }^{5,26,36}$.

Whereas an earlier study reported hand dominance as a risk factor for displacement (26), others found similar numbers in dominant and non-dominant arms (3). Our results suggest that fractures in the non-dominant arm are at increased risk for displacement, which might be explained by less stability of the fracture by less developed muscles in the non-dominant forearm.

As with earlier reports ${ }^{3-5,8,9,26}$ the severity of the fracture in our study seemed highly predictive of displacement. Complete fractures significantly increased the risk for displacement, a finding supported by some studies s-5,8,9,26 but not others $^{4,11}$. Whereas translation of the ulna on lateral radiographs has been reported as a risk factor for displacement ${ }^{32}$, shortening has not. Complete fractures with translation and shortening seem to be more unstable than angulated greenstick fractures with intact periosteum on one side. Angulation of the fracture did not appear to be a risk 
Table 3. Factors associated with displacement of the fracture with multivariate logistic regression analysis. Only significant odds ratios are provided (Cl, confidence interval);

$P A$, posteroanterior; lat, lateral

\begin{tabular}{|c|c|c|c|}
\hline Factors & Rate of displacement (\%) & Odds ratio $(95 \% \mathrm{Cl})$ & p-value \\
\hline \multicolumn{4}{|l|}{ Gender } \\
\hline Male $(n=147)$ & $29.9(n=44)$ & 0.561 & \\
\hline Female $(n=100)$ & $29.0(n=29)$ & & \\
\hline Dominant arm fractured & & & 0.024 \\
\hline No $(n=149)$ & $31.5(n=47)^{*}$ & $0.46(0.23$ to 0.89$)$ & \\
\hline Yes $(n=98)$ & $24.5(n=24)^{*}$ & & \\
\hline Fracture location & & & 0.751 \\
\hline Metaphyseal $(n=110)$ & $32.7(n=36)$ & & \\
\hline Diaphyseal $(n=137)$ & $27.0(n=37)$ & & \\
\hline Type of fracture & & & 0.040 \\
\hline Complete $(n=120)$ & $45.0(n=54)$ & 3.34 (1.63 to 6.86$)$ & \\
\hline Greenstick $(n=127)$ & $15.0(n=19)$ & & \\
\hline \multicolumn{4}{|l|}{ Primary displacement § } \\
\hline Angulation PA radius & & & 0.760 \\
\hline Angulation lat radius & & & 0.126 \\
\hline Angulation PA ulna & & & 0.779 \\
\hline Angulation lat ulna & & & 0.261 \\
\hline Translation PA radius & & & 0.189 \\
\hline Translation lat radius & & & 0.915 \\
\hline Translation PA ulna & & & 0.952 \\
\hline Translation lat ulna & & $0.98(0.96$ to 0.99$)$ & 0.014 \\
\hline Shortening of radius and/or ulna & & & 0.019 \\
\hline No $(n=199)$ & $21.6(n=43)$ & & \\
\hline Yes $(n=48)$ & $62.5(n=30)$ & 5.67 (2.27 to 14.17$)$ & \\
\hline Rotation of radius and/or ulna & & & 0.065 \\
\hline No $(n=232)$ & $27.2(n=63)$ & & \\
\hline Yes $(n=15)$ & $66.7(n=10)$ & & \\
\hline Reduced fracture & & & 0.452 \\
\hline No $(n=87)$ & $19.5(n=17)$ & & \\
\hline Yes $(n=160)$ & $35.0(n=56)$ & & \\
\hline Location of reduction & & & 0.445 \\
\hline Emergency ward $(n=28)$ & $28.6(n=8)$ & & \\
\hline Operation room $(n=129)$ & $36.7(n=47)$ & & \\
\hline Type of cast & & & 0.085 \\
\hline Above-elbow $(n=188$ ) & $34.6(n=65)$ & & \\
\hline Below-elbow $(n=59)$ & $13.6(n=8)$ & & \\
\hline Cast index $\S$ & & & 0.597 \\
\hline
\end{tabular}




\section{Chapter 7}

factor for displacement in this or previous studies ${ }^{3,11,37}$. Also, location in the diaphysis or metaphysis had no significant influence on displacement, a finding supported by Monga et al (26) but not Younger et $\mathrm{al}^{27}$.

Although several studies considered displacement to be related to an aboveor below-elbow cast ${ }^{3,10,26,27}$ this was not supported by our results. Also, several studies $4,8,10,11,25,32$ reported quality of the cast as a risk factor, while others found no such correlation ${ }^{9,26}$. The cast index was not considered as a risk factor in our study ${ }^{25,32}$.

Our study has several limitations. Because it is impossible to differentiate between imperfectly reduced and redisplaced fractures, we excluded children with reduced fractures that showed displacement at the first available radiographs after the reduction. Similarly, we could not analyse imperfect reduction as a risk factor for displacement. Furthermore, we measured the cast index in non-circumferential casts whereas this measurement is only validated for circumferential casts ${ }^{25,32}$. Nevertheless, we assumed that the cast index is also important in noncircumferential casts because it indicates how well the cast is moulded to the contour of the forearm. This is supported by a study in which there were similar rates of displacement in circumferential and non-circumferential casts ${ }^{3}$.

In summary, reduced and unreduced fractures of both bones of the forearm in children displaced frequently, even if treated with an above-elbow cast. The most severe fractures in the non-dominant arm had the highest risk for displacement. Radiographs at set times during treatment might identify early displacement, which should be treated before malunion occurs, especially in older children with less potential for remodelling. 


\section{REFERENCES}

1. Gibbons CL, Woods DA, Pailthorpe C, Carr AJ, Worlock P. The management of isolated distal radius fractures in children. J Pediatr Orthop. 1994;14(2):207-10.

2. Haddad FS, Williams RL. Forearm fractures in children: avoiding redisplacement. Injury. 1995;26(10):691-2.

3. Proctor MT, Moore DJ, Paterson JM. Redisplacement after manipulation of distal radial fractures in children. J Bone Joint Surg Br. 1993;75(3):453-4.

4. Voto SJ, Weiner DS, Leighley B. Redisplacement after closed reduction of forearm fractures in children. J Pediatr Orthop. 1990;10(1):79-84.

5. Zamzam MM, Khoshhal KI. Displaced fracture of the distal radius in children: factors responsible for redisplacement after closed reduction. J Bone Joint Surg Br. 2005;87(6):841-3.

6. Prommersberger KJ, Froehner SC, Schmitt RR, Lanz UB. Rotational deformity in malunited fractures of the distal radius. J Hand Surg [Am]. 2004;29(1):110-5.

7. Roberts JA. Angulation of the radius in children's fractures. J Bone Joint Surg Br. 1986;68(5):751-4.

8. Alemdaroglu KB, Iltar S, Cimen O, Uysal M, Alagoz E, Atlihan D. Risk factors in redisplacement of distal radial fractures in children. J Bone Joint Surg Am. 2008;90(6):122430.

9. Pretell Mazzini J, Rodriguez Martin J. Paediatric forearm and distal radius fractures: risk factors and re-displacement—role of casting indices. Int Orthop.34(3):407-12.

10. Webb GR, Galpin RD, Armstrong DG. Comparison of short and long arm plaster casts for displaced fractures in the distal third of the forearm in children. J Bone Joint Surg Am. 2006;88(1):9-17.

11. Younger AS, Tredwell SJ, Mackenzie WG, Orr JD, King PM, Tennant W. Accurate prediction of outcome after pediatric forearm fracture. J Pediatr Orthop. 1994;14(2):200-6.

12. Boyer BA, Overton B, Schrader W, Riley P, Fleissner P. Position of immobilization for pediatric forearm fractures. Journal of pediatric orthopedics. 2002;22(2):185-7.

13. Choi KY, Chan WS, Lam TP, Cheng JC. Percutaneous Kirschner-wire pinning for severely displaced distal radial fractures in children. A report of 157 cases. J Bone Joint Surg Br. 1995;77(5):797-801.

14. Daruwalla JS. A study of radioulnar movements following fractures of the forearm in children. Clin Orthop Relat Res. 1979(139):114-20. 


\section{Chapter 7}

15. Jones K, Weiner DS. The management of forearm fractures in children: a plea for conservatism. J Pediatr Orthop. 1999;19(6):811-5.

16. Mani GV, Hui PW, Cheng JC. Translation of the radius as a predictor of outcome in distal radial fractures of children. J Bone Joint Surg Br. 1993;75(5):808-11.

17. Maric D, Petkovic L, Tomasevic V, Bajic L, Gajdobranski D, Marcikic A. [Osteosynthesis with Kirschner wires in the treatment of dislocation fractures of the forearm in children]. Med Pregl. 2002;55(3-4):140-5.

18. Noonan KJ, Price CT. Forearm and distal radius fractures in children. J Am Acad Orthop Surg. 1998;6(3):146-56.

19. Tynan MC, Fornalski S, McMahon PJ, Utkan A, Green SA, Lee TQ. The effects of ulnar axial malalignment on supination and pronation. J Bone Joint Surg Am. 2000;82-A(12):1726-31.

20. Zimmermann R, Gabl M, Angermann P, Lutz M, Reinhart C, Kralinger F, et al. [Late sequelae of fractures of the distal third of the forearm during the growth period]. Handchir Mikrochir Plast Chir. 2000;32(4):242-9.

21. Gustilo RB, Simpson L, Nixon R, Ruiz A, Indeck W. Analysis of 511 open fractures. Clin Orthop Relat Res. 1969;66:148-54.

22. Colaris JW, Biter LU, Allema JH, Bloem RM, van de Ven CP, de Vries MR, et al. Belowelbow cast for metaphyseal both-bone fractures of the distal forearm in children: a randomised multicentre study. Injury. 2012;43(7):1107-11.

23. Colaris JW, Allema JH, Biter LU, de Vries MR, van de Ven CP, Bloem RM, et al. Redisplacement of stable distal both-bone forearm fractures in children: a randomised controlled multicentre trial. Injury. 2013;44(4):498-503.

24. Naimark A, Kossoff J, Leach RE. The disparate diameter. A sign of rotational deformity in fractures. J Can Assoc Radiol. 1983;34(1):8-11.

25. Chess DG, Hyndman JC, Leahey JL, Brown DC, Sinclair AM. Short arm plaster cast for distal pediatric forearm fractures. J Pediatr Orthop. 1994;14(2):211-3.

26. Monga P, Raghupathy A, Courtman NH. Factors affecting remanipulation in paediatric forearm fractures. J Pediatr Orthop B.19(2):181-7.

27. Younger AS, Tredwell SJ, Mackenzie WG. Factors affecting fracture position at cast removal after pediatric forearm fracture. J Pediatr Orthop. 1997;17(3):332-6.

28. Blount WP. Forearm fractures in children. Clin Orthop Relat Res. 1967;51:93-107. 


\section{Risk factors for displacement of fractures}

29. Friberg KS. Remodelling after distal forearm fractures in children. I. The effect of residual angulation on the spatial orientation of the epiphyseal plates. Acta Orthop Scand. 1979;50(5):537-46.

30. Kiely PD, Kiely PJ, Stephens MM, Dowling FE. Atypical distal radial fractures in children. J Pediatr Orthop B. 2004;13(3):202-5.

31. Van Leemput W, De Ridder K. Distal metaphyseal radius fractures in children: reduction with or without pinning. Acta Orthop Belg. 2009;75(3):306-9.

32. Bochang C, Jie Y, Zhigang W, Weigl D, Bar-On E, Katz K. Immobilisation of forearm fractures in children: extended versus flexed elbow. J Bone Joint Surg Br. 2005;87(7):994-6.

33. Chan CF, Meads BM, Nicol RO. Remanipulation of forearm fractures in children. N Z Med J. 1997;110(1047):249-50.

34. Kay S, Smith C, Oppenheim WL. Both-bone midshaft forearm fractures in children. J Pediatr Orthop. 1986;6(3):306-10.

35. Schmittenbecher PP. State-of-the-art treatment of forearm shaft fractures. Injury. 2005;36 Suppl 1:A25-34.

36. Bohm ER, Bubbar V, Yong Hing K, Dzus A. Above and below-the-elbow plaster casts for distal forearm fractures in children. A randomized controlled trial. J Bone Joint Surg Am. 2006;88(1):1-8. 


\section{PART V}

\section{LIMITATION OF}

\section{FOREARM ROTÁAION}




\section{Chapter 8}

\section{Pronation and supination after}

forearm fractures in children: reliability of visual estimation and conventional goniometry measurement.

Injury. 2010 Jun;41(6):643-6.

Colaris J, van der Linden M, Selles R, Coene N, Allema JH, Verhaar J. 


\section{Chapter 8}

\section{AbStRACT}

Background: Forearm fractures are common amongst children and often result in limited rotational function. In daily practice, pronation and supination of the arm are often visually estimated or measured using a conventional goniometer. The aim of this study was to compare the reliability of these two methods in paediatric patients that had previously sustained a forearm fracture.

Methods: Intra- and interrater reliability of visual estimation and conventional goniometry were determined in 47 children who had previously sustained a forearm fracture.

Results: Intra- and interrater reliability of visual estimation and conventional goniometry was fair to excellent, with Intraclass Correlation Coefficients (ICC's) ranging between 0.75 and 0.94 . In addition, the overall goniometer data consistently showed lower Smallest Detectable Differences (SDD's) compared to the visual estimation data, also indicating better reliability for the goniometer method.

Conclusions: A conventional goniometer is an easy, fast and reliable method to determine the pronation and supination in a child who had sustained a forearm fracture. If an uncooperative child hinders the measurement, visual estimation is a good second choice. Measurements are more reliable when repeated by the same professional. 


\section{INTRODUCTION}

Forearm rotation, consisting of pronation and supination, is commonly used in daily life for tasks such as eating, typing, picking up small objects and accepting change ${ }^{1}$. In children up to the age of 15 years, pronation of 50-80 degrees and supination of 80-120 degrees is considered normal ${ }^{2}$. In a number of pathologies, pronation and supination can be limited, such as following a forearm fracture, which is rather common among children ${ }^{1,3}$. Measurement of pronation and supination limitation is important for clinical decision making and outcome evaluation for these fractures.

In the past, many devices have been developed to measure pronation and supination of the forearm. These devices include gravity-dependent methods, tubular handles, voltage gated sensors and measurements of digital photographs ${ }^{1,4-9}$. For many of these devices, reliability is fair to excellent, as expressed by Intraclass Correlation Coefficients (ICCs) (10) ranging between 0.78 - 0.99 for intrarater reliability ${ }^{4,6,9}$ and $0.72-0.98$ for interrater reliability $4,5,7,9$. However, the above-mentioned devices are complex and are difficult to use in standard clinical care. In addition, they may intimidate little children. Therefore, forearm rotation in children is still generally evaluated by visual estimation or conventional goniometry. Although limitations of pronation and supination are often visually estimated in clinical practice, to our knowledge, no studies have yet investigated the reliability of visual estimation in any age group. In addition, the reliability of conventional goniometry has been investigated only scarcely in children ${ }^{1}$, and slightly more often in adults ${ }^{4-6,9,11-13}$.

Furthermore, most of the authors report the reliability of the goniometer measurements only in a healthy population $5,6,9,11,13$, whereas only one study evaluated the reliability of measuring rotational impairments after a trauma ${ }^{4}$. Because visual estimation and goniometrical measurement of pronation and supination are often used in clinical care as well as in clinical research, the aim of the current study is to compare the reliability of these two methods in paediatric patients that had previously sustained a forearm fracture. 


\section{Chapter 8}

\section{Patients and Methods}

\section{Subjects}

All patients were treated at the department of Traumatology of the Juliana Children's Hospital, The Hague, the Netherlands. The inclusion criteria for this study were: (1) patients with a midshaft or distal both-bone forearm fracture (2) the fracture was sustained in the last 2 years (3) the fracture was united (4) patients were between 6 and 16 years of age. All patients were categorised in 3 age groups: (1) 6 - 9 years old, (2) 10 - 13 years old and (3) 14 - 16 years old. The regional medical ethics committee approved the study and written informed consent was obtained for participation.

\section{Measurements}

Two different methods were used to measure the pronation-supination range of the fractured forearm: visual estimation and conventional goniometry. Before each measurement, the examiner ensured that the child was standing in an upright position. Meanwhile, the elbow was positioned firmly against the torso to eliminate compensating forearm rotation by using movements of the elbow and shoulder. The elbow was flexed in 90 degrees with the forearm in mid-position and the wrist in neutral.

Visual estimation: At the start of the experiment, both examiners visually estimated the pronation and supination range of the traumatised arm, blinded for the results of the other examiner (Figures 1 and 2). The visual estimation was not repeated because we anticipated that the examiner would remember the score on the first measurement. 
Measurement of pronation and supination

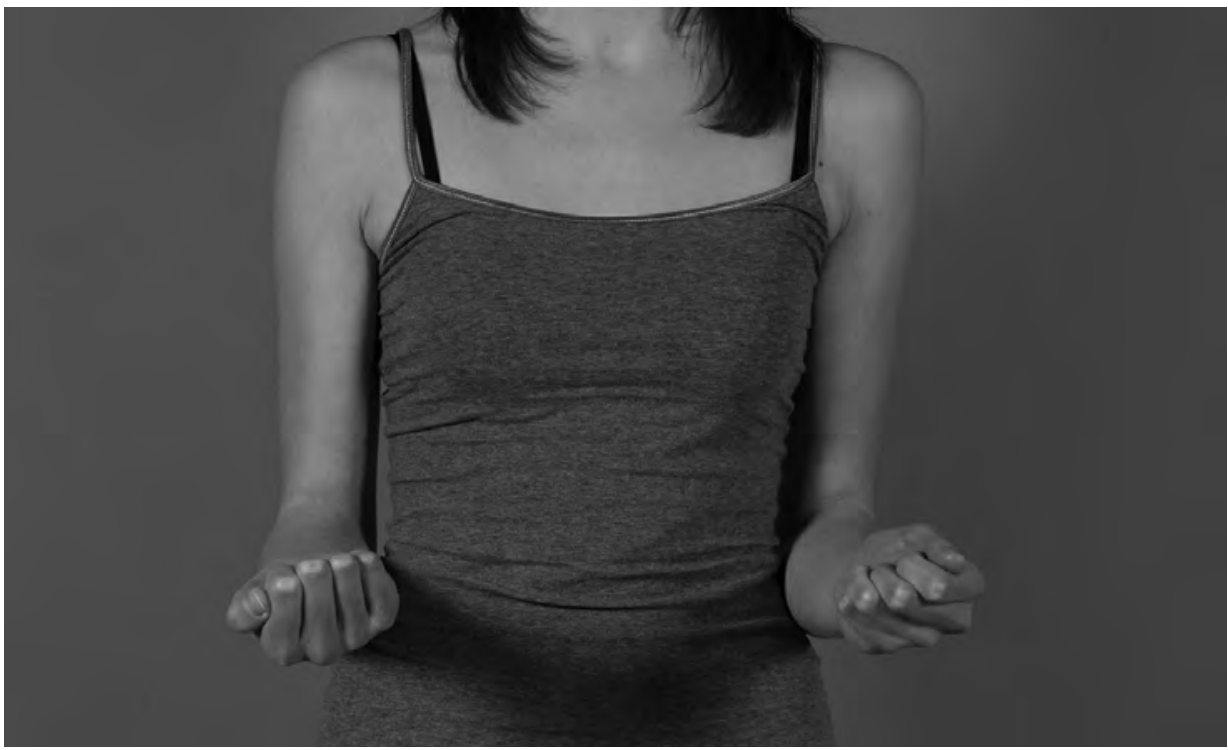

Figure 1. Visual estimation of supination in a 15-year-old girl with impairments of her left arm after a united forearm fracture.

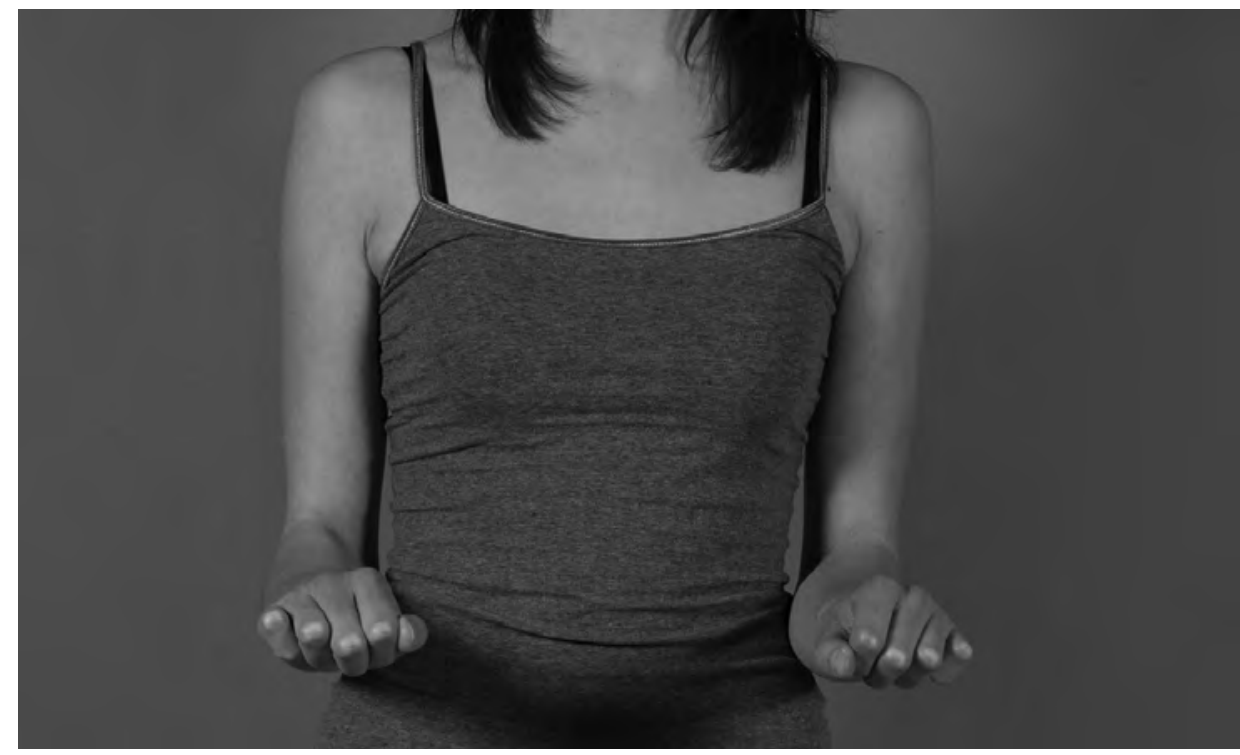

Figure 2. Visual estimation of pronation. 


\section{Chapter 8}

Goniometer measurement: We used a 180-degrees protractor goniometer with 2 movable arms of $30 \mathrm{~cm}$, constructed of clear, flexible plastic (Figures 3 and 4). One arm of the goniometer was lined up parallel to the upper arm of the patient, the other arm was placed parallel to the distal third of the forearm. The goniometer was blocked on the front-side in order to blind the examiners during the measurement. Both examiners performed 3 independent measurements of full pronation and supination, to determine the interrater reliability. To obtain intrarater reliability, the first observer repeated the same three measurements a second time. All measurements were marked on separate forms to blind the examiners from previous results. The examiners were graduate students of the faculty of Human Movement Sciences at the VU University in Amsterdam. They were trained in measuring pronation and supination in a paediatric population by the first author.

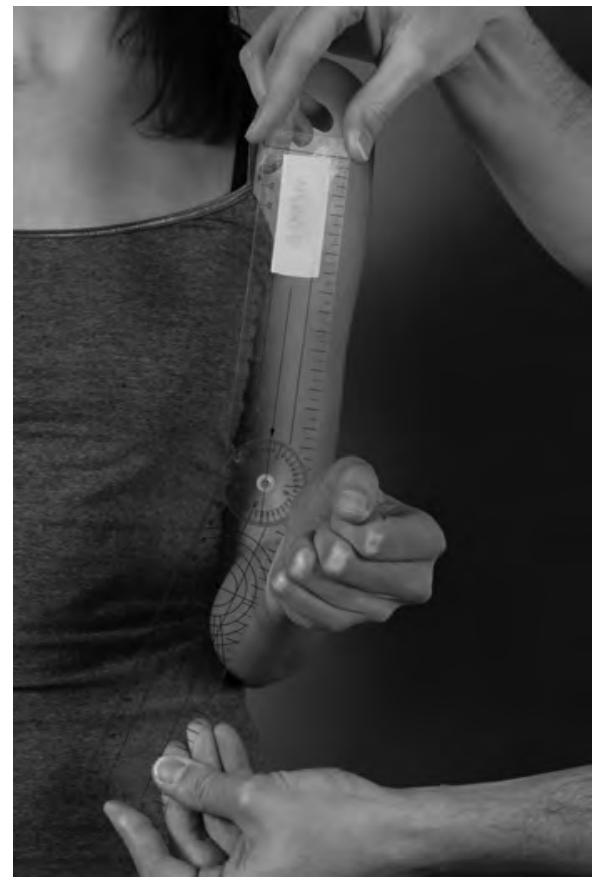

Figure 3. Measurement of supination with a conventional goniometer (not blinded).

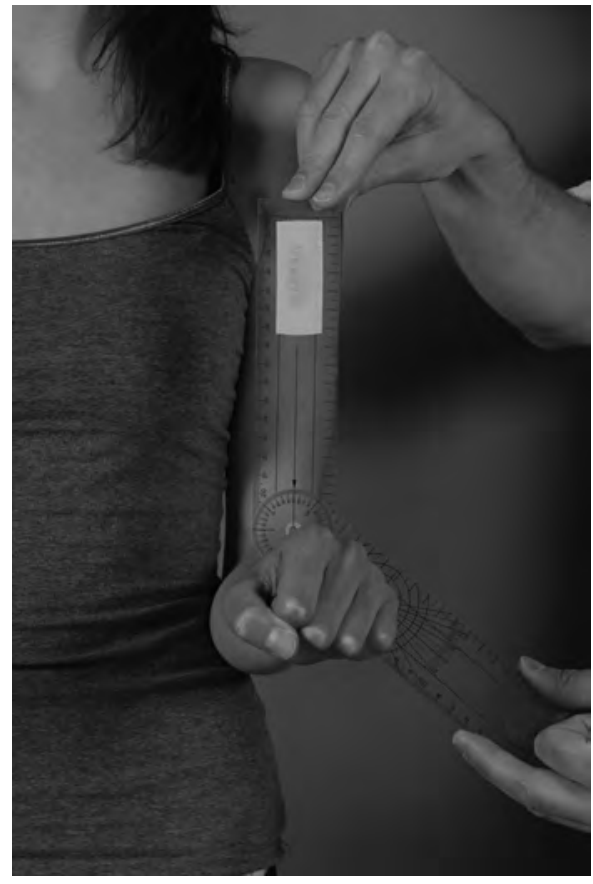

Figure 4. Measurement of pronation with a conventional goniometer (not blinded). 


\section{Statistical analysis}

First, the results of the 3 measurements of each examination were averaged. Using SPSS 13.0, ICCs were calculated. When assessing reliability, a distinction between intra-observer and inter-observer reliability was made. Intra-observer reliability investigates the capability of one tester to produce consistent results. Inter-observer reliability examines the extent of concurrence between the results of different observers.

In addition to the ICC, the smallest detectable difference (SDD) were calculated (10). The SDD is specifically valuable for clinical use since this index allows distinguishing between measurement error and a real (treatment) change in individual measurements since only a difference between consecutive measurements that exceeds the SDD can be considered a real change. For example, a SDD of 5 degrees indicates that a follow-up measurement should differ by at least 5 degrees from a baseline measurement to be sure that there is a real change in pronation or supination angle of an individual subject. Hence, the SDD value reflects the smallest clinically detectable change. Paired t-tests were used to compare the 2 experimental methods. The effect of age on the measurement results was addressed by analysis of variance (ANOVA) with Bonferoni post-hoc comparisons. The level of significance was set at $\mathrm{p}<0.05$.

\section{Results}

Forty-seven children (34 boys and 13 girls) were included in this study. The mean age was $11.1 \pm 3.1$ years (range 6-16 years). The dominant arm was fractured in 19 children. All 47 children successfully completed the study protocol. The results of the visual estimation and goniometrical measurements are demonstrated in Table 1, presenting the data of the whole group (6-16 years) and the data stratified according to the 3 age groups: 6-9 years (15 patients), 10-13 years (16 patients) and 14-16 years (16 patients). Visual estimation showed higher pronation, supination and total range of motion (ROM) angles compared to the goniometer data in all age groups. In the overall group, this difference was statistically significant for the total ROM only. For the 6-9 year old children, visual estimation angles were significantly larger than goniometer angles for supination and total ROM. 


\section{Chapter 8}

Table 1. Means, standard deviation (SD), minimum and maximum for pronation, supination and total range of motion (ROM) in degrees. The table compares the outcomes of the goniometer measurement (left) with those of the visual estimation (right). Age is in years. * indicates significant difference between the mean goniometer and mean visual estimation data.

\section{Goniometer}

Visual estimation

\begin{tabular}{llcccccccc}
\hline & Age & Mean & SD & Minimum & Maximum & Mean & SD & Minimum & Maximum \\
\hline Pronation & $6-16$ & 71 & 10 & 25 & 88 & 73 & 19 & 33 & 90 \\
& $6-9$ & 74 & 6 & 62 & 87 & 78 & 15 & 45 & 90 \\
& $10-13$ & 69 & 14 & 25 & 87 & 73 & 21 & 33 & 90 \\
& $14-16$ & 69 & 7 & 60 & 88 & 69 & 20 & 38 & 90 \\
\hline Supination & $6-16$ & 85 & 9 & 64 & 111 & 87 & 11 & 50 & 113 \\
& $6-9$ & 86 & 10 & 67 & 111 & $90 *$ & 8 & 78 & 113 \\
& $10-13$ & 87 & 8 & 64 & 100 & 86 & 12 & 53 & 98 \\
\hline ROM & $14-16$ & 83 & 8 & 64 & 92 & 86 & 13 & 50 & 98 \\
\hline $6-16$ & 156 & 13 & 119 & 188 & $160 *$ & 24 & 90 & 200 \\
& $6-9$ & 160 & 11 & 136 & 188 & $168^{*}$ & 17 & 123 & 200 \\
& $10-13$ & 156 & 15 & 119 & 172 & 158 & 25 & 103 & 180 \\
& $14-16$ & 152 & 12 & 127 & 172 & 156 & 28 & 90 & 183 \\
\hline
\end{tabular}

The interrater reliability of both methods is illustrated in Table 2. In the overall group, the goniometer method had ICCs ranging from 0.84 to 0.89 , while visual estimation had slightly lower ICCs, ranging from 0.75 to 0.88 . Except for two subgroup comparisons, the ICCs of the goniometer method were higher than those of visual estimation, suggesting a better interrater reliability of the goniometer method. In addition, the overall goniometer data consistently showed lower SDD values as compared to the visual estimation data (SDD: $10-15^{\circ}$ vs $16-24^{\circ}$ ), also indicating better reliability for the goniometer method. When comparing the different age groups for the goniometer data, the eldest children consistently showed the lowest SDD scores. We did not find the same effect for visual estimation, where the youngest age group showed the lowest SDD scores. Subgroup analysis of the ICCs did not show a clear age effect. 
Table 2. Interrater reliability values per age group and measurement method. SDD = smallest detectable difference, ICC = intraclass correlation coefficient. Age is in years and SDD is in degrees.

\begin{tabular}{|c|c|c|c|c|c|}
\hline \multicolumn{4}{|c|}{ Goniometer } & \multicolumn{2}{|c|}{ Visual estimation } \\
\hline Measurement & Age & SDD & ICC & SDD & ICC \\
\hline \multirow[t]{4}{*}{ Pronation } & $6-16$ & 10 & 0.89 & 23 & 0.82 \\
\hline & $6-9$ & 10 & 0.65 & 20 & 0.78 \\
\hline & $10-13$ & 12 & 0.92 & 22 & 0.87 \\
\hline & $14-16$ & 7 & 0.89 & 28 & 0.77 \\
\hline \multirow[t]{4}{*}{ Supination } & $6-16$ & 10 & 0.84 & 16 & 0.75 \\
\hline & $6-9$ & 7 & 0.93 & 7 & 0.89 \\
\hline & $10-13$ & 15 & 0.63 & 20 & 0.70 \\
\hline & $14-16$ & 5 & 0.96 & 17 & 0.78 \\
\hline \multirow[t]{4}{*}{ Range of motion } & $6-16$ & 15 & 0.85 & 24 & 0.88 \\
\hline & $6-9$ & 11 & 0.89 & 18 & 0.88 \\
\hline & $10-13$ & 19 & 0.85 & 20 & 0.92 \\
\hline & $14-16$ & 7 & 0.88 & 34 & 0.83 \\
\hline
\end{tabular}

The intrarater reliability of the goniometer method is illustrated in Table 3. In the overall group, intrarater ICCs ranged from 0.92 to 0.94 with SDDs ranging from 6 to $10^{\circ}$ respectively. Compared to the interrater reliability, the intrarater reliability (ICC 0.92-0.94) was consistently higher (see Table 2). Furthermore, the intrarater SDDs $\left(6-10^{\circ}\right)$ were lower than the interrater SDDs $\left(10-15^{\circ}\right)$. 


\section{Chapter 8}

Table 3. Intrarater reliability values of conventional goniometry, stratified according to age group. $S D D=$ smallest detectable difference, $I C C=$ intraclass correlation coefficient. Age is in years, SDD is in degrees.

\begin{tabular}{|c|c|c|c|}
\hline \multicolumn{4}{|c|}{ Goniometer measurement } \\
\hline & Age & SDD & ICC \\
\hline \multirow[t]{4}{*}{ Pronation } & $6-16$ & 7 & 0.94 \\
\hline & $6-9$ & 9 & 0.73 \\
\hline & $10-13$ & 7 & 0.97 \\
\hline & $14-16$ & 4 & 0.96 \\
\hline \multirow[t]{4}{*}{ Supination } & $6-16$ & 6 & 0.93 \\
\hline & $6-9$ & 5 & 0.97 \\
\hline & $10-13$ & 9 & 0.80 \\
\hline & $14-16$ & 5 & 0.96 \\
\hline \multirow[t]{4}{*}{ Range of Motion } & $6-16$ & 10 & 0.92 \\
\hline & $6-9$ & 8 & 0.94 \\
\hline & $10-13$ & 14 & 0.90 \\
\hline & $14-16$ & 7 & 0.93 \\
\hline
\end{tabular}

\section{Discussion}

The aim of this study was to determine the intra- and interrater reliability of visual estimation and conventional goniometry for measuring forearm pronation and supination in a paediatric population with a united both-bone forearm fracture. Regarding the interrater reliability, the present results demonstrated a fair to excellent reliability for both visual estimation and goniometer measurements (ICCs 0.75 to 
0.89). These results are similar to previous studies with ICCs ranging from 0.72 to 0.98 , using more complex devices to measure forearm rotation ${ }^{4,5,7,9}$. In this study, we found that the goniometer measurements had significantly higher ICCs and lower SDDs as compared to visual estimation, indicating better overall reliability and higher specificity. This difference may partly be explained by the higher specificity of the goniometer (1-degree steps) as compared to visual estimation (5-degree steps). To our knowledge, the only study that has dealt with visual estimation dates back to 1976 and concluded that goniometer measurements were more reliable than estimation of elbow flexion and wrist extension ${ }^{12}$. When analysing the effect of age on the reliability of measuring forearm rotation, we found no consistent effect of age on the ICCs. However, the SDD values of the goniometer method were consistently lower in the eldest children. This indicates that the differences between repeated measures are smaller in older children. For visual estimation the opposite was found: SDD values of visual estimation were lowest in the youngest children. However, visual estimation was still less accurate as compared to goniometer measurements in the younger aged. The intrarater reliability of the goniometer measurements in the present study was excellent, ranged between 0.92 to 0.94 , which is comparable with the intrarater reliability that has previously been found using more complex devices, ranging from 0.78 to $0.99^{4,6,9}$. The intrarater reliability in the present study was consistently higher that interrater reliability, indicating that repeated examination by the same professional should generally be preferred.

A limitation of this study is that we compared only two examiners, both of whom were graduate students without extensive clinical experience in working with this paediatric population. It should be noted, however, that previous literature showed that the accuracy of measurements is independently of the type of professional ${ }^{4}$. Another limitation was that the intrarater reliability of visual estimation could not be reliably tested in the current study design, which consisted of a one day visit of the children. The particular strengths of this study included the blinded design, the measurement of a relevant group of patients and the use of conventional goniometry as well as visual estimation as primary methods. Furthermore, the evaluation of the intra- and inter reliability, as well as use of smallest detectable difference scores, gives it substantial clinical relevance. In conclusion, based on the present study, we recommend the use of the conventional goniometer for measuring 


\section{Chapter 8}

pronation and supination in daily practice. If an uncooperative child interferes with the measurement, visual estimation is a good second choice. To minimise the variability of the measurements, professionals should measure the forearm rotation with the arms in the same documented position. 


\section{REFERENCES}

1. Holdsworth BJ, Sloan JP. Proximal forearm fractures in children: residual disability. Injury. 1982;14(2):174-9.

2. Daruwalla JS. A study of radioulnar movements following fractures of the forearm in children. Clin Orthop Relat Res. 1979(139):114-20.

3. Kasten P, Krefft M, Hesselbach J, Weinberg AM. How does torsional deformity of the radial shaft influence the rotation of the forearm? A biomechanical study. J Orthop Trauma. 2003;17(1):57-60.

4. Armstrong AD, MacDermid JC, Chinchalkar S, Stevens RS, King GJ. Reliability of range-ofmotion measurement in the elbow and forearm. J Shoulder Elbow Surg. 1998;7(6):573-80.

5. Flowers KR, Stephens-Chisar J, LaStayo P, Galante BL. Intrarater reliability of a new method and instrumentation for measuring passive supination and pronation: a preliminary study. J Hand Ther. 2001;14(1):30-5.

6. Greene BL, Wolf SL. Upper extremity joint movement: comparison of two measurement devices. Arch Phys Med Rehabil. 1989;70(4):288-90.

7. Karagiannopoulos C, Sitler M, Michlovitz S. Reliability of 2 functional goniometric methods for measuring forearm pronation and supination active range of motion. J Orthop Sports Phys Ther. 2003;33(9):523-31.

8. Patrick J. A study of supination and pronation, with especial reference to the treatment of forearm fractures. J Bone Joint Surg Br. 1946;28:737-48.

9. Urban V, Kalberer F, Roos M, Dumont CE. [Reliability of active range-of-motion measurement of the rotation in the forearm: comparison of three measurement devices]. Z Orthop Ihre Grenzgeb. 2002;140(1):72-6.

10. Weir JP. Quantifying test-retest reliability using the intraclass correlation coefficient and the SEM. J Strength Cond Res. 2005;19(1):231-40.

11. Boone DC, Azen SP, Lin CM, Spence C, Baron C, Lee L. Reliability of goniometric measurements. Phys Ther. 1978;58(11):1355-90.

12. Low JL. The reliability of joint measurement. Physiotherapy. 1976;62(7):227-9.

13. Rothstein JM, Miller PJ, Roettger RF. Goniometric reliability in a clinical setting. Elbow and knee measurements. Phys Ther. 1983;63(10):1611-5. 

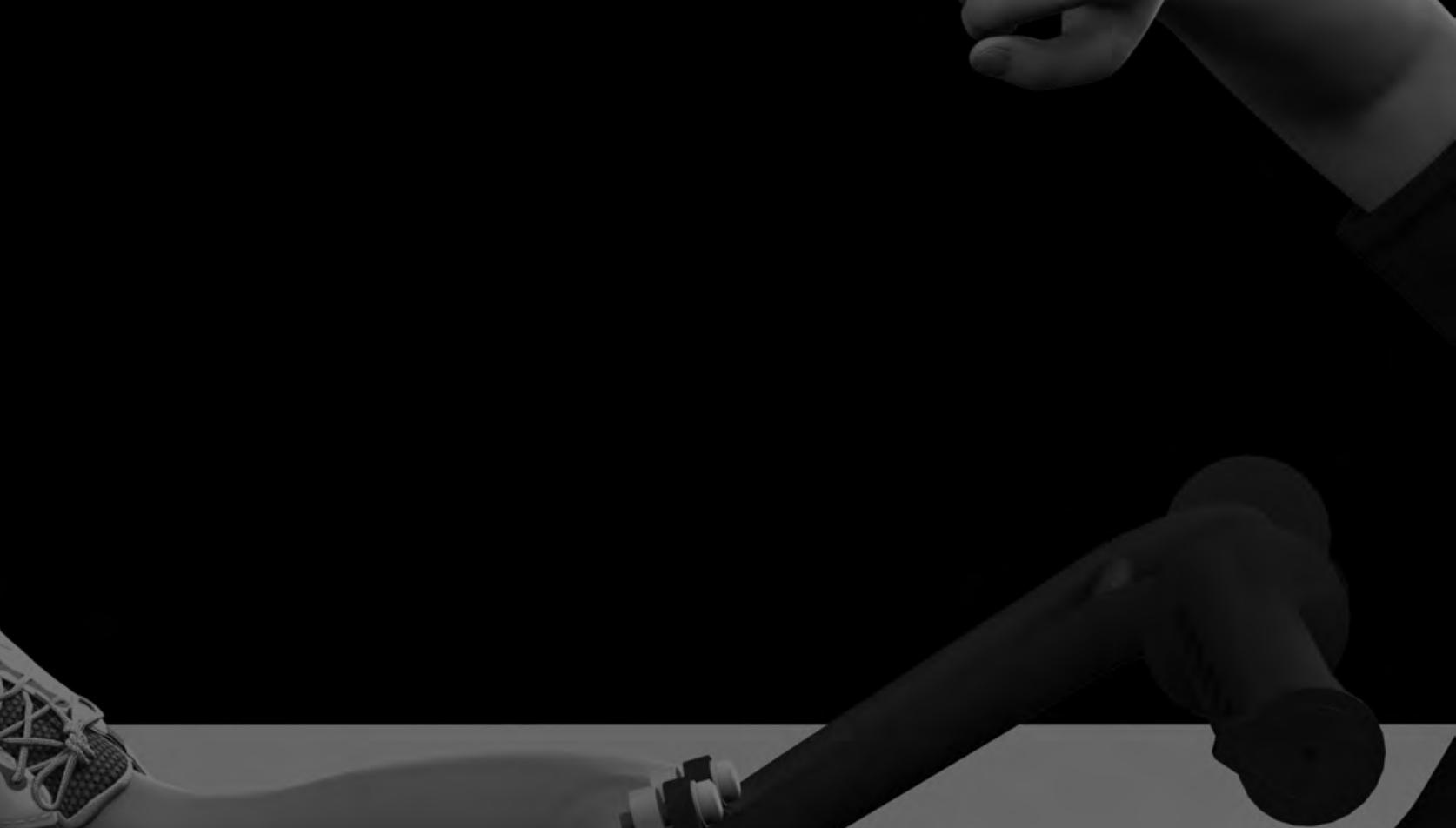


\section{Chapter 9}

Which factors affect limitation of pronation/supination after forearm fractures in children? A prospective multicentre study

Injury. 2014 Apr;45(4):696-700.

Colaris JW, Allema JH, Reijman M, de Vries MR, Ulas Biter L, Bloem RM, van de Ven CP, Verhaar JA. 


\section{Chapter 9}

\section{AbStRACT}

Introduction: Both-bone forearm fractures in children frequently result in a limitation of pronation/supination, which hinders daily activities. The purpose of this prospective multicentre study was to investigate which clinical factors are related to the limitation of pronation/supination in children with a both-bone forearm fracture.

Methods: In four Dutch hospitals consecutive children ( $<16$ years) who sustained a both-bone forearm fracture were included. Children were followed for 6-9 months and data from questionnaires, physical examination, and X-rays were collected. Univariate and multivariate logistic regression analyses were used to assess the relationship between limitation of pronation/supination ( $\geq 20$ degrees) and several clinical factors.

Results: A group of 410 children with both-bone forearm fractures were included of which 10 children missed the final examination (follow-up rate of $97.6 \%$ ). We found that a re-fracture (odds ratio (OR) 11.7, 95\% confidence interval (Cl) 1.2; 118.5), a fracture in the diaphysis $(\mathrm{OR} 3.3,95 \% \mathrm{Cl} 1.4 ; 7.9)$ and less physiotherapy during follow-up (OR $0.9,95 \% \mathrm{Cl} 0.82 ; 0.98)$ were independently associated with a limitation of pronation/supination of 20 degrees or more.

Conclusions: These findings imply that a re-fracture and a diaphyseal located fracture were independently of each other associated with a limitation of pronation/supination in children with a both-bone forearm fracture. Furthermore, in children with severe limitation extensive physiotherapy is associated with better functional outcome. 


\section{INTRODUCTION}

Severe limitation of pronation/supination following both-bone forearm fractures in children hinders daily activities. For example, while pronation is used for writing and typing, movements such as perineal hygiene and accepting monetary change require supination. Fortunately, the ipsilateral shoulder can compensate mild limitation of pronation by abduction and internal rotation, and mild limitation of supination by adduction and external rotation.

Pronation/supination of the forearm is not a simple rotational motion but a complex motion with rotation and translation ${ }^{1}$. This complex motion in combination with the complex anatomy of the forearm makes it difficult to find the exact cause of this limitation. In general, it can be caused by pathology of the bones or soft tissue around it. Pathology of the bones consists of a malunion of the radius and/or ulna and is a well-known cause of limitation of pronation/supination ${ }^{2-9}$. The soft-tissue pathology as cause of limitation is less well known. Some studies reported on contractures of the interosseous membrane ${ }^{10,11}$ while others stressed the role of contractures around wrist and elbow ${ }^{12,13}$.

Although previous literature has reported on pathology of bones and soft tissue as a cause of limitation of pronation/supination, many other clinical factors associated with this limitation have not yet been explored. However, knowledge on these factors can contribute to better clinical care by change of treatment (when required) and detailed information provided to parents and children.

Therefore, we designed a prospective multicentre study with the purpose of investigating which clinical factors are related to the limitation of pronation/ supination in children with a both-bone forearm fracture.

\section{Materials ANd Methods}

\section{Study design and participants}

This prospective study included consecutive children with a forearm fracture of radius and ulna who visited the emergency department of one of four participating Dutch hospitals: Erasmus Medical Center (Rotterdam), HAGA Hospital (The Hague), Reinier de Graaf Hospital (Delft) and Sint Franciscus Hospital (Rotterdam). The 


\section{Chapter 9}

regional medical ethics committee approved the study. Informed consent for participation was obtained from all parents and from all children aged $\geq 12$ years.

We included children aged $<16$ years who sustained a both-bone forearm fracture in the diaphysis or distal metaphysis. The criteria for reduction were a priori defined and based on previous studies ${ }^{14-23}$ (Table 1). Exclusion criteria were torus fractures of both radius and ulna, fractures older than 1 week, severe open fractures (Gustilo II and III) $^{24}$ and re-fractures.

Table 1. Criteria for reduction of the fracture of radius and/or ulna based on posteroanterior and/or lateral radiographs.

\begin{tabular}{lcc} 
Type of deformity & Age in years & Deformity \\
\hline Angulation & $<10$ & $>15$ degrees \\
& $10-16$ & $>10$ degrees \\
Translation & $<16$ & $>$ half of bone diameter \\
Rotation & $<16$ & $>0$ \\
\hline
\end{tabular}

\section{Procedures}

The included children participated in several randomised controlled studies. The study protocol distinguished different types of both-bone forearm fractures (Table 2). Briefly, distal metaphyseal fractures without need for reduction were treated with below-elbow cast (BEC) or above-elbow cast (AEC) for 4 weeks $^{25}$, while distal metaphyseal fractures with reduction were treated with or without Kirschner wires (K wires) in combination with AEC for 4 weeks ${ }^{26}$. In addition, diaphyseal fractures without reduction and reduced stable diaphyseal fractures were treated for 6 weeks AEC, or a combination of 3 weeks AEC and 3 weeks BEC. Finally, unstable diaphyseal fractures were fixated with 1 or 2 intramedullary nails in combination with 3 weeks AEC. In case of an AEC, the elbow was set in 90 degrees of flexion with the forearm in neutral position. A BEC allowed free movement of the elbow joint. 


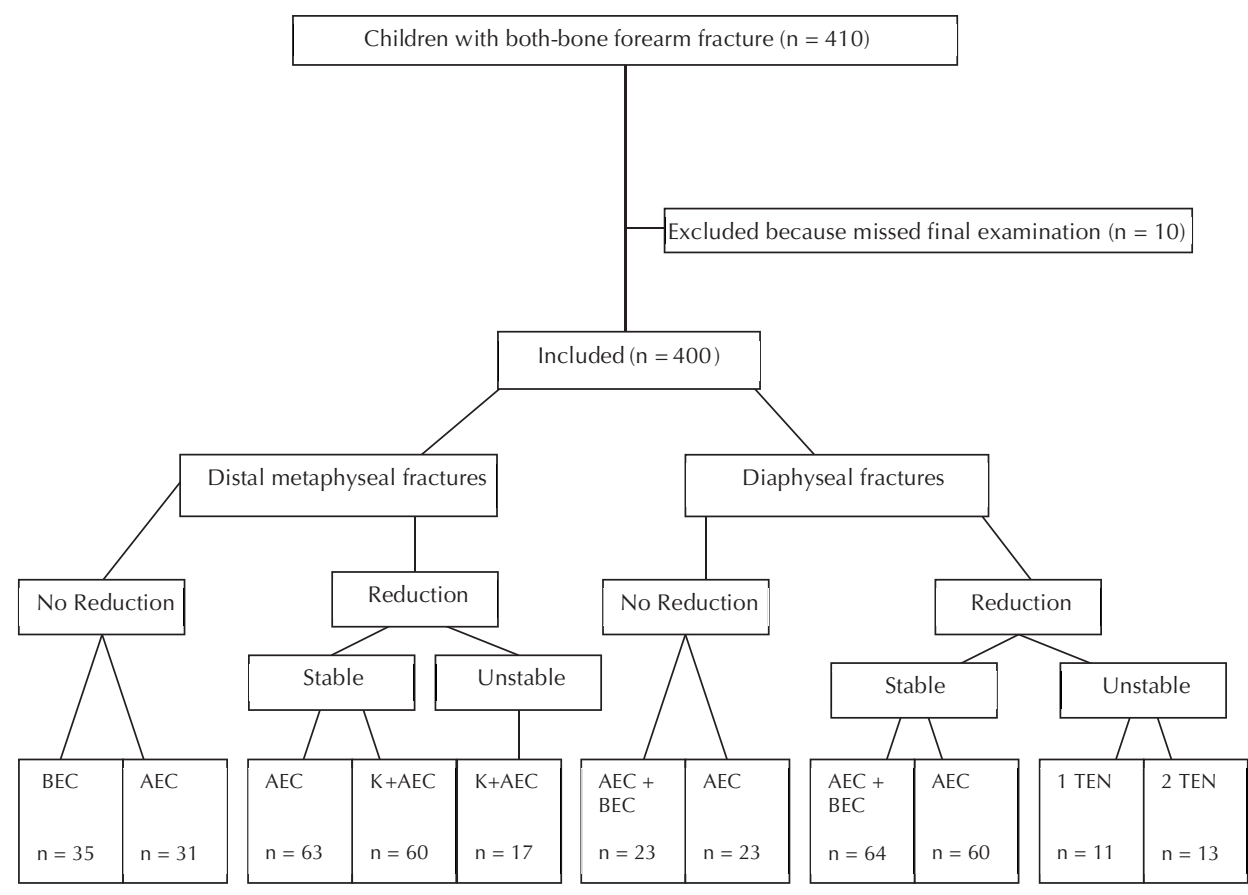

$n=$ number of children; $B E C=$ below elbow cast; $A E C=$ above elbow cast;

$K=$ Kirschner wires; TEN $=$ Titanium Elastic Nail.

Table 2. Flowchart of enrolment in the study

All children were clinically and radiographically evaluated during the first 6 weeks after trauma by a surgeon. Fracture displacement during follow-up, as defined by the loss of reduction according to the primary reduction criteria (Table 1), required new fracture reduction. Finally, the cast and transcutaneous hardware were removed in the plaster room, while buried hardware was removed in the operating room.

One orthopaedic surgeon, who was not involved in primary treatment, examined all children 2 and 6 months after trauma. Only the children with unstable diaphyseal fractures were examined 2 and 9 months after initial trauma because intramedullary nails were removed at 8 months after trauma. During both examinations, the orthopaedic surgeon measured pronation/supination of both arms. 


\section{Chapter 9}

This technique was standardised with the use of a $180^{\circ}$ goniometer constructed of clear, flexible plastic with 2 movable arms of $30 \mathrm{~cm}^{27}$. Children who suffered from at least 30 degree of limitation at the 2-month examination were referred to a physiotherapist.

Radiographs were taken directly after trauma, after reduction, during the treatment in cast, and at final follow-up. The orthopaedic surgeon measured angulation, translation, rotation and shortening of all fractures to determine primary displacement, displacement during treatment with cast, and final displacement. Rotation was detected by differences in diameter of diaphysis of ulna and radius on lateral and posteroanterior radiographs ${ }^{28}$. To assess the interrater reproducibility of the radiological assessment, a trauma surgeon who was not involved in treatment, re-measured the angulation of the fracture in 45 children independently of the orthopaedic surgeon.

\section{Multivariate analysis}

Our dependent variable was limitation of pronation/supination of 20 degrees or more at the end of follow-up. For the following factors we assessed whether they were related to the above-mentioned dependent variable: age at time of fracture, dominant arm fractured, location of the fracture (diaphysis vs. distal metaphysis), type of fracture (torus, greenstick, complete), primary displacement of the fracture, number of reductions, presence of a re-fracture, duration of AEC, number of physiotherapy visits, and final displacement of the fracture.

This choice of factors was based on the assumption that less limitation would be found in children of younger age because of their higher repair capacity ${ }^{7}$. Furthermore, less limitation was expected as the fracture occurred in the dominant arm due to the need for the dominant arm in daily activities. The assumption of less limitation in distal metaphyseal fractures, less severe type of fractures, less primary displacement of the fracture, fewer reductions and no re-fracture, is in all these cases based on less soft tissue damage $\mathrm{e}^{6,7,29}$. Thereby, we postulated that short immobilisation of the elbow in AEC and frequent visits to a physiotherapist might cause less limitation ${ }^{30}$. The effect of malunion on limitation has been mentioned by others $^{2-9}$. 


\section{Statistical Analysis}

To assess which factors were related to limitation of pronation/supination of 20 degrees or more at the end of follow-up, multivariate logistic regression analysis (via the 'enter' method) was used to calculate odds ratios (ORs) and 95\% confidence intervals $(95 \% \mathrm{CI})$. In all analyses, a two-sided p-value of $\leq 0.05$ was considered significant. Statistical analyses were performed with SPSS 17.0 (SPSS Inc., Chicago, USA).

\section{Results}

Between January 2006 and August 2010 a total of 410 children with both-bone forearm fractures were included. Ten children missed the final examination and were therefore excluded (follow-up rate of $97.6 \%$ ). The included children had several types of both-bone forearm fractures (Table 2). The mean length of follow-up was 218 ( \pm 49) days.

Table 3 presents the results of both groups and of the univariate and multivariate analyses. Six of 10 factors had a significant univariate relationship with limitation of pronation/supination. Half of these factors also showed a significant multivariate relationship and therefore had an independent relation with limitation of pronation/supination.

The presence of a re-fracture was strongly associated with limitation of pronation/supination (Figure 1) with an OR of 11.7 (95\% Cl 1.2; 118.5). Thereby, the location of the fracture (diaphyseal vs. distal metaphyseal) and number of physiotherapy visits were significant in the multivariate analyses with an OR of 3.3 $(95 \% \mathrm{Cl} 1.4 ; 7.9)$ and $0.90(95 \% \mathrm{Cl} 0.82 ; 0.98)$, respectively. These findings imply that a re-fracture, a diaphyseal located fracture and less physiotherapy were independently of each other associated with a limitation of pronation/supination of 20 degrees or more in children with a both-bone forearm fracture. The OR of 11.7 for a re-fracture implies that a child who sustained a re-fracture had an almost 12 times increased risk to end up with a limitation of pronation/supination of 20 degrees or more. 


\section{Chapter 9}

Table 3. Factors associated with limitation of pronation/supination.

Logistic regression analyses

\begin{tabular}{|c|c|c|c|c|}
\hline & No limitation & Limitation & Univariate & Multivariate \\
\hline & & & OR $(95 \% \mathrm{Cl})$ & OR $(95 \% \mathrm{Cl})$ \\
\hline Age at time of fracture, years & $7.7 \pm 3.4$ & $8.9 \pm 3.6$ & $1.1(1.0 ; 1.2)$ & - \\
\hline Dominant arm fractured, \% & 39.4 & 40.7 & - & - \\
\hline Location of fracture, $\%$ & & & $2.7(1.7 ; 4.2)$ & $3.3(1.4 ; 7.9)$ \\
\hline Distal metaphyseal & 57.9 & 33.9 & & \\
\hline Diaphyseal & 42.1 & 66.1 & & \\
\hline Type of fracture radius, \% & & & - & - \\
\hline Torus & 1.4 & 0.9 & & \\
\hline Greenstick & 44.4 & 49.1 & & \\
\hline Complete & 54.2 & 50.0 & & \\
\hline Type of fracture ulna, \% & & & - & - \\
\hline Torus & 5.2 & 8.3 & & \\
\hline Greenstick & 54.2 & 59.3 & & \\
\hline Complete & 40.6 & 32.4 & & \\
\hline \multicolumn{5}{|l|}{ Primary deformity of fracture } \\
\hline Angulation, degrees & $24.2 \pm 14.4$ & $24.3 \pm 12.4$ & - & - \\
\hline Translation, $\%$ of width & $37.6 \pm 44.4$ & $27.9 \pm 41.2$ & - & - \\
\hline Rotation, \% & 9.4 & 9.3 & - & - \\
\hline Shortening, \% & 35.2 & 25.9 & - & - \\
\hline Number of reductions, $\%$ & & & - & - \\
\hline 0 & 27.0 & 20.2 & & \\
\hline 1 & 67.2 & 67.9 & & \\
\hline 2 & 5.5 & 11.0 & & \\
\hline 3 & 0.3 & 0.9 & & \\
\hline Presence of a re-fracture, $\%$ & 1.0 & 12.8 & $14.1(4.0 ; 50.1)$ & $11.7(1.2 ; 118.5)$ \\
\hline Days in above-elbow cast & $29.4 \pm 8.6$ & $32.7 \pm 12.1$ & $1.0(1.0 ; 1.1)$ & - \\
\hline Number of physiotherapy visits & $7.5 \pm 7.5$ & $4.3 \pm 4.1$ & $0.9(0.8 ; 1.0)$ & $0.90(0.82 ; 0.98)$ \\
\hline \multicolumn{5}{|l|}{ Final deformity of fracture } \\
\hline Angulation, degrees & $9.3 \pm 4.4$ & $8.3 \pm 4.1$ & $1.0(0.9 ; 1.0)$ & - \\
\hline Translation, $\%$ of width & $6.8 \pm 13.1$ & $4.9 \pm 9.2$ & - & - \\
\hline
\end{tabular}

Limitation is defined as limitation of pronation and supination of 20 degrees or more; $\%=$ percentage; Values are presented as mean \pm standard deviation unless stated otherwise; $\mathrm{OR}=0$ dds Ratio; $\mathrm{Cl}=$ Confidence Interval. In the table of odds ratio only the significant results are mentioned. 

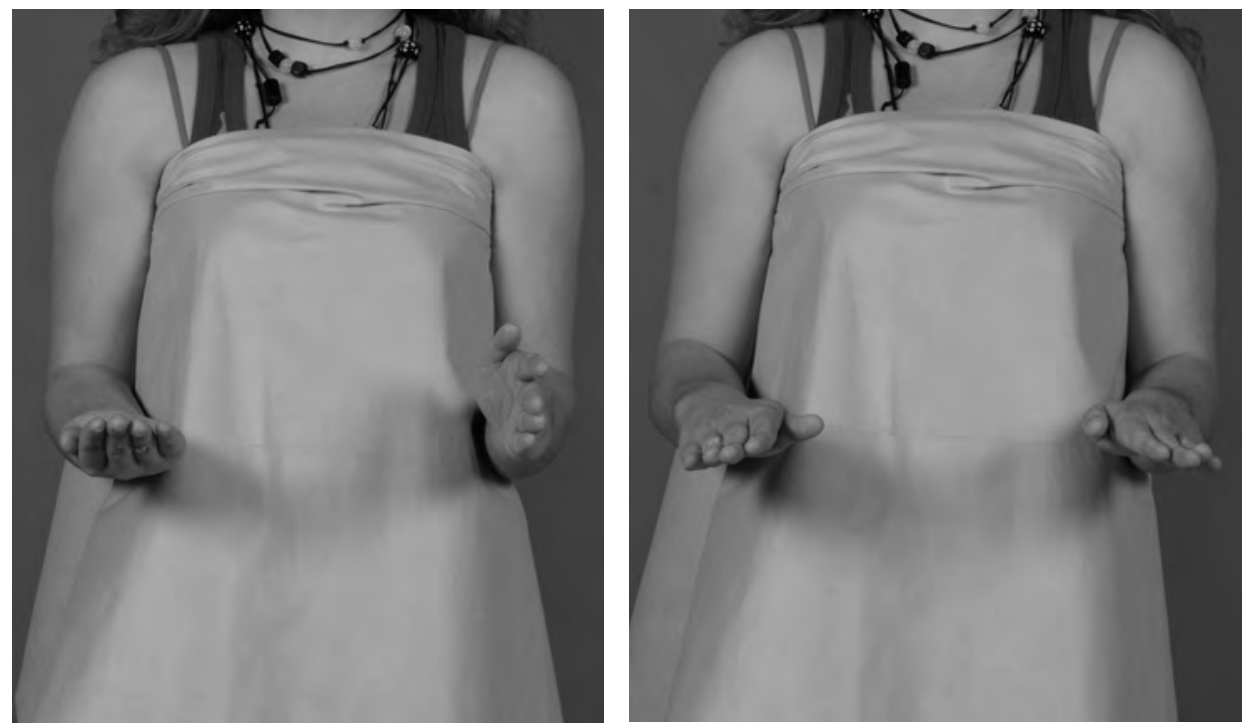

Figure 1. Child with a limitation of supination of her left arm after a both-bone forearm fracture

\section{Discussion}

The purpose of this prospective multicentre study was to investigate which clinical factors are related to the limitation of pronation/supination in children with a both-bone forearm fracture. The results suggest an increased risk of limitation of pronation/ supination of 20 degrees or more in case of a re-fracture and a fracture localised in the diaphysis. Furthermore, an increased risk was found in children with a limitation of $>30$ degrees at the 2-month examination who had received less physiotherapy.

The strong relationship between re-fractures and limitation might be explained by additional injury to the forearm that was still recovering from the primary fracture. Repeated immobilisation in cast might have resulted in more severe contractures with a higher limitation of pronation/supination. The influence of diaphyseal fractures on limitation can be explained by the great amount of energy necessary to fracture the thick cortex of diaphyseal bone. This high energy level may result in severe injury to the interosseous membrane, which could affect the complex motion of pronation/supination by contractures. Thereby, the benefits of physiotherapy also 


\section{Chapter 9}

suggest a role of contractures in limitation of pronation/ supination. In conclusion, our findings suggest that soft tissue injury during trauma can result in contractures resulting in limitation of pronation/supination.

\section{Previous studies}

Of all the factors we assessed to establish whether they were related to limitation of pronation/supination, several had been studied previously. Robert et al. reported on greater limitation in older children, whereas Price et al. mentioned that age had no influence $^{6,7}$. In our multivariate analysis age had no significant relation with limitation. Several studies support our finding that diaphyseal location of a forearm fracture has a significant relation with limitation of pronation/supination ${ }^{6,7,29}$. Moreover, Webb et al. reported a better arc of elbow motion in favour of BEC compared to $\mathrm{AEC}^{30}$; however, this finding was not supported by our analysis.

Previous studies most frequently discuss two main causes of limitation of pronation/supination after forearm fractures in children, namely malunion and soft tissue contractures. Nevertheless, an interaction between these two causes can occur when a malunion changes the tension of the interosseous membrane $e^{5,9,13,31}$. Malunion as cause of limitation of pronation/supination after forearm fractures is often reported and consists of malalignment in angulation, translation or rotation ${ }^{2-}$ 9,29 . Angular malalignment of $\geq 20$ degrees may result in significant limitation, as described earlier ${ }^{2,5}$. Thereby, malunions with malalignment in translation resulted in limitation of pronation/supination by the loss of radial bow or impingement between the forearm bones ${ }^{7-9,29}$. Furthermore, in cadaver studies, rotational malalignment of ulna and radius in the opposite direction caused the greatest limitation ${ }^{3,4,8}$. In contrast with these studies, we found no significant relation between malunion and limitation in our multivariate analysis.

In line with our findings, others also reported that malunion was not a cause of limitation of pronation/supination ${ }^{6,31-36}$. Some found a poor correlation between residual angular malunion and the final range of pronation/supination ${ }^{6}$. Others stated that perfect anatomical fracture alignment did not always result in complete restoration of pronation/supination ${ }^{31,34}$. Thus, anatomical corrective osteotomies for malunited forearm fractures did not always resolve the limitation of pronation/ supination ${ }^{35,36}$. 
Furthermore, several studies support the important role of contractures of soft tissue in limitation of pronation/supination after forearm fractures ${ }^{7,10-13}$. Some reported on contractures of the interosseous membrane ${ }^{10,11}$ while others described the role of contractures around wrist and elbow ${ }^{12,13}$. One study described a correlation between initial fracture displacement, MR-detected interosseous membrane alternations, and limitation of pronation/supination ${ }^{37}$.

In summary, previous studies have conflicting opinions about the role of malunion in the limitation of pronation/supination after forearm fractures in children. We found a significant role of malunion based on univariate analysis. In contrast, no significant role was found in our multivariate logistic regression analysis, suggesting that malunion is not independently associated with a limitation of pronation/supination of 20 degrees or more.

Our results suggest that scarring of the injured soft tissue around the fracture can lead to contractures that probably play an important role in limitation of pronation/supination.

\section{Limitations}

The present study has several limitations. Primarily, rotation of the fracture was detected by differences in the diameter of diaphysis of ulna and radius on lateral and posteroanterior radiographs ${ }^{28}$; this technique probably overlooks subtle rotation of fractures. However, Kasten et al. found limitation of pronation/supination only in fractures with more than 30 degrees of malrotation, which should have been detected with the method used ${ }^{4}$.

Secondly, ideally our follow-up period should have been longer in this young population with the capacity to correct malunion by growth. Nevertheless, malunion was not independently associated with higher limitation in our multivariate analysis.

Thirdly, we cannot exclude injury to the distal or proximal radio-ulnar joint as a possible cause of limitation of pronation/supination.

\section{Conclusion}

The results of this prospective multicentre study, with an analysis of 400 children, suggest that children who suffered from a diaphyseal fracture or sustained a refracture have an increased risk of limitation of pronation/supination during follow-up. 


\section{Chapter 9}

Furthermore, in children with severe limitation extensive physiotherapy is associated with better functional outcome. 


\section{ReferenCES}

1. Nakamura T, Yabe Y, Horiuchi Y, Yamazaki N. In vivo motion analysis of forearm rotation utilizing magnetic resonance imaging. Clin Biomech (Bristol, Avon). 1999;14(5):315-20.

2. Bronstein AJ, Trumble TE, Tencer AF. The effects of distal radius fracture malalignment on forearm rotation: a cadaveric study. J Hand Surg [Am]. 1997;22(2):258-62.

3. Dumont CE, Thalmann R, Macy JC. The effect of rotational malunion of the radius and the ulna on supination and pronation. J Bone Joint Surg Br. 2002;84(7):1070-4.

4. Kasten P, Krefft M, Hesselbach J, Weinberg AM. How does torsional deformity of the radial shaft influence the rotation of the forearm? A biomechanical study. J Orthop Trauma. 2003;17(1):57-60.

5. Matthews LS, Kaufer H, Garver DF, Sonstegard DA. The effect on supination-pronation of angular malalignment of fractures of both bones of the forearm. J Bone Joint Surg Am. 1982;64(1):14-7.

6. Price CT, Scott DS, Kurzner ME, Flynn JC. Malunited forearm fractures in children. J Pediatr Orthop. 1990;10(6):705-12.

7. Roberts JA. Angulation of the radius in children's fractures. J Bone Joint Surg Br. 1986;68(5):751-4.

8. Trousdale RT, Linscheid RL. Operative treatment of malunited fractures of the forearm. J Bone Joint Surg Am. 1995;77(6):894-902.

9. Yasutomi T, Nakatsuchi Y, Koike H, Uchiyama S. Mechanism of limitation of pronation/supination of the forearm in geometric models of deformities of the forearm bones. Clin Biomech (Bristol, Avon). 2002;17(6):456-63.

10. Nakamura T, Yabe Y, Horiuchi Y, Seki T, Yamazaki N. Normal kinematics of the interosseous membrane during forearm pronation-supination-a three-dimensional MRI study. Hand Surg. 2000;5(1):1-10.

11. Nakamura T, Yabe Y, Horiuchi Y. [A biomechanical analysis of pronation-supination of the forearm using magnetic resonance imaging: dynamic changes of the interosseous membrane of the forearm during pronation-supination]. Nippon Seikeigeka Gakkai Zasshi. 1994;68(1):14-25.

12. Kleinman WB, Graham TJ. The distal radioulnar joint capsule: clinical anatomy and role in posttraumatic limitation of forearm rotation. J Hand Surg Am. 1998;23(4):588-99. 


\section{Chapter 9}

13. Shirai $\mathrm{H}$, Ryu J, Kish V, Abe M. The rotational effect of pronation and supination osteotomies of the forearm in a cadaver model: a comparison of osteotomy sites on the radius and the ulna. J Hand Surg Eur Vol. 2007;32(4):440-6.

14. Boyer BA, Overton B, Schrader W, Riley P, Fleissner P. Position of immobilization for pediatric forearm fractures. Journal of pediatric orthopedics. 2002;22(2):185-7.

15. Choi KY, Chan WS, Lam TP, Cheng JC. Percutaneous Kirschner-wire pinning for severely displaced distal radial fractures in children. A report of 157 cases. J Bone Joint Surg Br. 1995;77(5):797-801.

16. Daruwalla JS. A study of radioulnar movements following fractures of the forearm in children. Clin Orthop Relat Res. 1979(139):114-20.

17. Gibbons CL, Woods DA, Pailthorpe C, Carr AJ, Worlock P. The management of isolated distal radius fractures in children. J Pediatr Orthop. 1994;14(2):207-10.

18. Jones K, Weiner DS. The management of forearm fractures in children: a plea for conservatism. J Pediatr Orthop. 1999;19(6):811-5.

19. Mani GV, Hui PW, Cheng JC. Translation of the radius as a predictor of outcome in distal radial fractures of children. J Bone Joint Surg Br. 1993;75(5):808-11.

20. Maric D, Petkovic L, Tomasevic V, Bajic L, Gajdobranski D, Marcikic A. [Osteosynthesis with Kirschner wires in the treatment of dislocation fractures of the forearm in children]. Med Pregl. 2002;55(3-4):140-5.

21. Noonan KJ, Price CT. Forearm and distal radius fractures in children. J Am Acad Orthop Surg. 1998;6(3):146-56.

22. Tynan MC, Fornalski S, McMahon PJ, Utkan A, Green SA, Lee TQ. The effects of ulnar axial malalignment on supination and pronation. J Bone Joint Surg Am. 2000;82-A(12):1726-31.

23. Zimmermann R, Gabl M, Angermann P, Lutz M, Reinhart C, Kralinger F, et al. [Late sequelae of fractures of the distal third of the forearm during the growth period]. Handchir Mikrochir Plast Chir. 2000;32(4):242-9.

24. Gustilo RB, Simpson L, Nixon R, Ruiz A, Indeck W. Analysis of 511 open fractures. Clin Orthop Relat Res. 1969;66:148-54.

25. Colaris JW, Biter LU, Allema JH, Bloem RM, van de Ven CP, de Vries MR, et al. Belowelbow cast for metaphyseal both-bone fractures of the distal forearm in children: a randomised multicentre study. Injury. 2012;43(7):1107-11. 
26. Colaris JW, Allema JH, Biter LU, de Vries MR, van de Ven CP, Bloem RM, et al. Redisplacement of stable distal both-bone forearm fractures in children: a randomised controlled multicentre trial. Injury. 2013;44(4):498-503.

27. Colaris J, van der Linden M, Selles R, Coene N, Allema JH, Verhaar J. Pronation and supination after forearm fractures in children: Reliability of visual estimation and conventional goniometry measurement. Injury. 2010;41(6):643-6.

28. Naimark A, Kossoff J, Leach RE. The disparate diameter. A sign of rotational deformity in fractures. J Can Assoc Radiol. 1983;34(1):8-11.

29. Kuderna $\mathrm{H}$. [Connection between deviated axis and impaired function after fractures of the forearm (author's transl)]. Unfallchirurgie. 1980;6(1):7-13.

30. Webb GR, Galpin RD, Armstrong DG. Comparison of short and long arm plaster casts for displaced fractures in the distal third of the forearm in children. J Bone Joint Surg Am. 2006;88(1):9-17.

31. Tarr RR, Garfinkel AI, Sarmiento A. The effects of angular and rotational deformities of both bones of the forearm. An in vitro study. J Bone Joint Surg Am. 1984;66(1):65-70.

32. Hogstrom $\mathrm{H}$, Nilsson BE, Willner S. Correction with growth following diaphyseal forearm fracture. Acta Orthop Scand. 1976;47(3):299-303.

33. Nilsson BE, Obrant K. The range of motion following fracture of the shaft of the forearm in children. Acta Orthop Scand. 1977;48(6):600-2.

34. Krukhaug Y, Hove LM. Corrective osteotomy for malunited extra-articular fractures of the distal radius: a follow-up study of 33 patients. Scand J Plast Reconstr Surg Hand Surg. 2007;41(6):303-9.

35. Nagy L, Jankauskas L, Dumont CE. Correction of forearm malunion guided by the preoperative complaint. Clin Orthop Relat Res. 2008;466(6):1419-28.

36. Price CT, Knapp DR. Osteotomy for malunited forearm shaft fractures in children. J Pediatr Orthop. 2006;26(2):193-6.

37. Beyer W, Stolzenburg T, Paris S. [Functional limitation of the forearm after shaft fracture in childhood. Possible role of the antebrachial interosseous membrane: MRI and ultrasound studies]. Unfallchirurgie. 1995;21(6):275-84. 

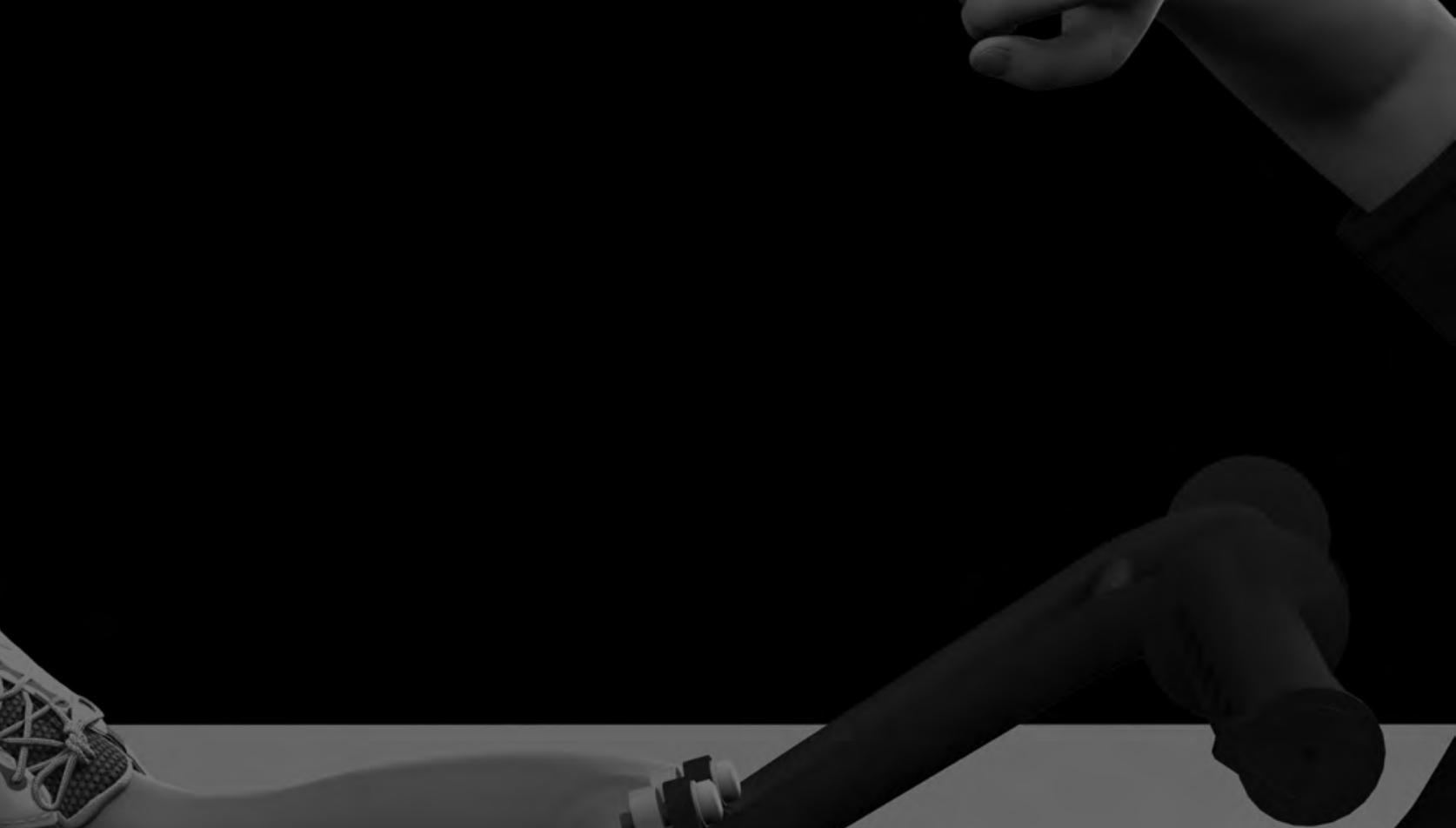


\section{Chapter 10}

Angular malalignment as cause of limitation of forearm rotation: an analysis of prospectively

\section{collected data of both-bone} forearm fractures in children

Injury. 2014 Jun;45(6):955-9.

Colaris JW, Reijman M, Allema JH, de Vries MR, Biter LU, Bloem RM, van de Ven CP, Verhaar JA. 


\section{Chapter 10}

\section{AbStRACT}

Introduction: Although limitation of pronation/supination following both-bone forearm fractures in children is often attributed to an angular malunion, no clinical study has compared pronation/supination and angular malalignment of the same child by analysis of prospectively collected clinical data. Therefore, the purpose of this trial was to explore whether limitation of pronation/supination can be predicted by the degree of angular malalignment in children who sustained a both-bone forearm fracture.

Methods: In four Dutch hospitals, consecutive children aged $\leq 16$ years with a bothbone forearm fracture were prospectively followed for 6-9 months. At final follow-up, pronation/supination and angular malunion on radiographs were determined.

Results: Between January 2006 and August 2010 a total of 410 children were prospectively followed of which 393 children were included for analysis in this study. The mean age of the children was $8.0( \pm 3.5)$ years, $63 \%$ was male and $40 \%$ fractured their dominant arm. The mean time to final examination was $219( \pm 51)$ days. Children with a metaphyseal both-bone fracture of the distal forearm with an angular malalignment of $\leq 15$ degrees had a $9-13 \%$ chance to develop a clinically relevant limitation (i.e. $<50$ degrees of pronation and/or supination), while children with an angular malalignment of $\geq 16$ degrees had a $60 \%$ chance. Children with diaphyseal both-bone forearm fractures with $\leq 5$ degrees of angular malalignment had a $13 \%$ chance to develop a clinically relevant limitation, which showed no significant increase with a further increase of angular malalignment.

Conclusions: Children who sustained a both-bone forearm fracture localized in the distal metaphysis have a higher chance to develop a clinically relevant limitation of forearm rotation in case of a more severe angular malalignment, while children with a diaphyseal both-bone forearm fracture had a moderate chance of limitation, irrespective of the severity of the angular malalignment. 


\section{INTRODUCTION}

Both-bone forearm fractures in children might result in a limitation of forearm rotation that only affects daily activities if pronation and/or supination is $\leq 50$ degrees ${ }^{1}$. This limitation is often attributed to an angular malunion as a result of neglected primary or secondary fracture displacement. In case of a displaced fracture in a child, the remodelling capacity of the growing bone often confronts the clinician with a dilemma regarding treatment, i.e. whether to perform a reduction of the fracture, or to accept some degree of displacement with possibly less favourable cosmetic and functional results.

Studies of artificially created deformities in human upper-extremity cadaver specimens indicated that angular deformities of the forearm of 10 degrees or less resulted in minimum limitation of pronation/supination, while 20 degrees of angulation caused an important $\operatorname{loss}^{2,3}$. Others compared these experimental results with data obtained from clinical and radiographic examination and found that the experimental results predicted the clinical loss of pronation and supination relatively well ${ }^{4}$.

Although these findings are highly relevant for the clinician's decision-making process, no clinical study has compared pronation/supination and angular malalignment of the same child by analysis of prospectively collected clinical data. Therefore, the purpose of this trial was to explore whether limitation of pronation/supination can be predicted by the degree of angular malalignment in children who sustained a both-bone forearm fracture.

\section{Materials AND Methods}

\section{Study design and participants}

A prospective study was performed on all consecutive children with a forearm fracture of radius and ulna who visited the emergency department of one of four participating hospitals. The Dutch hospitals that participated were Erasmus Medical Center (Rotterdam), HAGA Hospital (The Hague), Reinier de Graaf Hospital (Delft) and Sint Franciscus Hospital (Rotterdam). The regional medical ethics committee approved the study. Informed consent was obtained for participation by all parents and all children aged $\geq 12$ years. 


\section{Chapter 10}

Included in the study were children aged $\leq 16$ years who sustained a both-bone forearm fracture in diaphysis or distal metaphysis. The criteria for reduction were a priori defined and based on previous studies ${ }^{5-14}$ (Table 1). Exclusion criteria were torus fractures of both radius and ulna, fractures older than 1 week, severe open fractures (Gustilo II and III) ${ }^{15}$, re-fractures, and children lost to follow-up.

Table 1. Criteria for reduction of the fracture of radius and/or ulna based on posteroanterior and/or lateral radiographs

\begin{tabular}{lcc} 
Type of displacement & Age in years & Displacement \\
\hline Angulation & $<10$ & $>15$ degrees \\
& $10-16$ & $>10$ degrees \\
Translation & $<16$ & $>$ half of bone diameter \\
Rotation & $<16$ & $>0$ degrees \\
\hline
\end{tabular}

\section{Procedures}

The included children participated in several randomized controlled studies. The study protocol distinguished between different types of both-bone forearm fractures (Table 2). The separate studies are described in detail in previous publications ${ }^{16,17}$. Briefly, distal metaphyseal fractures without need for reduction were treated with below or above-elbow cast for 4 weeks, while distal metaphyseal fractures with reduction were treated with or without Kirschner wires in combination with aboveelbow cast for 4 weeks. Furthermore, diaphyseal fractures without reduction and reduced stable diaphyseal fractures were treated with 6 weeks above-elbow cast, or a combination of 3 weeks above-elbow cast and 3 weeks below-elbow cast. Finally, unstable diaphyseal fractures were fixated with 1 or 2 intramedullary nails in combination with 3 weeks above-elbow cast.

An orthopaedic surgeon (not involved in treatment) examined all children at 2 and 6 months after initial trauma using a standardized technique to measure flexion and extension of wrist and elbow in combination with pronation and supination of both $\operatorname{arms}^{18}$. Final radiographs were made 6 months after the initial trauma. Only the children who were treated with intramedullary nails had a final examination and 
final radiographs at 9 months. All children with at least 30 degrees of functional impairment (combined functional impairment of pronation/supination and flexion/extension of wrist/elbow) at the 2-months examination were referred to a physiotherapist. A clinically relevant limitation of forearm rotation was defined as pronation and/or supination of $\leq 50$ degrees in the injured forearm ${ }^{1}$.

Table 2. Flowchart of enrolment in the study

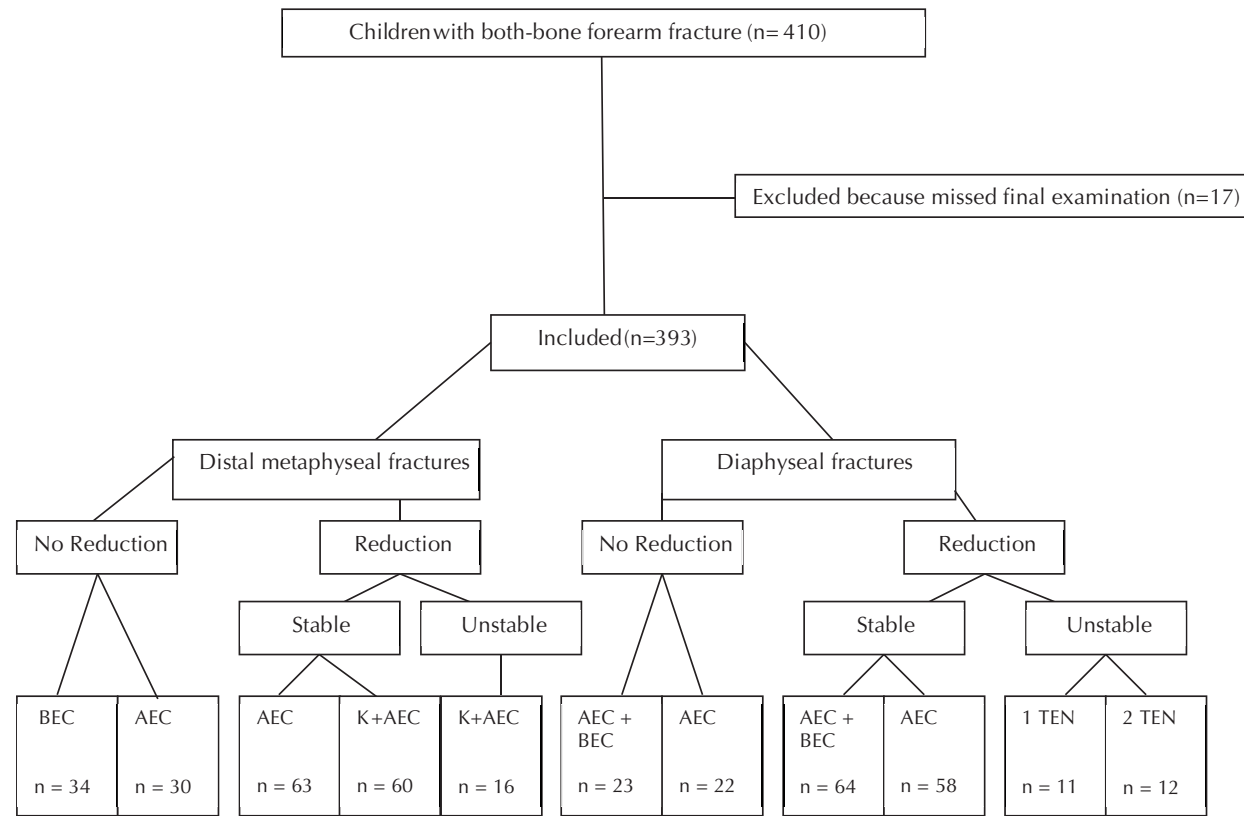

$n=$ number of children; $B E C=$ below elbow cast; $A E C=$ above elbow cast;

$K=$ Kirschner wires; TEN = Titanium Elastic Nail

\section{Radiographic analysis}

Angulation of radius and ulna was measured on final posteroanterior and lateral radiographs (at 6-9 months) to determine angular malalignment by one orthopaedic surgeon (not involved in treatment). The maximum angular malalignment of radius or ulna on either the posteroanterior or lateral radiograph was used for the analysis. To assess the inter-rater reproducibility of the radiological assessment, a trauma surgeon (not involved in treatment) re-measured the angulation of the fracture in 45 children. 


\section{Chapter 10}

\section{Statistical analysis}

First, it was established whether the variables had a normal distribution using the normality Shapiro-Wilk test. Based on these analyses, the results are presented as means and range.

The main study items (limitation of pronation/supination of the fractured arm $\leq 50$ degrees as dependent variable and degree of angular malalignment as independent variable) were analysed using logistic regression analysis. If necessary, adjustments were made for unbalanced covariates. Statistical analyses were performed with the SPSS version 17.0 (SPSS Inc., Chicago, USA).

\section{ResUlts}

Between January 2006 and August 2010 a total of 410 children were prospectively followed in four Dutch hospitals; of these, 393 children were included for analysis in the present study (Table 2). The excluded children had either no clinical and/or no radiological examination at the end of follow-up. The mean time to final examination was 219 (99-440) days. The mean age of the children was 8.0 (0-16) years. The children were divided in two groups in accordance with their limitation of forearm rotation, i.e. more or less than 50 degrees of impairment. Table 3 presents the baseline characteristics of the total study population and per group. There was a significant difference between the two groups in location of fracture, and type of fracture of both the radius and ulna; therefore, the statistical analyses were corrected for these baseline variables.

Table 4 presents different categories of maximum angular malalignment on final radiographs in relation to clinically relevant limitation of forearm rotation at final clinical examination, i.e. $<50$ degrees of pronation and/or supination. Overall 86 children had a malunion of $\leq 5$ degrees of which $9.3 \%$ showed a clinically relevant limitation of forearm rotation at final follow-up. The most severe malunion groups (11-15 and $>16$ degrees of malunion) had significantly more children with a clinically relevant limitation of forearm rotation $(p<0.0001)$.

Table 5 presents the limitation of forearm rotation in correlation with the severity of malunion and location of the fracture (distal metaphyseal/diaphyseal). A significantly higher percentage of children with a clinically relevant limitation of forearm rotation 
Table 3. Baseline characteristics of the study population.

\begin{tabular}{|c|c|c|c|}
\hline & \multicolumn{3}{|c|}{ pronation/supination } \\
\hline & Total & $<50$ degrees & $>50$ degrees \\
\hline Number & 393 & 80 & 313 \\
\hline Age in years at time of fracture: mean (range) & $8.0(0-16)$ & $8.1(3-15)$ & $8.0(0-16)$ \\
\hline Gender, $\%$ male & 63 & 69 & 61 \\
\hline Dominant arm fractured, $\%$ & 40 & 34 & 41 \\
\hline Follow-up in days: mean (range) & $219(99-440)$ & $212(143-440)$ & $219(99-406)$ \\
\hline \multicolumn{4}{|l|}{ Location of fracture $(\%)^{*}$, } \\
\hline diaphyseal & 48 & 70 & 43 \\
\hline metaphyseal & 52 & 30 & 57 \\
\hline \multicolumn{4}{|l|}{ Type of fracture ulna $(\%)^{* *}$, } \\
\hline torus & 6 & 3 & 7 \\
\hline greenstick & 55 & 42 & 58 \\
\hline complete & 39 & 55 & 35 \\
\hline \multicolumn{4}{|l|}{ Type of fracture radius $(\%)^{* * *}$, } \\
\hline torus & 1 & 0 & 2 \\
\hline greenstick & 45 & 35 & 47 \\
\hline complete & 54 & 65 & 51 \\
\hline
\end{tabular}

Significant differences between the two groups in location of fracture $\left({ }^{*} p<0.0001\right)$,

type of fracture ulna $\left(^{* *} p=0.004\right)$ and type of fracture radius $\left({ }^{* *} p=0.038\right)$

was found only in the distal metaphyseal localized fractures with $>16$ degrees of malunion ( $p<0.0001$ ). Furthermore, the significant differences found between the two groups were similar with and without adjustment for unbalanced covariates. 


\section{Chapter 10}

Table 4. Angular malunion in relation to clinical relevant limitation of pronation and/or supination.

\begin{tabular}{ll} 
Maximum angular malunion, degrees & $<50$ degrees of pronation and/or supination, \% (ratio) \\
\hline $0-5$ & $9.3(8 / 86)^{1,2}$ \\
$6-10$ & $15.6(28 / 179)$ \\
$11-15$ & $31.9(30 / 94)^{1}$ \\
$>16$ & $41.2(14 / 34)^{2}$ \\
\hline
\end{tabular}

1,2 : Significant differences between two groups $(p<0.0001)$, with and without adjustment for location of fracture, and type of fracture of ulna and radius.

Table 5. Angular malunion in relation to clinically relevant limitation of pronation/supination with differentiation between fracture location.

Maximum angular malunion: degrees $<50$ degrees of pronation and/or supination: \% (ratio)

\begin{tabular}{lll}
\hline & Distal metaphysis & Diaphysis \\
\hline $0-5$ & $8.5(6 / 71)^{1}$ & $13.3(2 / 15)$ \\
$6-10$ & $9.0(9 / 100)$ & $24.1(19 / 79)$ \\
$11-15$ & $13.0(3 / 23)$ & $38.0(27 / 71)$ \\
$>16$ & $60.0(6 / 10)^{1}$ & $33.3(8 / 24)$ \\
\hline
\end{tabular}

1 Significant difference between the two groups $(p<0.0001)$, with and without adjustment for location of fracture, and type of fracture of ulna and radius.

\section{Discussion}

This study shows that children who sustained a both-bone forearm fracture localized in the distal metaphysis have a high chance $(60 \%)$ to develop a clinically relevant limitation of forearm rotation in case of a more severe angular malalignment $(>16$ degrees), while children with a diaphyseal both-bone forearm fracture have a moderate chance of limitation (13-33\%) irrespective of the severity of the angular malalignment.

Fractures of the distal metaphysis are localized close to the most active distal growth plate of the forearm, which makes remodelling by growth more likely than 
fractures in the diaphysis. Therefore, a distal metaphyseal fracture with a mild to moderate angular displacement ( $\leq 15$ degrees) does not always need to be reduced, especially in younger children with a high potential for remodelling by growth. In contrast, clinicians should remain alert regarding children with diaphyseal fractures, because even mild angular malalignment resulted in a clinically relevant limitation of forearm rotation. Because diaphyseal fractures showed no significant increase in limitation of pronation/supination in more severe angular malalignment fractures, contractures of the injured interosseous membrane might also play a role.

\section{Previous studies}

Malunion as cause of limitation of pronation/supination after forearm fractures is often reported and might consist of malalignment in angulation, translation or rotation ${ }^{2,19-26}$.

Two studies of artificially created deformities in human upper-extremity cadaver specimens indicated that angular deformities of the forearm of 10 degrees or less resulted in minimum limitation of pronation/supination, whereas 20 degrees of angulation caused an important loss of forearm rotation ${ }^{2,3}$. These findings are supported by our study only in distal metaphyseal fractures, whereas many diaphyseal fractures even showed a limitation in minor angular malalignment. Moreover, previous studies mentioned that angular malalignment in diaphyseal fractures more often resulted in limitation of pronation/supination than similar angular malalignment in metaphyseal fractures ${ }^{2,3}$. This finding was confirmed in our study with up to 16 degrees of angular malalignment.

Malalignment in translation is reported to be a cause of limitation of pronation/ supination by the loss of radial bow or impingement between the forearm bones ${ }^{22,24-}$ 26 . In the present study the primary translational displacement of the fracture was changed by appositional periosteal bone formation and at final follow-up only minimal callus without notable translational malalignment was seen on the radiographs. This made us believe that malalignment in translation did not significantly contribute to limitation of forearm rotation.

One cadaveric study described that rotational malalignment might result in limitation of pronation/supination, especially if the rotational malalignment of the ulna and radius was in the opposite direction. In our clinical study the final radiographs did not show any rotational malalignment. 


\section{Chapter 10}

\section{Study limitations}

In the analysis based on differentiation of fracture location, because the number of included children was relatively small these results should be interpreted with caution. Furthermore, the impairment of forearm rotation might hinder a perfect positioning of the forearm during radiography, which might influence measurement of the angular malalignment. In this way, subtle rotational malalignment might contribute to the limitation of forearm rotation and is difficult to measure on a conventional radiograph. Thereby the present study focused only on limitations related to malalignments, while contractures of traumatized soft tissue and pathology in the distal or proximal radio ulnar joint may also have played a role. The final limitation is the relatively short follow-up, as there is a remodelling of malunions by growth in children which possible influences the forearm rotation.

\section{Conclusion}

This study shows that children who sustained a both-bone forearm fracture localized in the distal metaphysis have a high chance to develop a clinically relevant limitation of forearm rotation in the case of more severe angular malalignment, while children with a diaphyseal both-bone forearm fracture have a moderate chance of limitation irrespective of the severity of the angular malalignment. 


\section{REFERENCES}

1. Morrey BF, Askew LJ, Chao EY. A biomechanical study of normal functional elbow motion. The Journal of bone and joint surgery American volume. 1981;63(6):872-7.

2. Matthews LS, Kaufer H, Garver DF, Sonstegard DA. The effect on supination-pronation of angular malalignment of fractures of both bones of the forearm. J Bone Joint Surg Am. 1982;64(1):14-7.

3. Tarr RR, Garfinkel AI, Sarmiento A. The effects of angular and rotational deformities of both bones of the forearm. An in vitro study. J Bone Joint Surg Am. 1984;66(1):65-70.

4. Sarmiento A, Ebramzadeh E, Brys D, Tarr R. Angular deformities and forearm function. Journal of orthopaedic research : official publication of the Orthopaedic Research Society. 1992;10(1):121-33.

5. Boyer BA, Overton B, Schrader W, Riley P, Fleissner P. Position of immobilization for pediatric forearm fractures. Journal of pediatric orthopedics. 2002;22(2):185-7.

6. Choi KY, Chan WS, Lam TP, Cheng JC. Percutaneous Kirschner-wire pinning for severely displaced distal radial fractures in children. A report of 157 cases. J Bone Joint Surg Br. 1995;77(5):797-801.

7. Daruwalla JS. A study of radioulnar movements following fractures of the forearm in children. Clin Orthop Relat Res. 1979(139):114-20.

8. Gibbons CL, Woods DA, Pailthorpe C, Carr AJ, Worlock P. The management of isolated distal radius fractures in children. J Pediatr Orthop. 1994;14(2):207-10.

9. Jones K, Weiner DS. The management of forearm fractures in children: a plea for conservatism. J Pediatr Orthop. 1999;19(6):811-5.

10. Mani GV, Hui PW, Cheng JC. Translation of the radius as a predictor of outcome in distal radial fractures of children. J Bone Joint Surg Br. 1993;75(5):808-11.

11. Maric D, Petkovic L, Tomasevic V, Bajic L, Gajdobranski D, Marcikic A. [Osteosynthesis with Kirschner wires in the treatment of dislocation fractures of the forearm in children]. Med Pregl. 2002;55(3-4):140-5.

12. Noonan KJ, Price CT. Forearm and distal radius fractures in children. J Am Acad Orthop Surg. 1998;6(3):146-56.

13. Tynan MC, Fornalski S, McMahon PJ, Utkan A, Green SA, Lee TQ. The effects of ulnar axial malalignment on supination and pronation. J Bone Joint Surg Am. 2000;82-A(12):1726-31. 


\section{Chapter 10}

14. Zimmermann R, Gabl M, Angermann P, Lutz M, Reinhart C, Kralinger F, et al. [Late sequelae of fractures of the distal third of the forearm during the growth period]. Handchir Mikrochir Plast Chir. 2000;32(4):242-9.

15. Gustilo RB, Simpson L, Nixon R, Ruiz A, Indeck W. Analysis of 511 open fractures. Clin Orthop Relat Res. 1969;66:148-54.

16. Colaris JW, Allema JH, Biter LU, de Vries MR, van de Ven CP, Bloem RM, et al. Redisplacement of stable distal both-bone forearm fractures in children: a randomised controlled multicentre trial. Injury. 2013;44(4):498-503.

17. Colaris JW, Biter LU, Allema JH, Bloem RM, van de Ven CP, de Vries MR, et al. Belowelbow cast for metaphyseal both-bone fractures of the distal forearm in children: a randomised multicentre study. Injury. 2012;43(7):1107-11.

18. Colaris J, van der Linden M, Selles R, Coene N, Allema JH, Verhaar J. Pronation and supination after forearm fractures in children: Reliability of visual estimation and conventional goniometry measurement. Injury. 2010;41(6):643-6.

19. Bronstein AJ, Trumble TE, Tencer AF. The effects of distal radius fracture malalignment on forearm rotation: a cadaveric study. J Hand Surg [Am]. 1997;22(2):258-62.

20. Dumont CE, Thalmann R, Macy JC. The effect of rotational malunion of the radius and the ulna on supination and pronation. J Bone Joint Surg Br. 2002;84(7):1070-4.

21. Kasten $\mathrm{P}$, Krefft M, Hesselbach J, Weinberg AM. How does torsional deformity of the radial shaft influence the rotation of the forearm? A biomechanical study. J Orthop Trauma. 2003;17(1):57-60.

22. Kuderna $\mathrm{H}$. [Connection between deviated axis and impaired function after fractures of the forearm (author's transl)]. Unfallchirurgie. 1980;6(1):7-13.

23. Price CT, Scott DS, Kurzner ME, Flynn JC. Malunited forearm fractures in children. J Pediatr Orthop. 1990;10(6):705-12.

24. Roberts JA. Angulation of the radius in children's fractures. J Bone Joint Surg Br. 1986;68(5):751-4.

25. Trousdale RT, Linscheid RL. Operative treatment of malunited fractures of the forearm. J Bone Joint Surg Am. 1995;77(6):894-902.

26. Yasutomi T, Nakatsuchi Y, Koike H, Uchiyama S. Mechanism of limitation of pronation/supination of the forearm in geometric models of deformities of the forearm bones. Clin Biomech (Bristol, Avon). 2002;17(6):456-63. 

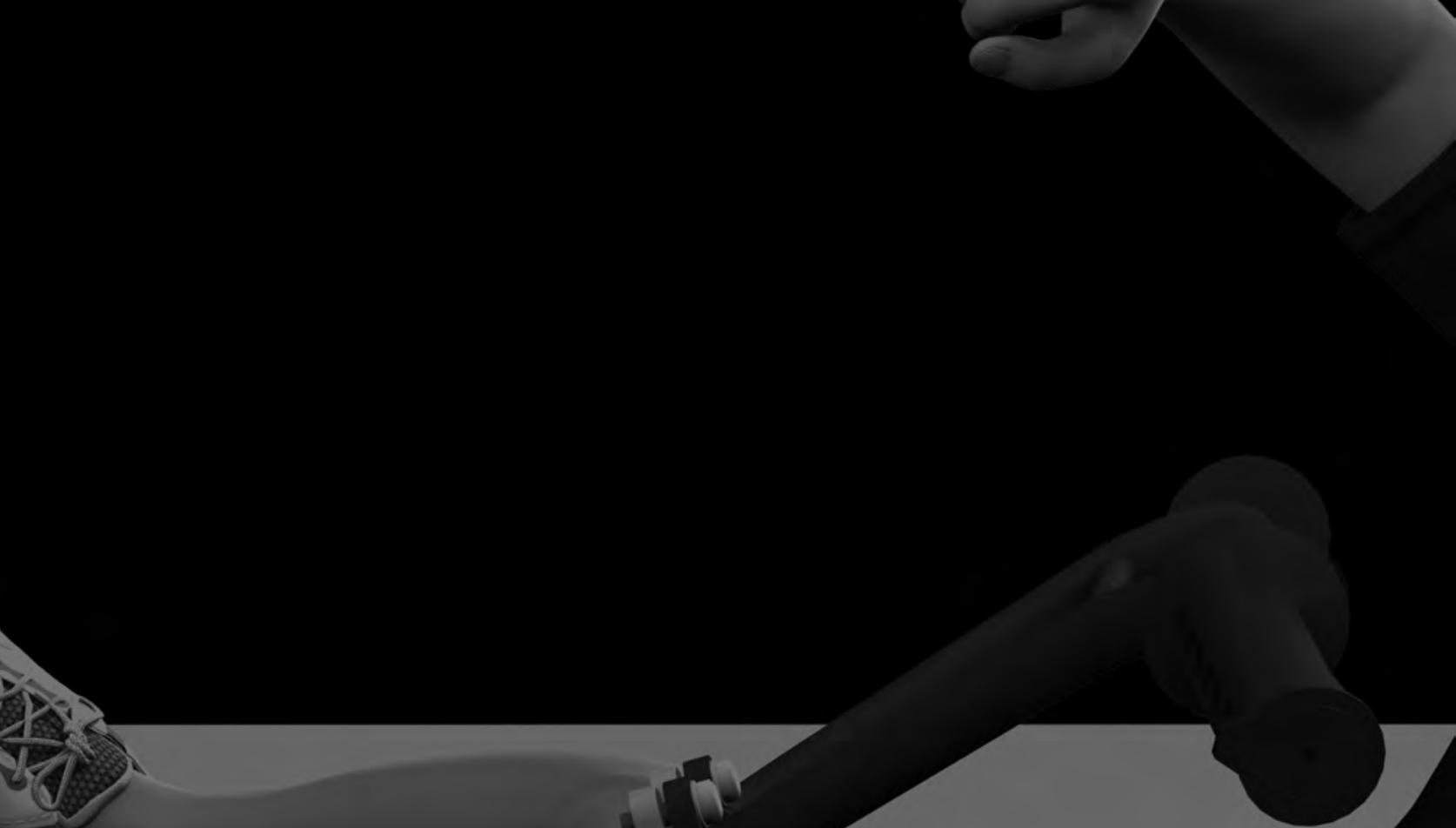


\section{Chapter 11}

Three-dimensional imaging of children with severe limitation of pronation/supination after a both-bone forearm fracture

Arch Orthop Trauma Surg. 2014 Mar; 134(3):333-41

Colaris JW, Oei S, Reijman M, Holscher H, Allema JH,Verhaar JAN. 


\section{Chapter 11}

\section{ABSTRACT}

Introduction: Although both-bone forearm fractures in children may result in severe limitation of forearm rotation, finding the cause remains a diagnostic challenge. This study tries to evaluate the role of rotational malunion, bony impingement and contractures of the interosseous membrane.

Patients and methods: Children (5-16 years) who suffered from a both-bone forearm fracture in diaphysis or distal metaphysis with a limitation of pronation/supination $\geq$ 40 degrees at $\geq 6$ months after trauma were included for analysis with conventional radiographs, computed tomography $(\mathrm{CT})$ and magnetic resonance imaging (MRI).

Results: A total of 410 children with a both-bone forearm fracture were prospectively followed in four Dutch hospitals. At a median of 205 days, 7.3\% suffered from a limitation of pronation/supination $\geq 40$ degrees. 14 children were included (median limitation of 40 degrees) and the radiographs revealed a median maximum angular malunion of 16 degrees. CT analysis showed rotational malunion of both radius (median 19 degrees) and ulna (median 9 degrees). MRI analysis revealed neither bony impingement nor contractures of the interosseous membrane.

Conclusions: Three-dimensional imaging of children with a severe limitation of pronation/supination after a both-bone forearm fracture revealed rotational malunions of both radius and ulna without bony impingement or soft tissue contractures. 


\section{INTRODUCTION}

Both-bone forearm fractures in children generally heal without complications. While a limitation of pronation/supination of $>20$ degrees has been reported in 3-30\% of children after a both-bone forearm fracture, especially the severe limitations of rotation may interfere with daily activities ${ }^{1-4}$.

Although a malunion is often mentioned as main cause of limitation of forearm rotation $^{5-12}$ there is no consensus on this. Whereas several studies described limitation without a malunion ${ }^{11,13,14}$, others mentioned malunions without limitation ${ }^{15}$ or persistent limitation after a corrective osteotomy with restoration of anatomical alignment ${ }^{16-18}$. Other bone-related causes of limitation are a synostosis, or an impingement between radius and ulna ${ }^{9,11,19}$. The exact role of soft tissue involvement in limitation of rotation remains unknown ${ }^{20-25}$. Contractures of the interosseous membrane might play a more significant role than contractures of capsules of wrist and elbow ${ }^{2,3,15}$.

Unravelling the exact cause of limitation after a both-bone forearm fracture in children remains a diagnostic challenge. Therefore this study tries to evaluate the role of rotational malunion, bony impingement and contractures of the interosseous membrane by three-dimensional imaging.

\section{Materials ANd Methods}

\section{Study design and participants}

A prospective study was performed including consecutive children with a forearm fracture of radius and ulna who visited the emergency department of one of four Dutch hospitals: Erasmus Medical Center (Rotterdam), HAGA Hospital (The Hague), Reinier de Graaf Hospital (Delft) and Sint Franciscus Hospital (Rotterdam). The regional medical ethics committee approved the study. Informed consent was obtained from all parents and all children aged $>12$ years. For the present study we included children aged 5-16 years who sustained a both-bone forearm fracture in diaphysis or distal metaphysis with a limitation of pronation/supination $\geq 40$ degrees at final examination ( $\geq 6$ months after trauma) (Figure 1). 
Chapter 11
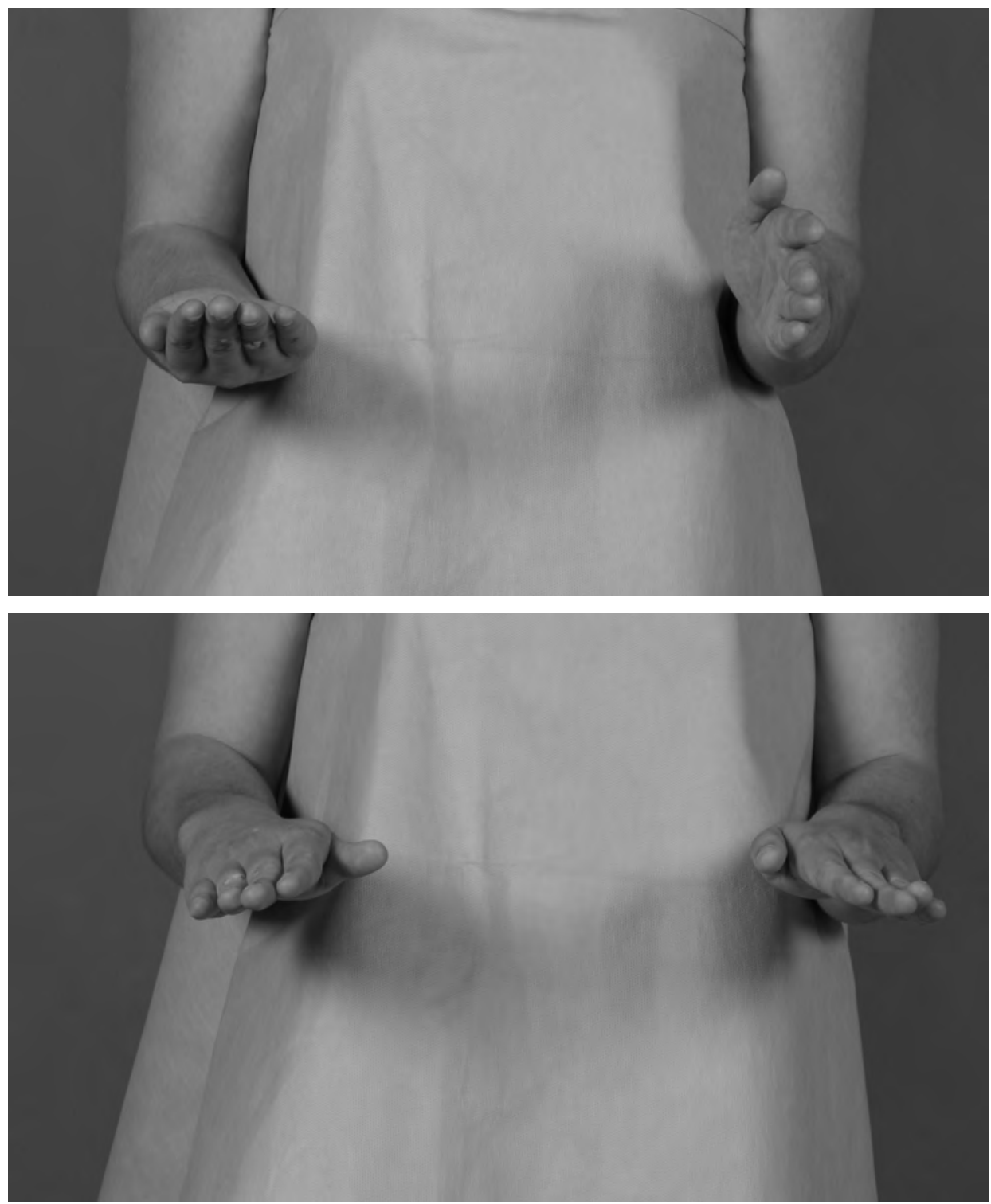

Figure 1. A severe limitation of supination after a both-bone forearm fracture. 


\section{Clinical examination}

The included children were treated based on the study protocol. This protocol distinguished several types of fractures with several types of treatment. Briefly, distal metaphyseal fractures without need for reduction were treated with below-elbow or above-elbow cast for 4 weeks ${ }^{2}$, while distal metaphyseal fractures with reduction were treated with or without Kirschner wires in combination with above-elbow cast for 4 weeks ${ }^{1}$. Furthermore, diaphyseal fractures without reduction and reduced stable diaphyseal fractures were treated with 6 weeks above-elbow cast, or a combination of 3 weeks above-elbow cast and 3 weeks below-elbow cast ${ }^{3}$. Finally, unstable diaphyseal fractures were fixated with 1 or 2 intramedullary titanium nails in combination with 3 weeks above-elbow cast ${ }^{4}$.

One orthopaedic surgeon (who was not involved in primary treatment) measured pronation/supination of both arms two months after initial trauma. This technique was standardized with the use of a $180^{\circ}$ goniometer constructed of clear, flexible plastic with 2 movable arms of $30 \mathrm{~cm}^{26}$. Patients with at least 30 degrees of limitation 2 months after initial trauma were referred to physiotherapy.

Six to nine months after the initial trauma the orthopaedic surgeon re-measured the pronation/supination of the traumatised arm. Children with a limitation of pronation/supination of $\geq 40$ degrees were asked to participate in this study.

\section{Radiographic analysis}

\section{Conventional radiography}

One orthopaedic surgeon measured the fracture characteristics on conventional posteroanterior and lateral radiographs directly after trauma and at final examination (6-9 months after trauma) (Table 2 and 3).

\section{Computer tomography}

Torsion angle of the radius/ulna was defined as the angle between the proximal and distal metaphysis in the transverse plane ${ }^{27}$. To compare torsion angles of left and right radius/ulna, a computed tomography (CT) scanner was used to scan elbow and wrist joints of both sides. We defined rotational malunion as a difference in torsion angles of respectively radius and ulna between the injured and uninjured arm. All images were acquired using a GE Lightspeed 4-slice CT scanner (General Electric 


\section{Chapter 11}

Healthcare; Milwaukee, WI, USA). Image acquisition parameters were a X-ray tube potential of $80 \mathrm{kVp}$, a tube current of $30 \mathrm{~mA}$ and 2.50-mm slice thickness. Images were reconstructed using a high spatial frequency reconstruction algorithm (Boneplus).

With the child lying prone in the scanner, both arms were placed in overhead position; the elbows were extended and the forearms were pronated so that the volar aspect of the elbow was placed flat on the table. Axial images through the maximum prominence of the bicipital tuberosity and the distal two centimetres of both radii were made simultaneously with use of a routine $\mathrm{CT}$ imaging protocol. This technique of scanning has shown good reproducibility ${ }^{27}$. The measurements of torsion angles of radius and ulna of both arms were performed with the tools integrated in the PACS system used in our institution, i.e. iSite Radiology 3.5 (Philips Medical Systems, Best, the Netherlands). The difference in torsion angles of the radius of the traumatized arm and non-traumatized arm was calculated and defined as rotational malunion of the radius. The same procedure was repeated to determine the rotational malunion of the ulna. The orthopaedic surgeon and a senior resident of the radiology department (independently of each other) measured the torsion angle of the radius and ulna of both arms using the standardized techniques described by Bindra et al. and ${ }^{27}$ by Freitas et al..$^{28}$ for the radius and by Dumont et al..$^{29}$ and by Aufauvre et al. for the ulna ${ }^{30}$ (Figure 2). All techniques were used three times to calculate the intraand interobserver variability (ICCs). 
Proximal

Radius

Method of Bindra et al.
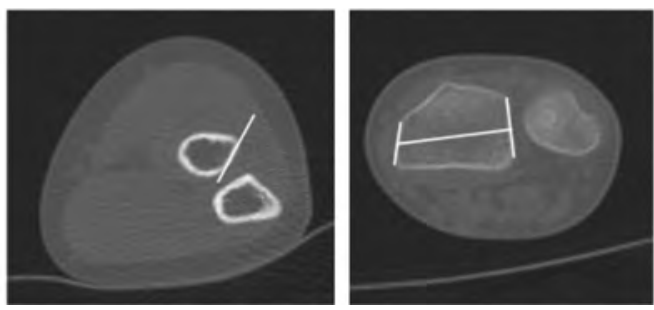

Method of de Freitas et al.
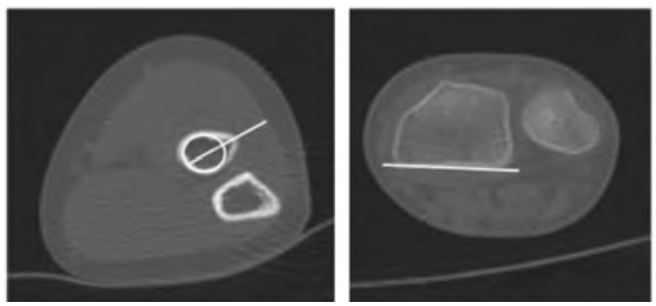

Ulna

Method of Dumont et al.
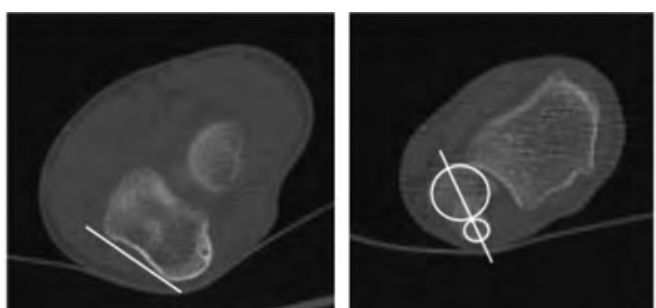

Method of Aufauvre et al.
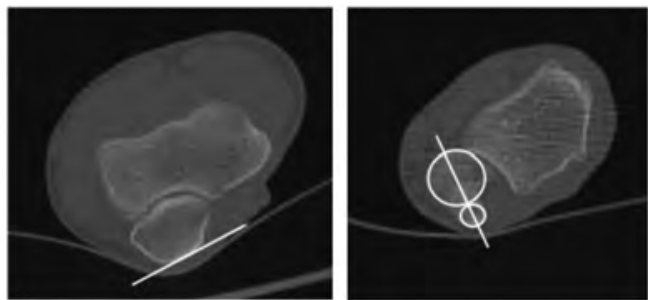

Figure 2. Measurement of torsion angle of radius and ulna by four different techniques. 


\section{Chapter 11}

\section{Magnetic resonance imaging}

The fractured forearm was scanned by MRI to visualise contractures of the interosseous membrane, edema, callus formation, periosteal reaction and bony impingement between radius and ulna. The MRI studies were obtained with a 1.0T magnetic resonance imaging unit (Gyroscan NT, Philips Medical Systems, Best, the Netherlands) using an extremity coil. During MRI the fractured arm was along the body with the forearm placed in full supination. In addition one sequence was obtained while the forearm was placed in full pronation to rule out bony impingement between the radius and ulna as cause of the limitation. We performed coronal T1-weighted turbo spin echo images, coronal and axial fat-suppressed T2weighted images and axial T1-weighted gradient echo images. The whole forearm was imaged during the coronal, sagittal and axial T1 gradient echo sequences. The axial T2-weighted sequence was obtained from the area around the fracture.

\section{Statistical methods}

The results are presented as median (interquartile range (IQR)). When assessing reliability, a distinction between intra-observer and inter-observer reliability was made. Intra-observer reliability investigates the capability of one tester to produce consistent results. Inter-observer reliability examines the extent of concurrence between the results of different observers. The ICCs were calculated using SPSS 17.0 (SPSS Inc., Chicago, USA).

\section{Results}

Between January 2006 and August 2010 a total of 410 children with both-bone forearm fractures were followed prospectively. Of these, 30 (7.3\%) suffered from a limitation of $\geq 40$ degrees of forearm rotation of whom 14 children were included in the present study (Figure 3). 
The median age was 12.3 years [interquartile range IQR of 9.5; 14.7] (Table 1). There was an equal distribution of children with a limitation of pronation or supination. At a median of 205 days [IQR 194; 225], the median limitation of pronation and supination was 40 degrees [IQR 40; 55] and the median maximum angular malunion on conventional radiographs was 16 degrees [IQR 13; 19] (Table 3).

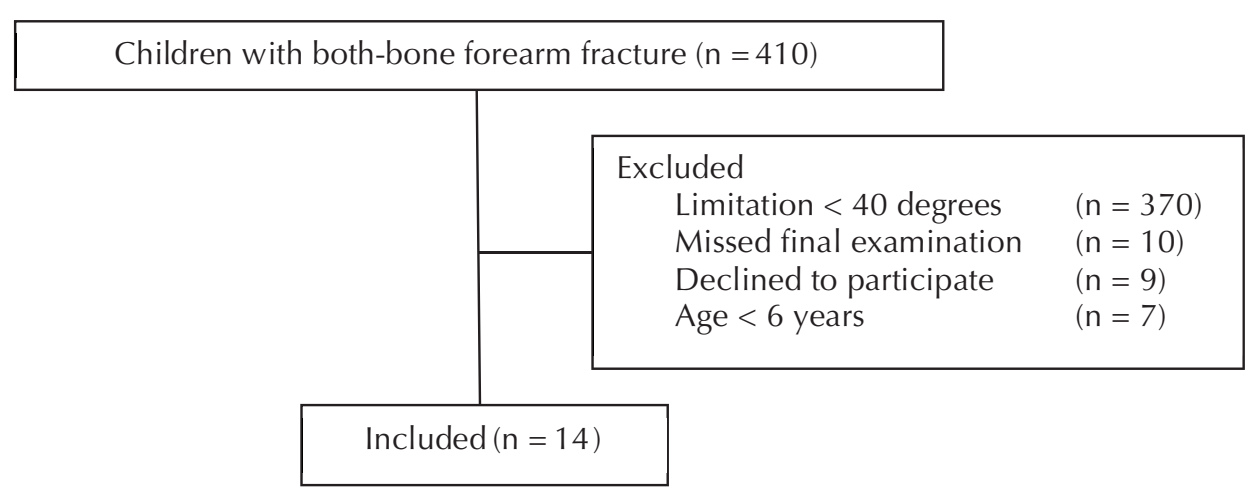

$n=$ number of children.

Figure 3. Flowchart of enrolment in the study.

The values of rotational malunion of radius and ulna measured with CT are reported in Table 4. CT analysis showed rotational malunion of both radius (median 19 degrees [IQR 12; 21]) and ulna (median 9 degrees [IQR 4; 12]) with no significant difference $(p=0.07)$. Torsion angle measurement of the radius was impossible in 5 children due to imaging problems of the radial tuberosity, i.e. only a part was imaged, the images were oblique and not comparable with the contralateral arm, or the radial tuberosity was not fully developed. In line with this, a not fully developed ulnar styloid precluded measurement of the ulnar torsion angle by the described techniques. For that reason, we used a tangential line that passes the sulcus for the extensor carpi ulnaris as distal reference point for the measurement of torsion (Figure 4). For the different measurement methods, the ICCs for intra-observer reliability were 0.77-0.99 and for interobserver reliability they were 0.69-0.92.

Rotational malunion was defined as the difference in torsion angles of the radius/ulna of the traumatized arm and the non-traumatized arm; Values are 


\section{Chapter 11}

Table 1. Outcomes of the study population.

\begin{tabular}{llllllll} 
Child & $\mathbf{1}$ & $\mathbf{2}$ & $\mathbf{3}$ & $\mathbf{4}$ & $\mathbf{5}$ & $\mathbf{6}$ & $\mathbf{7}$ \\
\hline Age in years at time of fracture & 8.0 & 13.9 & 4.9 & 14.3 & 15.7 & 7.2 & 10.0 \\
Male gender & - & + & + & + & + & + & - \\
Dominant arm fractured & + & + & - & - & + & - & + \\
Number of fracture reductions & 1 & 1 & 1 & 1 & 1 & 1 & 1 \\
Stabilization devices & - & - & - & - & TEN & - & - \\
Days in AEC & 26 & 42 & 29 & 41 & 28 & 21 & 21 \\
Days in BEC & 15 & 14 & 14 & 0 & 0 & 28 & 21 \\
Complications & - & - & - & - & $\alpha \beta$ & - & $\gamma$ \\
Number of visits physiotherapy & 20 & 12 & 3 & 6 & 10 & 4 & 6 \\
Days between fracture and CT/MRI & 256 & 300 & 218 & 74 & 919 & 265 & 316
\end{tabular}

Data in the Total column are presented as median [interquartile range] or percentage; $\mathrm{D}=$ diaphysis, $\mathrm{M}=$ metaphysis; $\mathrm{K}=$ Kirschner wires; $\mathrm{AEC}=$ above-elbow cast, $\mathrm{BEC}=$ below-elbow cast.

Table 2. Outcomes of conventional radiography after trauma.

\begin{tabular}{|c|c|c|c|c|c|c|c|}
\hline Child & 1 & 2 & 3 & 4 & 5 & 6 & 7 \\
\hline Location of fracture & D & D & $M$ & D & $D$ & D & D \\
\hline Type fracture radius & g & $c$ & $c$ & $c$ & NR & $g$ & $c$ \\
\hline Type fracture ulna & g & $c$ & c & $c$ & NR & $g$ & 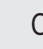 \\
\hline \multicolumn{8}{|l|}{ Angulation (degrees) } \\
\hline PAU & 30 & 27 & 50 & 2 & NR & 0 & 4 \\
\hline PAR & 26 & 34 & 33 & 12 & NR & 4 & 2 \\
\hline Lat U & 56 & 12 & 8 & 6 & NR & 13 & 9 \\
\hline Lat $\mathrm{R}$ & 56 & 8 & 3 & 6 & NR & 23 & \\
\hline \multicolumn{8}{|c|}{ Translation (\% of width) } \\
\hline PA U & 0 & 0 & 0 & 10 & NR & 0 & 1 \\
\hline PA R & 0 & 0 & 95 & 90 & NR & 0 & 0 \\
\hline Lat U & 0 & 60 & 0 & 20 & NR & 0 & \\
\hline Lat R & 0 & 0 & 35 & 0 & NR & 0 & 0 \\
\hline \multicolumn{8}{|l|}{ Shortening } \\
\hline Shortening $\mathrm{R}$ & - & - & + & - & NR & - & - \\
\hline Shortening U & - & - & - & - & NR & - & - \\
\hline \multicolumn{8}{|l|}{ Rotation } \\
\hline Rotation R & - & - & - & - & NR & - & . \\
\hline Rotation U & - & - & - & - & $N R$ & - & \\
\hline
\end{tabular}




$\begin{array}{llllllll}8 & 9 & 10 & 11 & 12 & 13 & 14 & \text { Total } \\ 11.1 & 14.6 & 15.3 & 15.2 & 11.1 & 13.5 & 10.2 & 12.3[9.5 ; 14.7] \\ + & + & + & + & + & + & + & 86 \% \\ - & - & - & + & - & - & - & 36 \% \\ 2 & 1 & 1 & 1 & 0 & 1 & 1 & \\ - & - & K & - & - & - & - & \\ 47 & 45 & 33 & 27 & 29 & 26 & 18 & 29[25 ; 41] \\ 0 & 0 & 0 & 0 & 0 & 0 & 25 & 18[14 ; 26] \\ \gamma \delta & \alpha & - & - & \alpha & - & - & \\ 13 & 24 & 7 & 6 & 0 & 15 & 2 & 7[4 ; 14] \\ 776 & 346 & 258 & 217 & 242 & 806 & 274 & 270[236 ; 454]\end{array}$

$\mathrm{C}=$ complete fracture, $\mathrm{G}=$ greenstick fracture; $\mathrm{NR}=$ no radiographs available; TEN $=$ titanium elastic nails. Complications: $\alpha$ : neurapraxia, $\beta$ : nonunion ulna, $\gamma$ : re-fracture, $\delta$ : re-reduction

$\begin{array}{lllllll}8 & 9 & 10 & 11 & 12 & 13 & 14 \\ \text { D } & \text { D } & \text { M } & \text { M } & \text { M } & \text { M } & \text { D } \\ \text { C } & \text { C } & \text { C } & \text { C } & \text { g } & \text { C } & \text { C } \\ \text { C } & \text { C } & \text { C } & \text { C } & \text { g } & \text { g } & \text { C }\end{array}$

$\begin{array}{lllllll}2 & 1 & 41 & 40 & 4 & 10 & \zeta \\ 5 & 1 & 31 & 45 & 6 & 14 & \zeta \\ 25 & 13 & 55 & 31 & 14 & 32 & 109 \\ 18 & 11 & 43 & 32 & 7 & 34 & 106\end{array}$

$\begin{array}{lllllll}20 & 5 & 0 & 100 & 0 & 0 & 0 \\ 20 & 95 & 40 & 50 & 0 & 45 & 0 \\ 10 & 0 & 0 & 80 & 0 & 0 & 100 \\ 0 & 65 & 100 & 90 & 0 & 100 & 0\end{array}$

Angulation presented in degrees; Translation presented in percentage of width; $\mathrm{PA}=$ posteroanterior, Rotation X trauma: + = rotation of radius and/or ulna; $\mathrm{CO}=$ corrective osteotomy done; $\zeta=$ no PA 


\section{Chapter 11}

Table 3. Outcomes at final follow-up.

\begin{tabular}{lllllllll} 
Child & $\mathbf{1}$ & $\mathbf{2}$ & $\mathbf{3}$ & $\mathbf{4}$ & $\mathbf{5}$ & $\mathbf{6}$ & $\mathbf{7}$ \\
\hline Days until final examination & 194 & 197 & 199 & 168 & 274 & 224 & 202 \\
Limitation pro & 15 & 35 & 25 & 20 & 30 & 30 & 0 \\
Limitation sup & 25 & 5 & 30 & 55 & 15 & 10 & 55 \\
Limitation total pro/sup & 40 & 40 & 55 & 75 & 45 & 40 & 55 \\
\hline \multicolumn{7}{c}{} & & \multicolumn{7}{l}{ Final examination } \\
\hline Angulation PA U & 3 & 8 & 0 & co & 3 & 1 & 3 \\
Angulation PA R & 1 & 6 & 4 & Co & 1 & 12 & 13 \\
Angulation lat U & 6 & 6 & 0 & Co & 3 & 0 & 13 \\
Angulation lat R & 14 & 12 & 13 & co & 1 & 15 & 19
\end{tabular}

Pro/sup = pronation/supination in degrees; $\mathrm{PA}=$ posteroanterior, Lat $=$ lateral; $\mathrm{U}=\mathrm{ulna}, \mathrm{R}=$ radius;

Data in the 'Total' column are presented as median and interquartile range.

Table 4. Outcomes of computed tomography.

\begin{tabular}{llllllll} 
Child & $\mathbf{1}$ & $\mathbf{2}$ & $\mathbf{3}$ & $\mathbf{4}$ & $\mathbf{5}$ & $\mathbf{6}$ & $\mathbf{7}$ \\
\hline Rotational malunion radius & & & & & & & \\
\hline Bindra et al. observer 1 & 15 & 14 & $*$ & $*$ & 16 & 35 & 21 \\
Bindra et al. observer 1 & 11 & 19 & $*$ & $*$ & 8 & 29 & 18 \\
Bindra et al. observer 2 & 24 & 8 & $*$ & $*$ & 24 & 32 & 22 \\
de Freitas et al. observer 1 & 31 & 10 & 9 & $*$ & 16 & 14 & 2 \\
de Freitas et al. observer 1 & 25 & 3 & 11 & $*$ & 16 & 40 & 1 \\
de Freitas et al. observer 2 & 19 & 15 & 21 & $*$ & 15 & 14 & 2 \\
\hline Total & & & & & & & \\
\hline Rotational malunion ulna & & & & & & & \\
\hline Ulnar styloid & - & + & + & - & + & - & + \\
Dumont et al. observer 1 & 7 & 21 & 2 & 2 & 10 & 25 & 35 \\
Dumont et al. observer 1 & 4 & 16 & 11 & 8 & 6 & 10 & 2 \\
Dumont et al. observer 2 & 5 & 2 & 2 & 8 & 2 & 4 & 19 \\
Aufauvre et al. observer 1 & 4 & 4 & 3 & 4 & 7 & 6 & 40 \\
Aufauvre et al. observer 1 & 5 & 9 & 1 & 4 & 5 & 2 & 12 \\
Aufauvre et al. observer 2 & 44 & 8 & 1 & 5 & 2 & 4 & 38 \\
\hline
\end{tabular}

Total 


\begin{tabular}{llllllll}
8 & 9 & 10 & 11 & 12 & 13 & 14 & Total \\
\hline 193 & 305 & 193 & 208 & 209 & 209 & 227 & $205[194 ; 225]$ \\
70 & 25 & 10 & 35 & 30 & 20 & 20 & $25[19 ; 31]$ \\
5 & 15 & 30 & 20 & 10 & 20 & 20 & $20[10 ; 30]$ \\
75 & 40 & 40 & 55 & 40 & 40 & 40 & $40[40 ; 55]$ \\
9 & 7 & 8 & 3 & 3 & 5 & 17 & $3\{3 ; 8\}$ \\
7 & 18 & 5 & 18 & 5 & 18 & 5 & $6\{5 ; 16\}$ \\
8 & 7 & 4 & 4 & 8 & 2 & 10 & $6\{3 ; 8\}$ \\
20 & 11 & 5 & 19 & 16 & 10 & 13 & $13\{11 ; 18\}$
\end{tabular}

$\begin{array}{lllllllll}8 & 9 & 10 & 11 & 12 & 13 & 14 & \text { Total }\end{array}$

$\begin{array}{llllllll}11 & * & 11 & * & * & 35 & 7 & 15[11 ; 28] \\ 9 & * & 17 & * & * & 41 & 1 & 17[9 ; 24] \\ 27 & * & 11 & * & * & 30 & 14 & 24[13 ; 29] \\ 19 & * & 7 & * & 5 & 6 & 4 & 9[5 ; 16] \\ 29 & * & 25 & * & 2 & 2 & 22 & 16[2 ; 25] \\ 26 & * & 4 & * & 12 & 18 & 64 & 15[12 ; 21]\end{array}$

$\begin{array}{llllllll}+ & + & + & + & - & + & + & \\ 7 & 1 & 1 & 19 & 15 & 7 & 12 & 9[2 ; 20] \\ 15 & 5 & 5 & 17 & 15 & 10 & 13 & 10[5 ; 15] \\ 14 & 1 & 2 & 25 & 8 & 1 & 20 & 5[2 ; 15] \\ 12 & 1 & 6 & 6 & 1 & 0 & 4 & 4[3 ; 6] \\ 16 & 13 & 1 & 23 & 9 & 7 & 3 & 6[3 ; 12] \\ 13 & 2 & 3 & 3 & 3 & 3 & 7 & 4[3 ; 9] \\ & & & & & & & 9[4 ; 12]\end{array}$




\section{Chapter 11}

rotational malunions and presented in degrees; ${ }^{*}=$ measurement not possible; + ulnar styloid used for measurement; - ulnar styloid not used for measurement; Data in the 'Total' column are presented as median [interquartile range] in degrees; No significant difference was found between the total rotational malunion of radius and ulna $(p=0.07)$.
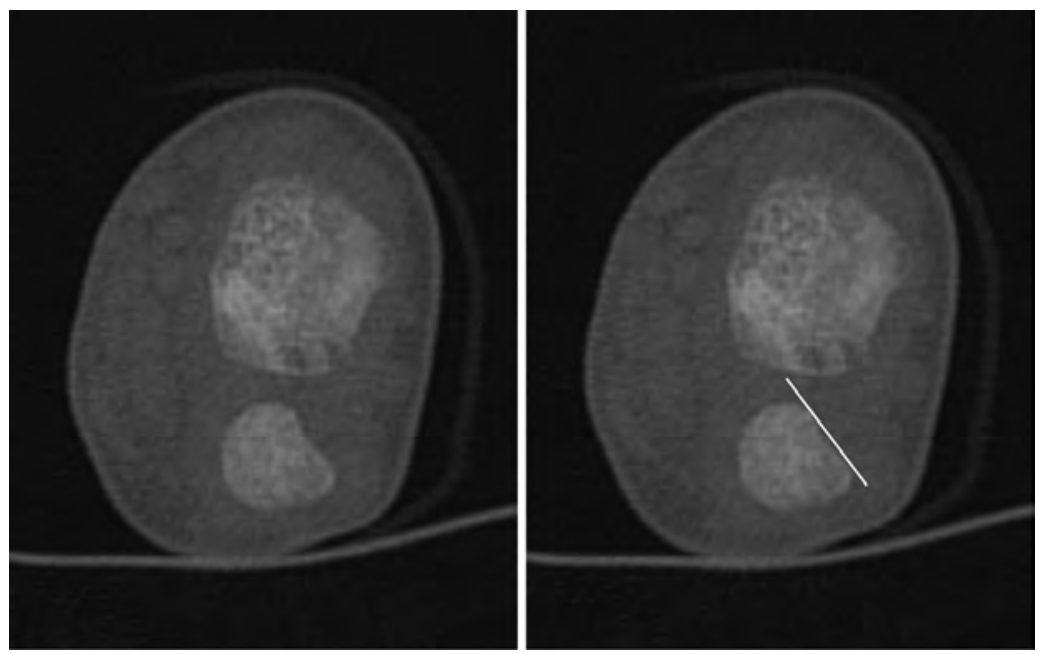

Figure 4. If ulnar styloid was not full-grown, a tangential line passes the sulcus for the extensor carpi ulnaris was used as a distal reference point for measurements of torsion angle of the ulna.

Table 5. Outcomes of magnetic resonance imaging.

\begin{tabular}{|c|c|c|c|c|c|c|}
\hline Child & 1 & 2 & 3 & 4 & 5 & 6 \\
\hline Contracture interosseous membrane & 0 & 0 & 0 & 0 & 0 & 0 \\
\hline Oedema & 0 & 0 & 0 & 2 & 0 & 0 \\
\hline Periosteal reaction & 0 & 0 & 0 & 2 & 0 & 0 \\
\hline Synostosis & 0 & 0 & 0 & 0 & 0 & 0 \\
\hline Callus & 1 & 1 & 0 & 2 & 0 & 1 \\
\hline Bony impingement & 0 & 0 & 0 & 0 & 0 & 0 \\
\hline
\end{tabular}

$0=$ no pathology, $1=$ moderate pathology, 2 = severe pathology. 
The outcomes on MRI showed neither contractures of the interosseous membrane nor bony impingement between radius and ulna (Table 5); oedema, periosteal reaction and callus formation around the fractures was found in $29 \%$ of children.

\section{Discussion}

This prospective study evaluated severe limitation of pronation/supination using 3D imaging in children who sustained a both-bone forearm fracture. CT analysis showed rotational malunions of both radius and ulna, MRI demonstrated neither contractures of the interosseous membrane nor bony impingement.

Although several studies measured the torsion angle of radius and ulna by $\mathrm{CT}$ in cadavers or in healthy volunteers ${ }^{27-30}$, we found this technique difficult to apply in our group of children ${ }^{27}$. Malalignment of the forearm and the severe limitation of pronation/supination made it difficult for children to place the volar aspect of the elbow flat on the table. This resulted in scans with only a part of the radial tuberosity imaged or different angles of images of the radial tuberosity, making comparison difficult between the injured and uninjured site. Furthermore, measurement of torsion angle was impossible in some children with not fully developed radial tuberosity.

Because we encountered the same problem with the measurement of ulnar torsion in case of a not-ossified ulnar styloid, a new technique was applied that showed an inter- and intra-observer reliability that was similar to previously used techniques.

$\begin{array}{llllllll}7 & 8 & 9 & 10 & 11 & 12 & 13 & 14 \\ 0 & 0 & 0 & 0 & 0 & 0 & 0 & 0 \\ 2 & 0 & 0 & 1 & 2 & 0 & 0 & 0 \\ 1 & 0 & 0 & 1 & 1 & 0 & 0 & 0 \\ 0 & 0 & 0 & 0 & 0 & 0 & 0 & 0 \\ 0 & 0 & 0 & 0 & 0 & 0 & 0 & 0 \\ 0 & 0 & 0 & 0 & 0 & 0 & 0 & 0\end{array}$




\section{Chapter 11}

\section{Torsion angle of the radius}

Bindra et al. measured the torsion angle of the radius with CT and Dumont et al. repeated this measurement using MRI. The ICCs for intra-observer reliability $(0.88$ and 0.95$)$ and inter-observer reliability (0.94 and 0.82$)$ of both studies were similar to ours (0.98 and 0.85). Freitas et al. also measured the torsion angle of the radius and found ICCs for intra-observer reliability of 0.28-0.91 and for inter-observer reliability of 0.75-0.90. The ICCs in the present study were relatively high with 0.920.99 for intra-observer reliability and 0.69-0.78 for inter-observer reliability.

\section{Torsion angle of the ulna}

Dumont et al. measured the torsion angle of the ulna using MRI and found an ICC for intra-observer reliability of 0.95 and an ICC for inter-observer reliability of 0.91 . The ICCs in the present study were 0.80-0.88 for intra-observer reliability and 0.850.87 for inter-observer reliability. In their study, Aufauvre and colleagues did not measure ICCs.

\section{Magnetic Resonance Imaging}

Our MRI findings showed only a few alterations, which were in line with an earlier study (20). In our study group, oedema, callus and periosteal reaction detected on MRI may be normal in the healing process of severe both-bone forearm fractures. While impingement is mentioned as a potential cause of limitation of pronation/supination after forearm fractures, we found no impingement between the radius and ulna in maximum pronation/supination ${ }^{9,11,19}$. Although studies have described the important role of contractures of the interosseous membrane in limitation of pronation/supination after forearm fractures, in our study group these were not detected on $\mathrm{MRI}^{9,11,22-24}$. However, the question remains whether the contractures did not in fact exist, or whether they were not detectable on MRI.

\section{Study limitations}

Our CT protocol did not succeed in visualizing all radial tuberosity's, which precluded determination of the torsion of the radius in some children. This could have been avoided by using a CT of both whole forearms with a bone and a soft tissue setting. Different angles of anatomical landmarks between the two forearms 
could have been corrected using an isotropic dataset. In this way, the soft tissue window could have visualized the insertion of the biceps tendon that might serve as a reference for the radial tuberosity. Nevertheless, this technique would also not visualize the tuberosity's that were not fully developed. Furthermore, this method of scanning employs a higher dose of radiation which is potentially hazardous for children.

MRI of both arms with a higher resolution might have detected more soft tissue pathology. However, the sparse availability of the MRI unit made scanning of both arms impossible and the use of an extremity coil compensated for the relatively low resolution.

Ideally our follow-up period should have been longer in this young population to see if correction of malunion by growth would have influenced the limitation of forearm rotation.

\section{Conclusion}

This prospective study evaluated severe limitation of pronation/supination using 3D imaging in children who sustained a both-bone forearm fracture. The MRI demonstrated neither contractures of the interosseous membrane nor bony impingement. CT analysis showed rotational malunions of both radius and ulna. Because malunion, impaired forearm rotation and a not fully developed radial tuberosity hindered measurement of rotational malunion in several children, further research should be done with a CT of both whole forearms with a bone and a soft tissue setting. 


\section{Chapter 11}

\section{REFERENCES}

1. Colaris JW, Allema JH, Biter LU, de Vries MR, van de Ven CP, Bloem RM, et al. Redisplacement of stable distal both-bone forearm fractures in children: a randomised controlled multicentre trial. Injury. 2013;44(4):498-503.

2. Colaris JW, Biter LU, Allema JH, Bloem RM, van de Ven CP, de Vries MR, et al. Belowelbow cast for metaphyseal both-bone fractures of the distal forearm in children: a randomised multicentre study. Injury. 2012;43(7):1107-11.

3. Colaris JW, Reijman M, Allema JH, Biter LU, Bloem RM, van de Ven CP, et al. Early conversion to below-elbow cast for non-reduced diaphyseal both-bone forearm fractures in children is safe: preliminary results of a multicentre randomised controlled trial. Arch Orthop Trauma Surg. 2013 Oct;133(10):1407-14.

4. Colaris J, Reijman M, Allema JH, Kraan G, van Winterswijk P, de Vries M, et al. Single-bone intramedullary fixation of unstable both-bone diaphyseal forearm fractures in children leads to increased re-displacement: a multicentre randomised controlled trial. Arch Orthop Trauma Surg. 2013 Aug;133(8):1079-87

5. Bronstein AJ, Trumble TE, Tencer AF. The effects of distal radius fracture malalignment on forearm rotation: a cadaveric study. J Hand Surg [Am]. 1997;22(2):258-62.

6. Dumont CE, Thalmann R, Macy JC. The effect of rotational malunion of the radius and the ulna on supination and pronation. J Bone Joint Surg Br. 2002;84(7):1070-4.

7. Kasten P, Krefft M, Hesselbach J, Weinberg AM. How does torsional deformity of the radial shaft influence the rotation of the forearm? A biomechanical study. J Orthop Trauma. 2003; 17(1):57-60.

8. Kuderna $\mathrm{H}$. [Connection between deviated axis and impaired function after fractures of the forearm (author's transl)]. Unfallchirurgie. 1980;6(1):7-13.

9. Matthews LS, Kaufer H, Garver DF, Sonstegard DA. The effect on supination-pronation of angular malalignment of fractures of both bones of the forearm. J Bone Joint Surg Am. 1982;64(1):14-7.

10. Roberts JA. Angulation of the radius in children's fractures. J Bone Joint Surg Br. 1986;68(5):751-4.

11. Tarr RR, Garfinkel AI, Sarmiento A. The effects of angular and rotational deformities of both bones of the forearm. An in vitro study. J Bone Joint Surg Am. 1984;66(1):65-70. 


\section{3-D imaging of severe limitation of pronation/supination}

12. Trousdale RT, Linscheid RL. Operative treatment of malunited fractures of the forearm. J Bone Joint Surg Am. 1995;77(6):894-902.

13. Hogstrom $\mathrm{H}$, Nilsson BE, Willner S. Correction with growth following diaphyseal forearm fracture. Acta Orthop Scand. 1976;47(3):299-303.

14. Nilsson BE, Obrant K. The range of motion following fracture of the shaft of the forearm in children. Acta Orthop Scand. 1977;48(6):600-2.

15. Nenopoulos SP, Beslikas TA, Gigis JP. Long-term follow-up of combined fractures of the proximal radius and ulna during childhood. J Pediatr Orthop B. 2009;18(5):252-60.

16. Krukhaug Y, Hove LM. Corrective osteotomy for malunited extra-articular fractures of the distal radius: a follow-up study of 33 patients. Scand J Plast Reconstr Surg Hand Surg. 2007;41(6):303-9.

17. Nagy L, Jankauskas L, Dumont CE. Correction of forearm malunion guided by the preoperative complaint. Clin Orthop Relat Res. 2008;466(6):1419-28.

18. Price CT, Knapp DR. Osteotomy for malunited forearm shaft fractures in children. J Pediatr Orthop. 2006;26(2):193-6.

19. Graham TJ, Fischer TJ, Hotchkiss RN, Kleinman WB. Disorders of the forearm axis. Hand clinics. 1998;14(2):305-16.

20. Beyer W, Stolzenburg T, Paris S. [Functional limitation of the forearm after shaft fracture in childhood. Possible role of the antebrachial interosseous membrane: MRI and ultrasound studies]. Unfallchirurgie. 1995;21(6):275-84.

21. Kihara H, Palmer AK, Werner FW, Short WH, Fortino MD. The effect of dorsally angulated distal radius fractures on distal radioulnar joint congruency and forearm rotation. J Hand Surg [Am]. 1996;21(1):40-7.

22. Nakamura T, Yabe Y, Horiuchi Y. [A biomechanical analysis of pronation-supination of the forearm using magnetic resonance imaging: dynamic changes of the interosseous membrane of the forearm during pronation-supination]. Nippon Seikeigeka Gakkai Zasshi. 1994;68(1):14-25.

23. Nakamura T, Yabe Y, Horiuchi Y, Seki T, Yamazaki N. Normal kinematics of the interosseous membrane during forearm pronation-supination-a three-dimensional MRI study. Hand Surg. 2000;5(1):1-10.

24. Price CT, Scott DS, Kurzner ME, Flynn JC. Malunited forearm fractures in children. J Pediatr Orthop. 1990;10(6):705-12. 


\section{Chapter 11}

25. Yasutomi T, Nakatsuchi Y, Koike H, Uchiyama S. Mechanism of limitation of pronation/supination of the forearm in geometric models of deformities of the forearm bones. Clin Biomech (Bristol, Avon). 2002;17(6):456-63.

26. Colaris J, van der Linden M, Selles R, Coene N, Allema JH, Verhaar J. Pronation and supination after forearm fractures in children: Reliability of visual estimation and conventional goniometry measurement. Injury. 2010;41(6):643-6.

27. Bindra RR, Cole RJ, Yamaguchi K, Evanoff BA, Pilgram TK, Gilula LA, et al. Quantification of the radial torsion angle with computerized tomography in cadaver specimens. The Journal of bone and joint surgery American volume. 1997;79(6):833-7.

28. Freitas LF, Barbieri CH, Mazzer N, Zatiti SC, Bellucci AD, Nogueira-Barbosa MH. Intraobserver and interobserver reliability of radial torsion angle measurements by a new and alternative method with computed tomography. Clinics (Sao Paulo). 2010;65(11):10937.

29. Dumont CE, Pfirrmann CW, Ziegler D, Nagy L. Assessment of radial and ulnar torsion profiles with cross-sectional magnetic resonance imaging. A study of volunteers. J Bone Joint Surg Am. 2006;88(7):1582-8.

30. Aufauvre B, Garcier JM, Boisgard S, Tanguy A. [Measurement of the torsion of the two bones of the forearm: evaluation of tomodensitometric reference points]. Bull Assoc Anat (Nancy). 1996;80(248):5-8. 


\section{PART VI}

\section{General Discussion}

\section{AND SUMMARY}




\section{Chapter 12}

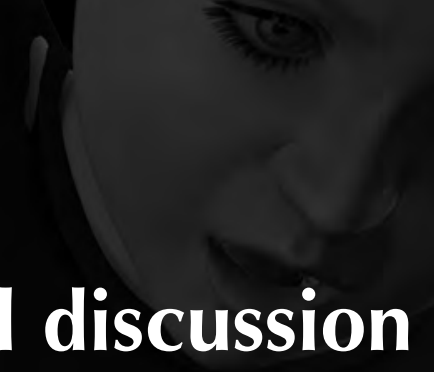

General discussion 
Chapter 12 


\section{Part 1 Metaphyseal both-bone fractures of the distal forearm}

Metaphyseal both-bone fractures of the distal forearm are among the most frequent fractures in childhood. This thesis reveals that minimally displaced fractures can be safely treated in a below-elbow cast, which is supported by previous studies ${ }^{1-3}$. In case of a displaced fracture the clinician is often confronted with a treatment dilemma, i.e. whether to accept some degree of displacement, or to perform a reduction of the fracture. A perfect anatomical fracture alignment is not always necessary in children because natural growth remodels malalignment. The highest remodelling by growth takes place in fractures that are close to the most active distal growth plate. Therefore, previous studies stated that metaphyseal fractures of the distal forearm with an angulation $\leq 15$ degrees can be treated without reduction in children of all ages ${ }^{4}$. In accordance with these findings, we found that children with an angular malalignment of $\leq 15$ degrees had a less than $13 \%$ chance to develop a clinically relevant limitation (i.e. $<50$ degrees of pronation and/or supination), while children with an angular malalignment of $\geq 16$ degrees had a $60 \%$ chance.

Therefore, fractures in which the angulation exceeds 15 degrees need to be reduced in the operating room under general anaesthesia with fluoroscopic guidance. Because this thesis shows that secondary displacement of these reduced fractures occurred in $45 \%$ of children treated with only an above-elbow cast, we advise to perform stabilisation of the radius fracture by means of two crossed percutaneous Kirschner wires (K-wires). In this case, the surgeon should also consider stabilisation of an unstable ulnar fracture, because secondary fracture displacement of the ulna was seen in $5 \%$ of children in which only the radius was stabilised with K-wires. Whereas some groups buried the K-wires subcutaneously, requiring an additional operation for removal ${ }^{5}$, in our study the K-wires were placed transcutaneously to facilitate removal in the outpatient clinic. Nevertheless, in our study, $11 \%$ of the K-wires became subcutaneous thereby making an additional operation necessary. This complication might have been avoided by not cutting the K-wires too short. Although the K-wires were placed transcutaneously, only $3 \%$ of the children in our study developed a superficial infection; this rate is similar to that reported by others ${ }^{6}$. In our study, no child had symptoms of neuromas of either the radial sensory nerve, lateral cutaneous nerve of the forearm, or posterior cutaneous 


\section{Chapter 12}

nerve of the forearm. This may be explained in two ways: by using a proper surgical technique with a small skin incision and blunt dissection of soft tissue and, secondly, due to the less vulnerable nerves in children; this is confirmed by the absence of literature reporting on iatrogenic neuromas in childhood.

\section{Part 2 Diaphyseal both-bone forearm fractures}

Because of the relatively long distance between a diaphyseal fracture and the distal and proximal growth plates, only minimal correction of malalignment by growth can be expected. A previous study stated that diaphyseal fractures in children need to be reduced in accordance with their age, i.e. in children up to 9 years of age an angulation up to 15 degrees can be excepted, while in children 9 years of age or older, 10 degrees of angulation is acceptable ${ }^{4}$. Nevertheless, in our opinion also fractures with less angulation might benefit by reduction because our results indicate that children with $\leq 5$ degrees of angular malalignment already have a $13 \%$ chance to develop a clinically relevant limitation (i.e. $<50$ degrees of pronation and/or supination).

Based on the results of our randomised controlled study, diaphyseal both-bone forearm fractures without need for reduction could be safely be treated with an above-elbow cast for 3 weeks, followed by a below-elbow cast. In general, among our group of children, 6 weeks of cast was long enough. Nevertheless, painful fractures without formation of callus on radiographs should be treated in cast for a longer period. Because even minimally displaced fractures showed a tendency for secondary displacement in cast, radiographs at weekly intervals until removal of the cast should be made to avoid malalignment.

Displaced diaphyseal both-bone forearm fractures should be reduced in the operation room under general anaesthesia with fluoroscopic guidance. If the reduction is easy and the fracture seems to be stable, an above-elbow cast has to be applied to stabilise the fracture. Similar to the treatment of the non-reduced fractures, following the results of our randomised controlled study, the above-elbow cast can be safely replaced by a below-elbow cast after 3 weeks.

Compared with previous studies, limitation of pronation/supination was relatively high in our group of diaphyseal both-bone fractures ${ }^{7-13}$. Using the grading 
system (9) we found 21-33\% excellent results, whereas others found excellent results in 44-100\%. Previous studies reported a re-displacement rate of $7-27 \%$ in conservatively treated forearm fractures ${ }^{7,10,11,14-17}$ whereas our rate was $23-34 \%$.

Fractures that seem to be unstable during reduction should be stabilised with intramedullary nails. Several non-randomised and mostly retrospective studies advocated stabilisation of both-bone forearm fractures with only one intramedullary nail in either the radius or ulna, in combination with a supplementary cast ${ }^{18-28}$. In those studies, the surgeon could choose per-operatively for single-bone or both-bone fixation depending on the stability of the fracture, whereas we performed a study with randomisation between one or two intramedullary nails irrespective of the fracture stability. The group of children treated with one intramedullary nail showed inferior results because of displacement of the non-fixated bone. Such redisplacement in single-bone intramedullary fixation of both-bone forearm fractures is not uncommon ${ }^{19,20,24,27}$. We suggest that these unstable diaphyseal fractures should be stabilised with an intramedullary nail in both the radius and ulna to prevent re-displacement and to enable unloaded exercises of the arm without cast to improve final function.

\section{Part 3 Fracture displacement}

A both-bone forearm fracture destabilises the structural columns of the forearm. Although the clinician tries to re-stabilise the fractured forearm by cast, K-wires, intramedullary nails or plates, fracture displacement occurs frequently. Previous studies described fracture displacement of 7-91\% in the distal metaphysis ${ }^{17,29-36}$ compared to $33 \%$ in our study, and fracture displacement in the diaphysis $7,10,11,14-17,37$ was found in $7-52 \%$ compared to $27 \%$ in our study. There are several explanations for our relatively high percentage of displacement. First, we included only both-bone forearm fractures that are notorious for instability ${ }^{1,38}$. Second, we had a detailed prospective follow-up with scheduled radiographs. Third, our malalignment criteria were relatively strict, especially for young children with a high potential for remodelling by growth. Fourth, a non-circumferential cast was applied directly after reduction. Finally, the test used to distinguish between stable and unstable fractures might have been influenced by the opinion of the surgeon. 


\section{Chapter 12}

As expected, fractures stabilised by K-wires or intramedullary nails showed less displacement than fractures treated with cast only. However, also in this group, displacement was seen by improper surgical technique or displacement of the nonfixated bone.

Our prospective multivariate regression analysis revealed fractures of the nondominant arm to be a risk factor for fracture displacement in cast, which was not found by others ${ }^{34,39}$. Less stability of the fracture by less developed muscles in the non-dominant forearm might be an explanation for this increased risk of fracture displacement in the non-dominant forearm. Furthermore, our analysis showed that the severity of fracture displacement directly after the trauma is highly predictive for secondary displacement in cast. In more detail: complete fractures were at higher risk for displacement than greenstick fractures, a finding supported by some clinicians $^{15,34,36,40,41}$ but not by others ${ }^{17,42}$. Fractures with translation of the ulna on lateral radiographs were at risk for displacement, as reported once before ${ }^{15}$. Shortening of fractures has not previously been reported as a risk factor. Thus, in our study, fracture angulation did not appear to be a risk factor for displacement, as also found in previous studies ${ }^{34,42}$. In summary, complete fractures with translation and shortening seem to be more unstable than angulated greenstick fractures with an intact periosteal sleeve on one side.

Several studies reported that the quality of the cast (cast index) is a risk factor for fracture displacement ${ }^{2,17,40,42}$; however, this was not supported by our studies and by others ${ }^{15,41}$. Although an above-elbow cast was generally considered more likely to prevent fracture displacement than a below-elbow cast, we found a tendency towards less fracture displacement in children treated with a below-elbow cast. This finding has been reported before and might be explained by several theories $^{1-3}$. First, the application of an above-elbow cast might be more difficult, resulting in an inferior cast with less three-point fixation. Second, an above-elbow cast restricts wrist and elbow motion and, therefore, induces forced movements of the fractured arm in daily use. Third, elbow motion in a below-elbow cast results in micro-movements in the fracture, which facilitates secondary fracture healing. Finally, it is possible that an above-elbow cast results in more atrophy with less stabilising soft tissue around the fracture.

Our results suggest that a diaphyseal or metaphyseal location of the fracture 
has no significant influence on displacement, a finding supported by one group ${ }^{15,39}$ but not by another ${ }^{15,39}$. Furthermore, we found no significant effect of reduction with or without general anaesthesia ${ }^{36,39}$. Although fracture displacement occurred more frequently in the group of reduced fractures than in non-reduced fractures, clinicians should also be aware of secondary displacement of minimally displaced fractures.

Similar to other studies ${ }^{1,5,34}$ only half of our re-displaced fractures were reduced a second time, although this was suggested in our study protocol. Although not planned, this illustrates the restraint of treating clinicians to decide on a second reduction. On the one hand, the surgeon may hope or expect correction of the malalignment by growth whereas, on the other hand, the surgeon may be reluctant to burden the child again or may find it difficult to accept failure of the initial treatment. Nevertheless, the results of our study revealing the relation between malunion and limitation of pronation/supination, suggest that better functional results are achieved if clinicians follow the study protocol.

In conclusion, all both-bone forearm fractures in children need to be monitored carefully using weekly radiographs to enable early detection of fracture displacement. In case of displacement, the clinician should bear several factors in mind when considering treatment, i.e. the severity of displacement, fracture in the dominant arm, age of the child, and the distance between the fracture and the most active distal growth plate.

\section{Part 4 Limitation of forearm rotation}

Although most of the both-bone forearm fractures heal uneventfully, limitation of pronation and supination can give disappointing results ${ }^{11,43-45}$. While movement of the ipsilateral shoulder can compensate mild limitation of pronation/supination, more severe limitation hinders daily activities. To function properly both pronation and supination need to be at least 50 degrees ${ }^{46}$; in our study this was not obtained by $20 \%$ of the children after a mean period of $218( \pm 49)$ days. In our study the mean limitation of forearm rotation was $12( \pm 14)$ degrees. Despite the absence of other prospective studies, our results seem to be slightly less successful than other series. This might be explained in several ways. First, we only included children with 


\section{Chapter 12}

relatively severe injuries that resulted in fractures of both the radius and the ulna. Second, ours was a prospective study with a precise registration of arm function. Third, we included many diaphyseal fractures, which are prone to impaired forearm rotation. Fourth, a relatively large number of fractures healed in malalignment, which increases the chance of limitation of forearm rotation. Finally, the relatively short follow-up period, with less correction of malalignment by growth, had a negative impact on our results.

Although not fully elucidated in literature, malunion and soft tissue contractures are generally thought to cause impaired forearm rotation after a forearm fracture. An interaction between these two causes may occur when a malunion changes the tension of the interosseous membrane ${ }^{47-50}$.

Limitation of pronation/supination attributed to malunion consists of malalignment in angulation, translation or rotation ${ }^{12,47,49,51-56}$. Whereas some reported that angular malalignment may result in significant limitation $47,48,51,57$, others found a poor correlation between residual angular malunion and the final range of pronation/supination ${ }^{12,43,45,48,58-60}$. In our multivariate logistic regression analysis, angular malalignment was not independently associated with a limitation of pronation/supination. However, our clinical study relating impaired forearm rotation with angular malalignment showed that angular malalignment in fractures resulted in a clinically relevant limitation of pronation/supination.

Malalignment in translation is considered to cause impingement between the forearm bones, resulting in limitation of pronation and supination ${ }^{49,54-56}$. However, in our study, the primary translational displacement of the fracture was changed by appositional periosteal bone formation and at final follow-up only minimal callus without notable translational malalignment was seen on the radiographs. Furthermore, magnetic resonance imaging of children in our study population who suffered from a severe limitation revealed no bony impingement between the radius and ulna.

In cadaver studies rotational malalignment of the ulna and radius caused limitation of forearm rotation ${ }^{52,53,55}$. Our clinical study with computer tomography confirmed a rotational malalignment of both the radius and ulna in children suffering from severe limitation of pronation/supination.

Several studies suggested that soft tissue contractures following forearm fractures lead to limitation of pronation/supination ${ }^{50,54,61-63}$. These contractures may 
originate from muscles, capsules and the interosseous membrane. It is reported that a volar fracture haematoma following a distal radius fracture caused a contracture of the pronator quadratus muscle, with subsequent a limitation of supination ${ }^{64}$. In line with this, a fracture haematoma of the pronator quadratus muscle and the pronator teres muscle can result in contractures with limitation of supination, while contractures of the supinator muscle and the biceps muscle can result in limitation of pronation. Because we found more limitation of pronation than supination (29\% vs. $23 \%$ ) in distal metaphyseal both-bone forearm fractures, we assume that contractures of the pronator quadratus muscle are probably not the main cause of limitation. Furthermore, if contracture of the biceps muscle plays a role in the limitation of pronation, then we would also expect a limitation of elbow extension because the biceps muscle acts as both a supinator and an elbow flexor.

Contractures of the capsule of wrist and elbow have been reported as a cause of impaired forearm rotation ${ }^{50,63}$. However, this argument is not applicable in our study population, because capsule contractures should have also led to impaired flexion and extension of wrist and elbow, which was not the case in our children.

Our multivariate analysis revealed a diaphyseal fracture to be an independent risk factor for limitation of forearm rotation. Thereby, diaphyseal fractures with minimal angular malaligment ( $\leq 5$ degrees) already had a $13 \%$ chance of severe limitation of forearm rotation and this chance showed no significant increase with more severe malalignment. Therefore, we assume that contractures of the interosseous membrane play an important role in the limitation of pronation/ supination in diaphyseal fractures. This can be explained in several ways. First, in our study, because about $75 \%$ of diaphyseal fractures were severe displaced, we assume that the high force of injury that fractures the thick cortices of both the radius and ulna is associated with significant injury to the interosseous membrane. Second, previous studies described five ligamentous components of the interosseous membrane, of which only the two most proximal cords showed a substantial change in length during forearm rotation ${ }^{65}$. Immobilisation of a diaphyseal fracture in an above-elbow cast might result in a reduced amount of lengthening of these injured proximal cords and, consequently, impairment of forearm rotation. Other independent risk factors revealed in our multivariate analysis were less physiotherapy and re-fractures. Both of these suggest a substantial role of soft tissue contractures 


\section{Chapter 12}

in limitation of forearm rotation: while physiotherapy decreases contractures by stretching, a re-fracture gives rise to more contractures by an extra injury in regenerating soft tissue. Finally, contractures of the interosseous membrane as a cause of limitation of forearm rotation was confirmed in a study that found a correlation between initial fracture displacement, MRI-detected interosseous membrane alternations, and limitation of pronation/supination ${ }^{66}$.

Furthermore, pathology of the distal or proximal radio-ulnar joint may impair forearm rotation. Although pathology in these joints seems obvious in Galeazzi or Monteggia fracture dislocations, tightening of the triangular fibrocartilage complex has also been described as a cause of impaired forearm rotation following radius fractures ${ }^{67-69}$. Nevertheless, we assume that pathology of the distal or proximal radioulnar joint mainly occurs if the energy of impact causes a single-bone fracture and soft tissue injury along the other bone.

Taking all these findings into consideration, we conclude that only children with a severe angular malalignment of a metaphyseal fracture have a high risk of impaired forearm rotation, while children with diaphyseal fractures have a moderate chance to develop a limitation irrespective of the severity of the angular malalignment. In this latter group we expect a contracture of the interosseous membrane to play a substantial role, even though we were unable to detect it on (low resolution) MRI. Impingement between malunions of the radius and ulna did not affect limitation, and rotational malunion seems to have some influence but is, however, difficult to detect.

Overall, the work in this thesis has revealed more insight in the treatment and complications of both-bone forearm fractures in children. 


\section{REFERENCES}

1. Bohm ER, Bubbar V, Yong Hing K, Dzus A. Above and below-the-elbow plaster casts for distal forearm fractures in children. A randomized controlled trial. J Bone Joint Surg Am. 2006;88(1):1-8.

2. Webb GR, Galpin RD, Armstrong DG. Comparison of short and long arm plaster casts for displaced fractures in the distal third of the forearm in children. J Bone Joint Surg Am. 2006;88(1):9-17.

3. Paneru SR, Rijal R, Shrestha BP, Nepal P, Khanal GP, Karn NK, et al. Randomized controlled trial comparing above- and below-elbow plaster casts for distal forearm fractures in children. J Child Orthop. 2010;4(3):233-7.

4. Noonan KJ, Price CT. Forearm and distal radius fractures in children. The Journal of the American Academy of Orthopaedic Surgeons. 1998;6(3):146-56.

5. McLauchlan GJ, Cowan B, Annan IH, Robb JE. Management of completely displaced metaphyseal fractures of the distal radius in children. A prospective, randomised controlled trial. J Bone Joint Surg Br. 2002;84(3):413-7.

6. Subramanian P, Kantharuban S, Shilston S, Pearce OJ. Complications of Kirschner-wire fixation in distal radius fractures. Tech Hand Up Extrem Surg. 2012;16(3):120-3.

7. Bochang C, Jie Y, Zhigang W, Weigl D, Bar-On E, Katz K. Immobilisation of forearm fractures in children: extended versus flexed elbow. J Bone Joint Surg Br. 2005;87(7):994-6.

8. Boero S, Michelis MB, Calevo MG, Stella M. Multiple forearm diaphyseal fracture: reduction and plaster cast control at the end of growth. Int Orthop. 2007;31(6):807-10.

9. Daruwalla JS. A study of radioulnar movements following fractures of the forearm in children. Clin Orthop Relat Res. 1979(139):114-20.

10. Jones K, Weiner DS. The management of forearm fractures in children: a plea for conservatism. J Pediatr Orthop. 1999;19(6):811-5.

11. Kay S, Smith C, Oppenheim WL. Both-bone midshaft forearm fractures in children. J Pediatr Orthop. 1986;6(3):306-10.

12. Price CT, Scott DS, Kurzner ME, Flynn JC. Malunited forearm fractures in children. J Pediatr Orthop. 1990;10(6):705-12.

13. Shah AS, Lesniak BP, Wolter TD, Caird MS, Farley FA, Vander Have KL. Stabilization of adolescent both-bone forearm fractures: a comparison of intramedullary nailing versus open reduction and internal fixation. J Orthop Trauma.24(7):440-7. 


\section{Chapter 12}

14. Chan CF, Meads BM, Nicol RO. Remanipulation of forearm fractures in children. N Z Med J. 1997;110(1047):249-50.

15. Monga $\mathrm{P}$, Raghupathy $\mathrm{A}$, Courtman $\mathrm{NH}$. Factors affecting remanipulation in paediatric forearm fractures. J Pediatr Orthop B.19(2):181-7.

16. Schmittenbecher PP. State-of-the-art treatment of forearm shaft fractures. Injury. 2005;36 Suppl 1:A25-34.

17. Voto SJ, Weiner DS, Leighley B. Redisplacement after closed reduction of forearm fractures in children. J Pediatr Orthop. 1990;10(1):79-84.

18. Alnaib M, Taranu R, Lakkol S, Aldlyami E, Alcelik I, Tulloch C. Radius-only intramedullary nailing for both-bones diaphyseal forearm fractures in children. Acta orthopaedica Belgica. 2011;77(4):458-63.

19. Cullen MC, Roy DR, Giza E, Crawford AH. Complications of intramedullary fixation of pediatric forearm fractures. J Pediatr Orthop. 1998;18(1):14-21.

20. Dietz JF, Bae DS, Reiff E, Zurakowski D, Waters PM. Single bone intramedullary fixation of the ulna in pediatric both bone forearm fractures: analysis of short-term clinical and radiographic results. J Pediatr Orthop.30(5):420-4.

21. Flynn JM, Waters PM. Single-bone fixation of both-bone forearm fractures. J Pediatr Orthop. 1996;16(5):655-9.

22. Houshian S, Bajaj SK. Forearm fractures in children. Single bone fixation with elastic stable intramedullary nailing in 20 cases. Injury. 2005;36(12):1421-6.

23. Kirkos JM, Beslikas T, Kapras EA, Papavasiliou VA. Surgical treatment of unstable diaphyseal both-bone forearm fractures in children with single fixation of the radius. Injury. 2000;31(8):591-6.

24. Lee S, Nicol RO, Stott NS. Intramedullary fixation for pediatric unstable forearm fractures. Clin Orthop Relat Res. 2002(402):245-50.

25. Meier R, Prommersberger KJ, van Griensven M, Lanz U. Surgical correction of deformities of the distal radius due to fractures in pediatric patients. Arch Orthop Trauma Surg. 2004;124(1):1-9.

26. Myers GJ, Gibbons PJ, Glithero PR. Nancy nailing of diaphyseal forearm fractures. Single bone fixation for fractures of both bones. J Bone Joint Surg Br. 2004;86(4):581-4.

27. Shoemaker SD, Comstock CP, Mubarak SJ, Wenger DR, Chambers HG. Intramedullary Kirschner wire fixation of open or unstable forearm fractures in children. J Pediatr Orthop. 1999;19(3):329-37. 
28. Yung PS, Lam CY, Ng BK, Lam TP, Cheng JC. Percutaneous transphyseal intramedullary Kirschner wire pinning: a safe and effective procedure for treatment of displaced diaphyseal forearm fracture in children. J Pediatr Orthop. 2004;24(1):7-12.

29. Blount WP. Forearm fractures in children. 1967. Clin Orthop Relat Res. 2005(432):4-7.

30. Friberg KS. Remodelling after distal forearm fractures in children. I. The effect of residual angulation on the spatial orientation of the epiphyseal plates. Acta Orthop Scand. 1979;50(5):537-46.

31. Gibbons CL, Woods DA, Pailthorpe C, Carr AJ, Worlock P. The management of isolated distal radius fractures in children. J Pediatr Orthop. 1994;14(2):207-10.

32. Haddad FS, Williams RL. Forearm fractures in children: avoiding redisplacement. Injury. 1995;26(10):691-2.

33. Kiely PD, Kiely PJ, Stephens MM, Dowling FE. Atypical distal radial fractures in children. J Pediatr Orthop B. 2004;13(3):202-5.

34. Proctor MT, Moore DJ, Paterson JM. Redisplacement after manipulation of distal radial fractures in children. J Bone Joint Surg Br. 1993;75(3):453-4.

35. Van Leemput W, De Ridder K. Distal metaphyseal radius fractures in children: reduction with or without pinning. Acta Orthop Belg. 2009;75(3):306-9.

36. Zamzam MM, Khoshhal KI. Displaced fracture of the distal radius in children: factors responsible for redisplacement after closed reduction. J Bone Joint Surg Br. 2005;87(6):841-3.

37. Bowman EN, Mehlman CT, Lindsell CJ, Tamai J. Nonoperative treatment of both-bone forearm shaft fractures in children: predictors of early radiographic failure. Journal of pediatric orthopedics. 2011;31(1):23-32.

38. Green JS, Williams SC, Finlay D, Harper WM. Distal forearm fractures in children:the role of radiographs during follow up. Injury. 1998;29(4):309-12.

39. Younger AS, Tredwell SJ, Mackenzie WG. Factors affecting fracture position at cast removal after pediatric forearm fracture. J Pediatr Orthop. 1997;17(3):332-6.

40. Alemdaroglu KB, Iltar S, Cimen O, Uysal M, Alagoz E, Atlihan D. Risk factors in redisplacement of distal radial fractures in children. J Bone Joint Surg Am. 2008;90(6):1224-30.

41. Pretell Mazzini J, Rodriguez Martin J. Paediatric forearm and distal radius fractures: risk factors and re-displacement—role of casting indices. Int Orthop.34(3):407-12.

42. Younger AS, Tredwell SJ, Mackenzie WG, Orr JD, King PM, Tennant W. Accurate prediction of outcome after pediatric forearm fracture. J Pediatr Orthop. 1994;14(2):200-6. 


\section{Chapter 12}

43. Hogstrom H, Nilsson BE, Willner S. Correction with growth following diaphyseal forearm fracture. Acta Orthop Scand. 1976;47(3):299-303.

44. Bhaskar AR, Roberts JA. Treatment of unstable fractures of the forearm in children. Is plating of a single bone adequate? J Bone Joint Surg Br. 2001;83(2):253-8.

45. Nilsson BE, Obrant $\mathrm{K}$. The range of motion following fracture of the shaft of the forearm in children. Acta Orthop Scand. 1977;48(6):600-2.

46. Morrey BF, Askew LJ, Chao EY. A biomechanical study of normal functional elbow motion. The Journal of bone and joint surgery American volume. 1981;63(6):872-7.

47. Matthews LS, Kaufer H, Garver DF, Sonstegard DA. The effect on supination-pronation of angular malalignment of fractures of both bones of the forearm. J Bone Joint Surg Am. 1982;64(1):14-7.

48. Tarr RR, Garfinkel AI, Sarmiento A. The effects of angular and rotational deformities of both bones of the forearm. An in vitro study. J Bone Joint Surg Am. 1984;66(1):65-70.

49. Yasutomi T, Nakatsuchi Y, Koike H, Uchiyama S. Mechanism of limitation of pronation/ supination of the forearm in geometric models of deformities of the forearm bones. Clin Biomech (Bristol, Avon). 2002;17(6):456-63.

50. Shirai H, Ryu J, Kish V, Abe M. The rotational effect of pronation and supination osteotomies of the forearm in a cadaver model: a comparison of osteotomy sites on the radius and the ulna. J Hand Surg Eur Vol. 2007;32(4):440-6.

51. Bronstein AJ, Trumble TE, Tencer AF. The effects of distal radius fracture malalignment on forearm rotation: a cadaveric study. J Hand Surg [Am]. 1997;22(2):258-62.

52. Dumont CE, Thalmann R, Macy JC. The effect of rotational malunion of the radius and the ulna on supination and pronation. J Bone Joint Surg Br. 2002;84(7):1070-4.

53. Kasten $\mathrm{P}$, Krefft M, Hesselbach J, Weinberg AM. How does torsional deformity of the radial shaft influence the rotation of the forearm? A biomechanical study. J Orthop Trauma. 2003;17(1):57-60.

54. Roberts JA. Angulation of the radius in children's fractures. J Bone Joint Surg Br. 1986;68(5):751-4.

55. Trousdale RT, Linscheid RL. Operative treatment of malunited fractures of the forearm. J Bone Joint Surg Am. 1995;77(6):894-902.

56. Kuderna $\mathrm{H}$. [Connection between deviated axis and impaired function after fractures of the forearm (author's transl)]. Unfallchirurgie. 1980;6(1):7-13. 
57. Sarmiento A, Ebramzadeh E, Brys D, Tarr R. Angular deformities and forearm function. Journal of orthopaedic research : official publication of the Orthopaedic Research Society. 1992;10(1):121-33.

58. Krukhaug Y, Hove LM. Corrective osteotomy for malunited extra-articular fractures of the distal radius: a follow-up study of 33 patients. Scand J Plast Reconstr Surg Hand Surg. 2007;41(6):303-9.

59. Price CT, Knapp DR. Osteotomy for malunited forearm shaft fractures in children. J Pediatr Orthop. 2006;26(2):193-6.

60. Nagy L, Jankauskas L, Dumont CE. Correction of forearm malunion guided by the preoperative complaint. Clin Orthop Relat Res. 2008;466(6):1419-28.

61. Nakamura T, Yabe Y, Horiuchi Y, Seki T, Yamazaki N. Normal kinematics of the interosseous membrane during forearm pronation-supination-a three-dimensional MRI study. Hand Surg. 2000;5(1):1-10.

62. Nakamura T, Yabe Y, Horiuchi Y. [A biomechanical analysis of pronation-supination of the forearm using magnetic resonance imaging: dynamic changes of the interosseous membrane of the forearm during pronation-supination]. Nippon Seikeigeka Gakkai Zasshi. 1994;68(1):14-25

63. Kleinman WB, Graham TJ. The distal radioulnar joint capsule: clinical anatomy and role in posttraumatic limitation of forearm rotation. J Hand Surg Am. 1998;23(4):588-99.

64. Slutsky DJ, Osterman AL. Fractures and injuries of the distal radius and carpus the cutting edge. Philadelphia, Pa.: Saunders/Elsevier; 2009. Available from: http://www.clinicalkey.com/dura/browse/bookChapter/3-s2.0-B9781416040835X00017.

65. Moritomo H, Noda K, Goto A, Murase T, Yoshikawa H, Sugamoto K. Interosseous membrane of the forearm: length change of ligaments during forearm rotation. J Hand Surg Am. 2009;34(4):685-91.

66. Beyer W, Stolzenburg T, Paris S. [Functional limitation of the forearm after shaft fracture in childhood. Possible role of the antebrachial interosseous membrane: MRI and ultrasound studies]. Unfallchirurgie. 1995;21(6):275-84.

67. Adams BD. Effects of radial deformity on distal radioulnar joint mechanics. J Hand Surg Am. 1993;18(3):492-8. 


\section{Chapter 12}

68. Crisco JJ, Moore DC, Marai GE, Laidlaw DH, Akelman E, Weiss AP, et al. Effects of distal radius malunion on distal radioulnar joint mechanics - an in vivo study. Journal of orthopaedic research : official publication of the Orthopaedic Research Society. 2007;25(4):547-55.

69. Schuind F, An KN, Berglund L, Rey R, Cooney WP, 3rd, Linscheid RL, et al. The distal radioulnar ligaments: a biomechanical study. J Hand Surg Am. 1991;16(6):1106-14. 
General discussion 

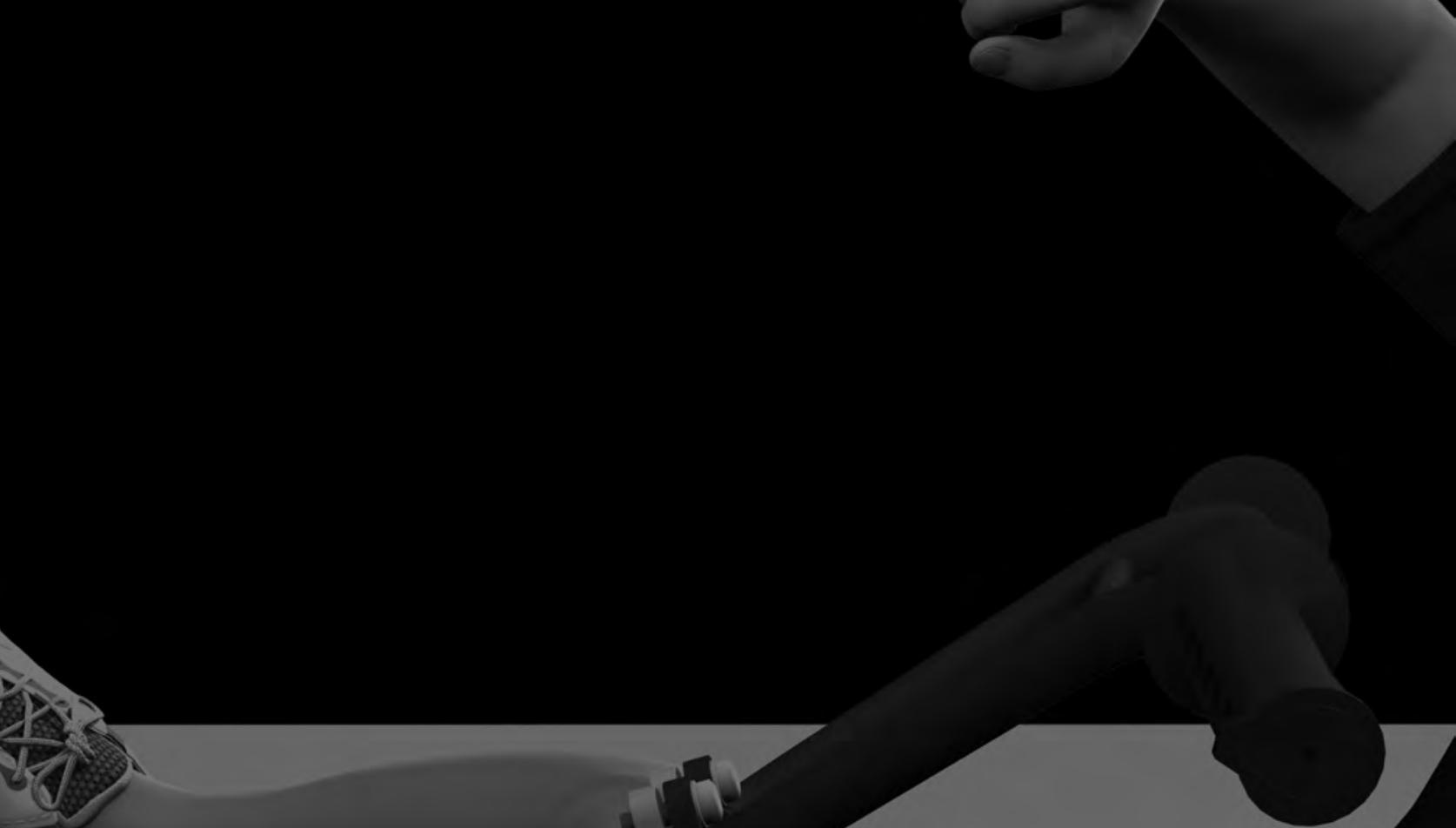


\section{Chapter 13}

Recommendations

for future research 
Chapter 13 
Although this thesis aimed to further enhance the knowledge on both-bone forearm fractures in children, several questions remain to be answered. The results of this thesis were based on a follow-up period of approximately 7 months. Therefore, a longer period of follow-up may provide new insights into the role of (corrected) malunions on impaired forearm rotation.

Thereby, conservatively treated fractures might benefit from improved treatment with cast, i.e. direct application of circumferential cast by a cast technician.

Because we allocated reduced metaphyseal both-bone fractures of the distal forearm to treatment with an above-elbow cast with or without additional Kirschner wires, we still do not know whether such fractures can be treated by Kirschner wires and a below-elbow cast.

Although we considered soft tissue contractures to be an important contributor of impaired forearm rotation, our magnetic resonance imaging (MRI) study could not confirm this. Therefore, a MRI with a higher resolution may expose soft tissue contractures.

Furthermore, computed tomography (CT) of both whole forearms with a bone and a soft tissue setting may reveal the complex configuration of a malunion and may make three-dimensional corrective osteotomy using a computer simulation system possible.

Finally, the development of a treatment algorithm for children with impaired forearm rotation after a both-bone forearm fracture will probably be very helpful. 

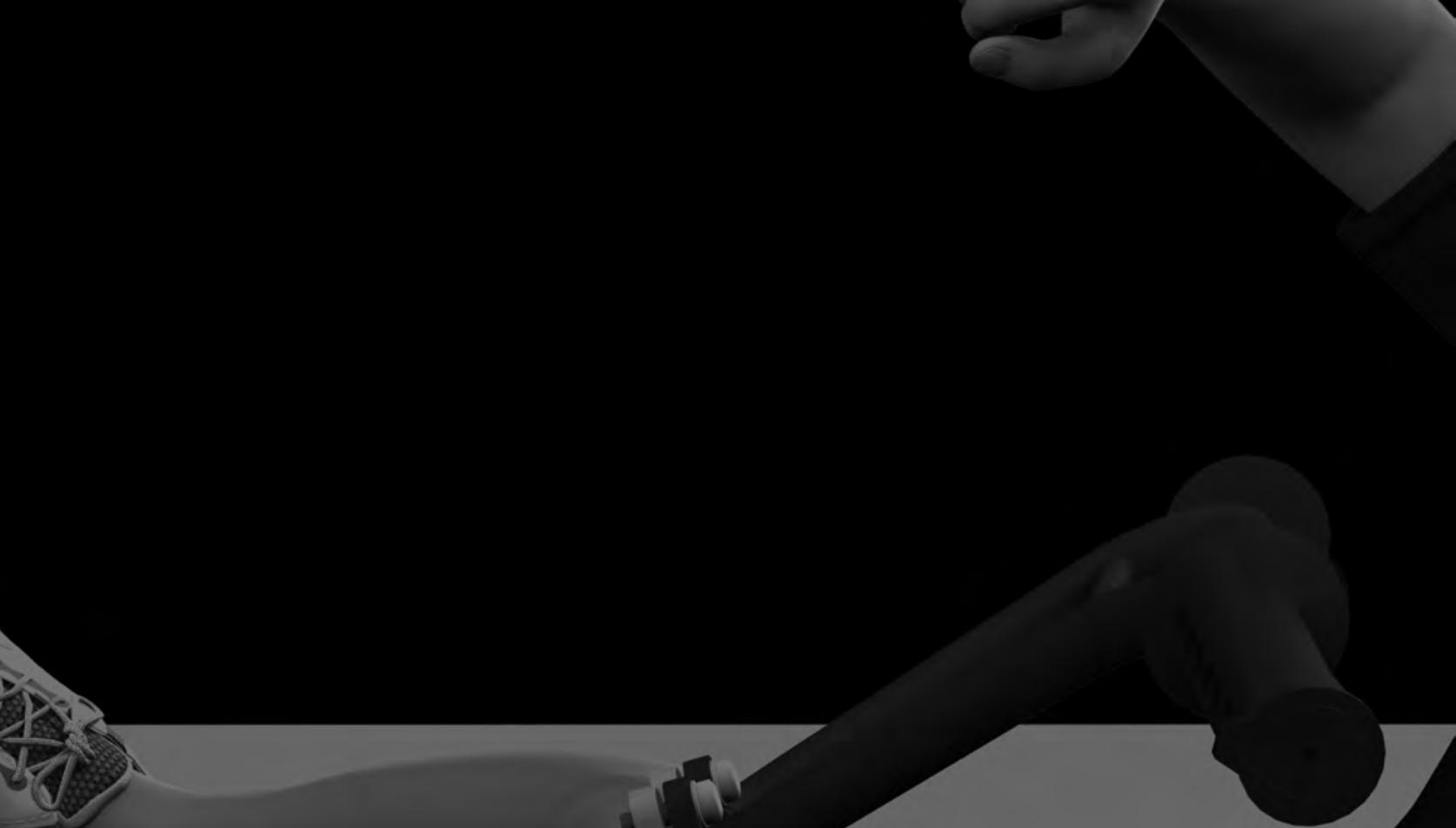


\section{Chapter 14}

\section{General summary}


Chapter 14 
This thesis aimed to unravel several aspects of both-bone forearm fractures in children by conducting a prospective randomised controlled study which included 410 children in four Dutch hospitals. Finally, a total of 400 children were assessed both clinically and radiologically at a mean of $218( \pm 49)$ days.

\section{Part 1 Metaphyseal both-bone fractures of the distal forearm}

In Chapter 2 children with minimally-displaced metaphyseal both-bone fractures of the distal forearm were randomised to 4 weeks below-elbow cast (BEC) or 4 weeks above-elbow cast (AEC). Children treated with BEC encountered higher cast comfort and needed less help with dressing; furthermore, the BEC group showed fewer complications. In conclusion, children with a minimally-displaced metaphyseal both-bone fracture of the distal forearm should be treated with a BEC.

The children investigated in Chapter 3, who sustained a displaced metaphyseal both-bone fracture of the distal forearm that was stable after reduction, were randomised to AEC with or without percutaneous fixation with Kirschner wires. The group of children treated with additional pinning showed less re-displacement, less limitation of pronation and supination, but more complications. This study demonstrated that pinning of apparently stable both-bone fractures of the distal forearm in children reduces fracture re-displacement. Furthermore, the frequently seen complications of pinning might be reduced by a proper surgical technique.

\section{Part 2 Diaphyseal both-bone forearm fractures}

In Chapters $\mathbf{4}$ and $\mathbf{5}$ we studied children with diaphyseal both-bone forearm fractures which were either non-reduced or stable after reduction. These children were randomly allocated to 6 weeks AEC, or to 3 weeks AEC followed by 3 weeks BEC. The results showed that the limitation of pronation/supination was similar in both groups. Thereby, all secondary outcomes (re-displacement of the fracture, limitation of flexion/extension of wrist and elbow, complication rate, assessments of radiographs, complaints in daily life and cosmetics of the fractured arm) were similar in both groups, with the exception of cast comfort - which was in favour of the BEC group only in the reduced fracture group. Therefore, we conclude that early 


\section{Chapter 14}

conversion to BEC cast in these children is safe and results in greater cast comfort.

Chapter 6 cautions against the use of single-bone fixation in all diaphyseal bothbone forearm fractures that are unstable after reduction. Single-bone fixation leads to increased re-displacement, (longer) cast immobilisation, and inferior clinical results.

\section{Part 3 Fracture displacement}

The aim of the study presented in Chapter 7 was to identify risk factors for fracture displacement of both-bone forearm fractures treated with cast, by means of multivariate logistic regression analyses. Both-bone forearm fractures in children have a strong tendency to displace, even in an above-elbow cast. The risk factors that, independently of each other, significantly increased the risk of fracture displacement were severe fractures (a complete fracture, a fracture with translation of the ulna on the lateral radiograph, and shortening of the fracture) of the nondominant arm.

\section{Part 4 Limitation of forearm rotation}

The study presented in Chapter 8 compared the intra- and interrater reliability of visual estimation and conventional goniometry in the determination of forearm rotation in paediatric patients that had previously sustained a both-bone forearm fracture. The results showed that the intra- and interrater reliability of visual estimation and conventional goniometry was fair to excellent, with lower smallest detectable differences in the conventional goniometry group. Thus, a conventional goniometer is an easy, fast and reliable method to determine the pronation and supination in a child who has sustained a forearm fracture. If an uncooperative child hinders the measurement, visual estimation is a good second choice. Finally, measurements proved to be more reliable when repeated by the same professional.

Chapter 9 describes which clinical factors are related to the limitation of pronation/supination in children with a both-bone forearm fracture, based on multivariate logistic regression analyses. The results imply that a re-fracture, a fracture in the diaphysis, and less physiotherapy during follow-up, were independently associated with a limitation of pronation/supination of 20 degrees or more. 
In Chapter $\mathbf{1 0}$ we aimed to predict the limitation of pronation/supination by the degree of angular malalignment. The results show that fractures localised in the distal metaphysis had a greater chance to develop a clinically relevant limitation of forearm rotation in case of a more severe angular malalignment, while diaphyseal fractures had a moderate chance of limitation independent of the severity of the angular malalignment.

In Chapter 11 we used three-dimensional imaging to evaluate malalignment, bony impingement and contractures of the interosseous membrane as a cause of severe limitation of forearm rotation following a both-bone forearm fracture in children. Conventional radiography, computed tomography (CT) and magnetic resonance imaging (MRI) revealed angular and rotational malunions of both radius and ulna without bony impingement or soft tissue contractures. 

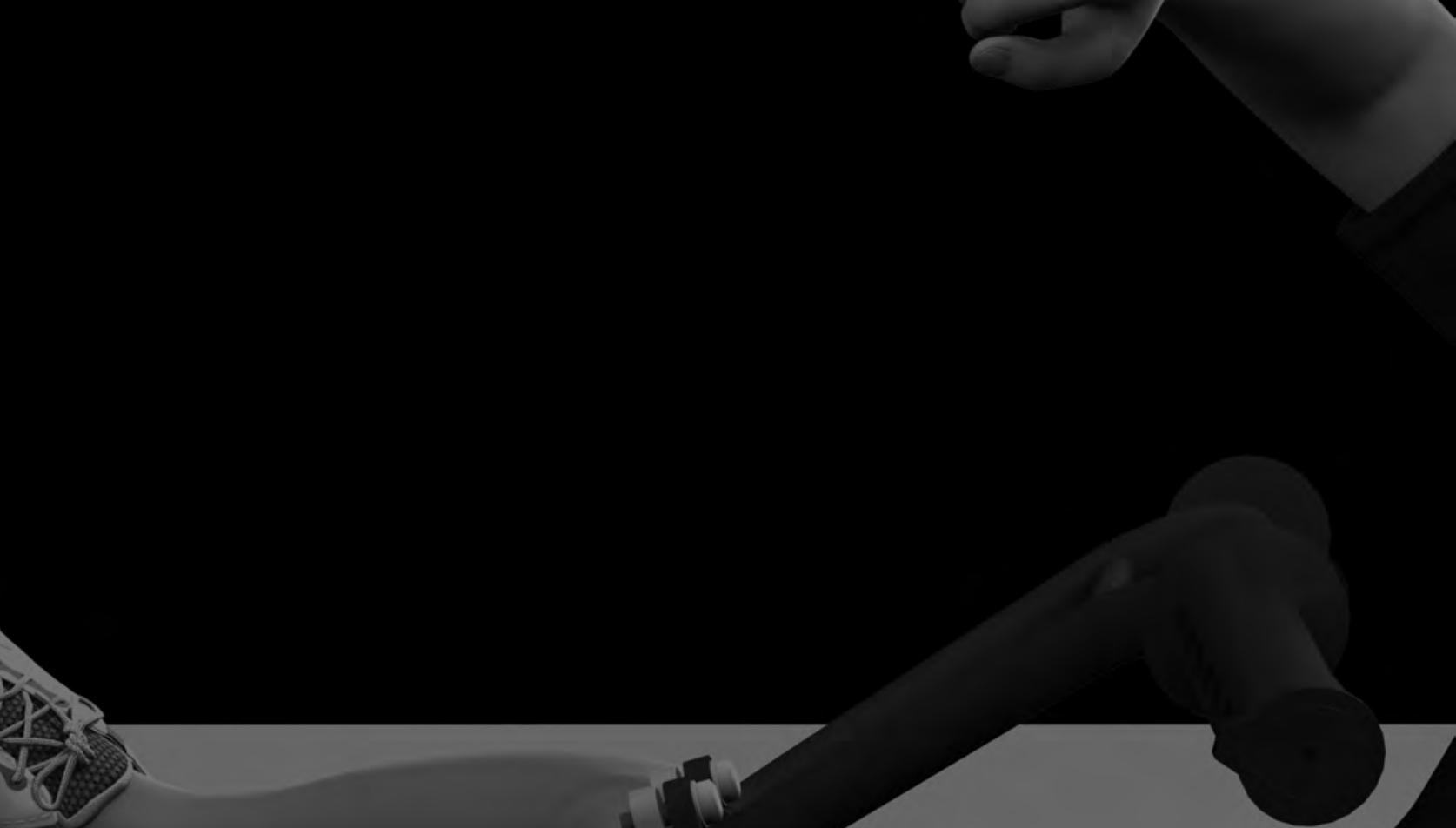


\section{HoOFdstuk 15}

\section{General summary in Dutch /}

Samenvatting in het Nederlands 
Chapter 15 


\section{Breuken VAN zowel het SPAAKbeen als De ellepijp}

Dit proefschrift gaat over kinderen die een breuk hebben opgelopen van zowel het spaakbeen als de ellepijp. In het Latijn wordt deze breuk de fractura antebrachii genoemd. De basis van dit proefschrift betreft een onderzoek met deelname van 410 kinderen in 4 verschillende ziekenhuizen. De behandeling van deze kinderen werd bepaald door loting tussen twee behandelingsvormen. Na gemiddeld 218 dagen werden 400 kinderen op de polikliniek teruggezien en werden röntgenfoto's gemaakt. Met deze gegevens werd geanalyseerd welke behandeling het beste is voor welk type breuk. De breuken zijn in te delen naar locatie (dichtbij de pols of in het midden van de onderarm), naar de mate van verplaatsing (weinig of fors verplaatst) en naar de mate van stabiliteit (stabiel of instabiel). De resultaten van de verschillende behandelingen zijn gerapporteerd in deel 1 en 2, terwijl de verplaatsing van de breuk in gips en verminderde functie van de onderarm aan bod komen in deel 3 en 4.

\section{Deel 1 Breuken dichtbij De pols}

In hoofdstuk 2 wordt een studie beschreven over de behandeling van breuken van zowel het spaakbeen als de ellepijp dichtbij de pols. Deze breuken waren weinig verplaatst en hoefden daarom niet in goede positie gezet te worden. Bij deze kinderen werd er geloot tussen een behandeling met gips tot aan de elleboog (onderarmgips) en gips voorbij de elleboog (bovenarmgips). De resultaten toonden dat de groep kinderen met onderarmgips het gips comfortabeler vonden en minder hulp nodig hadden met aankleden. Ook werden er minder complicaties gezien in deze groep. Concluderend kunnen kinderen met een weinig verplaatste breuk dichtbij de pols beter behandeld worden met een onderarmgips.

Hoofdstuk 3 gaat over kinderen met een fors verplaatste breuk dichtbij de pols waarbij het nodig was de breuk in goede positie te zetten in de operatiekamer. Nadat de breuk in goede positie was gezet, werd de stabiliteit van de breuk getest. Bij stabiele breuken werd er geloot tussen de behandeling met alleen bovenarmgips en een combinatie van 2 ijzeren pennetjes ter stabilisatie van de breuk en bovenarmgips. In de groep kinderen behandeld met een combinatie van 2 ijzeren 


\section{Chapter 15}

pennetjes en bovenarmgips werden minder verplaatsing van de breuk, een betere functie maar meer complicaties gezien ten opzichte van de groep behandeld met alleen bovenarmgips. Derhalve kunnen deze breuken beter gestabiliseerd worden met 2 ijzeren pennetjes om verplaatsing van de breuk tegen te gaan. Wel is een nauwkeurige chirurgische techniek noodzakelijk om complicaties te vermijden.

\section{Deel 2 Breuken in het midden van de onderarm}

Bij breuken van zowel het spaakbeen als de ellepijp in het midden van de onderarm werd een onderscheid gemaakt tussen weinig en fors verplaatste breuken, waarbij alleen de fors verplaatste breuken in goede positie werden gezet. Na het in goede positie zetten van de fors verplaatste breuken werd een onderscheid gemaakt tussen stabiele en instabiele breuken. Bij de weinig verplaatste breuken (studie beschreven in hoofdstuk 4) en de breuken die na het in goede positie zetten stabiel waren (studie beschreven in hoofdstuk 5), werd er geloot tussen de behandeling met respectievelijk 6 weken bovenarmgips en een combinatie van 3 weken bovenarmgips en 3 weken onderarmgips. In beide studies waren de resultaten tussen de twee groepen vergelijkbaar met uitzondering van een hoger comfort in gips in de groep behandeld met boven- en onderarmgips. Concluderend kunnen zowel weinig verplaatste breuken als fors verplaatste breuken die na het in goede positie zetten stabiel waren, het beste behandeld worden met een combinatie van bovenen onderarmgips.

Hoofdstuk 6 beschrijft de fors verplaatste breuken in het midden van de onderarm die na het in goede positie zetten instabiel waren. Deze breuken werden volgens loting gestabiliseerd met 1 of 2 pennen in het spaakbeen en/of de ellepijp. Breuken die werden gestabiliseerd met 1 pen vertoonden meer verplaatsing, werden langer behandeld met gips en hadden minder goede klinische resultaten. Derhalve kunnen deze breuken het beste worden gestabiliseerd met zowel een pen in het spaakbeen als in de ellepijp. 


\section{Deel 3 VerplaAtsing van de breuk in Gips}

Breuken van zowel het spaakbeen als de ellepijp hebben de neiging om te verplaatsen in gips. Om te onderzoeken welke factoren van invloed zijn op het verplaatsen van deze breuken in gips werden in hoofdstuk 7 de risicofactoren in kaart gebracht. Hieruit bleek dat met name zeer ernstige breuken van de niet dominante arm vaker verplaatsten in gips.

\section{Deel 4 Verminderde rotatie van de onderarm na de breuk}

Bij rotatie van de onderarm draait het spaakbeen om de ellepijp heen. Door een breuk van beide botten kan een verminderde rotatie in de onderarm ontstaan. Om de rotatie van de onderarm te meten gebruikt men vaak een gradenboog, de goniometer. In hoofdstuk $\mathbf{8}$ wordt de rotatie van de onderarm respectievelijk geschat en gemeten met een goniometer. Uit de resultaten blijkt dat het meten met een goniometer nauwkeuriger is dan het schatten van de rotatie. Ook is een vervolgmeting nauwkeuriger als dezelfde onderzoeker de meting herhaalt. In hoofdstuk 9 blijkt dat er drie onafhankelijke risicofactoren van invloed zijn op verminderde rotatie van de onderarm na een breuk van zowel het spaakbeen als de ellepijp; een recidief breuk, een breuk in het midden van de onderarm en weinig fysiotherapie. In hoofdstuk $\mathbf{1 0}$ werd onderzocht of het in een verkeerde positie vastgroeien van een onderarmbreuk van invloed is op een verminderde rotatie van de onderarm. Hieruit bleek dat er hoog risico was op het ontwikkelen van verminderde rotatie in geval van forse scheefstand bij breuken dichtbij de pols enerzijds, en in geval van milde scheefstand bij breuken in het midden van de onderarm anderzijds. In hoofdstuk 11 wordt 3-dimensionaal radiologisch onderzoek (MRI en CT) gebruikt om meer inzicht te krijgen in de oorzaak van de verminderde rotatie na een onderarmbreuk. Hieruit kwam naar voren dat, (1) deze breuken in een verkeerde rotatiestand kunnen vastgroeien, (2) dat er geen sprake was van botsen tussen het spaakbeen en de ellepijp tijdens rotatie en (3) dat er geen verlittekening was van de weke delen tussen het spaakbeen en de ellepijp. 


\section{PART VII}

\section{APPENDICES}

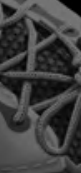




\section{PhD Portfolio}


PhD Portfolio 


\section{PhD Portfolio}

\section{COURSES}

Scientific writing in English for publication, Rotterdam

Developing a Cochrane systematic review, Amsterdam

Evidence based surgery in clinical practice, Zwolle

\section{ORAL PRESENTATIONS}

Which factors affect limitation of pronation/supination after forearm fractures in children? A prospective multicentre study. Dutch Orthopaedic Association. Rotterdam

Risk factors for the displacement of fractures of both-bones of the forearm in children. Dutch Orthopaedic Association. Rotterdam

Risk factors for the displacement of fractures of both bones of the 2013 forearm in children. Dutch trauma meeting, Amsterdam

Re-displacement of stable distal both-bone forearm fractures in 2012 children: A randomised controlled multicentre study. Netherlands Society for Hand Surgery, Amsterdam

Below-elbow cast for metaphyseal both-bone fractures of the distal forearm in children: A randomized multicentre study. Dutch Orthopaedic Association. Veldhoven

Re-displacement of stable distal both-bone forearm fractures in children: A randomised controlled multicentre study. Federation of European Societies for Surgery of the Hand, Antwerp

Re-displacement of stable distal both-bone forearm fractures in children: A randomised controlled multicentre study. Congress of the European Paediatric Surgeons Association, Rome 
Both-bone forearm fractures in children. The first results. Trauma meeting ZWOT, Rotterdam

Conversion to below-elbow cast after 3 weeks is safe for diaphyseal 2011 both-bone forearm fractures in children. Dutch Surgery Society, Ede

Re-displacement of stable distal both-bone forearm fractures in 2011 children: A randomised controlled multicentre study. Dutch Surgery Society, Ede

Re-displacement of stable distal both-bone forearm fractures in 2011 children: A randomised controlled multicentre study. Dutch trauma meeting, Amsterdam

Both-bone forearm fractures in children. The results of a multicentre 2011 study with inclusion of 410 children. Dutch Society for Paediatric Orthopaedics, Utrecht

\section{INVITED LECTURES}

Below-elbow cast for metaphyseal both-bone fractures of the distal 2013 forearm in children: A randomized multicentre study. Dutch Orthopaedic Trauma Society, Amsterdam

Both-bone forearm fractures in children. The results of a multicentre 2013 study with inclusion of 410 children. Dutch Society for Paediatric Surgery, Utrecht

Both-bone forearm fractures in children. The results of a multicentre 2013 study with inclusion of 410 children. Trauma meeting, Euregio, Hengelo

Both-bone forearm fractures in children. The results of a multicentre 2013 study with inclusion of 410 children. Trauma meeting, TOWN, the Hague 
Different kind of cast for the treatment of both-bone forearm fractures in children. Dutch trauma meeting, Amsterdam

\section{POSTER PRESENTATIONS}

Early conversion to below-elbow cast for displaced diaphyseal both-bone forearm fractures in children: a multicenter randomized controlled trial. Congress of the European Paediatric Surgeons Association. Rome

Pronation and supination after forearm fractures in children:

Reliability of visual estimation and conventional goniometry measurement. Dutch trauma meeting. Amsterdam

\section{HONORS AND AWARDS}

Biomet price

Best scientific research, Dutch Orthopaedic Association

NVOT Award

Best scientific article in Orthopaedic Trauma

Best oral presentation of Dutch trauma meeting

\section{SUPERVISING MASTER'S THESIS}

Leon Diederix, Resident Orthopaedic Surgery

Thesis: 5 years follow-up of both-bone forearm fractures in children 

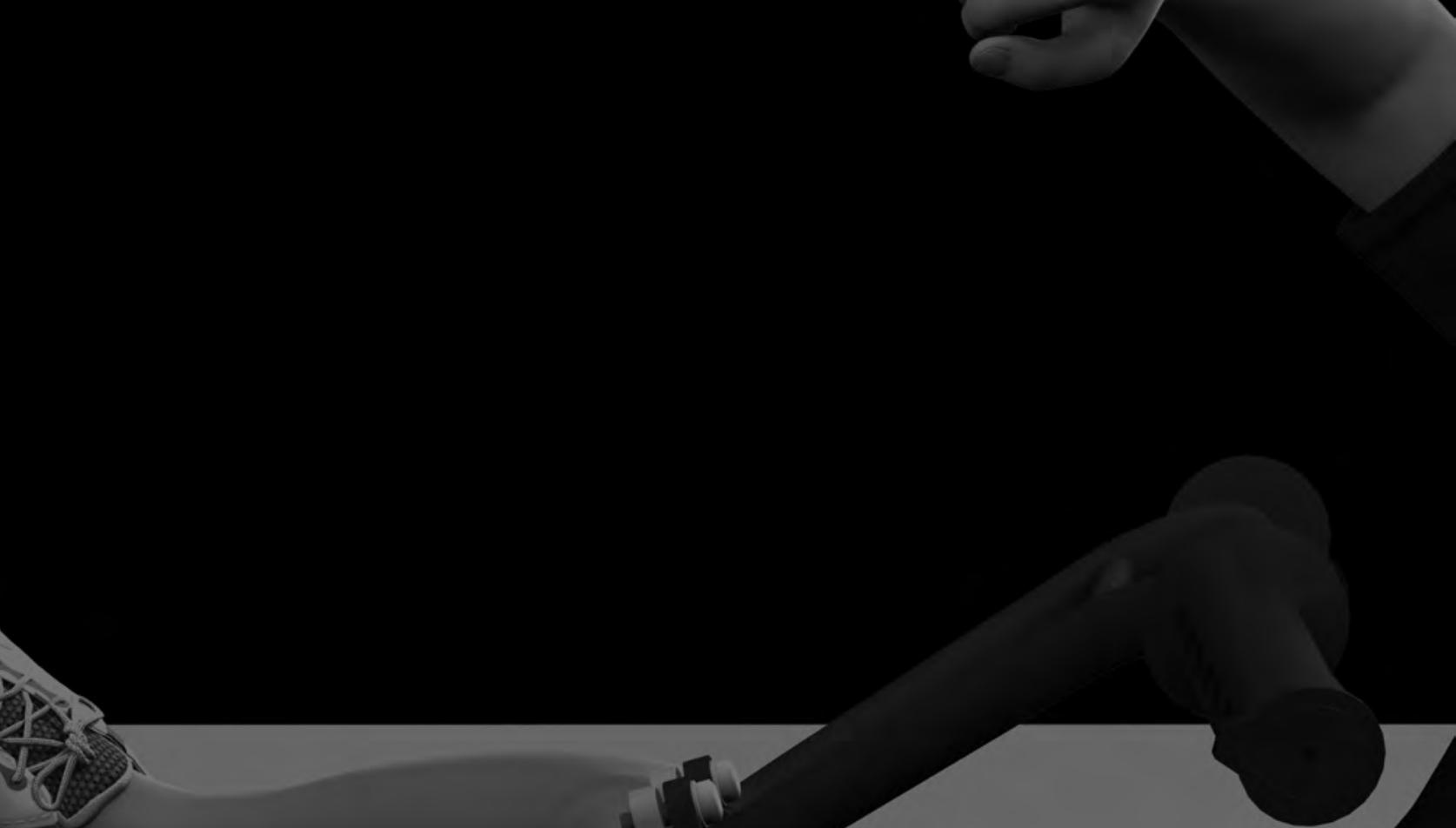


\section{List of Publications}

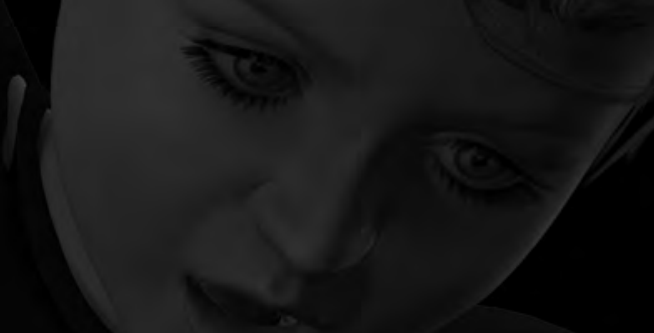


List of publications 


\section{LIST OF PUBLICATIONS}

Colaris JW, Oei S, Reijman M, Holscher H, Allema JH, Verhaar JA. Threedimensional imaging of children with severe limitation of pronation/supination after a both-bone forearm fracture. Arch Orthop Trauma Surg. 2014 Mar;134(3):333-41.

Colaris JW, Allema JH, Reijman M, de Vries MR, Ulas Biter L, Bloem RM, van de Ven CP, Verhaar JA. Which factors affect limitation of pronation/supination after forearm fractures in children? A prospective multicentre study. Injury. 2014 Apr;45(4):696-700.

Colaris JW, Allema JH, Biter LU, Reijman M, Ven CP, Vries MR, Bloem RM, Kerver AJ, Verhaar JA. Conversion to below-elbow cast after 3 weeks is safe for diaphyseal both-bone forearm fractures in children. Acta Orthop. 2013 Oct;84(5):489-94.

Colaris JW, Reijman M, Allema JH, Biter LU, Bloem RM, van de Ven CP, de Vries MR, Kerver AJ, Verhaar JA. Early conversion to below-elbow cast for nonreduced diaphyseal both-bone forearm fractures in children is safe: preliminary results of a multicentre randomised controlled trial. Arch Orthop Trauma Surg. 2013 Oct;133(10):1407-14.

Colaris J, Reijman M, Allema JH, Kraan G, van Winterswijk P, de Vries M, van de Ven C, Verhaar J. Single-bone intramedullary fixation of unstable both-bone diaphyseal forearm fractures in children leads to increased re-displacement: a multicentre randomised controlled trial. Arch Orthop Trauma Surg. 2013 Aug;133(8):1079-87.

Colaris JW, Allema JH, Reijman M, Biter LU, de Vries MR, van de Ven CP, Bloem RM, Verhaar JA. Risk factors for the displacement of fractures of both bones of the forearm in children. Bone Joint J. 2013 May;95-B(5):689-93. 


\section{List of publications}

Witteveen HJ, Colaris JW. [A woman with a painful elbow]. Ned Tijdschr Geneeskd. 2013;157(3):A4779. Dutch.

Colaris JW, Allema JH, Biter LU, de Vries MR, van de Ven CP, Bloem RM, Kerver AJ, Reijman M, Verhaar JA. Re-displacement of stable distal both-bone forearm fractures in children: a randomised controlled multicentre trial. Injury. 2013 Apr;44(4):498-503.

Peerbooms JC, Colaris JW, Hakkert AA, Van Appeldorn M, Bruijn DJ, Den Oudsten BL, Gosens T. No positive bone healing after using platelet rich plasma in a skeletal defect. An observational prospective cohort study. Int Orthop. 2012 Oct;36(10):2113-9.

Colaris JW, Biter LU, Allema JH, Bloem RM, van de Ven CP, de Vries MR, Kerver AJ, Reijman M, Verhaar JA. Below-elbow cast for metaphyseal both-bone fractures of the distal forearm in children: a randomised multicentre study. Injury. 2012 Jul;43(7):1107-11.

Joost W. Colaris, L. Ulas Biter, Jan Hein Allema, Rolf M. Bloem, Cees P. van de Ven, Mark R. de Vries, Albert J.H. Kerver, Max Reijman, Jan A.N. Verhaar. Onderarmgips bij distale fracturen van radius en ulna. Ned Tijdschr Geneeskd. 2012;156:A5332.

Zengerink I, Colaris JW. [A man without pronation and supination]. Ned Tijdschr Geneeskd. 2011;155(42):A2723. Dutch.

Peters S, Colaris JW. Carpal coalition: symptomatic incomplete bony coalition of the capitate and trapezoid—case report. J Hand Surg Am. 2011 Aug;36(8):1313-5.

Colaris J, van der Linden M, Selles R, Coene N, Allema JH, Verhaar J. Pronation and supination after forearm fractures in children: Reliability of visual estimation and conventional goniometry measurement. Injury. 2010 Jun;41(6):643-6. 
Peerbooms JC, de Wolf GS, Colaris JW, Bruijn DJ, Verhaar JA. No positive effect of autologous platelet gel after total knee arthroplasty. Acta Orthop. 2009 Oct;80(5):557-62.

Colaris JW, Horn TM, van den Ende ED, Allema JH, Merkus JW. Supracondylar fractures of the humerus in children. Comparison of results in two treatment periods. Acta Chir Belg. 2008 Nov-Dec;108(6):715-9.

J.W. Colaris, M.R. de Vries, C.P. van de Ven, A.J.H. Kerver, L.U. Biter, J.A.N. Verhaar. De fractura antebrachii studie. In dit Verband. 2008, nummer 3, jaargang $18, \mathrm{p} 22$.

J.W. Colaris, L.N.J.E.M. Coene. Is a biopsy necessary in diagnosing Kümmell's disease? Journal of Orthopaedics. 2007; 4(3)e13.

Colaris JW, Reijman M, Allema JH, de Vries MR, Biter LU, Bloem RM, van de Ven CP, Verhaar JA. Angular malalignment as cause of limitation of forearm rotation: an analysis of prospectively collected data of both-bone forearm fractures in children. Injury. 2014 Jun;45(6):955-9. 

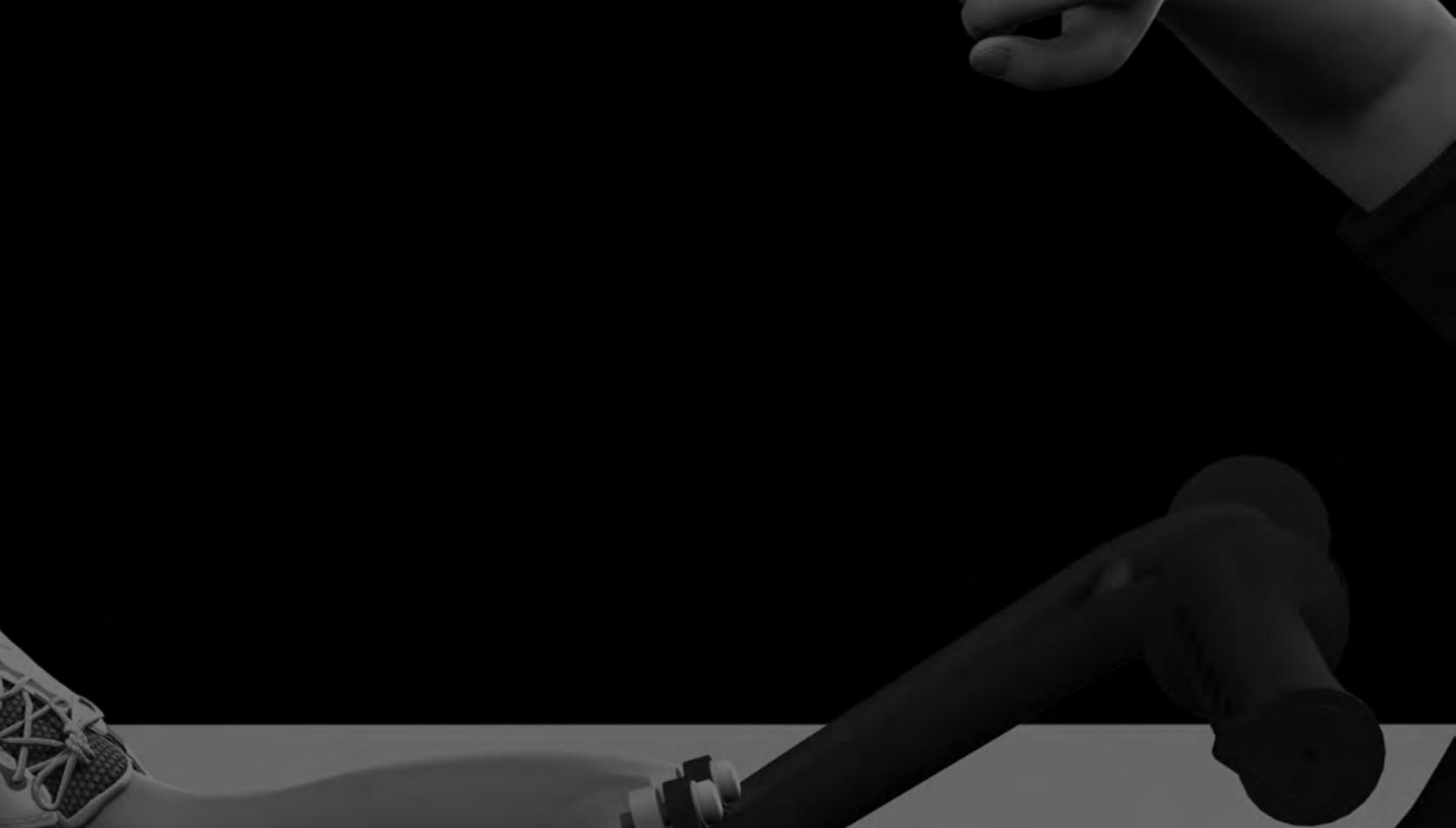


\section{Curriculum Vitae}


Curriculum Vitae 


\section{Curriculum Vitae}

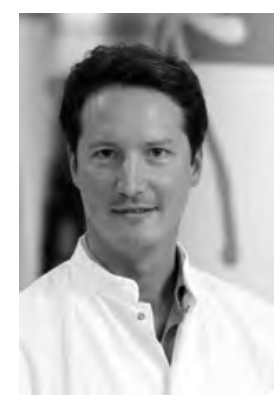

Joost Willem Colaris was born on the $29^{\text {th }}$ of February 1976 in Heerde, the Netherlands. He finished secondary school in 1995 at the Stedelijk Gymnasium in Apeldoorn. In the same year he moved to Belgium to study Medicine at the Catholic University of Leuven, where he completed his doctoral degree studies. Before starting his internships at the University of Leiden, he travelled through South-East Asia for 7 months. In 2003 he graduated cum laude.

His career in orthopaedic surgery began as a resident in the Rijnland Hospital in Leiderdorp (Dr. E.J. van Langelaan). In 2004 the residency of general surgery was started at the Rode Kruis Hospital in The Hague (Dr. H. Boutkan). During this period he initiated research that laid the foundation for this thesis. Training in orthopaedic surgery continued in the Leyenburg Hospital in The Hague (Dr. L.N.J.E.M. Coene), Erasmus Medical Center in Rotterdam (Prof. Dr. J.A.N. Verhaar) and the HAGA Hospital in The Hague (Dr. F.W.M. Faber).

In 2010 he became an orthopaedic surgeon at the Erasmus Medical Center in Rotterdam. From 2012 he was trained in hand and wrist surgery at the department of Plastic Surgery for one day a week (Prof. Dr. S.E.R. Hovius). In 2014 he passed the FESSH examination (Federation of European Societies for Surgery of the Hand) with a best diploma award.

Joost lives in The Hague with his wife Petra and their children Carmen and Louise. 